US Army Corps

of Engineers

Portland District

\title{
Acoustic Telemetry Evaluation of Juvenile Salmonid Passage and Survival Proportions at John Day Dam, 2009
}

\section{FINAL REPORT}

$\begin{array}{lll}\text { MA Weiland } & \text { J Kim } & \text { DM Faber } \\ \text { GR Ploskey } & \text { GE Johnson } & \text { KM Carter } \\ \text { JS Hughes } & \text { ES Fischer } & \text { JW Boyd } \\ \text { Z Deng } & \text { F Khan } & \text { RL Townsend } \\ \text { T Fu } & \text { SA Zimmerman } & \text { JR Skalski }\end{array}$

TJ Monter

AW Cushing MC Wilberding

MM Meyer

September 2011 


\title{
DISCLAIMER
}

This report was prepared as an account of work sponsored by an agency of the United States Government. Neither the United States Government nor any agency thereof, nor Battelle Memorial Institute, nor any of their employees, makes any warranty, express or implied, or assumes any legal liability or responsibility for the accuracy, completeness, or usefulness of any information, apparatus, product, or process disclosed, or represents that its use would not infringe privately owned rights. Reference herein to any specific commercial product, process, or service by trade name, trademark, manufacturer, or otherwise does not necessarily constitute or imply its endorsement, recommendation, or favoring by the United States Government or any agency thereof, or Battelle Memorial Institute. The views and opinions of authors expressed herein do not necessarily state or reflect those of the United States Government or any agency thereof.

\author{
PACIFIC NORTHWEST NATIONAL LABORATORY \\ operated by \\ BATTELLE \\ for the \\ UNITED STATES DEPARTMENT OF ENERGY \\ under Contract DE-AC05-76RL01830
}

Printed in the United States of America
Available to DOE and DOE contractors from the Office of Scientific and Technical Information,
P.O. Box 62, Oak Ridge, TN 37831-0062;
ph: (865) 576-8401
fax: $(865)$ 576-5728
email: reports@adonis.osti.gov

\begin{abstract}
Available to the public from the National Technical Information Service, U.S. Department of Commerce, 5285 Port Royal Rd., Springfield, VA 22161 ph: (800) 553-6847 fax: $(703) 605-6900$ email: orders@ntis.fedworld.gov online ordering: http://www.ntis.gov/ordering.htm
\end{abstract}

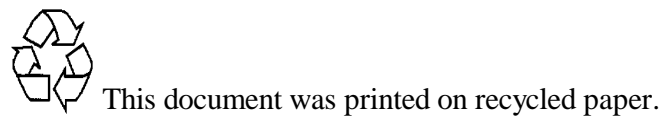




\section{Acoustic Telemetry Evaluation of Juvenile Salmonid Passage and Survival Proportions at John Day Dam, 2009}

\section{FINAL REPORT}

$\begin{array}{llll}\text { MA Weiland } & \text { J Kim } & \text { DM Faber } & \text { TJ Monter }^{1} \\ \text { GR Ploskey } & \text { GE Johnson } & \text { KM Carter } & \text { AW Cushing } \\ \text { JS Hughes } & \text { ES Fischer } & \text { JW Boyd } & \text { MC Wilberding } \\ \text { Z Deng } & \text { F Khan } & \text { RL Townsend }^{2} & \text { MM Meyer } \\ \text { T Fu } & \text { SA Zimmerman } & \text { JR Skalski }^{2} & \end{array}$

September 2011

Prepared for the

U.S. Army Corps of Engineers, Portland District Under a Government Order with the U.S. Department of Energy Contract DE-AC05-76RL01830

Pacific Northwest National Laboratory

Richland, Washington 99352

\footnotetext{
${ }^{1}$ Pacific States Marine Fisheries Commission, Portland, Oregon

${ }^{2}$ University of Washington, Seattle, Washington
} 
This report should be cited as follows:

Weiland, MA, GR Ploskey, JS Hughes, Z Deng, T Fu, J Kim, GE Johnson, GW Batten, ES Fischer, F Khan, SA Zimmerman, DM Faber, KM Carter, JW Boyd, RL Townsend, JR Skalski, TJ Monter, AW Cushing, MC Wilberding, and MM Meyer. 2011. Acoustic Telemetry Evaluation of Juvenile Salmonid Passage and Survival Proportions at John Day Dam, 2009. PNNL-20766. Draft report submitted by the Pacific Northwest National Laboratory to the U.S. Army Corps of Engineers, Portland District, Portland, Oregon. 


\section{Preface}

The study reported herein was funded as part of the Anadromous Fish Evaluation Program, which is managed by the U.S. Army Corps of Engineers (USACE). The Anadromous Fish Evaluation Program study code is SPE-P-08-03: Studies of Surface Spill at John Day Dam. The study was led by the Pacific Northwest National Laboratory (PNNL) for the USACE Portland District. The USACE technical leads were Robert Wertheimer, Sean Tackley, and Brad Eppard. The PNNL study project manager was Mark Weiland (509 427-5923). The data are archived at PNNL offices in North Bonneville, Washington. 


\section{Executive Summary}

Improving the survival rate of juvenile salmonids migrating downstream through the Federal Columbia River Power System (FCRPS) continues to be a high priority for the USACE and the region. Many of these fish are from populations listed as threatened or endangered under the Endangered Species Act. Increasing survival rates is necessary to ensure sustainable salmon populations in the future and meet performance standards set forth in the 2008 Biological Opinion (BiOp) and 2008 Columbia Basin Fish Accords on operation of the FCRPS. The BiOp mandates that a 96\% and 93\% survival rate be achieved for spring and summer downstream migrating juvenile salmonids, respectively. At John Day Dam (JDA), the Portland District is evaluating the provision of surface-flow outlets (SFOs) as a means to increase fish-passage efficiency and in turn increase the fish-passage survival rate by reducing turbine passage of juvenile salmonids. The goal of the study reported here was to provide fish-passage and survival data necessary to evaluate the performance of the prototype SFO, called a top-spill weir (TSW), and the dam as a whole relative to the performance standards in the BiOp. The Portland District and regional fisheries managers will use the data to adaptively manage the configuration and operation of JDA to maximize the survival rate for juvenile salmonids.

This is the report of research for the acoustic telemetry evaluation of juvenile salmonids during 2009 at JDA. The study was conducted by the Pacific Northwest National Laboratory and the University of Washington for the U.S. Army Corps of Engineers (USACE) Portland District.

\section{S.1 Objectives}

The overall purpose of the acoustic-telemetry study at JDA during 2009 was to determine the best configuration and operation for JDA prior to conducting BiOp performance standard tests. The primary objective was to determine the best operation between $30 \%$ and $40 \%$ spill treatments. Route-specific, JDA forebay-to-TDA forebay, JDA-to-The Dalles Dam (TDA) forebay survival estimates, passage distribution, and timing/behavior metrics were used for comparison of $30 \%$ and $40 \%$ spill treatments. A secondary objective was to evaluate the performance of TSWs installed in spill bays 15 and 16 and to estimate fish survival rates and passage efficiencies under $30 \%$ and $40 \%$ spill-discharge treatments each season.

It was initially planned to conduct this study using a paired-release model to estimate survival. Prior to the start of the study, the decision was made to release fish only above JDA and use a single-release model to improve the chance of detecting a significant difference between the two spill treatments as well as passage distribution and timing metrics. The survival estimate for the single-release model was calculated from JDA to TDA forebay. The spill bays with TSWs installed and southernmost spill bays (spill bays 15-20) where closed during the 2009 summer study period because of excessive predation by gulls in the TSW outfall plume. The field study period began with fish releases on April 27 and ended on August 25, 2009, when at least $90 \%$ of the acoustic tags from the last release had died, as estimated from the 2009 tag-life study.

The study objectives and sub-objectives, applied separately to yearling Chinook salmon (CH1), steelhead (STH), and subyearling Chinook salmon ( $\mathrm{CH} 0$ ) surgically implanted with acoustic tags at JDA during 2009, were to do the following: 
1. Estimate survival rates ${ }^{1}$ as follows:
a. JDA-to-TDA forebay (from the dam face at JDA to TDA forebay array $2 \mathrm{~km}$ upstream of TDA) and route-specific estimates
b. JDA forebay-to-TDA forebay (from the forebay array $2 \mathrm{~km}$ upstream of JDA to TDA forebay array $2 \mathrm{~km}$ upstream of TDA)
c. JDA seasonal and day/night trends
d. Association of JDA passage route and survival rates at TDA.

2. Estimate passage metrics and distributions as follows: TSW efficiency (TSWE), juvenile bypass system passage-efficiency (JBSE), spill-passage effectiveness (SPEF), and TSW effectiveness (TSWEF)
a. Fish-passage efficiency (FPE), spill-passage efficiency (SPE), fish-guidance efficiency (FGE),
b. Powerhouse horizontal distribution and the relationship between passage and discharge
c. Spillway horizontal distribution
d. Day/night trends in passage.

3. Characterize fish behavior as follows:
a. Approach patterns and eventual passage routes
b. Day/night behavior patterns
c. Vertical distribution behavior patterns
d. Travel times and forebay residence times.

4. Determine the effect of spill condition ( $30 \%$ versus $40 \%$ spill) on survival rates and passage efficiencies.

\section{S.2 Methods}

This study used the Juvenile Salmon Acoustic Telemetry System (JSATS). JSATS acoustic tags and passive integrated transponder (PIT) tags were surgically implanted in $3470 \mathrm{CH} 1$ and $3471 \mathrm{STH}$ in spring and in $3461 \mathrm{CH} 0$ in summer 2009. Median lengths of tagged fish were: $\mathrm{CH} 1=146 \mathrm{~mm}$; $\mathrm{STH}=212$ $\mathrm{mm} ; \mathrm{CHO}=110 \mathrm{~mm}$. Tagged $\mathrm{CH} 1$ and $\mathrm{STH}$ were released daily over a 29-day spring period (4/27 to 5/26/09) at Roosevelt, Washington. Similarly, CH0 implanted with acoustic transmitters were released in summer over a 29-day period (6/16 to 7/15/09) at Roosevelt, Washington (rkm 390).

To detect signals from fish tagged with JSATS acoustic transmitters for the JDA evaluation, six arrays of hydrophones were deployed. A dam-face cabled array was placed on the upstream side of JDA (rkm 349). Five arrays of autonomous receivers were deployed at river cross sections located $2 \mathrm{~km}$ upstream (rkm 351) and $2 \mathrm{~km}$ downstream (rkm 347) of JDA, $2 \mathrm{~km}$ upstream of TDA (rkm 311), $1.5 \mathrm{~km}$ upstream of Bonneville Dam (BON; rkm 236), and downstream of BON at Lady Island (rkm 192; Camas, Washington). The JDA forebay array was used to create a virtual release for fish known to have entered the forebay $2 \mathrm{~km}$ upstream of JDA to estimate forebay survival. The JDA dam-face array was used to

\footnotetext{
${ }^{1}$ See Section 2.1.3 for definitions.
} 
create a virtual release for fish known to have passed the dam and to estimate JDA-to-TDA forebay and route-specific-passage survival rates based on three-dimensional (3D) and last-detection data. Time of last detection on the dam-face array minus the time of first detection on the forebay entrance array at JDA was used to estimate forebay residence time. TDA forebay array was the primary array for estimating the survival rate for tagged smolts passing through JDA. The BON forebay array was used as the secondary array for estimating the passage survival rate from JDA to TDA forebay. The first BON tailwater array near Lady Island was used as the tertiary array for estimating the product of survival and detection rates $(\lambda)$ for tagged smolts passing through JDA.

Data from the receiving arrays were used to address the four main objectives. Single releaserecapture methods using tagged fish regrouped at the JDA forebay array or at the dam-face array were applied to estimate the survival rates for each fish stock. (Paired-release estimates could not be made in 2009 because no tagged fish were released in the JDA tailrace.) Using the smolts known to have passed through a specific route at the dam, absolute survival rates from the dam entrance to TDA forebay array were estimated using a single release-recapture model. No tag-life corrections (after Townsend et al. 2006) were applied to the individual release Cormack-Jolly-Seber survival estimates because all fish passed the tertiary array before tag-life failure occurred. The route-specific passage data were used to estimate passage efficiencies and distributions. Fish behavior was assessed by 3D tracking of JSATStagged fish in the immediate forebay of JDA. The effects of spill condition (30\% vs. $40 \%$ spill out of total project discharge) were statistically evaluated using the survival and passage efficiency data obtained within a randomized block design with 2-day treatments.

\section{S.3 Results}

\section{S.3.1 Environmental Conditions}

During the 2009 study period, mean daily project discharge was above the previous 10 -year average in spring and early summer, but dropped below average during July. Forebay water temperatures were 12 degrees below the 10-year average most of spring and within 1 degree of the 10 -year average most of summer, except for the last 1.5 weeks in July when they were 1-4 degrees above average. Run timing for the run-at-large of CH1 and STH both peaked in May 2009; 50\% passed by May 17 and May 10, respectively. Run timing for the run-at-large of $\mathrm{CH} 0$ salmon peaked in late June $2009 ; 50 \%$ passed by July 1, 2009. Length frequency distributions of tagged and run-of-river juvenile salmon populations were very similar for all three runs in 2009.

\section{S.3.2 JSATS Performance}

The combined detection probability of the dam-faced array for each of three tagged fish runs was $96.3 \%$ for $\mathrm{CH} 1,95.6 \%$ for $\mathrm{STH}$, and $97.9 \%$ for $\mathrm{CH}$. Detection probabilities for autonomous arrays were over $99 \%$ for arrays deployed upstream of TDA, 92 to $95 \%$ for the BON forebay array, 90 to $98 \%$ for the first tailwater reach below BON, and 92 to $95 \%$ for the second tailwater reach. For the BON forebay and tailrace arrays, detection probabilities were consistently higher for $\mathrm{CH} 0$ passing in summer (95 to $98 \%$ ) than they were for CH1 (92\%) and STH (90 to 92\%) passing in spring 2009. 
All acoustic tags in the tag-life study were active for the expected 23 days. Mean time to tag failure was $30 \pm 1.0$ (standard error) days. The range in time until tag failure was from 24 to 49 days. All stocks of fish passed the tertiary array before there were any tag failures due to battery life.

A major assumption of the survival models used in this study is that upstream detections do not affect downstream detection or survival probabilities. This assumption is assessed using Burnham Tests 2 and 3. For $\mathrm{CH} 1$, none of the results for Test 2 were significant, and out of 74 runs of Test 3, 6 (8\%) were significant at $\alpha=0.1$. For STH, 4 of 69 runs $(6 \%)$ for Test 2 and 4 of 69 for Test $3(6 \%)$ were significant. For CH0, 2 of 53 results (4\%) for Test 2 were significant and, for Test 3, 2 of 53 (4\%) were significant at $\alpha=0.1$.

\section{S.3.3 Survival Rates}

For JDA as a whole, JDA-to-TDA forebay single-release estimates of survival rates were highest for $\mathrm{CH} 1$ (0.927) and STH (0.953) and lowest for $\mathrm{CH} 0$ (0.839) (Table S.1). The highest survival rates were at the juvenile bypass system (JBS; 0.975 for $\mathrm{CH} 1,0.966$ for STH, and 0.908 for CH0). The TSW had the second highest route-specific survival rates in spring ( 0.951 for $\mathrm{CH} 1$ and 0.963 for STH; the TSW was not operated in summer during the $\mathrm{CH} 0$ migration). The lowest survival rates were observed at the turbine route. Generally, survival rates over successive 2-day periods for all three tagged populations tended to decrease slightly as the season progressed. Survival estimates for STH were generally higher during night than during day regardless of route of passage.

Table S.1. Single-Release Estimates of JDA-to-TDA Forebay (FB) and Route-Specific Survival During 2009

\begin{tabular}{lcccccc}
\hline & \multicolumn{2}{c}{ CH1 } & \multicolumn{2}{c}{ STH } & \multicolumn{2}{c}{ CH0 } \\
\hline \multicolumn{1}{c}{ Route } & Single $\backslash$ Release & $1 / 295 \%$ CI & Single Release & $1 / 295 \%$ CI & Single Release & $1 / 295 \%$ CI \\
\hline JDA-to-TDA FB & 0.927 & 0.010 & 0.953 & 0.008 & 0.839 & 0.014 \\
Non-TSW & 0.913 & 0.014 & 0.936 & 0.016 & 0.847 & 0.016 \\
TSW & 0.951 & 0.014 & 0.963 & 0.010 & - & -- \\
Turbine & 0.851 & 0.047 & 0.824 & 0.080 & 0.749 & 0.039 \\
JBS & 0.975 & 0.016 & 0.966 & 0.014 & 0.908 & 0.031 \\
\hline CI = confidence interval & \multicolumn{1}{c}{}
\end{tabular}

\section{S.3.4 Effect of Spill Condition on Survival and Passage}

During spring 2009, dam operators were able to meet spill treatment requirements for the first five of eight blocks in spring. Compared to spill treatments that occurred during the first five blocks that closely met prescribed treatments, a one-tailed paired t-test showed that survival rates for $\mathrm{CH} 1$ were significantly ( $\mathrm{P}=0.0330$ ) higher during the $30 \%$ spill treatment than they were during the $40 \%$ spill treatment. The survival difference for STH was not significant for the 5 block test $(\mathrm{P}=0.1430)$. During summer, the prescribed spill treatments were met reasonably well during the last seven blocks and very well during the last five blocks of the summer test. The TSWs and spill bays 17-20 were closed in summer and water was spilled only through spill bays $2-14$. This operational change was the result of hydraulic patterns that developed below the TSW bays and spill bays 17-20 that aided predatory birds in their search for 
juvenile fish, reducing survival rates of juvenile salmon through the dam. Survival rates from JDA-toTDA forebay for $\mathrm{CHO}$ were about $84-85 \%$ for both the $30 \%$ and $40 \%$ spill treatments and were not statistically different for either the five $(\mathrm{P}=0.2916)$ or seven block $(\mathrm{P}=0.4535)$ groups. Spill- passage efficiency was higher under the $40 \%$ spill treatment than under the $30 \%$ spill treatment, but the opposite was true for all other fish-passage metrics (Table S.2).

Table S.2. Estimates of Survival from JDA to TDA Forebay, Passage Efficiencies and Effectiveness by Spill Condition During 2009. Confidence intervals are provided in corresponding tables in the main body of the report and in all instances overlapped with those of the alternative spill condition. The TSW was not operated during summer 2009.

\begin{tabular}{lcccccc}
\hline & \multicolumn{2}{c}{ CH1 } & \multicolumn{2}{c}{ STH } & \multicolumn{2}{c}{ CH0 } \\
\hline \multicolumn{1}{c}{ Metric } & $30 \%$ & $40 \%$ & $30 \%$ & $40 \%$ & $30 \%$ & $40 \%$ \\
\hline JDA-to-TDA FB & 0.930 & 0.924 & 0.960 & 0.946 & 0.847 & 0.834 \\
FPE & 0.926 & 0.943 & 0.968 & 0.980 & 0.832 & 0.854 \\
FGE & 0.694 & 0.606 & 0.887 & 0.894 & 0.451 & 0.397 \\
SPE & 0.759 & 0.854 & 0.715 & 0.812 & 0.695 & 0.758 \\
TSWE & 0.315 & 0.226 & 0.485 & 0.518 & -- & -- \\
JBSE & 0.168 & 0.088 & 0.253 & 0.168 & 0.138 & 0.096 \\
SEF & 2.513 & 2.207 & 2.369 & 2.097 & 2.318 & 2.111 \\
TSWEF & 4.349 & 2.980 & 6.700 & 6.835 & -- & -- \\
\hline
\end{tabular}

\section{S.3.5 Passage Metrics and Distributions}

Passage metrics were highest for STH and lowest for $\mathrm{CH} 0$ (Table S.3). Of total project passage, $7 \% \mathrm{CH} 1,3 \% \mathrm{STH}$, and $15 \% \mathrm{CH} 0$ passed through turbines. Passage generally was highest at the end units of the powerhouse (T1-3 and T14-16). For each run, regressions of number of tagged fish passing into each unit in spring on unit-specific discharge were significant $(\mathrm{P}<0.0001)$ with discharge explaining a majority of the variation in passage into the powerhouse. Spillway horizontal distributions during spring were skewed with highest passage through the TSWs in spill bays 15 and 16. During summer, passage was fairly uniform at the open bays (S2-14). Total passage and spillway passage rates for $\mathrm{CH} 1$ and STH were higher during the day than they were at night, while passage rates for the powerhouse (JBS and turbines) were higher at night than during the day. For $\mathrm{CH}$, passage rates for the powerhouse, turbines, and JBS were higher at night than during the day; the opposite was true at the spillway.

Table S.3. Summary of Passage Efficiency and Effectiveness Data During 2009 at JDA. Confidence intervals are provided in corresponding tables in the main body of the report. The TSW was closed during the $\mathrm{CHO}$ migration in summer 2009.

\begin{tabular}{llcc}
\hline Metric & CH1 & STH & CH0 \\
\hline FPE & 0.934 & 0.974 & 0.845 \\
SPE & 0.806 & 0.763 & 0.732 \\
FGE & 0.662 & 0.890 & 0.422 \\
TSWE & 0.271 & 0.501 & -- \\
JBSE & 0.128 & 0.211 & 0.113 \\
SPEF & 2.366 & 2.239 & 2.211 \\
TSWEF & 3.663 & 6.781 & -- \\
\hline
\end{tabular}




\section{S.3.6 Fish Behavior}

The approach of $\mathrm{CH} 1$ at JDA during 2009 was as follows: $40 \%$ at the powerhouse, $13 \%$ at the skeleton bays, and $47 \%$ at the spillway (Figure S.1a). Of the tagged $\mathrm{CH} 1$ first detected approaching the powerhouse or skeleton bays, $66 \%$ eventually moved north and passed at the spillway. Fish approaching at the spillway were more likely to pass through the dam at the spillway ( $46 \%$ of total approach) than at the powerhouse (1.6\% of total approach).

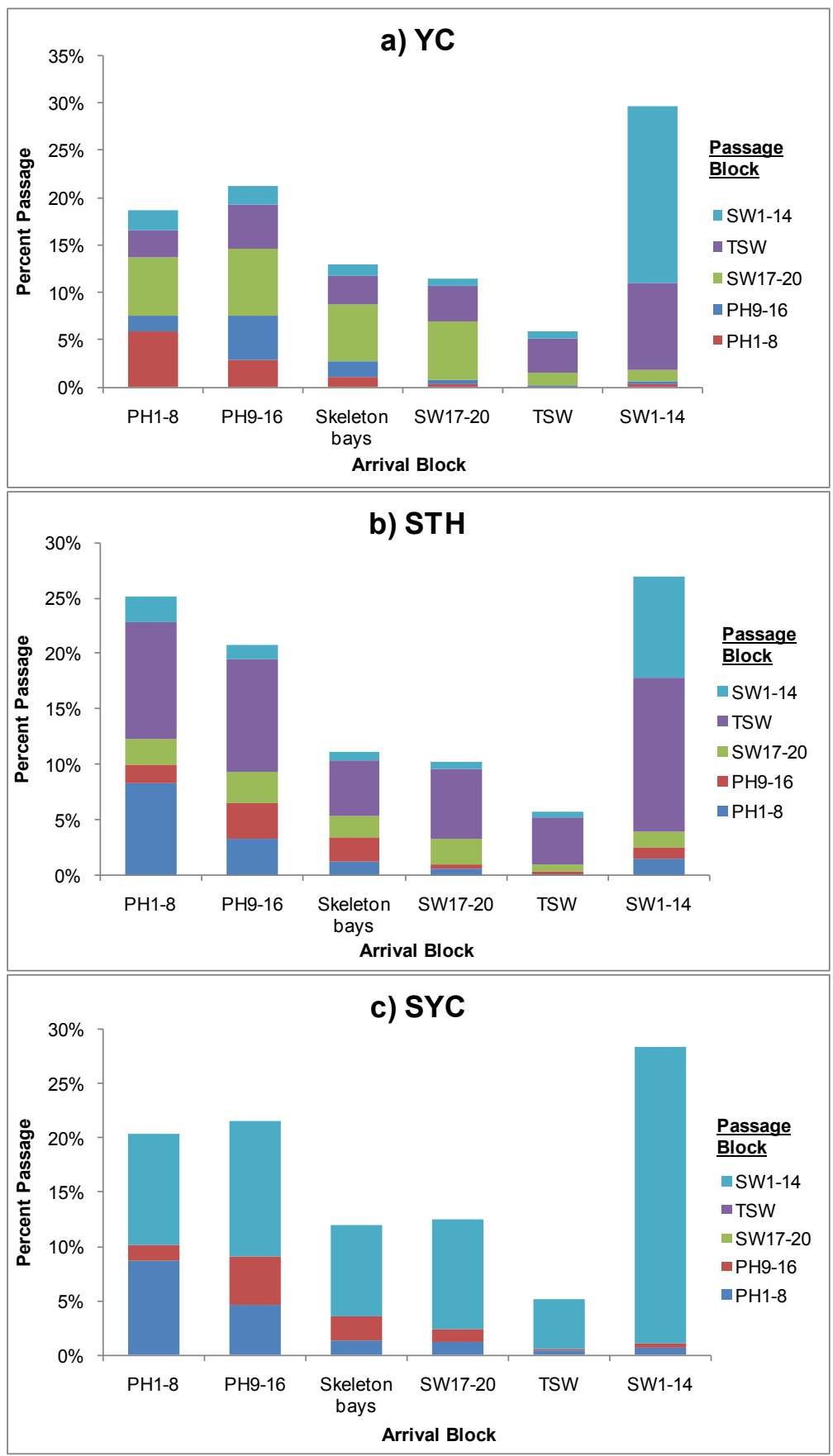

Figure S.1. Fish Behavior Expressed as Approach and Passage Patterns at the Forebay of JDA, 2009 
The forebay approach pattern for STH was $46 \%$ at the powerhouse, $11 \%$ at the skeleton bays, and $43 \%$ at the spillway (Figure S.1b). Of the tagged STH first detected approaching the powerhouse or skeleton bays, 65\% moved north and passed at the spillway. As with CH1, STH approaching at the spillway were more likely to pass through the dam at the spillway (39\% of total approach) than at the powerhouse $(3.8 \%$ of total approach).

For $\mathrm{CH} 0,42 \%$ approached in the forebay of the powerhouse, $12 \%$ at the skeleton bays, and $46 \%$ at the spillway forebay (Figure S.1c). Of the $\mathrm{CH} 0$ approaching at the powerhouse and skeleton bays, 58\% ended up passing at the spillway even with the TSWs closed. On the other hand, few CH0 approaching the spillway moved south to pass at the powerhouse ( $4.1 \%$ of total approach).

On a day/night basis, tagged fish passing the powerhouse at night tended to approach at the powerhouse. However, during daytime fish approaching the powerhouse were more likely to migrate to the spillway and pass there rather than pass at the powerhouse. A similar pattern held for fish approaching the skeleton bay area. Upon approaching the spillway, tagged fish displayed a tendency to pass there during the day; this pattern was also evident at night.

Vertical distribution in the forebay was surface oriented with most tagged fish in the surface 5 to $7 \mathrm{~m}$ of the water column. Steelhead were the shallowest and $\mathrm{CH} 0$ the deepest of the three tagged populations. Fish approaching the powerhouse (within $75 \mathrm{~m}$ ) tended to be about $5 \mathrm{~m}$ deeper than those approaching the spillway.

For the project as a whole, median residence times in the JDA forebay were 2.9 hours for $\mathrm{CH} 1$, 5.5 hours for $\mathrm{STH}$, and 3.8 hours for $\mathrm{CH}$ (Table S.4). Residence times were shortest for fish passing at the TSW and longest for fish passing at the powerhouse.

Table S.4. Residence Times (hours) in the JDA Forebay (defined as the $2 \mathrm{~km}$ upstream of the dam)

\begin{tabular}{lcccccc}
\hline & \multicolumn{2}{c}{ CH1 } & \multicolumn{2}{c}{ STH } & \multicolumn{2}{c}{ CH0 } \\
\hline \multicolumn{1}{c}{ Route } & Median & Mean & Median & Mean & Median & Mean \\
\hline Project & 2.9 & 4.8 & 5.5 & 8.9 & 3.8 & 7.2 \\
JBS & 4.0 & 5.8 & 7.5 & 10.2 & 3.8 & 8.2 \\
Turbine & 2.7 & 4.6 & 6.1 & 13.3 & 4.6 & 9.0 \\
TSW & 2.6 & 4.5 & 4.8 & 8.2 & -- & -- \\
Spillway (non-TSW) & 3.7 & 6.3 & 5.5 & 8.8 & 3.6 & 6.7 \\
\hline
\end{tabular}

\section{S.4 Conclusions}

The main conclusions from the acoustic telemetry evaluation of survival rates, fish-passage efficiencies and distributions, fish behavior, and effects of spill condition for $\mathrm{CH} 1$ salmon, $\mathrm{STH}$, and $\mathrm{CH} 0$ at JDA during 2009 are as follows. 
- Survival Rates

- For 2009, single-release estimates of JDA-to-TDA forebay- passage survival rates for CH1 $\left(0.927 \pm 0.010^{1}\right)$ and STH $(0.953 \pm 0.008)$ did not meet the $96 \%$ performance standard set forth in the $2008 \mathrm{BiOp}$ for yearling migrants. Estimates for $\mathrm{CH0}(0.839 \pm 0.014)$ are below the $\mathrm{BiOp}$ standard of $93 \%$ for subyearling migrants.

- The passage route with the highest survival rate is the JBS (0.908 to 0.975$)$ and, the turbines had the worst route survival $(0.749$ to 0.851$)$.

- Passage Efficiencies and Distributions

- Fish-passage metrics are generally highest for STH and lowest for CH0. Proportionately more $\mathrm{CH} 0$ than $\mathrm{CH} 1$ or STH pass the dam via turbines.

- Fish-passage rates at individual turbine units are strongly, positively correlated with unit-specific discharge.

- Fish Behavior

- Spill and TSW operations attracted downstream migrant juvenile salmonids to the spillway. About half of the tagged fish arriving in the forebay of the powerhouse and skeleton bays moved toward and passed at the spillway. In contrast, relatively few smolts approaching the spillway passed at the powerhouse.

- Fish approaching (within $100 \mathrm{~m}$ of the concrete) the spillway have the shortest median residence time of all approach paths (4 to 20 minutes, depending on fish run). The longest residence time is for fish approaching the powerhouse and then passing through the dam at the spillway or vice versa ( 2 to 7 hours).

- Downstream migrants are surface-oriented, being distributed in the upper portion of the water column $(<5-7 \mathrm{~m})$ on approach to the dam.

- Effect of Spill Condition (30\% versus 40\% spill)

- There is no statistically significant difference in fish performance between the two treatments when comparing the $30 \%$ versus $40 \%$ spill conditions over the entire study. Survival, however, was significantly higher at $30 \%$ spill for $\mathrm{CH} 1$ for the first five blocks when spill treatments were maintained accurately. Survival estimates, passage efficiencies, and fish behaviors are similar between the two spill conditions. The increase in spill discharge from $30 \%$ to $40 \%$ of total water discharge through the dam basically serves to pass incrementally more fish at non-TSW bays and incrementally fewer fish at the TSW bays.

- TSW Performance

- In terms of fish collection, the TSWs perform well when they are operated. Using about $20 \mathrm{kcfs}$, the TSW bays passed half of the STH and a quarter of the $\mathrm{CH} 1$, respective to totals passing through JDA.

\footnotetext{
${ }^{1} \pm 1 / 295 \%$ confidence interval.
} 
- As intended in the TSW design and operation, the TSW surface flows appeared to attract, or at the least provide a surface outlet opportunity, for fish that had originally arrived at the dam in the powerhouse forebay. Passage at the TSW bays was much higher during the day than it was at night, which is consistent with observations at many other SFOs (Johnson and Dauble 2006; Sweeney et al. 2007).

\section{S.5 Recommendations}

Based on the 2009 results, recommendations include the following:

- Assuming there would be no adverse impact on tailrace passage conditions, the TSWs should be moved closer to the powerhouse to maximize the collection of fish approaching the powerhouse and thereby minimize turbine passage.

- To date, there is only 1 year (2008) of TSW evaluation for CH0. Performance of the TSW during summer for $\mathrm{CH} 0$ should be addressed in future studies.

- After due diligence examination of tailrace hydraulics in a physical scale model, a comparison of $20 \%$ versus $40 \%, 10 \%$ versus $30 \%$, or other spill treatment with a larger range might be considered for future studies. 


\section{Acknowledgments}

Many people made valuable contributions to this study and deserve acknowledgment. The Pacific States Marine Fisheries Commission Supervisor at the JDA Smolt Monitoring Facility (SMF), Greg Kovalchuk, was very helpful in coordinating fish collections with daily fish sampling at the respective locations. Seasonal staff of the Pacific States Marine Fisheries Commission also helped with tagging fish: Terry Goss, Matt Meyer, and Randy Wall.

We thank PNNL staff for their assistance: project coordination (Geoff McMichael), surgery training (Rich Brown and Kate Deters), fish tagging, transport, and release (Chris Anderson and Kathleen Carter), tag-life study (Jim Boyd, Andy Solcz, and Scott Carpenter), Juvenile Salmon Acoustic Telemetry System development (Eric Choi, Brian LaMarche, Daniel Deng, Tao Fu, Thomas Seim, and Thomas Carlson), database entry and management (Jessica Carter) and report review and editing (George Batten, Matt Hennen, Ben Miller, Joanne Duncan, Susan Ennor, and Meghan Chalk). David Geist was the Ecology Group Manager at PNNL, and Dr. Stephan Schlahta was the Product-Line Manager during this study.

Advanced Telemetry Systems (ATS), Inc. manufactured the acoustic tags. Autonomous and dammounted hydrophones were manufactured by Sonic Concepts, Seattle, Washington. Precision Acoustic Systems, also in Seattle, made the quad channel receivers and conducted node acceptance tests for PNNL. Cascade Aquatics, Inc. in Ellensburg, Washington, activated and delivered the acoustic tags. Schlosser Machine Shop fabricated anchors for autonomous nodes and frames for star clusters that were deployed in the spillway forebay. 


\section{Acronyms and Abbreviations}

2D

3D

A1CR351

A2CR346

A3CR311

A4CR236

A5CR 192

A6CR113

AT

ATS

B2

$\mathrm{BiOp}$

BON

${ }^{\circ} \mathrm{C}$

$\mathrm{CF}$

cfs

CI

CSV

d

DART

DSP

FCRPS

FPE

FGE

FPGA

$\mathrm{ft}$

$\mathrm{g}$

GPS

$\mathrm{h}$

HA

JBS

JBSE

JDA two-dimensional

three-dimensional

John Day Dam forebay entrance array

John Day Dam tailwater egress array

The Dalles Dam forebay entrance array; John Day Dam primary survivaldetection array

Bonneville Dam forebay entrance array; John Day Dam secondary survivaldetection array; The Dalles Dam primary survival-detection array

First Bonneville tailwater array; John Day Dam tertiary survival-detection array; The Dalles Dam secondary survival-detection array

Second Bonneville Dam tailwater survival-detection array; The Dalles Dam tertiary survival-detection array

acoustic telemetry

Advanced Telemetry Systems, Inc.

(Bonneville) Powerhouse 2

Biological Opinion

Bonneville Dam

degree(s) Celsius or Centigrade

Compact Flash (card)

cubic feet per second

confidence interval (1/2 95\%)

comma-separated variables

day(s)

Data Access in Real Time

digital signal-processing card

Federal Columbia River Power System

fish-passage efficiency

fish-guidance efficiency (in-turbine screens)

field-programmable logic gate array

foot(feet)

$\operatorname{gram}(\mathrm{s})$

global positioning system

hour(s)

hydroacoustic

juvenile bypass system

juvenile bypass system-passage efficiency

John Day Dam 


\begin{tabular}{|c|c|}
\hline JSATS & Juvenile Salmon Acoustic Telemetry System \\
\hline $\mathrm{kcfs}$ & thousand cubic feet per second \\
\hline $\mathrm{km}$ & kilometer \\
\hline $\mathrm{L}$ & liters \\
\hline LRT & likelihood ratio test \\
\hline $\mathrm{m}$ & meter(s) \\
\hline $\min$ & minute(s) \\
\hline $\mathrm{mL}$ & milliliter \\
\hline $\mathrm{mm}$ & millimeter \\
\hline MSL & mean sea level \\
\hline NA & not applicable \\
\hline NOAA & National Oceanic and Atmospheric Administration \\
\hline PIT & passive integrated transponder \\
\hline PNNL & Pacific Northwest National Laboratory \\
\hline $\mathrm{rkm}$ & river kilometer \\
\hline RT & radio telemetry \\
\hline $\mathrm{s}$ & second(s) \\
\hline SPE & spill-passage efficiency \\
\hline SEF & spill-passage effectiveness \\
\hline SFO & surface-flow outlet \\
\hline SMF & Smolt Monitoring Facility (John Day Dam) \\
\hline STH & steelhead \\
\hline SW & spillway or spillway block \\
\hline $\mathrm{CHO}$ & subyearling Chinook salmon \\
\hline TDA & The Dalles Dam \\
\hline TOA & time of arrival \\
\hline TOAD & time of arrival difference \\
\hline TSW & top-spill weir \\
\hline TSWE & top-spill weir-passage efficiency \\
\hline TSWEF & top-spill weir-passage effectiveness \\
\hline$\mu \mathrm{Pa}$ & micro-Pascal \\
\hline$\mu \mathrm{s}$ & micro-seconds \\
\hline USACE & U.S. Army Corps of Engineers \\
\hline UW & University of Washington \\
\hline WEL & Wells Dam \\
\hline $\mathrm{CH} 1$ & yearling Chinook salmon \\
\hline
\end{tabular}




\section{Contents}

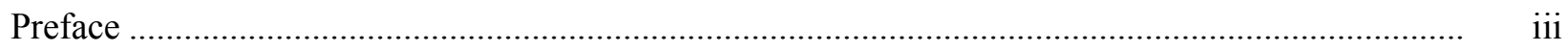

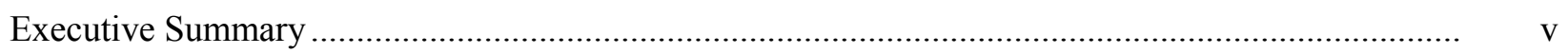

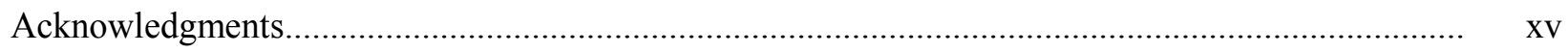

Acronyms and Abbreviations ........................................................................................... $\quad$ xvii

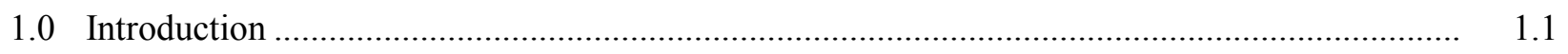

1.1 Previous Survival and Passage Studies ........................................................................ 1.1

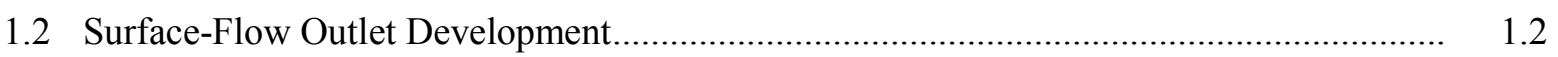

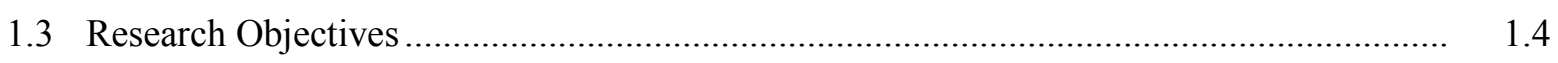

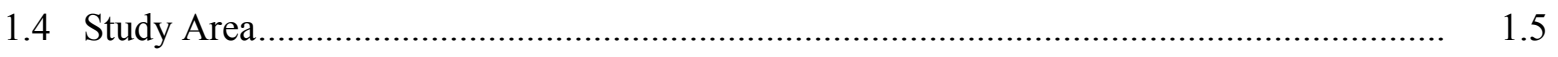

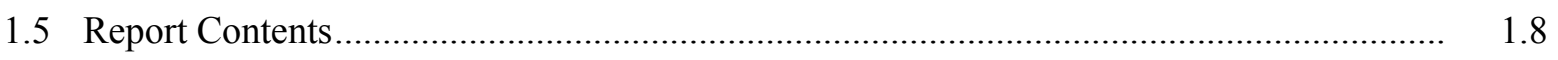

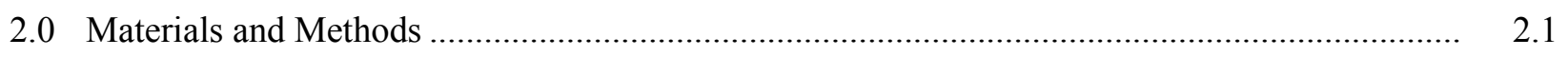

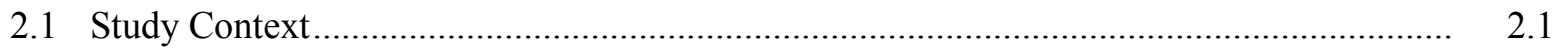

2.1.1 Water Discharge and Temperature ................................................................ 2.1

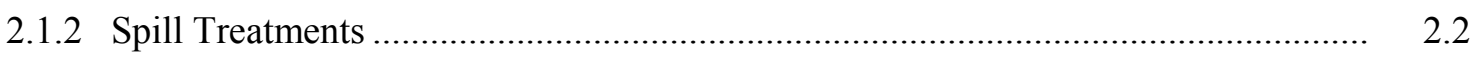

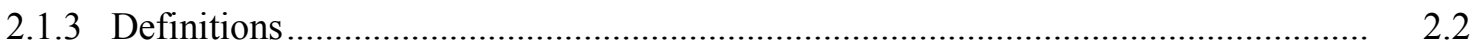

2.2 Fish Collection, Tagging, Transportation, and Release …............................................ 2.4

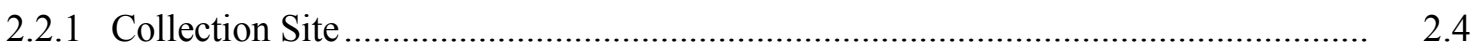

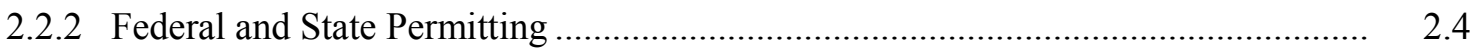

2.2.3 Sampling Methods.......................................................................................... 2.5

2.2.4 JSATS Acoustic Micro-Transmitter and Tag Implantation .................................. 2.7

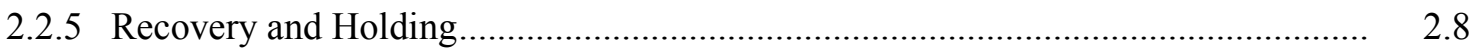

2.2.6 Fish Transportation and Release .................................................................. 2.9

2.3 Detection of Tagged Fish ................................................................................... 2.10

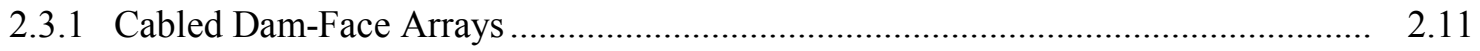

2.3.2 Autonomous Receiver Arrays ...................................................................... 2.14

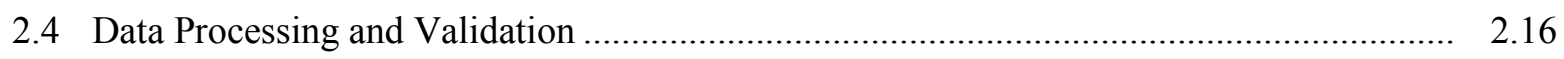

2.4.1 Signal Decoding and Filtering..................................................................... 2.16

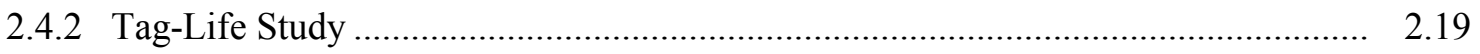

2.5 Statistical Methods for Estimating Survival Rates ....................................................... 2.19

2.5.1 Defining Virtual Releases for Estimating Survival Rates ..................................... 2.19

2.5.2 Estimation of JDA Forebay-to-TDA Forebay and JDA-to-TDA Forebay-
Passage Survival Rates ..................................................................................... 2.21

2.5.3 Tests of Assumptions ................................................................................ 2.22

2.5.4 Probabilities of Detection by Passage Route........................................................ 2.24

2.5.5 Route-Specific Relative Survival Rates ........................................................... 2.27

2.5.6 Route-Specific Passage Survival Rates ............................................................ 2.27

2.6 Statistical Methods - Fish Passage........................................................................... 2.28 


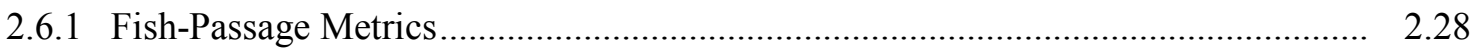

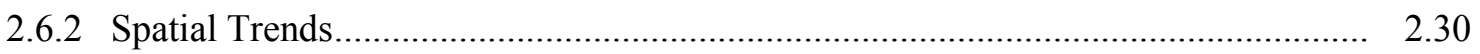

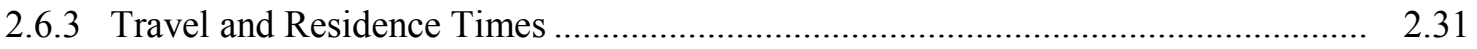

2.7 Statistical Methods - Fish Behavior..................................................................... 2.31

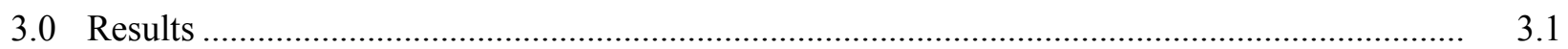

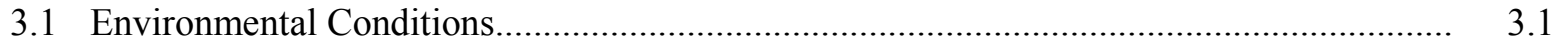

3.1.1 Dam Discharge and Temperature ............................................................... 3.1

3.1.2 Realized Spill Treatment Conditions ............................................................ 3.2

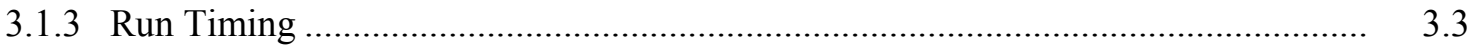

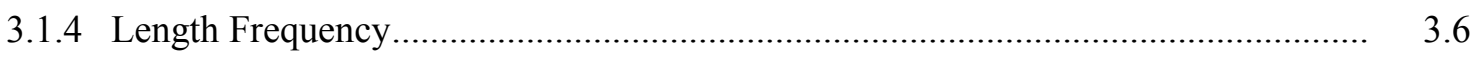

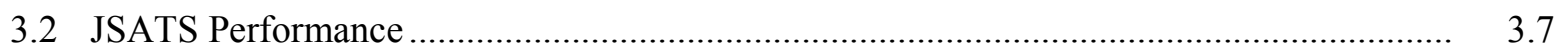

3.2.1 Detection Probabilities at Dam-Face Arrays .................................................... 3.7

3.2.2 Detection Probabilities and Fish Distributions at Autonomous Nodes .................... 3.8

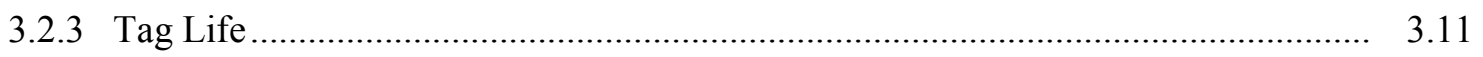

3.2.4 Tests of Survival-Model Assumptions ............................................................. 3.12

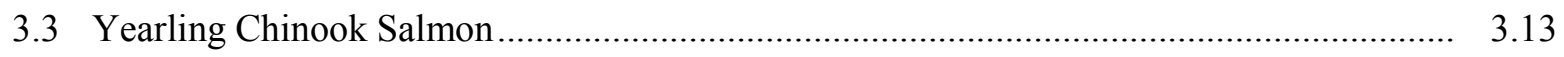

3.3.1 Effect of Spill Conditions on Fish .................................................................. 3.13

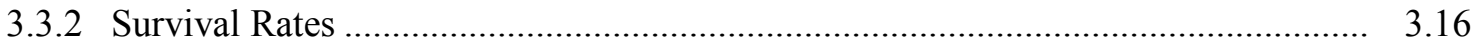

3.3.3 Passage Metrics and Distributions ............................................................. 3.20

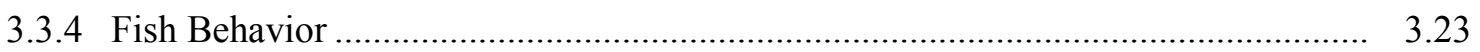

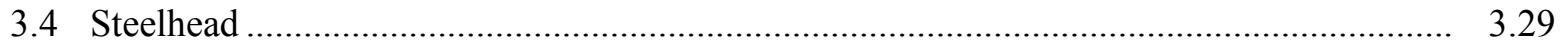

3.4.1 Effect of Spill Conditions on Fish ................................................................. 3.30

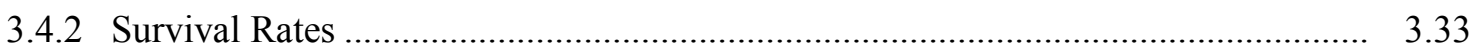

3.4.3 Passage Metrics and Distribution .................................................................... 3.36

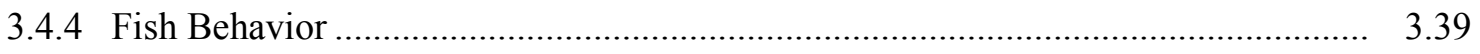

3.5 Subyearling Chinook Salmon............................................................................... 3.46

3.5.1 Effect of Spill Conditions on Fish ................................................................. 3.46

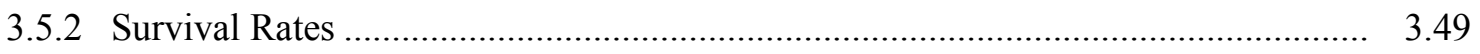

3.5.3 Passage Metrics and Distribution .............................................................. 3.52

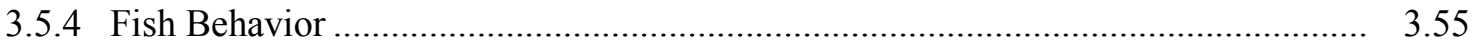

4.0 Discussion, Conclusions, and Recommendations ........................................................... 4.1

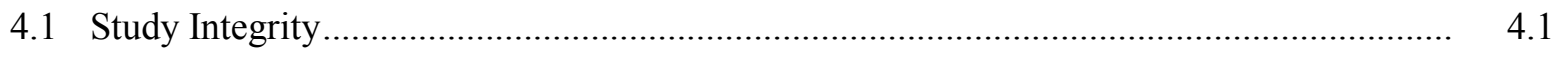

4.2 Comparison of Survival Rates and Passage Efficiencies for 30\% versus 40\% Spill

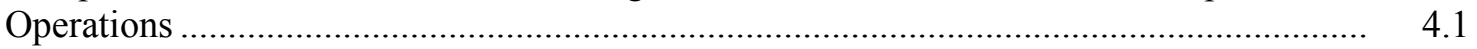

4.3 Performance of the Prototype TSW Surface Flow Outlet ............................................... 4.2

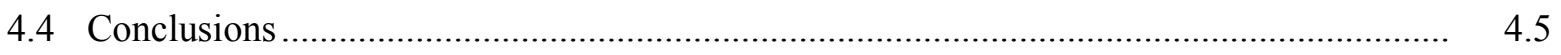

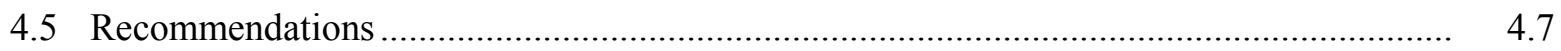

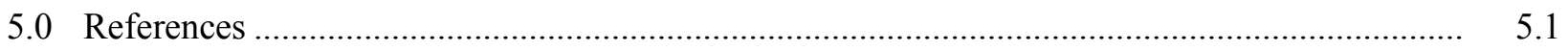

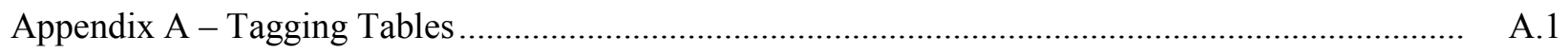


Appendix B - Hydrophone and Autonomous Node Deployment Tables ......................................... B.1

Appendix C - Survival and Detection Probabilities for Single Releases ....................................... C.1

Appendix D - Burnham Test Results ...................................................................................... D.1 


\section{Figures}

1.1 John Day Dam on the Columbia River ...............................................................................

1.2 2009 Study Area on the Columbia River from Roosevelt, Washington, to Camas,

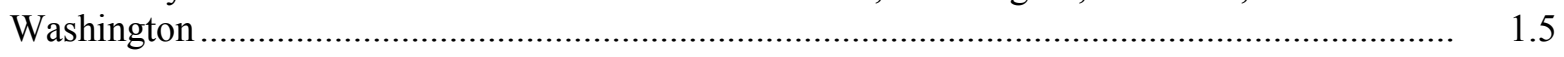

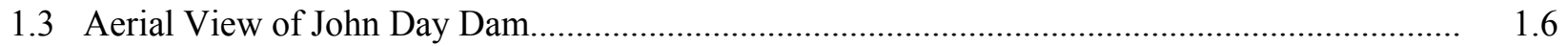

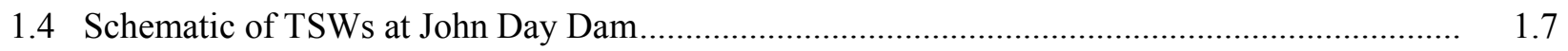

2.1 Spill Treatment Schedule at JDA from April 29 Through May 31, 2009............................... 2.2

2.2 Spill Treatment Schedule at JDA from June 14 Through July 20, 2009 ................................. 2.3

2.3 JSATS 0.43-g Acoustic Micro-Transmitter and PIT Tag Surgically Implanted in CH1, CH0,

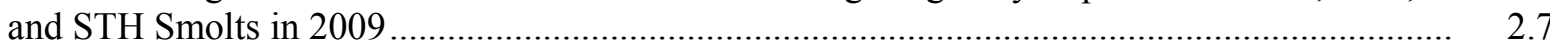

2.4 Surgical Implantation of PIT and Acoustic Tags in the John Day Smolt Monitoring Facility..... 2.8

2.5 Post-Surgery Holding Tank with Recovery Buckets ........................................................ 2.10

2.6 Schematic of the JSATS Dam-Face Receiver System Showing the Main Components and the Direction of Signal Acquisition and Processing ............................................................ 2.12

2.7 Location of Hydrophones on the Dam Face and in the Forebay of JDA, 2009 ....................... 2.13

2.8 Trolley Pipe Mounted on a Main Pier of the JDA Powerhouse.................................................. 2.13

2.9 Trolleys Used to Deploy Hydrophones at the John Day Powerhouse and Spillway, 2009 ......... 2.14

2.10 Side (left) and Bottom (right) Views of an Autonomous Node Top........................................ 2.14

2.11 Location of the Only Fish-Release Transect for the 2009 Study and Locations of Autonomous Nodes Deployed in Arrays to Detect Acoustically Tagged Fish Migrating Downstream

2.12 Autonomous Node Rigging ................................................................................ 2.16

2.13 Example of Time-Domain Waveforms and Corresponding Cross-Correlations Acquired at the JDA Spillway.....

2.14 Schematic of the Single-Release Design and Virtual Releases for Estimating JDA Forebayto-TDA Forebay and JDA-to-TDA Forebay-Passage Survival Rates at JDA.

2.15 Schematic of the Single-Release Design for Estimating Virtual TDA Forebay to BON Forebay-Passage Survival Rates at TDA in Spring and Summer

2.16 Schematic of Route-Specific Passage and Downstream Recoveries for Virtual Releases at

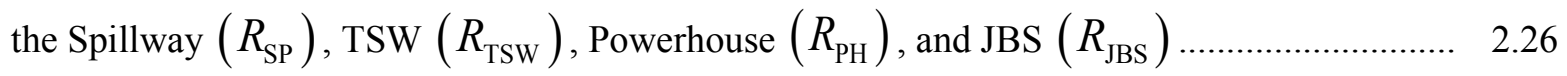

3.1 Estimated 2009 Daily Dam and Spillway Discharge Relative to the Previous 10-Year Average for JDA

3.2 Ten-Year Average Forebay Water Temperature Versus 2009 Daily Estimates from April 30 through July 30 at JDA.

3.3 Realized Spill Treatments at JDA, April 29 Through May 31, 2009.

3.4 Realized Spill Treatments at JDA, June 14 Through July 20, 2009.

3.5 Smolt Monitoring Program Passage Index for April 15-June 24, 2009, and the Number of STH Tagged Per Day

3.6 Smolt Monitoring Program Passage Index for April 15-June 24, 2009, and the Number of CH1 Tagged Per Day. 
3.7 Smolt Monitoring Program Passage Index for May 25-July 30, 2009, and the Number of CH0 Tagged Per Day .................................................................................................... 3.4

3.8 Length Frequency Distributions for Tagged and Run-of-River STH in 2009 .......................... 3.6

3.9 Length Frequency Distributions for Tagged and Run-of-River CH1 in 2009 .......................... 3.7

3.10 Length Frequency Distributions for Tagged and Run-of-River CH0 in 2009 .......................... 3.7

3.11 Detection Probabilities During 2009 by Reach for the Autonomous Arrays............................. 3.8

3.12 Percentage of Acoustic-Tag Detections by Fish Run on Autonomous Nodes During 2009.......... 3.9

3.13 Frequency of Detections on Multiple Autonomous Nodes During 2009 ................................. 3.10

3.14 Detection Probabilities as a Function of Water Discharge in Three Detection Arrays During 2009

3.15 Percentage of Acoustic Tags Still Transmitting Versus Time Since Tag Activation During 2009

3.16 Spill Treatments as Prescribed and Actual Conditions in Spring 2009

3.17 Seasonal Trend in Single-Release, JDA to TDA Forebay-Passage Survival Probability for CH1 at JDA in Spring 2009

3.18 Day and Night Single-Release Estimates of CH1 Survival Rates by Route of Passage During Spring 2009.

3.19 Seasonal Trend in Single-Release, Dam-Passage Survival Probability for CH1 at TDA in Spring 2009.

3.20 Percent Passage for Guided and Unguided CH1 and Percent Discharge by Turbine Unit for the John Day Powerhouse During Spring 2009

3.21 Regression of Fish-Passage on Percent Discharge for CH1 at the Powerhouse Turbine Units During Spring 2009

3.22 Percent CH1 Passage and Percent Discharge by Spill Bay During 2009 .

3.23 Average Percent Passage of CH1 Smolts and Percent Discharge Per Spill Bay Within Groups of Bays During 2009

3.24 Day and Night Differences in Passage Rates for CH1 During 2009

3.25 Day and Night Differences in Passage Rates for CH1 and Percentage of Discharge for Groups of Spill Bays During 2009.

3.26 Yearling Chinook Salmon Approach and Passage Distributions at JDA During Spring 2009....

3.27 Yearling Chinook Salmon Approach and Passage Behavior Patterns at JDA During 2009.

3.28 Yearling Chinook Salmon Approach and Passage Behavior Patterns During Day and Night, Spring 2009.

3.29 Approach and Passage Patterns for CH1 During Daytime at JDA, Spring 2009

3.26

3.30 Approach and Passage Patterns for CH1 Passing JDA at Night During Spring 2009.

3.26

3.31 Median Depths of Last Detection of Tagged CH1 at JDA During 2009.....

3.27

3.32 Median Depths of CH1 Passing into the JBS and Turbines, JDA 2009

3.27

3.33 Yearling Chinook Salmon Median Passage Times During 2009.

3.34 Yearling Chinook Salmon Day/Night Median Passage Times by Approach and Passage Blocks at JDA During 2009

3.35 Spill Treatments as Prescribed and Actual Conditions in Spring During 2009. The shaded areas represent odd numbered treatment blocks. 
3.36 Seasonal Trend in Single-Release, JDA-to-TDA Forebay-Passage Survival Probability for STH at JDA in Spring 2009.

3.37 Day and Night Single-Release Estimates of STH Survival Rates by Route of Passage During Spring 2009.

3.38 Seasonal Trend in Single-Release, TDA Forebay to BON Forebay-Passage Survival Probability for STH at TDA in Spring 2009.

3.39 Percent Passage for Guided and Unguided STH Smolts and Percent Discharge by Turbine Unit for the John Day Powerhouse During Spring 2009

3.40 Percent Passage for Guided and Unguided STH and Percent Discharge by Turbine Unit for the John Day Powerhouse During Spring 2009

3.41 Steelhead Passage and Percent Discharge by Spill Bay During 2009

3.42 Percent Passage of STH Smolts and Discharge for an Average Spill Bay Within Groups of Bays During 2009

3.43 Day and Night Passage Rates of STH by Route During Spring 2009

3.39

3.44 Day and Night Passage Rates for STH and Percent Discharge for Groups of Spill Bays .....

3.45 Steelhead Percent Passage by Approach and Passage Blocks at JDA During 2009.

3.40

3.46 Steelhead Approach and Passage Behavior Patterns at JDA During 2009

3.40

3.47 Steelhead Approach and Passage Patterns During Day and Night at JDA, 2009.

3.41

3.48 Approach and Passage Patterns for STH During Daytime, Spring 2009

3.41

3.49 Approach and Passage Patterns for STH During Nighttime, Spring 2009

3.42

3.50 Median Depths of Last Detection of Tagged STH at JDA During 2009.

3.42

3.51 Median Depths of Last Detection of Tagged STH Smolts at JDA During the Day ............

3.43

3.52 Median Depths of Last Detection of Tagged STH Smolts at JDA at Night

3.43

3.53 Steelhead Median Last-Detection Depths for Turbine- and JBS-Passed Fish.

3.44

3.54 Steelhead Median Passage Times by Approach and Passage Routes During 2009 ...

3.45

3.55 Steelhead Diel Median Passage Times at JDA.

3.46

3.56 Spill Treatments as Prescribed and Actual Conditions in Summer.

3.47

3.57 Seasonal Trend in Single-Release, Combined JDA to TDA Forebay-Passage Survival and Residualization Probability for CH0 at JDA in Summer 2009.

3.58 Day and Night Single-Release Estimates of CH0 Survival Rates by Route of Passage During Summer 2009

3.59 Seasonal Trend in Single-Release, Passage Surviva1/Residualization Probability for $\mathrm{CH} 0$ at TDA in Summer 2009.

3.60 Percent Passage for Guided and Unguided CH0 and Percent Discharge by Turbine Unit for the John Day Powerhouse During Summer 2009.

3.61 Percent Passage for Guided and Unguided CH0 and Percent Discharge by Turbine Unit for the John Day Powerhouse During Summer 2009

3.62 Percent Discharge and Passage of CH0 Smolts by Spill Bay During Summer 2009 ....

3.63 Day and Night Passage Rates by Route for CH0 During Summer 2009

3.64 Subyearling Chinook Salmon Percent Passage by Approach and Passage Blocks at JDA During 2009

3.65 Subyearling Chinook Salmon Approach and Passage Behavior Patterns at JDA During 2009 ... 3.56 
3.66 Subyearling Chinook Salmon Approach and Passage Patterns at JDA During Day and Night, 2009

3.67 Approach and Passage Patterns for CH0 During Daytime at JDA, Summer 2009.

3.68 Approach and Passage Patterns for CH0 During Nighttime at JDA, Summer 2009

3.69 Median Depths of the Last Detection of Tagged CH0 Smolts at JDA

3.70 Subyearling Chinook Salmon Median Last-Detection Depths for Turbine- and JBS-Passed Fish

3.71 Median Residence Times of CH0 at JDA, 2009

3.72 Subyearling Chinook Salmon Day/Night Median Passage Times at JDA, 2009.

4.1 Comparison of Passage and Survival Proportions for 30\% and 40\% Spill Conditions During 2008 and 2009

4.2 Turbine Passage Proportions Pre- and Post-TSW..... 


\section{Tables}

1.1 Radio-Telemetry Estimates of Survival Rates for Three Salmonid Stocks Passing Routes at JDA During 2000, 2002, and 2003 and Acoustic Telemetry Estimates During 2008.

1.2 Some Radio Telemetry (RT), Acoustic Telemetry (AT), and Hydroacoustic (HA) Estimates of Fish-Passage Efficiency and Spill-Passage Efficiency for JDA .......................................... 1.3

1.3 Lookup Table to Determine Distances (km) Between Locations Referenced in this Study........ $\quad 1.5$

1.4 Excerpt from an Engineering Design Document for the TSW ............................................. 1.7

2.1 Number of Fish Rejected by Criteria During Spring and Summer Tagging at JDA. ................ 2.6

2.2 Description, Location, Name, and Survival Model Function of Arrays Deployed in 2009......... 2.11

3.1 Yearly and Ten-Year Average of Run Timing for CH1 Sampled at the JDA SMF for Percentiles of the Passage Index.....

3.2 Yearly and Ten-Year Average of Run Timing for STH Sampled at the JDA SMF for Percentiles of the Passage Index.

3.3 Yearly and Ten-Year Average of Run Timing for CH0 Sampled at the JDA SMF for Percentiles of the Passage Index.....

3.4 Percent of the Run Passing a the John Day Dam SMF on the First and Last Days of Tagging and the Dates That 10\%, 25\%, 50\%, 75\%, and 90\% of Each Run Passed the Dam in 2009 According to SMF Data...

3.5 Detection Probabilities for the Dam-Face Arrays at JDA During 2009

3.6 Estimates of JDA Forebay-to-TDA Forebay Passage Survival Rates by Spill Treatment for CH1 During Spring 2009

3.7 Estimates of JDA Forebay-to-TDA Forebay Passage Survival Rates by Two-Day Block and Spill Treatment for CH1, for First Five Blocks, During Spring 2009

3.8 Results of a One-Tailed, Paired T-Test Comparing Estimates of JDA Forebay-to-TDA Forebay Passage Survival Rates by Two-Day Block and Spill Treatment for CH1, for First Five Blocks, During Spring 2009

3.9 Estimates of JDA Forebay-to-TDA-Forebay-Passage Survival Rates by Two-Day Block and Spill Treatment for CH1, for Seven Blocks, During Spring 2009.

3.10 Results of a One-Tailed, Paired T-Test Comparing Estimates of JDA Forebay-to-TDA Forebay Passage Survival Rates by Two-Day Block and Spill Treatment for CH1, for Seven Blocks, During Spring 2009.

3.11 Estimates of Major Passage Metrics by Spill Treatment for CH1 During Spring 2009

3.12 Single-Release Estimates of Survival for CH1 Smolts in Virtual Releases at JDA During 2009 Based on Detections at Three Downstream Arrays

3.13 Single-Release Estimates of TDA Passage Survival for CH1 That Previously Passed Through Six Routes at JDA During 2009......

3.14 Estimates of Major Passage Metrics for CH1 During Spring 2009.

3.15 Distance of Travel and Median and Mean Travel Times for Acoustic-Tagged CH1 Passing Through Specific River Reaches Between Roosevelt, Washington, and the BON Forebay

3.16 Estimates of JDA Forebay-to-TDA Forebay Passage Survival by Spill Condition for STH Smolts During Spring 2009 
3.17 Estimates of JDA Forebay-to-TDA Forebay-Passage Survival Rates by Two-Day Block and Spill Treatment for STH, for First Five Blocks, During Spring 2009

3.18 Results of a One-Tailed, Paired T-Test Comparing Estimates of JDA Forebay-to-TDA Forebay-Passage Survival Rates by Two-Day Block and Spill Treatment for STH, for First Five Blocks, During Spring 2009

3.19 Estimates of JDA Forebay-to-TDA Forebay Passage Survival Rates by Two-Day Block and Spill Treatment for STH, for Seven Blocks, During Spring 2009.

3.20 Results of a One-Tailed, Paired T-Test Comparing Estimates of JDA Forebay-to-TDA Forebay Passage Survival Rates by Two-Day Block and Spill Treatment for CH1, for Seven Blocks, During Spring 2009

3.21 Estimates of Major Passage Metrics by Spill Treatment for STH During Spring 2009

3.22 Single Release Estimates of Survival for STH Smolts Regrouped at the Corresponding Routes at the Dam to Form Virtual Releases During 2009.

3.23 Single-Release Estimates of TDA-Passage Survival for STH Smolts That Previously Passed Through Six Routes at JDA During 2009

3.24 Estimates of Major Passage Metrics for Yearling STH During Spring 2009

3.25 Distance of Travel and Median and Mean Travel Times for Acoustic-Tagged STH Passing Through Specific River Reaches Between Roosevelt, Washington, and the BON Forebay

3.26 Single Release Estimates of JDA Forebay-to-TDA Forebay Survival by Spill Condition for CH0 During Summer 2009

3.27 Estimates of JDA Forebay-to-TDA Forebay-Passage Survival Rates by Two-Day Block and Spill Treatment for CH0, for First Five Blocks, During Spring 2009

3.28 Results of a One-Tailed, Paired T-Test Comparing Estimates of JDA Forebay-to-TDA Forebay-Passage Survival Rates by Two-Day Block and Spill Treatment for CH0, for First Five Blocks, During Spring 2009

3.29 Estimates of JDA Forebay to TDA Forebay-Passage Survival Rates by Two-Day Block and Spill Treatment for CH0, for Seven Blocks, During Spring 2009

3.30 Results of a One-Tailed, Paired T-Test Comparing Estimates of JDA Forebay to TDA Forebay-Passage Survival Rates by Two-Day Block and Spill Treatment for CH0, for Seven Blocks, During Spring 2009

3.31 Estimates of Major Passage Metrics by Spill Treatment for CH0 During Summer 2009

3.32 Single-Release Estimates of Survival for Subyearling Chinook Smolts in Virtual Release at JDA Based on Three Downstream Arrays During 2009.

3.33 Single-Release Estimates of TDA-Passage Survival/Residualization for CH0 That Passed Through Three Available Routes at JDA in Summer 2009

3.34 Estimates of Major Passage Metrics for $\mathrm{CHO}$

3.35 Distance of Travel and Median Travel Time for CH0 Smolts Passing Through Specific River Reaches Between Roosevelt, Washington, and the BON Forebay....

4.1 Comparison of Performance for Various Surface-Flow Outlets in the Pacific Northwest 


\subsection{Introduction}

Improving the survival rate of juvenile salmonids migrating downstream through the Federal Columbia River Power System (FCRPS) continues to be a high priority for the U.S. Army Corps of Engineers (USACE) Portland District. Many of these fish are from populations listed as threatened or endangered under the Endangered Species Act. The increased survival rate is necessary to meet performance standards set forth in the 2008 Biological Opinion (BiOp; NMFS 2008) on operation of the FCRPS. The BiOp mandates that a $96 \%$ and $93 \%$ survival rate be achieved for spring and summer downstream migrating juvenile salmonids, respectively. At John Day Dam (JDA), the Portland District is evaluating the provision of surface-flow outlets (SFOs) as a means to increase fish-passage efficiency and in turn increase the fish-passage survival rate by reducing turbine passage of juvenile salmonids. The goal of the study reported here was to determine the 1) best configuration and operation for JDA prior to conducting BiOp performance standard tests by evaluating fish passage and survival at $30 \%$ and $40 \%$ spill treatments and 2) the performance of the prototype SFO. The Portland District and regional fisheries managers will use the data to adaptively manage the configuration and operation of JDA to maximize the survival rate for juvenile salmonids.

This is the report of research for the acoustic telemetry evaluation of juvenile salmonids during 2009 at JDA (Figure 1.1). The study also provides estimates of passage survival rates for The Dalles Dam (TDA) from the forebay of TDA to the Bonneville Dam (BON) forebay. The study was conducted by the Pacific Northwest National Laboratory (PNNL) and the University of Washington (UW) for the USACE Portland District.

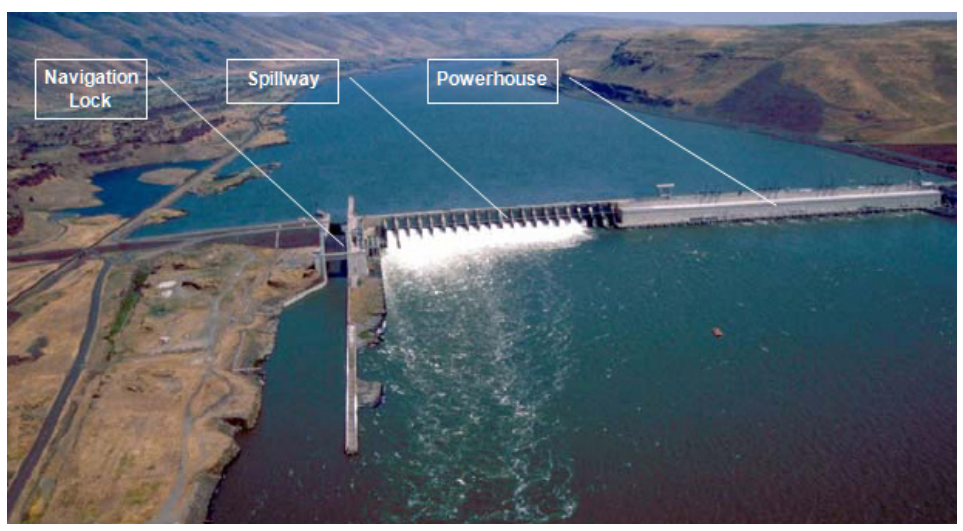

Figure 1.1. John Day Dam on the Columbia River

\subsection{Previous Survival and Passage Studies}

Radio telemetry was first used at JDA in 1999 to estimate fish survival rates (Counihan et al. 2002a) and passage proportions for turbine, screen bypass, and spillway routes through the dam (Hansel et al. 2000). For three stocks of salmonids that have been studied (yearling Chinook salmon [CH1], steelhead $[\mathrm{STH}]$, and subyearling Chinook salmon [CH0]), estimates of survival rates tend to be higher at the spillway than at the powerhouse, with whole-dam estimates in between as determined in radio telemetry studies in 2000, 2002, and 2003 (Table 1.1). The differences in survival rates between the powerhouse and spillway were greater for $\mathrm{CH} 1$ and $\mathrm{CH} 0$ than for $\mathrm{STH}$ (Table 1.1). These data indicate that the BiOp performance standard would not be met under previous conditions. 
Table 1.1. Radio-Telemetry Estimates of Survival Rates for Three Salmonid Stocks Passing Routes at JDA During 2000, 2002, and 2003 and Acoustic Telemetry Estimates During 2008. The ranges are for point estimates under different treatments. Point estimates $\pm 1 / 295 \%$ confidence intervals were provided for 2008 because there were no significant differences between spill treatments.

\begin{tabular}{lcccc}
\hline \multicolumn{1}{c}{$\begin{array}{c}\text { Study Year } \\
\text { (Passage Route) }\end{array}$} & CH1 & STH & CH0 & Reference \\
\hline 2000 (Dam) & 93.7 to $98.6 \%$ & 90.5 to $98.8 \%$ & --- & Counihan et al. 2002b \\
2002 (Spillway) & 99.3 to $100 \%$ & 93.2 to $95.8 \%$ & 98.5 to $100 \%$ & Counihan et al. 2006a \\
2002 (Powerhouse) & 77.8 to $83.2 \%$ & 89.9 to $93.0 \%$ & 86.6 to $96.6 \%$ & Ibid \\
2002 (Dam) & 92.9 to $96.3 \%$ & 91.5 to $94.0 \%$ & 92.8 to $99.2 \%$ & Ibid \\
2003 (Spillway) & 93.4 to $93.9 \%$ & -- & 90.1 to $95.5 \%$ & Counihan et al. 2006b \\
2003 (Powerhouse) & 76.4 to $82.0 \%$ & --- & 71.9 to $72.2 \%$ & Ibid \\
2003 (Dam) & 92.2 to $94.0 \%$ & --- & 84.5 to $88.6 \%$ & Ibid \\
2008 (Concrete) & $95.7 \pm 1.3 \%$ & $98.6 \pm 1.7 \%$ & $86.1 \pm 1.7 \%$ & Weiland et al. 2009 \\
2008 (Non-TSW Spillway) & $96.6 \pm 1.1 \%$ & $98.5 \pm 2.3 \%$ & $84.4 \pm 4.4 \%$ & Ibid \\
2008 (TSW Spill Bays) & $96.1 \pm 2.0 \%$ & $99.2 \pm 2.3 \%$ & $92.7 \pm 1.6 \%$ & Ibid \\
2008 (Turbine) & $85.5 \pm 3.4 \%$ & $74.9 \pm 6.2 \%$ & $72.8 \pm 5.6 \%$ & Ibid \\
2008 (JBS) & $97.6 \pm 4.5 \%$ & $100.0 \pm 1.9 \%$ & $97.3 \pm 5.7 \%$ & Ibid \\
\hline
\end{tabular}

At least six studies have estimated fish-passage efficiency and spill efficiency at JDA (Table 1.2). The radio and acoustic telemetry studies indicated that fish-passage efficiency ranged from $88 \%$ to $97 \%$ for $\mathrm{STH}, 82 \%$ to $93 \%$ for $\mathrm{CH} 1$, and from $70 \%$ to $84 \%$ for $\mathrm{CH} 0$. A hydroacoustic study in 2002 estimated a similar range of fish-passage efficiency for spring stocks but the estimate for $\mathrm{CHO}(88 \%$ to $92 \%)$ was higher than the radio-telemetry estimate that year. Estimates of spill efficiency for the three fish stocks were highly variable among years (Table 1.2).

\subsection{Surface-Flow Outlet Development}

Sweeney et al. (2007) provide a compendium on SFO development in the Pacific Northwest. Although the Portland District's SFO program for juvenile salmonids commenced in 1994 (USACE 1995), SFO development is in its early stages at JDA. To support this effort, baseline biological data on fish distributions were summarized by Giorgi and Stevenson (1995) and Anglea et al. (2001). Generally, yearling migrants approach the dam along the Washington side of the forebay, and $\mathrm{CH} 0$ approach using migration pathways near both shorelines. Tagged fish have been observed traversing the forebay laterally before passing.

Field work on a prototype surface spill SFO was conducted in 1997 when "over/under" weirs were placed at spill bays 18 and 19 at JDA. BioSonics (1999) found that passage at the prototype bays was higher during spring when the weirs were removed than when weirs were in place. During summer, passage rates between "in" and "out" treatment conditions were comparable. This study, however, was affected by very high spill through adjacent bays during a year of above-average river discharge. 
Table 1.2. Some Radio Telemetry (RT), Acoustic Telemetry (AT), and Hydroacoustic (HA) Estimates of Fish-Passage Efficiency and Spill-Passage Efficiency for JDA. See Section 2.6.1 for definitions of metrics. The ranges are for point estimates under different study treatments.

\begin{tabular}{lcccc}
\hline \multicolumn{1}{c}{ Study Year/Type } & CH1 & STH & CH0 & Reference \\
\hline $\begin{array}{l}\text { Fish-Passage Efficiency } \\
\text { 1999 RT }\end{array}$ & 82 to $88 \%$ & 90 to $94 \%$ & --- & Hansel et al. 2000 \\
2000 RT & 90 to $92 \%$ & 91 to $93 \%$ & --- & Beeman et al. 2003 \\
2002 RT & 84 to $85 \%$ & 88 to $91 \%$ & 70 to $72 \%$ & Beeman et al. 2006 \\
2002 HA & 89 to $94 \%$ & 88 to $92 \%$ & Moursund et al. 2003 \\
2003 RT & 84 to $86 \%$ & --- & 71 to $75 \%$ & Hansel et al. 2004 \\
2008 AT & 91 to $93 \%$ & 97 to $97 \%$ & 82 to $84 \%$ & Weiland et al. 2009 \\
Spill-Passage Efficiency & & & & \\
1999 RT & 53 to $66 \%$ & 45 to $53 \%$ & --- & Hansel et al. 2000 \\
2000 RT & 75 to $86 \%$ & 61 to $79 \%$ & --- & Beeman et al. 2003 \\
2002 RT & 48 to $57 \%$ & 54 to $64 \%$ & 42 to $58 \%$ & Beeman et al. 2006 \\
2002 HA & 72 to $78 \%$ & 58 to $61 \%$ & Moursund et al. 2003 \\
2003 RT & 47 to $57 \%$ & --- & 48 to $62 \%$ & Hansel et al. 2004 \\
2008 AT & 76 to $77 \%$ & 72 to $76 \%$ & 66 to $71 \%$ & Weiland et al. 2009 \\
\hline
\end{tabular}

Engineering and model studies examining skeleton bays as potential SFO sites were conducted in the 1990s (Montgomery Watson et al. 2000). At a physical model at the USACE Engineering, Research, and Development Center, observations of a 20,000-cfs SFO in a skeleton bay showed strong forebay flow nets, indicating a potential for fish to discover the SFO flow. However, because of concerns about cost and tailrace egress caused by a large eddy that formed in the spillway stilling basin adjacent to the SFO outfall plume, this effort was tabled.

The Portland District identified SFO development as a top priority in the John Day Configuration and Operation Plan (USACE 2007). Accordingly, new numerical and physical model investigations and engineering design work were undertaken to develop a prototype SFO for JDA. In winter 2007/2008, the Portland District installed prototype SFOs, called top-spill weirs (TSWs), at spill bays 15 and 16. A bulkhead on top of the weir provided hydraulic control, creating a critical entrance flow regime. The discharge was about $10,000 \mathrm{cfs}$ per bay. The weir was designed to minimize the angle of SFO jet impact on the ogee and to increase the fish-passage efficiency and passage survival rates of downstreammigrating juvenile salmonids at JDA.

The 2008 acoustic telemetry study showed that the survival rates of CH1 (96.1\%), STH (99.6\%), and CH0 (92.7\%) were high through the TSWs and second only to rates for smolts passing through the JBS. Using about $20 \mathrm{kcfs}$, the TSW bays passed half of the STH, a quarter of the $\mathrm{CH} 1$, and a fifth of the CH0 of the respective total number of fishes passing JDA. As was the intent of the design, the TSW surface flows appeared to attract, or at the least provide a surface outlet opportunity for, fish that had originally arrived at the dam in the powerhouse forebay. Passage at the TSW bays was much higher during the day than it was at night.

The 2008 study also showed that there were no significant differences in survival rates between posthoc $30 \%$ and $40 \%$ spill conditions at JDA. The only metric that showed a significant difference was spillpassage effectiveness, and it was significantly higher at 30\% spill than it was at $40 \%$ spill for STH and for CH0. The increase in spill discharge from $30 \%$ to $40 \%$ of total water discharge through the dam basically 
served to pass incrementally more fish at non-TSW bays and incrementally fewer at the TSWs. About half of the tagged fish arriving in the forebay of the powerhouse and skeleton bays moved toward and passed at the spillway including the TSWs. In contrast, few smolts approaching the spillway passed at the powerhouse, and fish approaching the spillway had the shortest median residence time. The longest residence time was for fish approaching the powerhouse and then passing at the spillway or vice versa. Because the $30 \%$ and $40 \%$ spill treatment conditions were largely unmet during the 2008 study period, the study was repeated during 2009.

\subsection{Research Objectives}

The overall purpose of the acoustic telemetry study at JDA during 2009 was to estimate fish survival rates and passage efficiencies under $30 \%$ and $40 \%$ spill-discharge treatments each season, and to evaluate the performance of TSWs installed in spill bays 15 and 16. The TSWs were not operated during the summer study because of excessive predation by gulls in the TSW outfall plume. Randomized block experimental designs were developed for spring and summer, and each 4-day block was designed to begin with one 2-day treatment randomly selected to be $30 \%$ or $40 \%$ spill discharge followed by the alternate treatment. The field study period began with fish releases on April 27 and ended on August 25, 2009, when $90 \%$ of the acoustic tags in fish had died, as estimated from the 2009 tag-life study.

The study objectives and sub-objectives, applied separately to acoustic-tagged $\mathrm{CH} 1, \mathrm{STH}$, and $\mathrm{CH} 0$ at JDA during 2009, were to do the following:

1. Estimate survival rates ${ }^{1}$ as follows:
a. JDA-to-TDA forebay(from the dam face at JDA to TDA forebay array $2 \mathrm{~km}$ upstream of TDA) and route-specific estimates
b. JDA forebay-to-TDA forebay (from the forebay array $2 \mathrm{~km}$ upstream of JDA to TDA forebay array $2 \mathrm{~km}$ upstream of TDA)
c. JDA seasonal and day/night trends
d. Association of JDA passage route and survival rates at TDA.

2. Estimate passage metrics and distributions as follows:
a. Fish-passage efficiency (FPE), spill-passage efficiency (SPE), fish-guidance efficiency (FGE), TSW efficiency (TSWE), juvenile bypass system-passage efficiency (JBSE), spill effectiveness (SEF), and TSW effectiveness (TSWEF)
b. Powerhouse horizontal distribution and the relationship between passage and discharge
c. Spillway horizontal distribution
d. Day/night trends in passage.

3. Characterize fish behavior as follows:
a. Approach patterns and eventual passage routes
b. Day/night behavior patterns

\footnotetext{
${ }^{1}$ See Section 2.1.3 for definitions.
} 

c. Vertical distribution behavior patterns
d. Travel times and forebay residence times.

4. Determine the effect of spill condition (30\% versus $40 \%$ spill) on survival rates and passage efficiencies.

\subsection{Study Area}

The study area for the acoustic telemetry evaluation of survival and passage at JDA during 2009 included 198 river kilometers (rkm) of the lower Columbia River from Roosevelt, Washington (rkm 390), where all tagged fish were released, to Lady Island (rkm 192) near Camas, Washington (Figure 1.2). JDA is located $41.4 \mathrm{~km}$ downstream of the fish release transect. JDA consists of a powerhouse with 16 turbine units and 4 skeleton bays (bays where turbines were never installed) on the Oregon side and a 20-bay spillway on the Washington side (Figure 1.2). The skeleton bays are in between the powerhouse turbine intakes and the spillway. Throughout this report, references are made to locations on the river that are varying distances apart, so a quick reference was created to clarify distances between locations (Table 1.3).

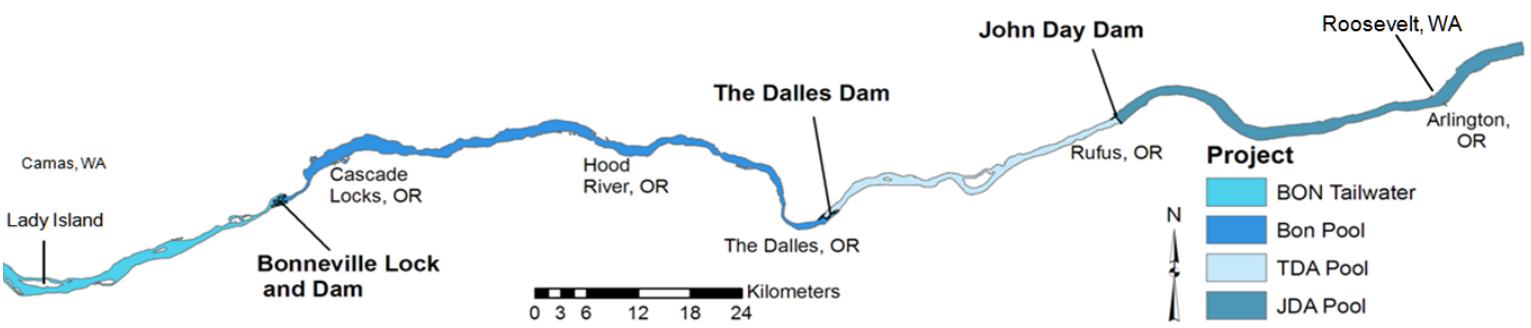

Figure 1.2. 2009 Study Area on the Columbia River from Roosevelt, Washington, to Camas, Washington

Table 1.3. Lookup Table to Determine Distances $(\mathrm{km})$ Between Locations Referenced in this Study

\begin{tabular}{|c|c|c|c|c|c|c|c|c|c|c|c|c|}
\hline Location & Study Function & $\begin{array}{c}\text { Distance } \\
\text { Upstream of } \\
\text { Columbia } \\
\text { River Mouth } \\
(\mathrm{km}) \\
\end{array}$ & 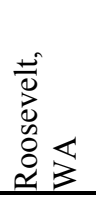 & 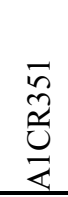 & 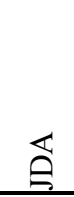 & 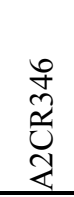 & 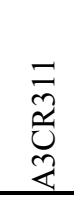 & 导 & 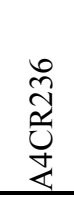 & Z & 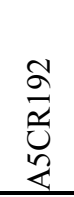 & 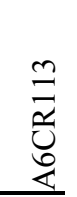 \\
\hline & & & 390 & 351 & 349 & 346 & 311 & 309 & 236 & 235 & 192 & 113 \\
\hline $\begin{array}{l}\text { Roosevelt, } \\
\text { WA }\end{array}$ & Release - Spr \& Sum & 390 & 0 & 39 & 41 & 44 & 79 & 81 & 154 & 155 & 198 & 277 \\
\hline A1CR351 & Forebay virtual Release & 351 & & 0 & 2 & 5 & 40 & 42 & 115 & 116 & 159 & 238 \\
\hline JDA & Effects & 349 & & & 0 & 3 & 38 & 40 & 113 & 114 & 157 & 236 \\
\hline A2CR346 & Egress rates & 346 & & & & 0 & 35 & 37 & 110 & 111 & 154 & 233 \\
\hline A3CR311 & $\begin{array}{l}\text { JDA primary } \hat{\mathrm{S}} \text {; Forebay } \\
\text { virtual release }\end{array}$ & 311 & & & & & 0 & 2 & 75 & 76 & 119 & 198 \\
\hline TDA & Effects & 309 & & & & & & 0 & 73 & 74 & 117 & 196 \\
\hline A4CR236 & $\begin{array}{l}\text { JDA secondary } \hat{\mathrm{S}} \text {; TDA } \\
\text { primary } \hat{\mathrm{S}}\end{array}$ & 236 & & & & & & & 0 & 1 & 44 & 123 \\
\hline$\overline{\mathrm{BON}}$ & Effects & 235 & & & & & & & & 0 & 43 & 122 \\
\hline A5CR192 & $\begin{array}{l}\text { JDA tertiary }(\lambda) ; \text { TDA } \\
\text { secondary } \hat{\mathrm{S}}\end{array}$ & 192 & & & & & & & & & 0 & 79 \\
\hline A6CR113 & TDA tertiary $(\lambda)$ & 113 & & & & & & & & & & 0 \\
\hline
\end{tabular}


JDA has a juvenile bypass system (JBS) that uses intake screens to divert fish out of turbine intakes and convey them through the dam to the tailrace. Basically, fish are diverted by submerged traveling screens from the upper part of the powerhouse turbines into the gatewell slots. They then pass through one of two gatewell orifices per gatewell into a bypass channel that runs the length of the powerhouse. The channel volume is reduced by dewatering to a volume small enough to pass through pipes to the Smolt Monitoring Facility (SMF) or to an outfall pipe discharging into the tailrace (Figure 1.3). At the SMF, fish are sampled as part of the regional Smolt Monitoring Program. Fish for the 2009 JDA acoustic-telemetry study were obtained from the SMF.

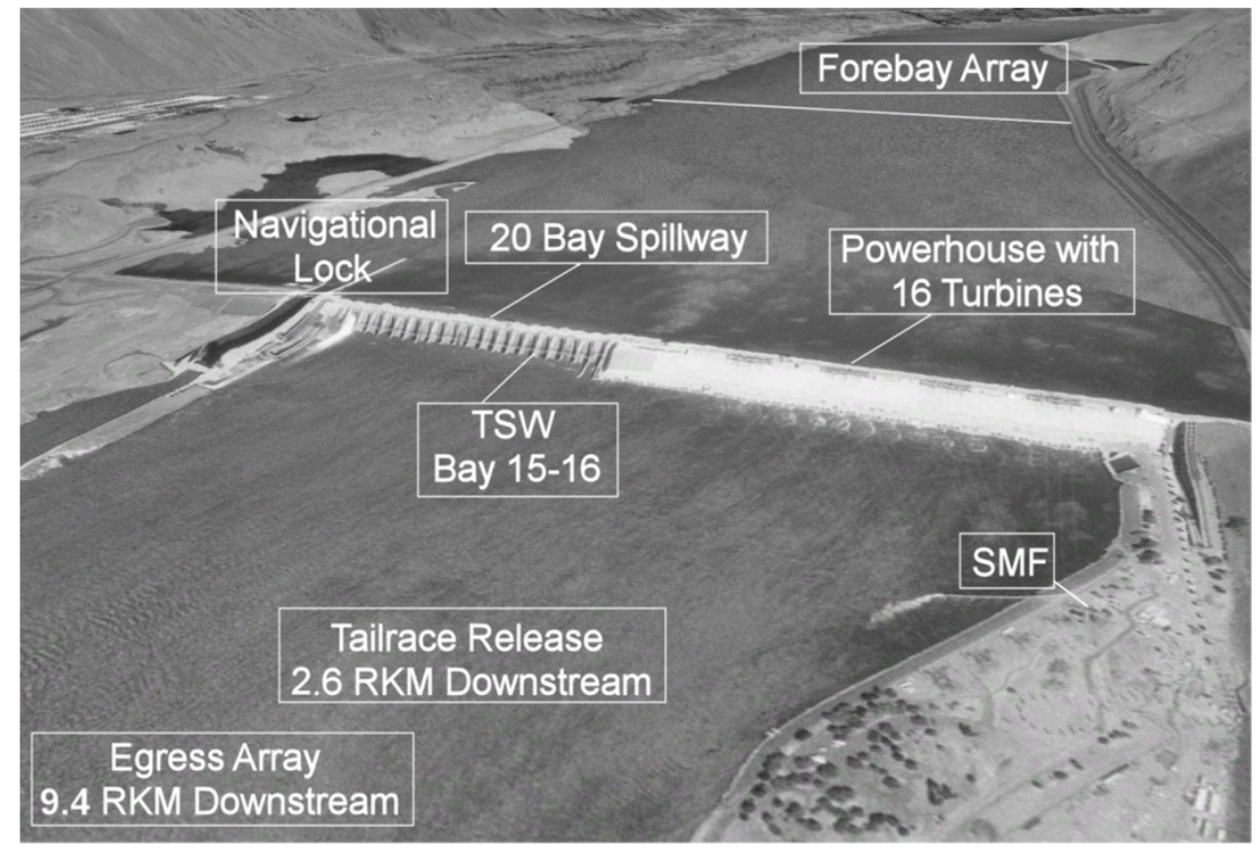

Figure 1.3. Aerial View of John Day Dam

At JDA, TSW SFOs were installed at spill bays 15 and 16. The TSWs are basically weirs formed by a stop log assembly that water flows over when the spill gates are raised (Figure 1.4). TSW discharge per bay is about $10,000 \mathrm{cfs}$. The TSWs create a flow field in the forebay that downstream migrants can discover and use to pass the dam instead of sounding through turbines. Spill at adjacent bays helps the tailrace egress conditions for fish in the TSW plume. (Overall design criteria are shown in Table 1.4). 


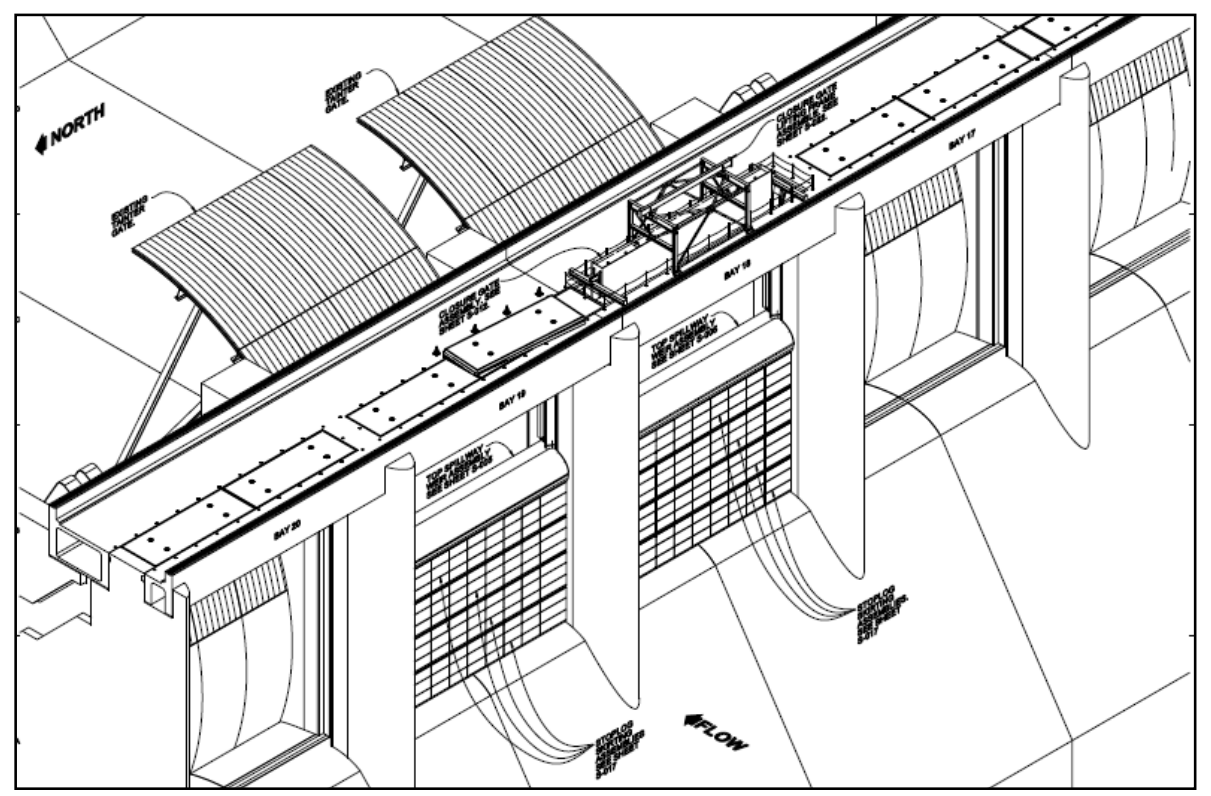

Figure 1.4. Schematic of TSWs at John Day Dam (provided by S. Askelson, USACE)

Table 1.4. Excerpt from an Engineering Design Document for the TSW (provided by S. Askelson, USACE)

\begin{tabular}{|c|c|c|}
\hline \multirow{3}{*}{$\begin{array}{l}\text { ENGINEERING DESIGN SHEET } \\
\text { PROJECT: John Day TSW }\end{array}$} & \multicolumn{2}{|c|}{ OFFICE SYMBOL: CENWP-EC-HD } \\
\hline & COMPUTED BY: SKEA & DATE: 10-MAY-07 \\
\hline & & SHEET: 1 OF: \\
\hline SUBJECT: TSW Shape Design Pro & & \\
\hline
\end{tabular}

During the Design of the design of the John Day TSW, the overall guiding design criteria were as follow:

* design for approximatly $10 \mathrm{kcfs}$ at typical forebay elevations during the fish passage season

* minimize the impact angle (angle created between the TSW nappe and the ogee upon impact)

* minimize the backroller pool formed by the nappe impact

* minimize areas of potential flow separation along the crest of the TSW

* provide the "smoothest" flow acceleration approaching the TSW device in the forebay

Based on hourly stage readings for juvenile fish migration passage period extending from 1 March through 30 November (period of record: 1995-1999) at John Day the forebay exceedance is as follows:

\begin{tabular}{ccc}
$\begin{array}{c}\text { Percent } \\
\text { Exceedance }\end{array}$ & & Stage (ft) \\
\cline { 1 - 1 } MAX & & 267.6 \\
1 & & 265.3 \\
5 & & 264.7 \\
10 & & 264.5 \\
20 & 264.3 \\
30 & 264.1 \\
40 & 264.0 \\
50 & 263.9 \\
60 & 263.7 \\
70 & 263.6 \\
80 & 263.3 \\
90 & 263.0 \\
95 & 262.6 \\
99 & 261.3 \\
99.9 & 258.5 \\
MIN & 257.0
\end{tabular}

Based on this information, the "design" forbay elevation was selected as $264 \mathrm{ft}$, but the TSW would be evaluated at forebay elevations from $257 \mathrm{ft}$ through $268 \mathrm{ft}$ (the entire operating range of the John Day forebay).

The TSW is expected to provide acceptable conditions from forebay elevation $262 \mathrm{ft}$ to $268 \mathrm{ft}$, but has been "optimized" for a forebay elevation of $264 \mathrm{ft}$. The forebay elevation at John Day is $264 \pm 1 \mathrm{ft}$ for more than $85 \%$ of the juvenile passage season.

Based on previous TSW work at McNary (NWW), it was determined to achieve a $10 \mathrm{kcfs}$ total flow rate at a forebay elevation of $264 \mathrm{ft}$, the crest elevation of the TSW would need to have approximatly $14 \mathrm{ft}$ of head, thus setting the crest elevation at an elevation of $250 \mathrm{ft}$. 


\subsection{Report Contents}

The ensuing sections of this report present the study materials and methods (Section 2.0). The results are in Section 3.0 and the discussion, conclusions, and recommendations are in Section 4.0. References may be found in Section 5.0. The four appendices contain tagging data tables (Appendix A), hydrophone locations (Appendix B), detection probabilities and capture histories (Appendix C), and results of Burnham Tests 2 and 3 (Appendix D). 


\subsection{Materials and Methods}

In this section, we describe the materials and methods used for the 2009 acoustic telemetry evaluation at JDA. The primary research tool was the Juvenile Salmon Acoustic Telemetry System (JSATS).

The Portland District has been directing and funding the development of the JSATS to evaluate juvenile salmonid passage performance and survival rates. Currently, two types of JSATS receivers are used: autonomous nodes can be deployed in most environments where external power is not available and cabled systems can be deployed were an external power source is available. The autonomous nodes are best suited for detecting tagged fish and estimating survival rates, whereas the cabled array has the advantage of precise synchronized time keeping and is well suited for two-dimensional (2D) or 3D tracking and for determining the route of passage. The JSATS technology has several advantages over previously used radio telemetry. The acoustic tag does not require an external antenna, making it less invasive to the fish than a radio transmitter. Acoustic telemetry can detect acoustic signals over a greater range and depth than radio telemetry, thereby increasing the detection area and reducing depth-related bias. When appropriate, an acoustic telemetry system can be deployed for $2 \mathrm{D}$ and 3D tracking that can be used to determine route of passage, forebay residence behavior, and aid in estimating route-specific survival rates.

Acoustic telemetry has been used on the lower Columbia River to describe fish passage and approach behavior at BON (Faber et al. 2001) and TDA (Cash et al. 2005). The JSATS has been used below BON in the lower Columbia River and estuary to estimate in-river survival rates since 2004 (McComas et al. 2004, 2005, 2006, 2007, 2008). In 2006, the JSATS receivers were deployed at various locations between JDA and Camas, Washington (a 150-km reach of the river), to estimate turbine passage and tailwater survival rates at JDA, and dam-passage and tailwater-passage survival rates for TDA and BON (Ploskey et al. 2007). The first deployment of the JSATS cabled system was in 2007 at the BON spillway to estimate route-specific passage and survival rates (Ploskey et al. 2008). In 2008, acoustic telemetry route-specific survival studies were successfully conducted at three sites on the lower Columbia River: JDA (Weiland et al. 2009), BON spillway (Ploskey et al. 2009), and BON second powerhouse (Faber et al. 2009).

\subsection{Study Context}

The study context includes water discharge and temperature conditions, spill treatments $(30 \%$ versus $40 \%$ spill out of total water discharge through the dam), and definitions of various estimates of survival rates.

\subsubsection{Water Discharge and Temperature}

Water discharge data by spill bay and turbine unit and elevation data for the forebay and tailwater were acquired in 5-minute increments by the automated data-acquisition system at JDA and provided weekly by JDA operators. The 5-minute discharge data for the entire dam and spillway were averaged by day and plotted with daily averages for the previous 10-year period to provide some historical perspective for 2009 observations. Average water discharge and forebay water temperature data from 1999 through 2008 were downloaded from the DART (Data Access in Real Time) website (http://www.cbr.washington.edu/dart). 


\subsubsection{Spill Treatments}

The effects of $30 \%$ and $40 \%$ spill treatments on fish-passage and survival rates during spring and summer study periods according to a randomized block experimental design (Figures 2.1 and 2.2, respectively) were evaluated. The design called for 4-day blocks with each 2-day treatment randomly chosen to be $30 \%$ or $40 \%$ spill followed by the alternate treatment. Treatment changes were made at 0600 hours. The first treatment each season was in place a couple of days before the first study block and a few fish that arrived before the first treatment but under the same spill conditions were assigned to the first treatment. Similarly, the last treatment each season continued for more than 2 days and late-arriving fish under the same spill conditions were assigned to the last 2-day treatment. Performance metrics included FPE, SPE and SEF, TSWE and TSWEF (spring runs only), and estimates of JDA to TDA forebay-passage survival rate.

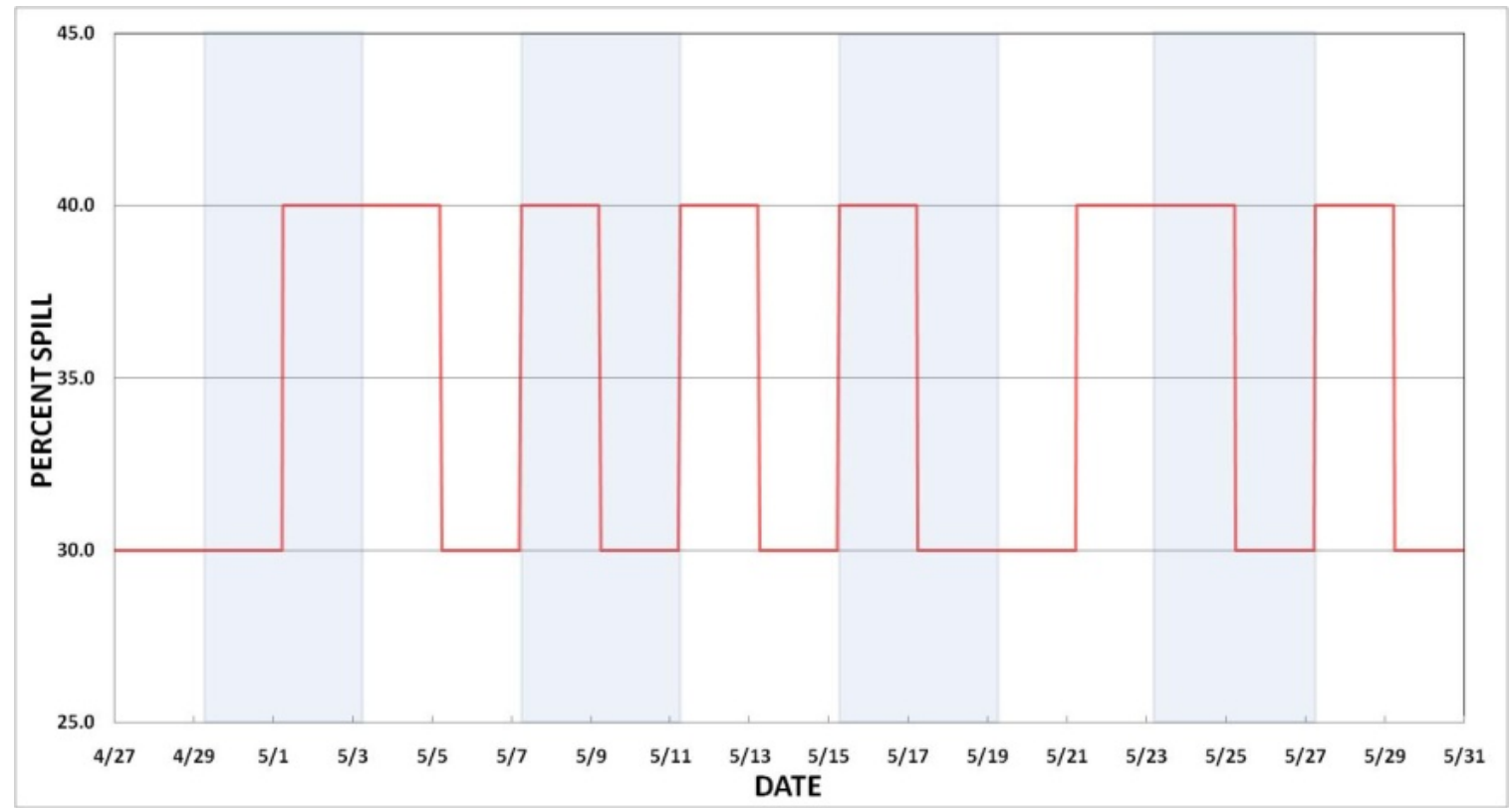

Figure 2.1. Spill Treatment Schedule at JDA from April 29 Through May 31, 2009. The design for spring 2009 called for eight treatment blocks with two treatments per block.

\subsubsection{Definitions}

Single-release reach survival rates by the upstream and downstream boundaries of the reach of interest are defined. The following additional definitions are needed to clarify the survival metrics:

Forebay is the segment of river immediately upstream of a dam where operations at the dam are the primary contributing factor to velocity and direction of water flow. The upstream boundary is where a significant alteration in the allocation of water flow through dam operational changes affects water velocity or direction of flow. Locations of the forebay entrance arrays of autonomous nodes for JDA and TDA were $2 \mathrm{~km}$ upstream of the dam face. The downstream boundary is the upstream face of the dam, where cabled arrays for tracking fish were installed. 


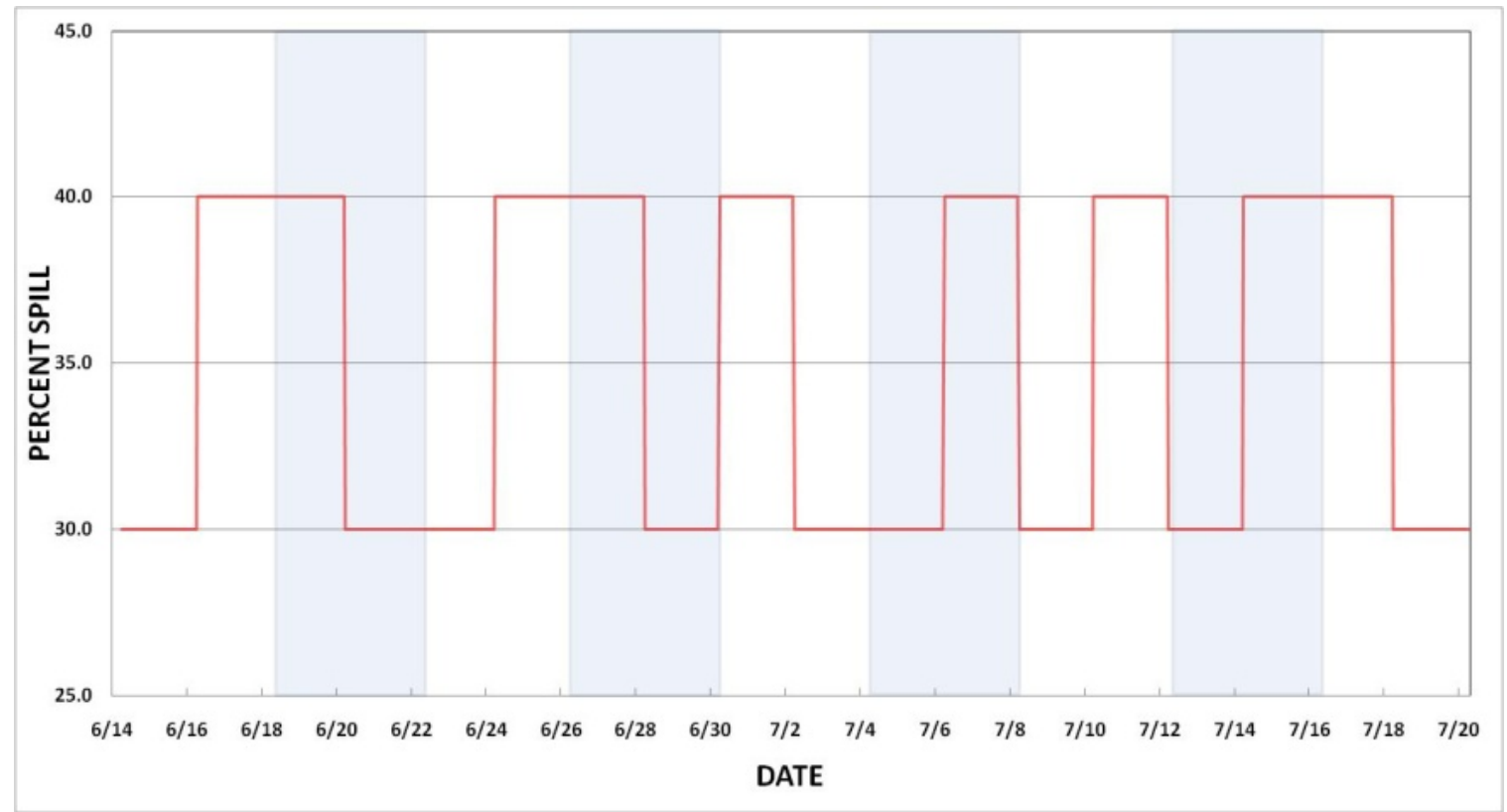

Figure 2.2. Spill Treatment Schedule at JDA from June 14 Through July 20, 2009. The design for summer 2009 called for nine treatment blocks with two treatments per block.

- Tailrace is the segment of river immediately downstream of the dam where dam operations are the primary factor affecting velocity and direction of flow. The upstream boundary of the tailrace is the downstream face of the dam and the downstream boundary is where operational changes at the dam no longer affect the direction of water flow and mixing from the spillway and powerhouse is complete.

- Reservoir or pool is the segment of river impounded by a dam where volume and water-surface elevations are controlled by the dam. A reservoir or pool may extend upstream to the tailrace of another dam. For example, TDA pool extends from TDA upstream to near the tailrace of JDA, although it also could be referred to as the tailwater of JDA. In this study, the only release site for fish was $41 \mathrm{~km}$ upstream of JDA instead of $121.4 \mathrm{~km}$ upstream in the McNary tailrace so the pool was truncated to $34 \%$ of the full length to minimize unnecessary losses of fish in the long JDA pool.

- Tailwater is the segment of river downstream of a dam tailrace, and it is synonymous with reservoir or pool when it lies between two dams.

- Project-passage survival rate normally is defined as the probability of fish surviving when passing from the upstream boundary of the pool upstream of a dam to the downstream boundary of the tailrace of the dam. A traditional estimate of project-passage survival rate was not made because the JDA pool was truncated to $34 \%$ of its full length and there were no tailrace reference releases in 2009 .

- Dam-passage survival rate normally is the probability of fish surviving when passing from the upstream boundary of the forebay to the downstream boundary of the tailrace and accounts for losses in the forebay, all routes of passage, and in the tailrace. In this study, there were no tailrace reference releases, so dam-passage survival included fish losses in the forebay, dam, tailrace, and tailwater down to the TDA forebay entrance array $2 \mathrm{~km}$ upstream of TDA, defined as JDA forebay-to-TDA forebay in this report. 
- Concrete-passage survival rate normally is defined as the probability of fish surviving when passing from the upstream dam face to the downstream boundary of the tailrace and does not include survival in the forebay or tailwater. This is how the $2008 \mathrm{BiOp}$ defines the dam-passage survival rate. The JDA concrete-passage survival rate in this study was based on a single-release model because there were no tailrace reference releases of fish. Therefore, the concrete-passage probability by necessity included losses of fish during route-specific passage, tailrace passage, and JDA tailwater passage down to the TDA forebay entrance array $2 \mathrm{~km}$ upstream of TDA, defined as JDA-to-TDA forebay in this report.

- Passage-route survival rate normally is defined as the probability of fish surviving when passing through any individual route (i.e., spillway, turbine, bypass, etc.) to the downstream boundary of the tailrace (release location of a tailrace reference group). However, in this study there were no reference releases of fish, so the passage-route survival probability included losses of fish during route-specific, tailrace, and JDA-tailwater passage. Passage routes at JDA included the JBS, turbines, and the spillway (also broken down into TSW spill bays and non-TSW spill bays in spring).

\subsection{Fish Collection, Tagging, Transportation, and Release}

The collection site, associated record-keeping related to meeting permitting requirements for fish collection and handling, sampling methods, JSATS acoustic micro-transmitter and tag implantation, fish recovery and holding, and subsequent transportation and release are described in the following sections. A total of $3470 \mathrm{CH} 1,3471 \mathrm{STH}$, and $3461 \mathrm{CH} 0$ were tagged and released.

\subsubsection{Collection Site}

Juvenile Chinook salmon and STH were collected and tagged at the JDA SMF. The SMF is situated on the south side of JDA at the downriver edge of the fish bypass system where bypassed juvenile salmonids and other fishes are routed through a series of flumes and dewatering structures. Smolts can be diverted into the SMF as part of a sample of the JBS population for routine smolt monitoring or directed into the tailrace through an outfall pipe located downstream of the facility. Routinely sampled smolts also were rerouted to the tailrace outfall after they were examined unless they were selected for tagging as part of this study of survival rates.

\subsubsection{Federal and State Permitting}

Records were kept on all smolts handled and collected (both target and non-target species) for permit accounting. Collections were conducted in conjunction with routine sampling at the SMF to minimize handling impacts. Surgical candidates collected from routine SMF target sample sizes were accounted for under permits issued to the SMF. Additional fish needed to meet research needs (beyond SMF goals) were accounted for under separate federal and state permits. A federal scientific take permit was authorized for this study by the National Oceanic and Atmospheric Administration (NOAA) Fisheries Hydropower Division's FCRPS Branch and administered by NOAA (permit number 13-09PNNL40). The Oregon Department of Fish and Wildlife authorized take for this study under permit number P14273. The federal and Oregon permits were both authorized under the 2008 FCRPS BiOp. All requirements and guidelines of both permits were met and reports of collection and release were reported to both agencies. 


\subsubsection{Sampling Methods}

Juvenile salmonids were diverted from the JBS and routed into a 1795-gal holding tank in the SMF. About 150-200 smolts and other fishes were crowded with a panel net into a 20 - by 24-in. pre-anesthetic chamber. Water levels in the chamber were lowered to about 8 in. $(48 \mathrm{~L})$ at which point fish were anesthetized with $60 \mathrm{~mL}$ of a stock tricaine methanesulfonate (MS-222) solution prepared at a concentration of $50 \mathrm{~g} / \mathrm{L}$. Once anesthetized, fish were routed into the examination trough. Technicians added MS-222 as needed to maintain sedation, and 5 to $10 \mathrm{~mL}$ of PolyAquaTM was added to reduce fish stress. Water temperatures were monitored in the main holding tank and in the examination trough, and water in the trough was refreshed before temperatures there increased more than $2^{\circ} \mathrm{C}$ above those observed in the main holding tank.

Once in the examination trough, smolts targeted for surgical procedures were evaluated in accordance with the following specific acceptance and rejection criteria:

- Qualifying (Acceptable) Conditions

- $\quad$ sized $>95 \mathrm{~mm}$

- visible elastomer tag(s) present or absent

- adipose-fin clipped or unclipped

- trematodes, copepods, leeches

- short operculum

- healed (moderate) injuries (e.g., bird strikes)

$-\quad \leq 3 \%$ fungal patch

- minor fin blood

- partial descaling (3-19\%)

- STH with eroded pectoral or ventral fins (likely hatchery STH).

- Disqualifying Conditions

$-\quad \geq 20 \%$ descaling

- body punctures (showing blood, e.g., predator marks, bird strikes, head wounds, nose/snout injuries)

- obvious signs of bacterial kidney disease

- $\quad$ eye hemorrhage or pop eye

- $\quad>3 \%$ coverage with fungus

- deformed

- holdovers (fish not "spring" yearling or "summer" subyearling)

- passive integrated transponder (PIT)- or radio-tagged or other post-surgical fishes

- notable operculum damage (except short operculum)

- columnaris, furuncles 
- injured caudal peduncles

- injured caudal fins

- fin hemorrhage.

Non-target species and fish that did not meet the above criteria were released to the river through the SMF holding system after a 30-minute recovery period. Accepted fish were counted and released into transfer buckets containing fresh river water before being moved to one of six 80 -gal pre-surgery holding tanks, where they were held for 18 to 30 hours prior to surgery. The pre-surgery holding duration depended on the time of collection and the time of tagging on the next day.

During spring and summer tagging seasons, 91 total fish were rejected for tagging. Fish that were rejected during the tagging process were placed in a recovery tank to allow for the anesthesia to be displaced from their system before releasing them. The total number of fish rejected and reason for their rejection are listed in Table 2.1.

Table 2.1. Number of Fish Rejected by Criteria During Spring and Summer Tagging at JDA.

\begin{tabular}{llc}
\hline \multicolumn{1}{c}{ Fish Run } & \multicolumn{1}{c}{ Rejection Criteria } & Number Rejected \\
\hline & BKD & 2 \\
CH1 & Fungus & 4 \\
& Lacerations & 4 \\
& Operculum Damage & 5 \\
& Popeye & 1 \\
& Skeletal Deform & 1 \\
& Already tagged & 1 \\
& Damaged Eye & 2 \\
& Descaling & 5 \\
STH & Fungus & 10 \\
& Lacerations & 3 \\
& Operculum. Damage & 3 \\
& Pit Tag & 1 \\
& Popeye & 2 \\
& Size & 24 \\
CH0 & Descaling & 3 \\
& Lacerations & 10 \\
Total Fish Collected & Operculum Damage & 4 \\
Number of Fish Rejected & Size & 5 \\
\hline & & 10,922 \\
\hline & & 90 \\
\hline
\end{tabular}




\subsubsection{JSATS Acoustic Micro-Transmitter and Tag Implantation}

Specifications of the JSATS acoustic tags used in 2009 (Figure 2.3) were as follows: dimensions $(\mathrm{mm})=12$ long x 5.21 wide $\times 3.77$ deep; mass $(\mathrm{g})=0.43$ in air and 0.29 in water; volume $(\mathrm{mL})=0.14$. The nominal pulse-repetition rate was one ping every 3 seconds, and this rate provided an expected tag life of at least 23 days. Tagging tables are presented in Appendix A.

A team of eight people was part of the tagging process to reduce the handling time between netting and post-surgery recovery. The team followed the latest guidelines for surgical implantation of acoustic transmitters in juvenile salmonids. Procedure development is an ongoing process initiated by the USACE for contractors conducting survival studies. Numerous steps were taken to minimize the handling impacts of collection and surgical procedures. Most smolts used for tagging were part of the routine collection for SMF monitoring and additional fish did not have to be collected to meet the tagging quota on most days.

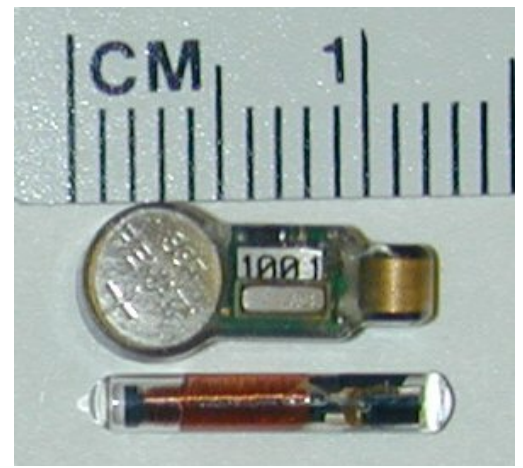

Figure 2.3. JSATS 0.43 -g Acoustic Micro-Transmitter and PIT Tag Surgically Implanted in $\mathrm{CH} 1, \mathrm{CH} 0$, and STH Smolts in 2009

The number of personnel on hand was the biggest contributor to ensuring that all tagged fish were handled as efficiently and un-intrusively as possible to minimize handling times. One individual was responsible for anesthetizing fish and delivering them to be weighed and measured. Two people were responsible for weighing, measuring, and recording data; three to four people performed surgeries to implant tags in the fish; and one or two people were responsible for moving tagged fish into the postsurgery tanks.

Fish were netted in small groups from the 80-gal holding tanks and placed in a 5-gal "knockdown" bucket with water and $20 \mathrm{~mL}$ of a $40-\mathrm{g} / \mathrm{L}$ stock solution of MS-222. Once a fish lost equilibrium, it was transferred to a processing table in a small container of river water. Each fish was measured (fork length $\pm 1 \mathrm{~mm}$ ); the species type and whether its adipose fin was intact or clipped were recorded on a GTCO CalComp Drawing Board VI digitizer board. Fish were weighed ( $\pm 0.01 \mathrm{~g})$ on an Ohaus Navigator scale and returned to the small transfer container along with an assigned PIT tag and an activated acoustic tag. Length, weight, species type, tag codes, and fin clip were all added automatically into the tagging database by PIT Tag Information System (PTAGIS) P3 software to minimize human error. The transfer container, fish, and tags were assigned a recovery bucket number and passed to a surgeon for tag implantation.

An established protocol was used in the tagging process to help minimize the handling impact on tagged fish. All surgical instruments were sterilized daily in an autoclave and each surgeon used 
four complete sets of instruments during each day's tagging. When a set was not being used, it was placed in a 70\% ethanol solution for approximately 10 minutes. The instruments were then transferred to a distilled water bath for 10 minutes, to remove residual ethanol and any remaining particles, before being used again. To reduce the disruption of the mucus membrane at the incision, Poly-Aqua was used to help replace the membrane that was removed from the fish's epidermal layers. Anesthesia buckets were kept within $\pm 1^{\circ} \mathrm{C}$ of river temperature. Anesthesia solutions were either replaced or cooled with ice when temperatures exceeded protocols. Recovery buckets were also kept within $\pm 1^{\circ} \mathrm{C}$ of river water temperature.

During surgery (Figure 2.4), each fish was placed ventral side up and a gravity-fed anesthesia supply line was placed into its mouth. The dilution of this "maintenance" line was $40 \mathrm{mg} / \mathrm{L}$. A 6-8-mm incision, using a \#15 stainless steel surgical blade or a Micro-Sharp stab scalpel with a 5-mm blade (depending on the surgeon's preference), was made ventrally, $3 \mathrm{~mm}$ from and parallel to the mid-ventral line and equidistant from the pelvic girdle and pectoral fin. The PIT tag was inserted first, followed by the acoustic tag. Both tags were inserted toward the anterior portion of the fish. Two interrupted sutures of 5-0 monofilament with an RB-1 needle were used to close the incision. With the incision closed, fish were then taken to an aerated recovery bucket containing river water.

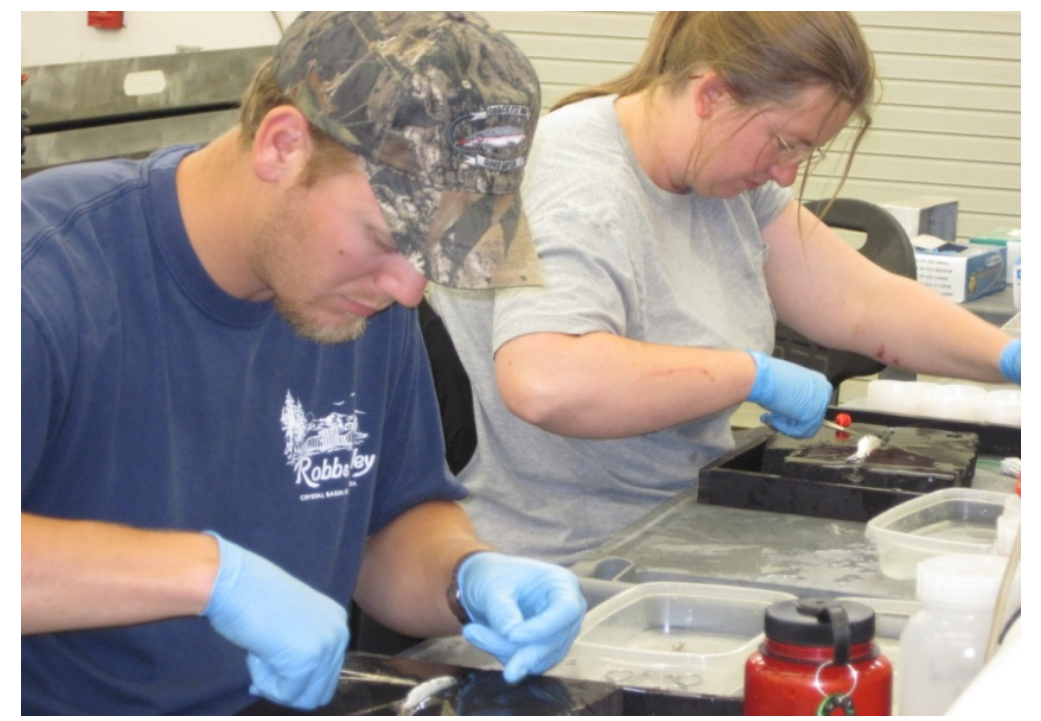

Figure 2.4. Surgical Implantation of PIT and Acoustic Tags in the John Day Smolt Monitoring Facility

\subsubsection{Recovery and Holding}

Tagged fish were placed in 5-gal aerated recovery buckets and closely monitored until fish had reestablished equilibrium. Each bucket held two to seven fish depending on the size of the fish and the number to be released at each site. The buckets were then carried to a larger holding tank where they were supplied with a continuous feed of river water (Figure 2.5). Fish were held and monitored for 18 to 30 hours prior to being released. The large holding tanks were insulated to keep the water temperature within acceptable limits. 


\subsubsection{Fish Transportation and Release}

To transport tagged fish, a 3/4-ton truck was outfitted with one 180-gal Bonar insulated tote and one 70-gal Bonar insulated tote. The 180-gal tote could hold ten 5-gal fish buckets, and the 70-gal tote could hold four 5-gal fish buckets. The totes had snug-fitting lids and some extra space inside so that ice could be added for cooling on hot days. A network of valves and plastic tubing was attached to an oxygen tank for delivering oxygen to the totes from a 2200-psi oxygen tank during transport. The Bonar totes were filled with fresh river water before fish buckets were removed from the post-surgery holding tanks and placed in the totes. Air lines were then placed into the totes. A YSI meter was used to measure the dissolved oxygen and the temperature of water in the totes before and after transport to ensure dissolved oxygen and temperature stayed within acceptable limits.

Just before fish were released in the river, fish buckets were opened to check for dead fish. Every dead fish was scanned with a BioMark portable transceiver PIT-tag scanner to identify the implanted PITtag code. The associated acoustic tag code was identified later from tagging data which recorded all pairs of PIT and acoustic tags implanted in fish the previous day. In 2009, there were no tailrace reference releases of tagged dead fish to determine whether dead fish were detected on downstream survivaldetection arrays. Therefore, PIT and acoustic tags in dead fish were recovered, sterilized, and implanted in a live fish the next day. Post-tagging, pre-release mortalities were low for each run of fish studied in $2009(\mathrm{CH} 1=0.2 \% ; \mathrm{STH}=0 \% ; \mathrm{CH} 0=0.46 \%)$.

The JSATS tagged fish from each of the three stocks were released $41 \mathrm{rkm}$ upstream of JDA near Roosevelt, Washington. The tagging information for every fish is summarized in Appendix A. Fish were released from a boat at three locations along a line transect across the river, unless river conditions were too rough for safe boat operation. The release location on the Oregon side of the channel had the longest fetch (i.e., distance with uninterrupted exposure to wind) followed by the mid-channel location. Sometimes the Oregon location, and less often, the Oregon and mid-channel locations had to be skipped due to strong winds generateing waves capable of swamping or capsizing a boat. On one occasion (July 12 at 2000 hours), river conditions were too rough to release fish from a boat, so the crew released fish from a nearby point of land that extended out into the river from the Washington shore.

For boat releases, fish buckets were moved from the Bonar transport totes into the stern of the boat. In preparation for fish release, the boat operator maneuvered the boat to the release waypoint using an onboard global positioning system (GPS) and put the motor in neutral. Each bucket was submerged in the water so that fish could swim out on their own volition. The release site and time were recorded to the nearest minute on field data sheets. 


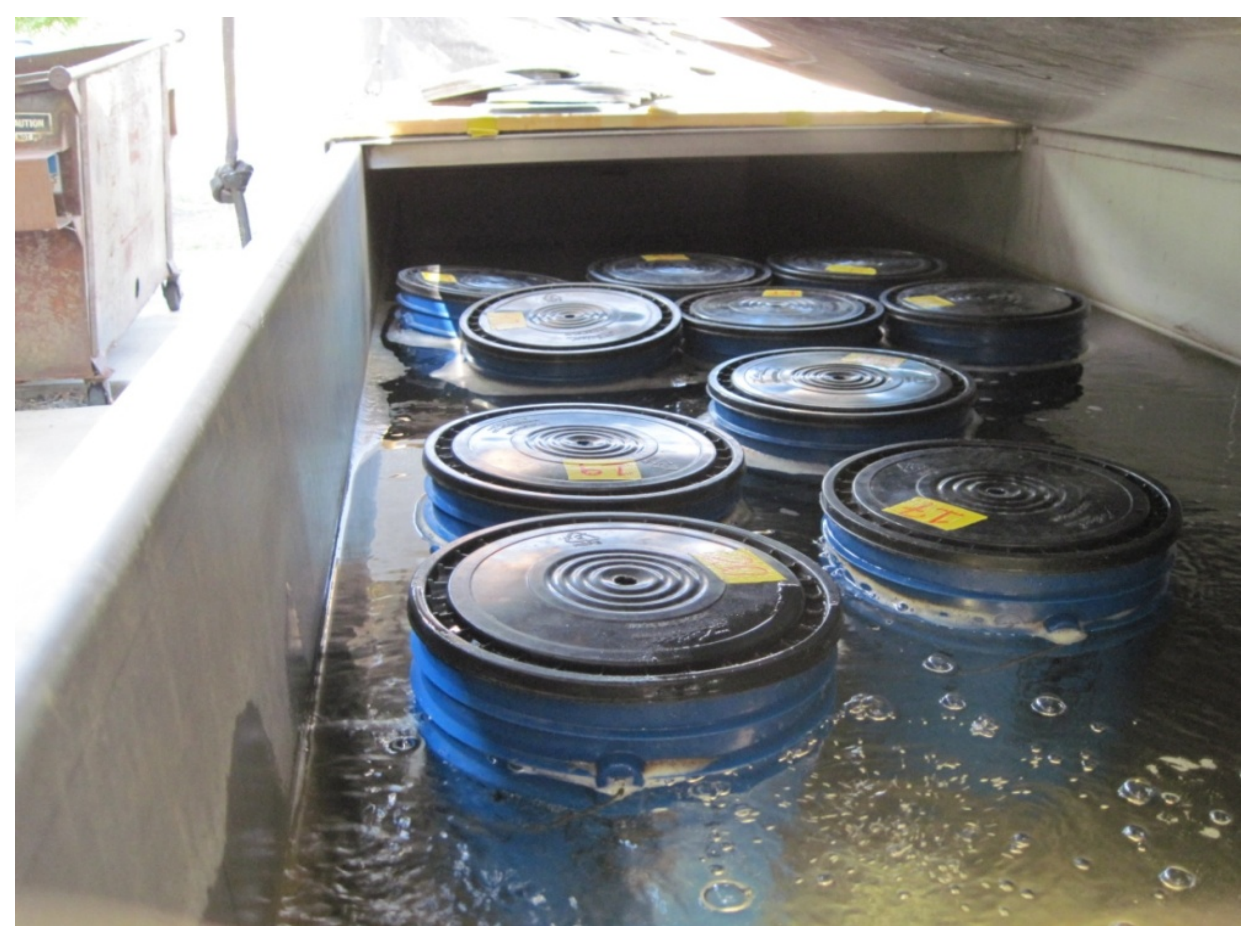

Figure 2.5. Post-Surgery Holding Tank with Recovery Buckets

\subsection{Detection of Tagged Fish}

Two types of JSATS receiver arrays - cabled and autonomous - were deployed to detect fish tagged with JSATS acoustic transmitters as they passed downstream through the study reach between the fish release site at Roosevelt, Washington, rkm 390; the JDA forebay array, rkm 351; and Kalama, Washington rkm 113 (Table 2.2). The JDA forebay array was used to create a virtual release for fish known to have entered the forebay $2 \mathrm{~km}$ upstream of JDA to estimate JDA forebay-to-TDA forebaypassage survival. The JDA dam-face array was used to create a virtual release for fish known to have passed JDA and to estimate JDA-to-TDA forebay and route-specific passage-survival rates based on 3D and last-detection data. Time of last detection on the dam-face array minus the time of first detection on the forebay entrance array at JDA was used to estimate forebay residence time. The time of first detection by the JDA tailwater egress array minus the time of last detection on the dam-face array provided an estimate of relative egress time. TDA forebay array was the primary array for estimating the survival rate for tagged smolts passing through JDA and for defining the virtual release of fish to estimate the survival rate for smolts passing through TDA. The BON forebay array was used as the secondary array for estimating the dam-passage survival rate at JDA and as the primary survival-detection array for virtual and reference releases of fish at TDA. The BON forebay array was also used to create a virtual release for BON survival studies at BON Powerhouse 2 [B2]), although those study results are not discussed in this report. The first BON tailwater array near Lady Island (Camas, Washington) was used as the tertiary array for estimating the product of survival and detection rates $(\lambda)$ for tagged smolts passing through JDA and as the secondary survival-detection array for estimating TDA-passage survival rate. The second BON tailwater array near Kalama, Washington, was used as a tertiary survival-detection array for estimating the product of survival and detection probabilities for estimating TDA-passage survival rate. The GPS positions of individual dam-face hydrophones and autonomous nodes are presented in Appendix B. 
Table 2.2. Description, Location, Name, and Survival Model Function of Arrays Deployed in 2009. Array names were a concatenation of "A" for autonomous or " $D$ " for dam face with a sequential number for each type (from upstream to downstream) with "CR" for Columbia River, and the nearest whole rkm.

\begin{tabular}{llll}
\hline \multicolumn{1}{c}{ Array Description } & \multicolumn{1}{c}{ Location } & Array & \\
\hline JDA Forebay & $2 \mathrm{~km}$ upstream JDA & A1CR351 & Regroup fish for virtual releases \\
JDA Dam Face & JDA & D1CR349 & Regroup fish for route-specific virtual releases \\
JDA Tailwater & $2.0 \mathrm{~km}$ downstream & A2CR346 & Detect tagged fish to estimate egress rate \\
& JDA & & \\
TDA Forebay & $2 \mathrm{~km}$ upstream TDA & A3CR311 & JDA primary; regroup fish for virtual releases \\
BON Forebay & 1.5 km upstream & A4CR236 & JDA secondary; regroup fish for virtual releases; \\
\multicolumn{1}{l}{ B2 Dam Face } & BON & D2CR235 & B2 route specific passage assignments \\
BON Tailwater 1 & Lady Island & A5CR192 & JDA tertiary; TDA secondary; BON primary; \\
BON Tailwater 2 & Near Kalama, WA & A6CR113 & TDA tertiary; BON secondary; \\
BON Tailwater 3 & Near Oak Point, WA & A7CR086 & BON tertiary \\
\hline B2 = Bonneville Dam Second Powerhouse; BON = Bonneville Dam; JDA = John Day Dam; TDA = The Dalles \\
Dam.
\end{tabular}

\subsubsection{Cabled Dam-Face Arrays}

The cabled dam-face receiver was designed by PNNL for the USACE Portland District using an offthe-shelf user-build system design. Each cabled receiver consists of a computer, data-acquisition software, digital signal-processing cards with field-programmable logic gate array (DSP+FPGA), GPS card, four-channel signal-conditioning receiver with gain control, hydrophones, and cables (Figure 2.6). The software that controls data acquisition and signal processing is the property of the USACE and is made available by the USACE as needed. 


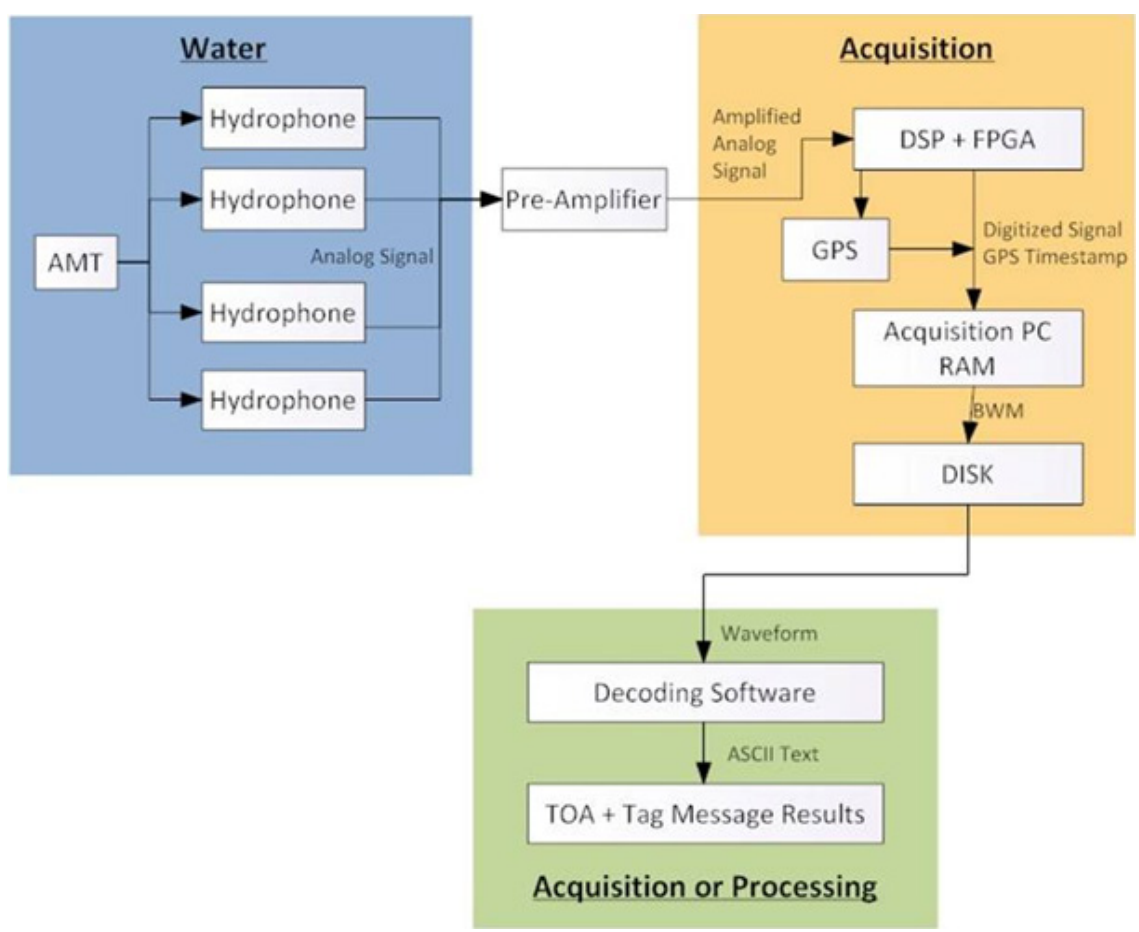

Figure 2.6. Schematic of the JSATS Dam-Face Receiver System Showing the Main Components and the Direction of Signal Acquisition and Processing. Abbreviations are as follows:

AMT $=$ acoustic micro-transmitter implanted in fish; DSP = digital signal processing card; FPGA = field programmable logic gate array; GPS = global positioning system; $\mathrm{PC}=$ personal computer; $\mathrm{RAM}=$ random access memory; $\mathrm{BWM}=$ binary waveform; $\mathrm{TOA}=$ time of arrival.

A modular JSATS cabled array was deployed along the upstream face of JDA to detect JSATStagged smolts approaching the dam. There were two hydrophones deployed at different depths on each main pier and eight hydrophones attached to clump mounts that were lowered to the bottom of the forebay about $33 \mathrm{~m}$ upstream of the dam face (Figure 2.7). Clump-mounted hydrophones were deployed to provide additional detections off of the plane of the dam face to increase the resolution of 3D tracking.

The dam-face cabled array consisted of 23 cabled receivers, each supporting four hydrophones. The receivers were housed in trailers on the forebay deck. The four hydrophones per cabled receiver were deployed on trolleys in pipes attached to the main piers at the powerhouse and spillway (Figure 2.7) in a known fixed geometry. Trolley pipes at the powerhouse were $4 \mathrm{in}$. in diameter and made of powdercoated schedule 40, 4-in.-internal-diameter steel pipes that were slotted down one side for deployment of the trolley. A cone was attached to the top of the pipe to assist with trolley insertion (Figure 2.8). Pipes at the powerhouse were $120 \mathrm{ft}$ long and extended from deck level at elevation $281 \mathrm{ft}$ above mean sea level (MSL) down to a mid-intake depth at elevation $164 \mathrm{ft}$ above MSL. One hydrophone on each pier was deployed at a shallow elevation (at $255.5 \mathrm{ft}$ above MSL) and another was deployed at a deep elevation (at $166.5 \mathrm{ft}$ above MSL) to provide acceptable geometries for tracking an acoustic-tagged fish in three dimensions and then assigning it a route of passage through the dam. 


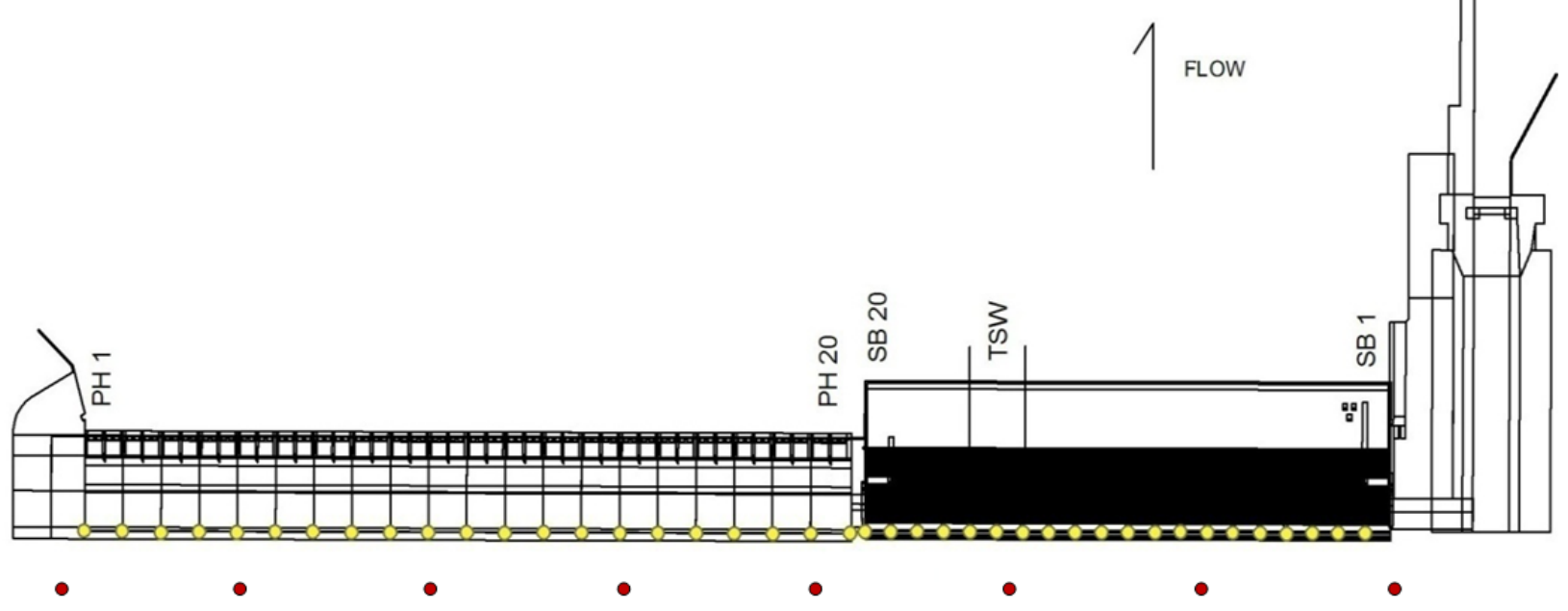

Figure 2.7. Location of Hydrophones on the Dam Face and in the Forebay of JDA, 2009

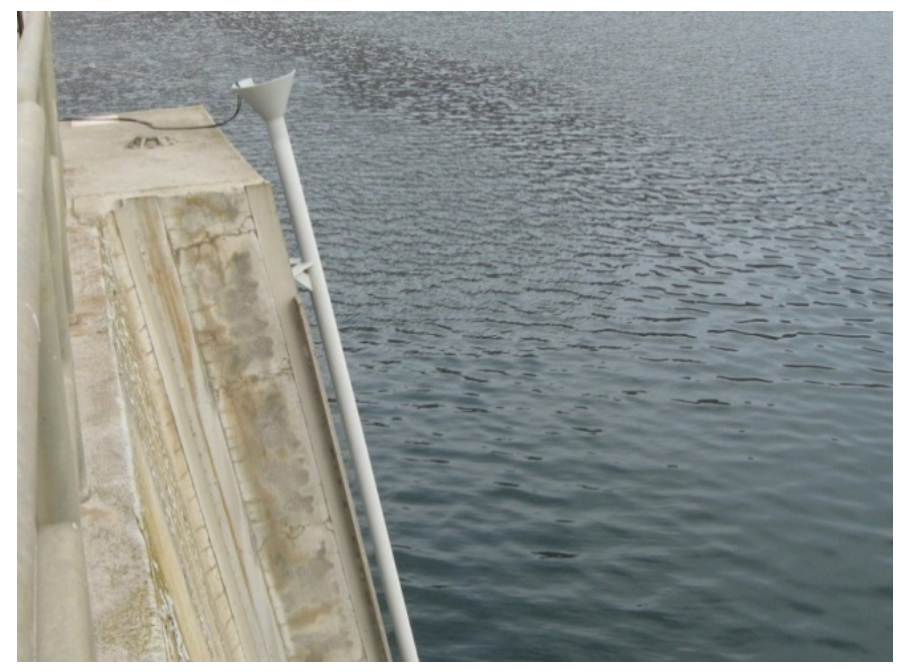

Figure 2.8. Trolley Pipe Mounted on a Main Pier of the JDA Powerhouse

At the spillway, hydrophones were mounted on trolleys that were deployed in 40-ft-long 8-in.diameter slotted pipes installed previously for radio-telemetry studies. Cones were added to the tops of the pipes to aid with installation of trolleys from the deck. At each spillway pier, one hydrophone was deployed at a shallow elevation (259.5 ft above MSL) and the other at a deep elevation ( $232.5 \mathrm{ft}$ above MSL). Each steel trolley slid down inside the pipe and was guided by an extension arm that protruded from the slot. The arm positioned the anechoic baffled hydrophone perpendicular to the face of the dam (Figure 2.9). 


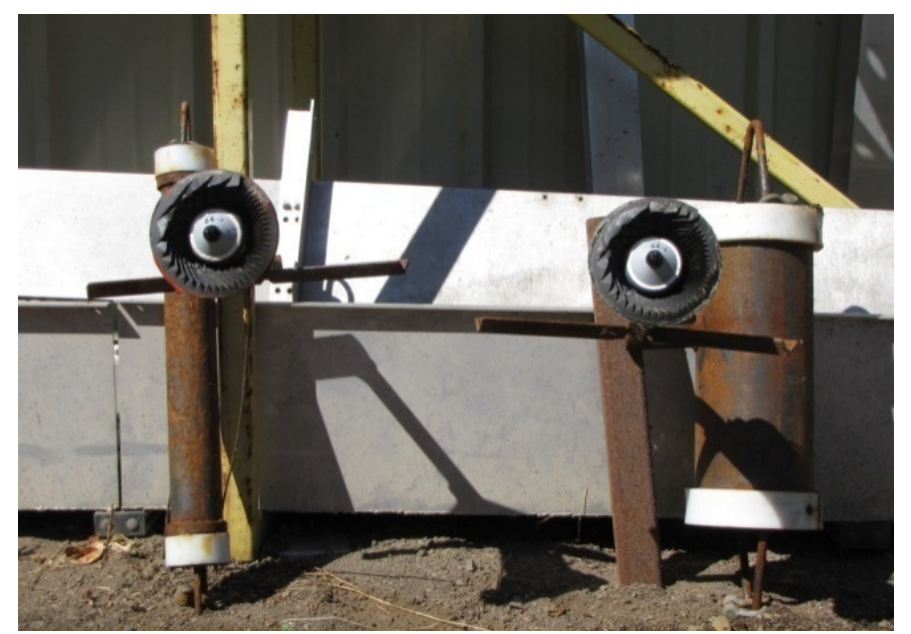

Figure 2.9. Trolleys Used to Deploy Hydrophones at the John Day Powerhouse and Spillway, 2009. A 4-in.-diameter trolley with hydrophone (left) for slotted pipes on powerhouse piers and an 8in.-diameter trolley with hydrophone (right) for slotted pipes on spillway piers. Each trolley had a steel arm to support a hydrophone that was surrounded by a plastic cone lined with anechoic material to prevent sound reception from a downstream direction.

\subsubsection{Autonomous Receiver Arrays}

Autonomous acoustic telemetry receivers were deployed in arrays at specific sites in the lower Columbia River study. An array is defined as a group of autonomous nodes deployed across the entire width of a river cross section to detect passing fish that have been surgically implanted with acoustic tags. Most arrays had autonomous nodes that were deployed within $400 \mathrm{ft}$ of each other and less than $250 \mathrm{ft}$ from shore. The hydrophone, pair of electronic circuit boards, compact flash (CF) card, and battery connectors were located in the node top (Figure 2.10).

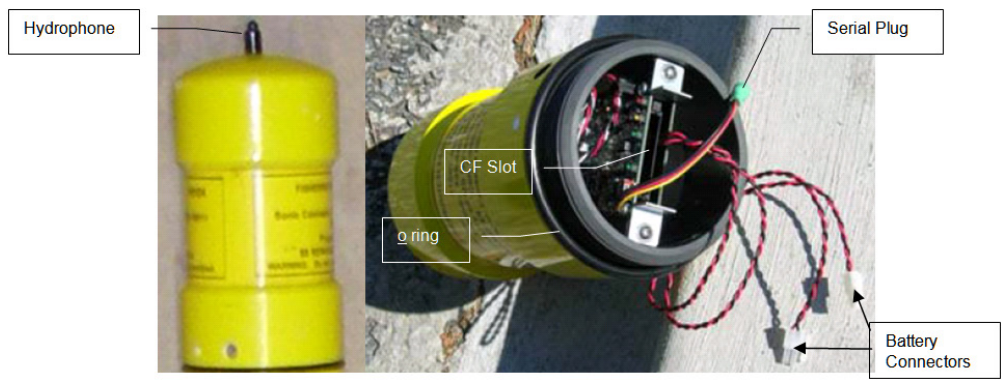

Figure 2.10. Side (left) and Bottom (right) Views of an Autonomous Node Top

Five arrays of autonomous nodes were deployed for this study (Figure 2.11). Arrays were named by concatenating several letters and numbers. For example, the first array was A1CR351, which is the concatenation of "A" (for autonomous node), a sequential array number (counting from upstream to downstream), "CR" (for Columbia River), and 351, which is the nearest river kilometer to that array site. This array was located $2 \mathrm{~km}$ upstream of JDA. A tailwater egress array (A2CR346) was located at rkm 346 about $2 \mathrm{~km}$ downstream of the tailrace deck of JDA. TDA forebay entrance array (A3CR311) was located $2 \mathrm{~km}$ upstream of TDA spillway. The BON forebay array (A4CR236) was located about $2 \mathrm{~km}$ upstream of B2. The tertiary array for estimating the product of detection and survival rates for JDA 
(A5CR192) was located near Lady Island in the BON tailwater. The tertiary array for estimating the product of detection and survival for TDA-passage survival estimate was deployed near Kalama, Washington. Appendix B lists the nominal GPS coordinates of autonomous nodes deployed in this study.

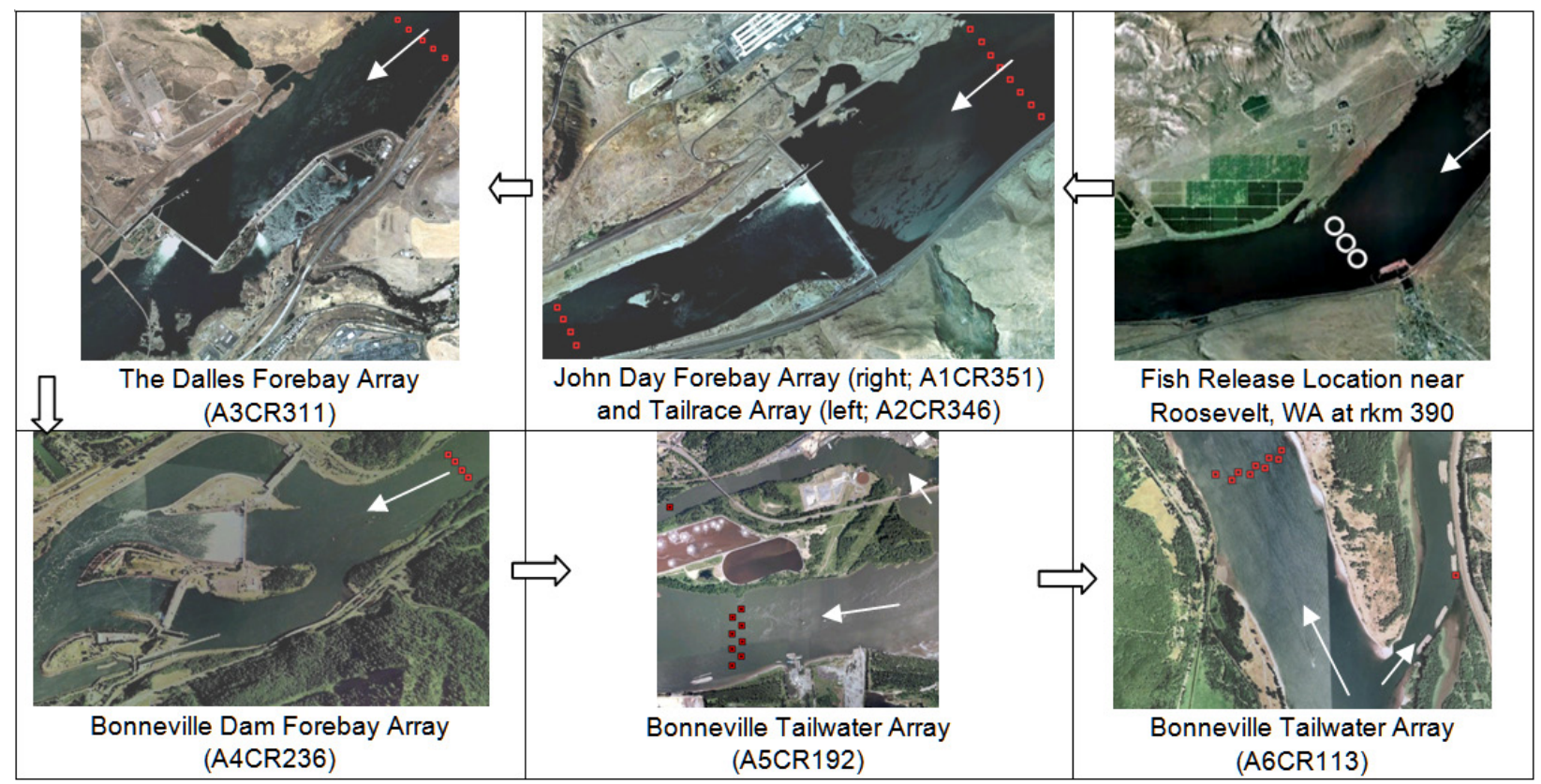

Figure 2.11. Location of the Only Fish-Release Transect (white circles in upper right panel) for the 2009 Study and Locations of Autonomous Nodes (red squares) Deployed in Arrays to Detect Acoustically Tagged Fish Migrating Downstream. Black arrows between Google Earth images indicate the order of images from upstream to downstream, and the direction of water flow within each image is indicated by white arrows. Array names are presented in parentheses, and the three-digit number at the end of each name is the river km upstream from the mouth of the Columbia River.

Nodes were typically retrieved by boat once every 2 weeks to download data, and batteries were replaced once every 28 days. The first step in servicing a node was to trigger its acoustic release. Staff entered a release-specific code into a topside command transceiver, and it transmitted an electrical signal to an underwater transducer, which in turn converted the electrical signal into underwater sound detectable by an acoustic modem on the upper end of the acoustic release mechanism. Upon receipt of a coded sound, the release mechanism usually would open and free the positively buoyant package from the anchor so that it would surface and could be retrieved by staff in the boat. The next step was to dry the node with a towel, open it, eject the CF card, and download the data from the card to a laptop computer. Each file was checked to verify that data were collected during the entire deployment, records were continuous, and records included time stamps and tag detections. The CF card was replaced every time nodes were retrieved. If data were corrupt, the node top was replaced with a new one and the faulty top was sent to Sonic Concepts for repair. Damage to the relatively delicate hydrophone tip was the most common problem. Nodes were deployed and serviced from April 22 until August 25, 2009.

Autonomous nodes were rigged with the configuration shown in Figure 2.12. A 5-ft section of rope with three 6-lb buoyancy floats was attached to a strap half way between the node tip and the bottom of the battery housing. An InterOcean Systems Model 111 acoustic release was attached to the other end of the 5-ft line. A 1-, 3-, or 6-ft length of wire rope was attached to the bottom of the acoustic release, 
depending on water depth, and the other end of that cable was shackled to a 75-lb steel anchor. The shorter 1-ft length of wire rope was used in water less than $40 \mathrm{ft}$ deep; the 3 - $\mathrm{ft}$ length was used in water over $40 \mathrm{ft}$ deep; and 6-ft lengths were used in deep locations were sandy substrates had the potential to gum up release mechanisms.

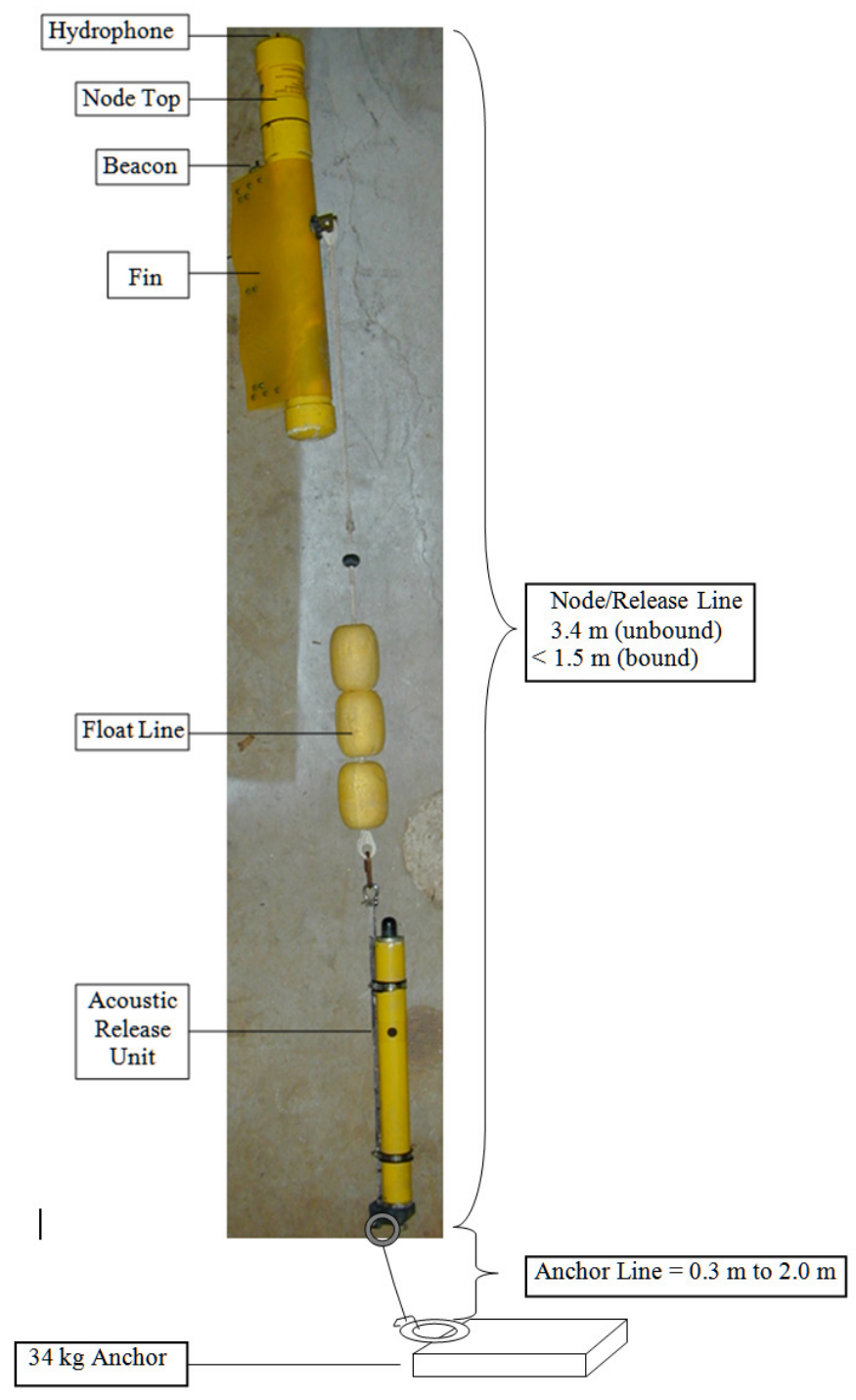

Figure 2.12. Autonomous Node Rigging

\subsection{Data Processing and Validation}

Data processing and validation efforts included decoding of acoustic signals, filtering the series of decoded signals, and conducting a tag-life study.

\subsubsection{Signal Decoding and Filtering}

Data collected by the JSATS cabled hydrophones were encoded candidate messages saved in binary time-domain waveform files. Figure 2.13 shows the waveforms of an actual example acquired at the JDA 
spillway on June 18, 2008. The waveform files were then processed by a decoding utility (Waveform Utilities developed by the USACE and PNNL) that identifies valid tag signals and computes the tag code and time of arrival using Binary Phase Shift keying. Binary Phase Shift keying is a digital-modulation technique that transmits messages by altering the phase of the carrier wave. Several filtering algorithms were then applied to the raw results from the decoding utilities to exclude spurious data and false positives.
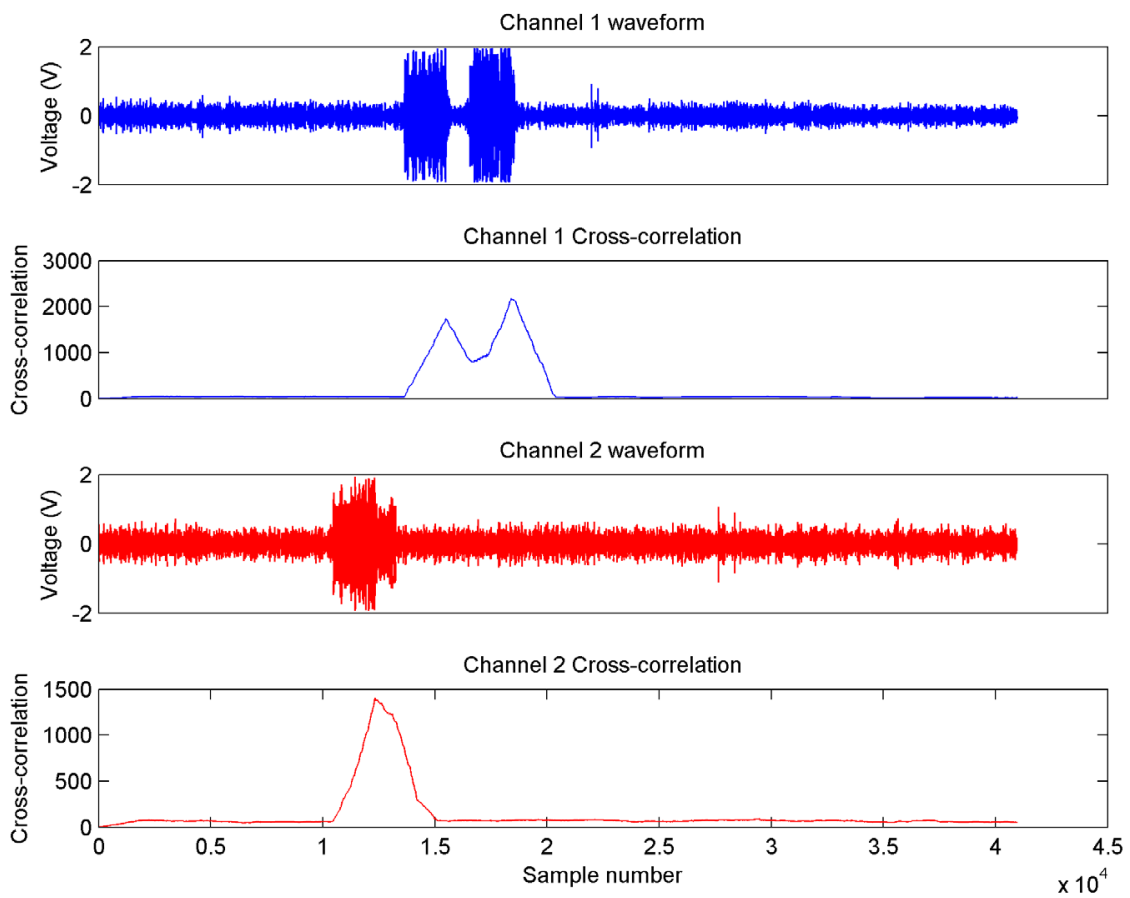

Figure 2.13. Example of Time-Domain Waveforms and Corresponding Cross-Correlations Acquired at the JDA Spillway. The message portion was 1860 samples (744 $\mu$ s long). Note that multipath components were present in both channels. Decodes from the multipath components were filtered out in post-processing.

Tag-detection data from JSATS autonomous nodes were processed by two independent groups as a quality-control measure like in previous studies (Ploskey et al. 2007, 2008; Weiland et al. 2009) using standardized methods. Regardless of processing method, tag, release, and detection data were merged into a single data set, and the same rules were applied to identify valid detections and to generate detection histories for every tag.

Steps for filtering raw autonomous node data to produce a clean detection data set included the following:

1. Decodes of the same tag within 0.156 seconds of the previous decode were assumed to be multipath and deleted.

2. Invalid detection events were deleted. A detection event was started when the time interval between any four identical decodes was $\leq 47.8$ seconds ( 3 -s tags), $\leq 79$ s ( 5 -s tags), or $\leq 157$ s (10-s tags).

Once started, the event continued until the time lapse between any two successive decodes exceeded the same time durations. 
3. Decodes within valid detection events, as described in Filter 2 above, were deleted if the time interval from the original decode in the series did not closely match an even multiple of one of the modes of the estimated pulse-repetition interval.

4. Remaining detection events for tag codes that were not used during the study year were flagged as orphans in hope of explaining the presence of those codes at a later date. Flagged detections were not used in any analysis unless they were explained. Resources for resolving issues included the list of codes of tags implanted in fish, lists of codes of beacons deployed on autonomous nodes or in forebays, and coordination with other researchers in the basin.

5. The remaining detections that occurred before a tag was released, at sites upstream of the listed release location, or on upstream arrays after a series of detections on downstream arrays were flagged. Analysts attempted to explain and resolve the flagged problems by examining all available information in the tagging, release, autonomous array, and cabled array data sets. Flagged detections were not used in any analysis unless the spatial or temporal discrepancies were adequately explained and resolved. Discrepancies might be explained by fish being released at the wrong site or incorrect data and time settings on an autonomous node.

Steps for filtering cabled array data to produce a clean detection data set included the following:

1. Decodes of a tag code within 0.156 seconds of a previous decode of the same code were assumed to be multipath and were deleted.

2. Invalid detection events were deleted. A detection event was started when the time interval between any four identical decodes was $\leq 47.8$ seconds ( 3 -s tags), $\leq 79$ seconds (5-s tags), or $\leq 157$ seconds (10-s tags). Once started, the event continued until the time lapse between any two successive decodes exceeded the same time durations.

3. Decodes within valid detection events, as described in Filter 2 above, were deleted if the time interval from the original decode in the series did not closely match an even multiple of one of the modes of the estimated pulse-repetition interval.

4. Remaining detection events for tag codes that were not used during the study year were flagged as orphans in hope of explaining the presence of those codes at a later date. Flagged detections were not used in any analysis unless they were explained. Resources for resolving issues included the list of codes of tags implanted in fish, lists of codes of beacons deployed on autonomous nodes or in forebays, and coordination with other researchers in the basin.

5. The remaining detections that occurred before a tag was released, at sites upstream of the listed release location, or on upstream arrays after a series of detections on downstream arrays were flagged. Analysts attempted to explain and resolve the flagged problems by examining all available information in the tagging, release, autonomous array, and cabled array data sets. Flagged detections were not used in any analysis unless the spatial or temporal discrepancies were explained and resolved. Discrepancies might be explained by fish being released at the wrong site or incorrect data and time settings on an autonomous node.

The final results from the steps above included a complete detection history for each tag: detection time (TOA), detection hydrophone location, and the signal-to-noise ratio. 


\subsubsection{Tag-Life Study}

For the JDA tag-life study, 98 acoustic tags (3-s ping rate) were randomly chosen from two manufacturing batches of Advanced Telemetry Systems, Inc. tags used in this 2009 study. Nine acoustic tags were already activated when received by PNNL for the tag-life study; thus only 89 tags were used in the tag-life analysis. The acoustic tags were divided into two approximately equal size groups and tag life was monitored separately for each group, but tag-life data from both manufacturing batches were pooled for analysis. All acoustic tags were enclosed in water-filled plastic bags and suspended from a rotating foam ring within a 2-m (diameter) fiberglass tank. Two $90^{\circ} \times 180^{\circ}$ hydrophones were positioned $90^{\circ}$ apart in the bottom of the tank and angled upward at approximately $60^{\circ}$ to maximize coverage for detecting acoustic signals. Hydrophones were cabled to a quad-channel receiver that amplified all acoustic signals. All acoustic signals were then saved, decoded, and postprocessed. Post-processing software calculated the number of hourly decodes for each acoustic tag, and therefore tag-failure times could be determined within $\pm 1 \mathrm{~h}$. Tag life expectancy was 23 days for all acoustic tags in this study.

\subsection{Statistical Methods for Estimating Survival Rates}

In this section, statistical methods and define test conditions are described.

\subsubsection{Defining Virtual Releases for Estimating Survival Rates}

Single fish-release location and all virtual release locations and arrays used to calculate survival estimates are described in the following sections.

\subsubsection{JDA Forebay-to-TDA Forebay, JDA-to-TDA Forebay, and Routes-Specific Survival Rates}

The PNNL team released $\mathrm{CH} 1$ and $\mathrm{STH}$ in spring and $\mathrm{CH} 0$ in summer into the river near Roosevelt, Washington, at rkm 390. Most of these tagged fish were detected by the JDA forebay entrance array (A1CR351) and detections were pooled over periods of several days to define virtual releases for estimating the single-release forebay-passage survival rate and the JDA forebay-to-TDA forebay-passage survival rate. Most of the fish also were detected on the dam-face array (D1CR349) and pooled over periods of several days to define virtual releases for estimating single-release JDA-to-TDA forebay and route-specific passage-survival rates. The JDA to TDA forebay- and route-specific passage-survival rates at JDA were estimated using subsequent detection histories for TDA forebay array (A3CR311, primary), BON forebay array (A4CR236, secondary), and the first BON tailwater array (A5CR192, tertiary) as diagramed in Figure 2.14. Paired-release estimates could not be made in 2009 because no tagged fish were released in the JDA tailrace. 


\section{$\mathrm{R}_{1}$}

390 km (Roosevelt, WA)
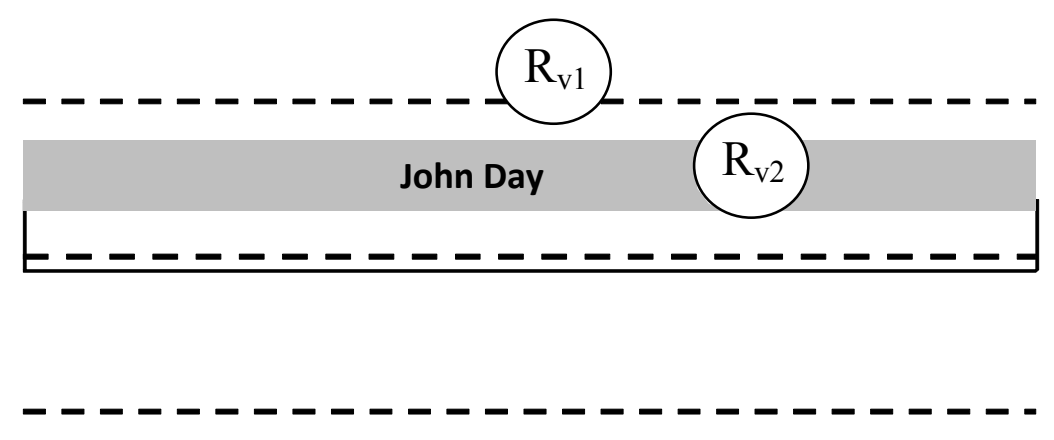

\section{The Dalle Dam}
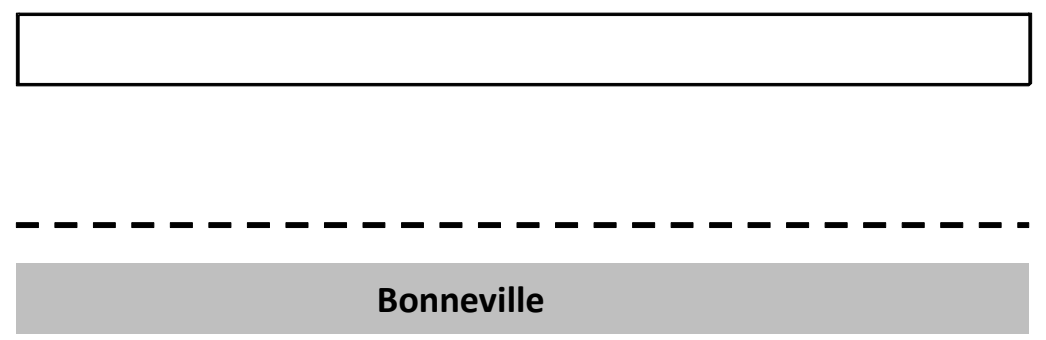

\section{Bonneville}

\section{$350.6 \mathrm{rkm} \mathrm{A1CR351}$ \\ 348.6 rkm D1CR349 \\ 346.0 rkm A2CR346}

311.0 rkm A3CR311

309.0 rkm (spillway)

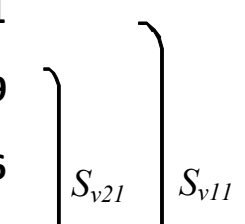

236.0 rkm A4CR236

$234.0 \mathrm{rkm}$

192.0 rkm A5CR192

Figure 2.14. Schematic of the Single-Release Design $\left(\mathrm{R}_{1}\right)$ and Virtual Releases $\left(\mathrm{R}_{\mathrm{v} 1}, \mathrm{R}_{\mathrm{V} 2}\right)$ for Estimating JDA Forebay-to-TDA Forebay and JDA-to-TDA Forebay-Passage Survival Rates $\left(S_{v 11}\right.$ and $S_{v 21}$, respectively) at JDA

\subsubsection{The Dalles Dam-Passage Survival Rates}

Many of the $\mathrm{CH} 1, \mathrm{STH}$, and $\mathrm{CH} 0$ released at site $\mathrm{R} 1$ also were detected on TDA forebay entrance array (A3CR311) and pooled over periods of several days to define virtual releases for making singlerelease estimates of TDA forebay to BON forebay-passage survival rate, as diagramed in Figure 2.15. Those estimates were based on capture-history data from three arrays downstream of TDA. Those arrays were located in the BON forebay (A4CR236) and the BON tailwater (A5CR192 and A6CR113). Pairedrelease estimates could not be made in 2009 because no tagged fish were released in TDA tailrace in 2009. 


\section{John Day Dam}
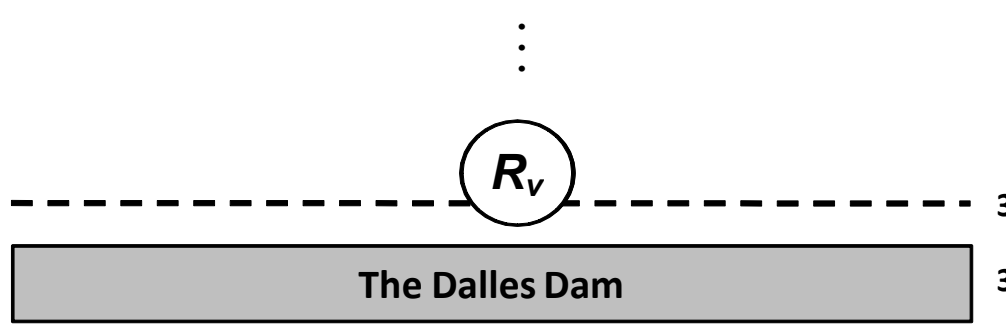

312.4 rkm A3CR312 $S_{v 1}$

The Dalles Dam 309.0 rkm (spillway)

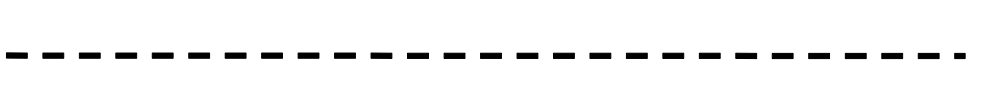

Bonneville Dam

$236.0 \mathrm{rkm}$ A4CR237

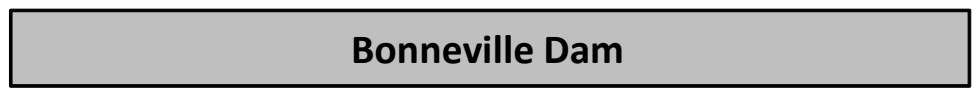

$234.0 \mathrm{rkm}$

$S_{v 2}$

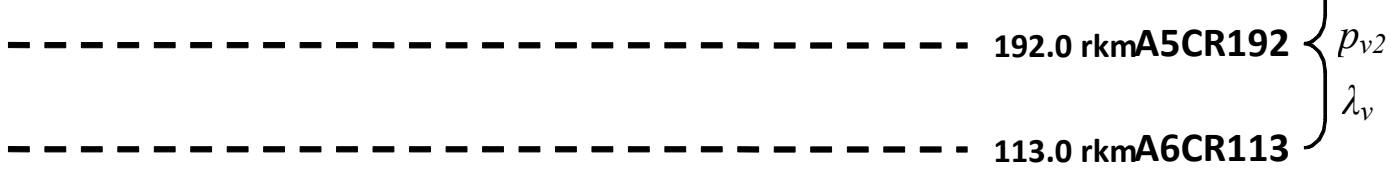

Figure 2.15. Schematic of the Single-Release Design for Estimating Virtual TDA Forebay to BON Forebay-Passage Survival Rates at TDA in Spring and Summer. Many of the tagged fish released upstream of JDA were detected on TDA forebay array and grouped to form virtual releases $\left(\mathrm{R}_{\mathrm{V}}\right)$ of fish known to have reached TDA. Detection histories of those fish on three downstream arrays provided needed inputs to estimate dam-passage survival.

\subsubsection{Estimation of JDA Forebay-to-TDA Forebay and JDA-to-TDA Forebay- Passage Survival Rates}

Single release-recapture methods using tagged fish regrouped at the JDA forebay array $\left(\mathrm{R}_{\mathrm{V} 1}\right)$, the dam-face array $\left(\mathrm{R}_{\mathrm{V} 2}\right)$ (Figure 2.14), the TDA forebay array (Figure 2.15) were used to estimate the survival rates for each fish stock. For JDA, the detection arrays at A3CR311, A4CR236, and A5CR192 provided $2^{3}=8$ possible capture histories for each release group $(111,011,101,001,110,010,100$, and 000), where a 1 indicates detection, and a zero indicates no detection on each of three successive survivaldetection arrays. For example, "111" indicates detection on all three arrays, whereas " 010 " indicates that detection on the second array but not on the first or third arrays. For TDA, detection arrays A4CR236, 
A5CR192, and A6CR113 also provided eight possible capture histories. Counts associated with each of the eight capture-history probabilities were input into the Survival with Proportional Hazards (SURPH 2.2b) software developed at the University of Washington (Lady et al. 2001) and generated single-release Cormack (1964), Jolly (1965), Seber (1965) (CJS) estimates of survival and its variance for each run of fish and virtual release grouping (usually pooled over several days). There were no paired-release estimates because reference releases were not made in 2009. Virtual releases were pooled for the entire season when detection probabilities for the three downstream arrays were homogeneous over time. When detection probabilities as a function of release date were heterogeneous, as indicated by a significant Chi square test, the number of fish in each virtual release was used to weight estimates of survival rate for individual ranges of virtual release dates. No tag-life corrections (after Townsend et al. 2006) were applied to the individual release CJS survival estimates because all fish passed the tertiary array before tag-life failure occurred.

\subsubsection{Tests of Assumptions}

Detections at multiple locations downstream of the single fish release site at Roosevelt, Washington, provided data required to estimate virtual-release reach survival rates based on the single releaserecapture model (Skalski et al. 1998). The assumptions of the single release-recapture model are as follows:

1. Individuals marked for the study are a representative sample from the population of interest.

2. Survival and capture probabilities are not affected by tagging or sampling. That is, tagged animals have the same probabilities as untagged animals.

3. All sampling events are "instantaneous." That is, sampling occurs over a negligible distance relative to the length of the intervals between sampling events.

4. The fate of each tagged individual is independent of the fate of all others.

5. All tagged individuals alive at a sampling location have the same probability of surviving until the end of that event.

6. All tagged individuals alive at a sampling location have the same probability of being detected at that event.

7. All tags are correctly identified and the status of the smolt (i.e., alive or dead) is correctly assessed.

The first assumption concerns making inferences from the sample to the target population. For example, if inferences are sought for Chinook salmon smolts, then the sample of tagged fish should be drawn from that class of fish. Otherwise, non-statistical inferences are necessary, justifying the similarity between the target population and the representativeness of fish implanted with acoustic transmitters. These assumptions could also be violated if smolts selected for acoustic tagging differ from the target population in a way that biases survival rates (either lower or higher).

Assumption 2 again relates to making inferences to the population of interest (i.e., untagged fish). If tagging has a detrimental effect on fish survival, then survival-rate estimates from the single releaserecapture design will tend to be negatively biased (i.e., underestimated). 
The third assumption specifies that mortality is negligible immediately in the vicinity of the sampling stations, so that the estimated mortality is related to the river reaches in question and not during the sampling event. In the case of out-migrating smolts, the time they spend in the vicinity of a hydrophone array is brief relative to the size of the river reaches in question. This assumption is for the sake of mathematical convenience and should be fulfilled by the nature of the outmigration dynamics and deployment of the hydrophone array.

The assumption of independence (4) implies that the survival or death of one smolt has no effect on the fates of others. In the larger river system with tens of thousands of smolts, this is likely true. Furthermore, this assumption is common to all tag analyses with little or no evidence collected to suggest it is not generally true. Nevertheless, violations of assumption 4 have little effect on the point estimate but might bias the variance estimate with precision being less than calculated.

Assumption 5 specifies that a smolt's prior detection history has no effect on its subsequent survival. This could be violated if some smolts were self-trained to repeatedly go through turbine or spill routes or, alternatively, avoid routes because of prior experience. This occurrence is unlikely and can be assessed from the detection histories of the individual smolts. The lack of handling following initial release of smolts implanted with acoustic transmitters further minimizes the risk that subsequent detections influence survival. Similarly, assumption 6 could be violated if downstream detections are influenced by upstream passage routes taken by the smolts. Violation of this assumption is minimized by placing hydrophone arrays across the breadth of the river or below the mixing zones for smolts following different passages at the dam.

Assumption 7 implies that the smolts do not lose their tags and are not subsequently misidentified as dead or not captured, nor are dead fish falsely recorded as alive at detection locations. The use of surgically implanted tags should minimize the chance for tag loss. Tag loss and tag failure would tend to result in a negative bias (i.e., underestimation) of smolt survival rates. The possibility of tag failure will depend on travel time relative to battery life. Dead fish drifting downstream could also result in falsepositive detections and upwardly bias estimates of survival rates. For this reason, tailrace hydrophone arrays are not proposed for this set of analyses.

For the single release-recapture model to be valid, certain data patterns should be evident from the capture histories. Virtual releases $R_{V 1} R_{V 2}$ and $R_{v}$ permit tests of goodness-of-fit to the release-recapture model. A series of tests of assumptions was performed to determine the validity of the model (i.e., goodness-of-fit). For example, the data from virtual release $R_{V 2}$ were summarized by an m-array matrix of the form provided below, where the value of $m_{i j}$ are the number of smolts detected at site $i$ that are next detected at site $j$ :

\begin{tabular}{lcccc}
\hline & & \multicolumn{3}{c}{ Recovery Site } \\
\cline { 3 - 5 } \multicolumn{2}{c}{ Virtual Release Site } & A3CR311(2) & A4CR236 (3) & A5CR192 (4) \\
\hline JDA Dam Face & $(1)$ & $m_{12}$ & $m_{13}$ & $m_{14}$ \\
TDA Forebay & $(2)$ & & $m_{23}$ & $m_{24}$ \\
BON Forebay & $(3)$ & & & $m_{34}$ \\
\hline
\end{tabular}


Burnham et al. (1987:65, 71-74) present a series of tests of assumptions called Test 2 that examine whether upstream detections affect downstream survival or detection. For each virtual release $R_{V 2}$, a contingency table test can be performed using a table constructed as follows:

Test 2.2

\begin{tabular}{|l|l|}
\hline$m_{13}$ & $m_{14}$ \\
\hline$m_{23}$ & $m_{24}$ \\
\hline
\end{tabular}

Tests were performed at $\alpha=0.10$. The multiple releases over the season were used to broaden the statistical inference and not to add evidence that the theoretical variances were reasonable. At best, estimates made from individual virtual releases might show some general seasonal trends if the trends are great enough and the detection probabilities were high enough.

Burnham et al. (1987:65, 71-74) also present a series of tests of assumptions called Test 3 that examine whether upstream capture histories affect downstream survival and/or capture. For release $R_{V 2}$, a contingency table can be constructed of the form:

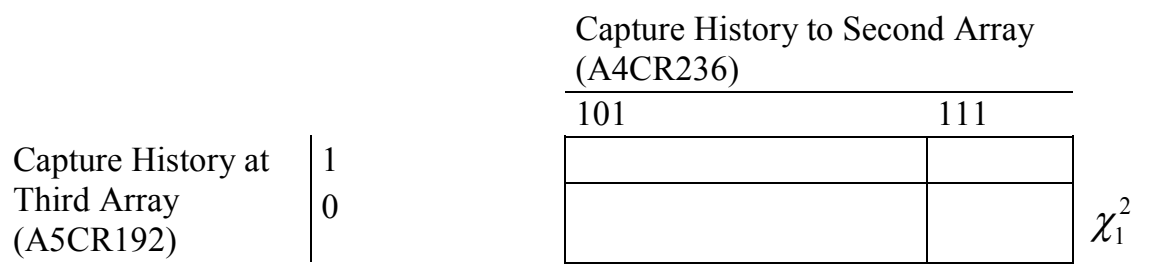

This contingency table tests whether detection at the first downstream array (A3CR311) has a subsequent effect on the capture history at the third downstream array (A5CR192).

\subsubsection{Probabilities of Detection by Passage Route}

Detection probabilities are an integral part of the survival estimation. For any particular passage route, the following variables are defined (Figure 2.16):

- $n_{10}=$ number of tagged smolts detected at the first array but not the second

- $n_{01}=$ number of tagged smolts detected at the second array but not the first

- $n_{11}=$ number of tagged smolts detected at both the first and second arrays.

From these counts of smolts with various route-specific detection histories, absolute passage abundance $(\hat{N})$ of tagged smolts can be estimated as

$$
\hat{N}=\frac{\left(n_{10}+n_{11}+1\right)\left(n_{01}+n_{11}+1\right)}{\left(n_{11}+1\right)}-1
$$


or

$$
\hat{N}=\frac{\left(n_{1}+1\right)\left(n_{2}+1\right)}{\left(n_{11}+1\right)}-1
$$

where $n_{1}=n_{10}+n_{11}$ and $n_{2}=n_{01}+n_{11}$ with associated variance estimate (Seber 1982:60)

$$
\widehat{\operatorname{Var}}(\hat{N})=\frac{\left(n_{1}+1\right)\left(n_{2}+1\right)\left(n_{1}-n_{11}\right)\left(n_{2}-n_{11}\right)}{\left(n_{11}+1\right)^{2}\left(n_{11}+2\right)}
$$

The estimated probability of detection $\left(p_{1}\right)$ in the first array is calculated as

$$
\hat{p}_{1}=\frac{n_{11}}{n_{2}}
$$

and the probability of detection $\left(p_{2}\right)$ in the second array as

$$
\hat{p}_{2}=\frac{n_{11}}{n_{1}}
$$

The overall probability of a smolt being detected in the double-array system is given by

$$
\hat{P}=1-\left(1-\hat{p}_{1}\right)\left(1-\hat{p}_{2}\right)=\frac{n_{11}\left(n_{1}+n_{2}+n_{11}\right)}{n_{1} n_{2}}
$$

Passage abundance was estimated for the powerhouse $\hat{N}_{P H}$, spillway $\hat{N}_{S P}$, and TSW $\left(\hat{N}_{T S W}\right)$. For the fish entering the JBS, the PIT-tag detection system was used to provide a complete tally of that passage abundance $\left(\hat{N}_{J B S}\right)$, assuming $100 \%$ detection efficiency.

The proportion of the acoustic-tagged smolts passing through the powerhouse $\hat{P}_{P H}$ was estimated as follows:

$$
\hat{P}_{\mathrm{PH}}=\frac{\hat{N}_{\mathrm{PH}}}{\hat{N}_{\mathrm{PH}}+\hat{N}_{\mathrm{SP}}+\hat{N}_{\mathrm{TSW}}+N_{\mathrm{JBS}}}
$$




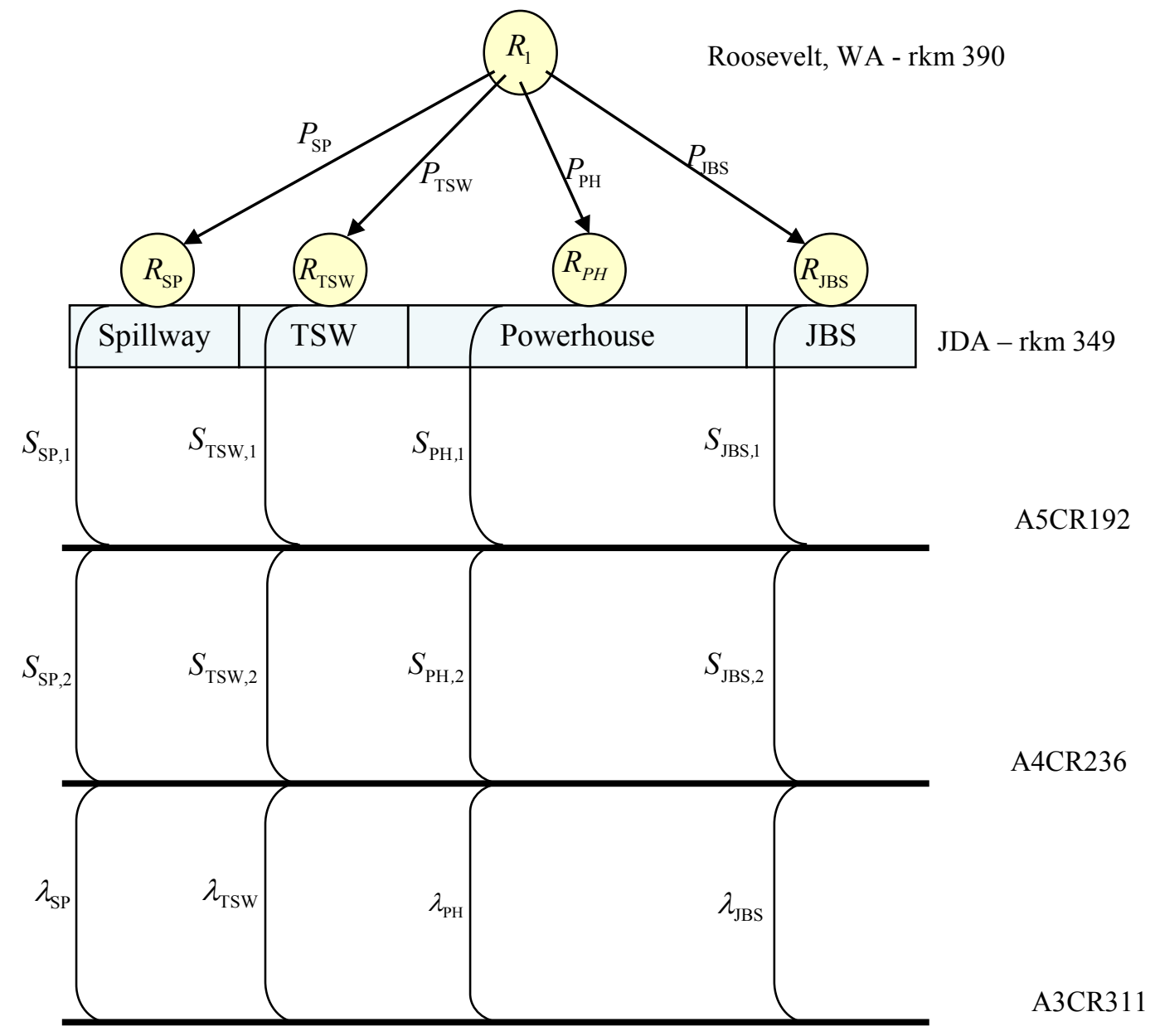

Figure 2.16. Schematic of Route-Specific Passage and Downstream Recoveries for Virtual Releases at the Spillway $\left(R_{\mathrm{SP}}\right)$, TSW $\left(R_{\mathrm{TSW}}\right)$, Powerhouse $\left(R_{\mathrm{PH}}\right)$, and JBS $\left(R_{\mathrm{JBS}}\right)$

Using the delta method (Seber 1982:7-9), the variance of $\hat{P}_{P H}$ is approximated by

$$
\widehat{\operatorname{Var}}\left(\hat{P}_{\mathrm{PH}}\right)=\frac{\hat{P}_{\mathrm{PH}}\left(1-\hat{P}_{\mathrm{PH}}\right)}{\hat{N}}+\hat{P}_{\mathrm{PH}}^{2}\left(1-\hat{P}_{\mathrm{PH}}\right)^{2} \cdot\left[\frac{\widehat{\operatorname{Var}}\left(\hat{N}_{\mathrm{PH}}\right)}{\hat{N}_{\mathrm{PH}}^{2}}+\frac{\widehat{\operatorname{Var}}\left(\hat{N}_{\mathrm{SP}}\right)+\widehat{\operatorname{Var}}\left(\hat{N}_{\mathrm{TSW}}\right)+\widehat{\operatorname{Var}}\left(\hat{N}_{\mathrm{JBS}}\right)}{\left(\hat{N}_{\mathrm{SP}}+\hat{N}_{\mathrm{TSW}}+N_{\mathrm{JBS}}\right)^{2}}\right],
$$

where $\hat{N}=\hat{N}_{\mathrm{PH}}+\hat{N}_{\mathrm{SP}}+\hat{N}_{\mathrm{TSW}}+N_{\mathrm{JBS}}$. Values of $\hat{P}_{S P}, \hat{P}_{T S W}$, and $\hat{P}_{J B S}$ were estimated analogously to Equation (2.9) and associated variances estimated analogously to Equation (2.10). Note for $N_{\mathrm{JBS}}$ that $\operatorname{Var}\left(N_{J B S}\right)=0$. 


\subsubsection{Route-Specific Relative Survival Rates}

The 3D hydrophone array on the JDA upstream dam face was used to identify fish known to have passed through the spillway, powerhouse, and TSWs (spill bays 15-16).

Smolts known to have passed through the various routes at JDA (Figure 2.16) were detected by listening devices on downstream arrays to obtain their capture histories. To estimate survival, you first must quantify the number of smolts passing by various routes, as follows:

- $R_{\mathrm{PH}}=$ number of smolts known to have passed through the powerhouse

- $n_{\mathrm{PH}}=$ number of smolts among $R_{\mathrm{PH}}$ detected downriver

- $R_{\mathrm{SP}}=$ number of smolts known to have passed through the spillway

- $n_{\mathrm{SP}}=$ number of smolts among $R_{\mathrm{SP}}$ detected downriver

- $R_{\mathrm{TSW}}=$ number of smolts known to have passed through the TSW

- $n_{\mathrm{TSW}}=$ number of smolts among $R_{\mathrm{TSW}}$ detected downriver

- $R_{\mathrm{JBS}}=$ number of smolts known to have passed through the JBS

- $n_{\mathrm{JBS}}=$ number of smolts among $R_{\mathrm{JBS}}$ detected downriver.

Using the relative recoveries of smolts through the various routes compared to the powerhouse, the relative route-specific survival probabilities can be estimated, e.g., the spill bay,

$$
R S_{\mathrm{SP} / \mathrm{PH}}=\frac{\left(\frac{n_{\mathrm{SP}}}{R_{\mathrm{SP}}}\right)}{\left(\frac{n_{\mathrm{PH}}}{R_{\mathrm{PH}}}\right)} .
$$

The variance of $R S_{\mathrm{SP} / \mathrm{PH}}$ is estimated by

$$
\widehat{\operatorname{Var}}\left(\widehat{R S}_{\mathrm{SP} / \mathrm{PH}}\right)=\widehat{R S}_{\mathrm{SP} / \mathrm{PH}}^{2}\left[\frac{1}{n_{\mathrm{PH}}}-\frac{1}{R_{\mathrm{PH}}}+\frac{1}{n_{\mathrm{SP}}}-\frac{1}{R_{\mathrm{SP}}}\right] .
$$

The estimators of relative survival rates for the other three routes are analogous to Equation (2.11) and their variances are analogous to Equation (2.12).

\subsubsection{Route-Specific Passage Survival Rates}

Using the smolts known to have passed through a specific route at the dam, absolute survival rates from the dam entrance to the TDA forebay array were estimated using a single release-recapture model 
(Figure 2.14). Route-specific survival rates and associated standard errors for the fish passed through the powerhouse, spillway, TSW, JBS, and turbines were estimated using the single-release CJS algorithms programmed in SURPH 2.2b.

\subsection{Statistical Methods - Fish Passage}

Fish-passage was characterized by estimating various passage efficiencies (e.g., SPE and TSWE). Spatial and temporal trends in passage and residence and egress times were also estimated, as described below.

\subsubsection{Fish-Passage Metrics}

Fish-passage efficiency (FPE) is defined as the proportion of fish that pass through the dam through non-turbine routes (i.e., spill, TSW, or JBS). In this study, FPE was estimated by the sum of the proportions of non-turbine passage proportions:

$$
\widehat{\mathrm{FPE}}=\hat{P}_{\mathrm{SP}}+\hat{P}_{\mathrm{TSW}}+\hat{P}_{\mathrm{JBS}}
$$

with associated variance estimator

$$
\begin{aligned}
\widehat{\operatorname{Var}}(\widehat{\mathrm{FPE}})= & \frac{\widehat{\mathrm{FPE}}(1-\widehat{\mathrm{FPE}})}{\hat{N}}+\widehat{\mathrm{FPE}}^{2}(1-\widehat{\mathrm{FPE}})^{2} \\
& \cdot\left[\frac{\widehat{\operatorname{Var}}\left(\hat{N}_{\mathrm{PH}}\right)}{\hat{N}_{\mathrm{PH}}^{2}}+\frac{\widehat{\operatorname{Var}}\left(\hat{N}_{\mathrm{SP}}\right)+\widehat{\operatorname{Var}}\left(\hat{N}_{\mathrm{TSW}}\right)+\widehat{\operatorname{Var}}\left(\hat{N}_{\mathrm{JBS}}\right)}{\left(\hat{N}_{\mathrm{SP}}+\hat{N}_{\mathrm{TSW}}+\hat{N}_{\mathrm{JBS}}\right)^{2}}\right] .
\end{aligned}
$$

Spill-passage efficiency (SPE) is defined as the proportion of fish that pass through the spillway (i.e., TSW and non-TSW spill bays). In the case of this study, SE refers to fish that pass through the spillway, or TSW. SE was estimated by the sum

$$
\widehat{\mathrm{SE}}=\hat{P}_{\mathrm{SP}}+\hat{P}_{\mathrm{TSW}}
$$

with associated variance estimator

$$
\begin{aligned}
\operatorname{Var}(\widehat{\mathrm{SE}})= & \frac{\widehat{\mathrm{SE}}(1-\widehat{\mathrm{SE}})}{\hat{N}}+\widehat{\mathrm{SE}}^{2}(1-\widehat{\mathrm{SE}})^{2} \\
& \cdot\left[\frac{\widehat{\operatorname{Var}}\left(\hat{N}_{\mathrm{SP}}\right)+\left(\hat{N}_{\mathrm{TSW}}\right)}{\left(\hat{N}_{\mathrm{SP}}+\hat{N}_{\mathrm{TSW}}\right)^{2}}+\frac{\widehat{\operatorname{Var}}\left(\hat{N}_{\mathrm{PH}}\right)+\widehat{\operatorname{Var}}\left(\hat{N}_{\mathrm{JBS}}\right)}{\left(\hat{N}_{\mathrm{PH}}+\hat{N}_{\mathrm{JBS}}\right)^{2}}\right] .
\end{aligned}
$$

Spill-passage effectiveness (SEF) is defined as the ratio of SE divided by the proportion of water passing the spillway relative to the total water discharge through the dam. In the case of this study, SEF was estimated as 


$$
\widehat{\mathrm{SEF}}=\frac{\hat{P}_{\mathrm{SP}}+\hat{P}_{\mathrm{TSW}}}{\left(\frac{f_{\mathrm{SP}}}{F}\right)}=\widehat{\mathrm{SE}}\left(\frac{F}{f_{\mathrm{SP}}}\right)
$$

where $F=$ total water volume discharge at the dam and $f=$ total water volume discharge through the spillway and TSW. The variance of $\widehat{\mathrm{SEF}}$ was calculated as

$$
\widehat{\operatorname{Var}}(\widehat{\mathrm{SEF}})=\widehat{\operatorname{Var}}(\widehat{\mathrm{SE}})\left(\frac{F}{f}\right)^{2}
$$

Top-spill weir passage efficiency (TSWE) is defined as the proportion of smolts passing the dam through the TSW spill bays. For this study, the efficiency of TSW passage was expressed by

$$
\widehat{\mathrm{TSWE}}=\hat{P}_{\mathrm{TSW}}
$$

with associated variance estimator

$$
\begin{aligned}
\widehat{\operatorname{Var}}(\widehat{\mathrm{TSWE}})= & \frac{\hat{P}_{\mathrm{TSW}}\left(1-\hat{P}_{\mathrm{TSW}}\right)}{\hat{N}}+\hat{P}_{\mathrm{TSW}}{ }^{2}\left(1-\hat{P}_{\mathrm{TSW}}\right)^{2} \\
& \cdot\left[\frac{\widehat{\operatorname{Var}}\left(\hat{N}_{\mathrm{TSW}}\right)}{\hat{N}_{\mathrm{TSW}}^{2}}+\frac{\widehat{\operatorname{Var}}\left(\hat{N}_{\mathrm{SP}}\right)+\widehat{\operatorname{Var}}\left(\hat{N}_{\mathrm{PH}}\right)+\widehat{\operatorname{Var}}\left(\hat{N}_{\mathrm{JBS}}\right)}{\left(\hat{N}_{\mathrm{SP}}+\hat{N}_{\mathrm{PH}}+\hat{N}_{\mathrm{JBS}}\right)^{2}}\right] .
\end{aligned}
$$

The TSW-passage effectiveness (TSWEF) is defined as TSWE divided by the proportion of water discharge through the dam that passed through TSW spill bays. For this study, the effectiveness of TSW was expressed as the quotient

$$
\widehat{\mathrm{TSWEF}}=\frac{\hat{P}_{\mathrm{TSW}}}{\left(\frac{f_{\mathrm{TSW}}}{F}\right)}=\widehat{\mathrm{TSWE}}\left(\frac{F}{f_{\mathrm{TSW}}}\right)
$$

where $f_{\text {TSW }}=$ total water volume discharge through the TSW.

The variance of the TSWEF was estimated by the quantity

$$
\widehat{\operatorname{Var}}(\widehat{\mathrm{TSWEF}})=\widehat{\operatorname{Var}}(\widehat{\mathrm{TSWE}}) \cdot\left(\frac{F}{f_{\mathrm{TSW}}}\right)^{2}
$$

Fish-guidance efficiency (FGE) is the proportion of smolts entering turbines that were subsequently guided by in-turbine screens to the JBS. It was estimated by the proportion 


$$
\widehat{\mathrm{FGE}}=\hat{P}_{\mathrm{JBS}}
$$

with the associated variance estimator

$$
\begin{aligned}
\widehat{\operatorname{Var}}(\widehat{\mathrm{FGE}})= & \frac{\widehat{\mathrm{FGE}}(1-\widehat{\mathrm{FGE}})}{\hat{N}}+\widehat{\mathrm{FGE}}^{2}(1-\widehat{\mathrm{FGE}})^{2} \\
& \cdot\left[\frac{\widehat{\operatorname{Var}}\left(\hat{N}_{\mathrm{JBS}}\right)}{\hat{N}_{\mathrm{JBS}}^{2}}+\frac{\widehat{\operatorname{Var}}\left(\hat{N}_{\mathrm{SP}}\right)+\widehat{\operatorname{Var}}\left(\hat{N}_{\mathrm{PH}}\right)+\widehat{\operatorname{Var}}\left(\hat{N}_{\mathrm{TSW}}\right)}{\left(\hat{N}_{\mathrm{SP}}+\hat{N}_{\mathrm{PH}}+\hat{N}_{\mathrm{TSW}}\right)^{2}}\right] .
\end{aligned}
$$

The passage efficiency of the JBS (JBSE) is the proportion of fish passing the dam through the JBS:

$$
\mathrm{JBSE}=\hat{P}_{\mathrm{JBS}}
$$

with the associated variance estimator

$$
\begin{aligned}
\widehat{\operatorname{Var}}(\widehat{\mathrm{JBSE}})= & \frac{\widehat{P}_{\mathrm{JBS}}\left(1-\widehat{P}_{\mathrm{JBS}}\right)}{\hat{N}}+\hat{P}_{\mathrm{JBS}}^{2}\left(1-\widehat{P}_{\mathrm{JBS}}\right)^{2} \\
& \cdot\left[\frac{\widehat{\operatorname{Var}}\left(\hat{N}_{\mathrm{JBS}}\right)}{\hat{N}_{\mathrm{JBS}}^{2}}+\frac{\widehat{\operatorname{Var}}\left(\hat{N}_{\mathrm{PH}}\right)+\widehat{\operatorname{Var}}\left(\hat{N}_{\mathrm{SP}}\right)+\widehat{\operatorname{Var}}\left(\hat{N}_{\mathrm{TSW}}\right)}{\left(\hat{N}_{\mathrm{PH}}+\hat{N}_{\mathrm{SP}}+\hat{N}_{\mathrm{TSW}}\right)^{2}}\right] .
\end{aligned}
$$

\subsubsection{Spatial Trends}

Estimates of the horizontal distribution of passage of each stock of fish at JDA according to the individual turbine and spill bay of passage were made based on detections on the dam-face array and 3D tracking. The same 3D tracking data set allowed evaluation of the vertical distribution of smolts within $75 \mathrm{~m}$ of the dam.

For a broader picture of fish behavior in the forebay, the distribution of smolts detected on the forebay entrance array $2 \mathrm{~km}$ upstream of JDA were compared with the distribution of smolt passage at the dam. Smolt detections on the forebay array were assigned to horizontal blocks corresponding to locations upstream of dam structures, as follows (from south to north): PH1-8 = powerhouse units 1-8, PH9-16= powerhouse units 9-16, skeleton bays, SW17-20 = spill bays 17-20, SW15-16 = spill bays 15-16 (each with a TSW), and SW1-14 = spill bays 1-14. Passage locations also were grouped into blocks of routes with the same names used to describe smolt arrivals, except that skeleton bays were dropped because they could not pass fish. This approach allowed examination of smolts behavioral responds to the dam by avoiding or selecting blocks of passage routes. Similar arrival and passage distributions would suggest that smolt responses to forebay conditions and operations were limited, whereas substantial shifts in those distributions would indicate that smolts were responding to forebay conditions or operations by selecting preferred blocks of routes. 


\subsubsection{Travel and Residence Times}

As mentioned above, the JDA forebay array was used to create a virtual release for fish as they enter the forebay $2 \mathrm{~km}$ upstream of JDA. The JDA dam-face array was used to create a virtual release for fish known to have passed JDA and to estimate the route of passage at the dam using 3D tracking and lastdetection data. The time of last detection by the dam-face array minus the time of first detection on the forebay array provides an estimate of forebay residence time. The time of first detection by the JDA tailwater egress array minus the time of last detection on the dam-face array provides an estimate of relative egress time.

\subsection{Statistical Methods - Fish Behavior}

Fish behavior was assessed by 3D tracking of JSATS-tagged fish in the immediate forebay of JDA. Acoustic tracking is a common technique in bioacoustics based on TOA differences (TOADs) among different hydrophones. Usually, the process requires a three-hydrophone array for 2D tracking and a four-hydrophone array for 3D tracking. For this study, only 3D tracking was performed.

Consider a transmitting source (tag) in the range of a four-hydrophone array. The boldface letters indicate matrices or vectors. The source $(\mathbf{S})$ and receiver $(\mathbf{r})$ position vectors are defined as follows:

$$
\begin{aligned}
& \mathbf{S}=\left(s_{x}, s_{y}, s_{z}\right)^{\mathrm{T}} \\
& \mathbf{r}_{i}=\left(x_{i}, y_{i}, z_{i}\right)^{\mathrm{T}} \quad i=0,1,2,3
\end{aligned}
$$

The distance between transmitting source and receivers gives

$$
\left(s_{x}-x_{i}\right)^{2}+\left(s_{y}-y_{i}\right)^{2}+\left(s_{z}-z_{i}\right)^{2}=c^{2}\left(t_{i}+T_{0}\right)^{2}, \quad i=0,1,2,3
$$

where $\mathrm{c}$ is the speed of sound, $T_{0}$ is the time of travel from the source to the reference receiver (receiver 0 ), and $t_{\mathrm{i}}$ is the TOAD between receiver $i$ and the reference receiver. With $t_{\mathrm{i}}$ measured by the common clock, the source position vector and $T_{0}$ are the four unknowns to be solved by the four distance equations.

There are several mathematical ways to obtain the exact solutions to the equations above (Watkins and Schevill 1972; Fang 1990; Spiesberger and Fristrup 1990; Juell and Westerberg 1993; Wahlberg et al. 2001). Wahlberg et al. (2001) applied a synthesis of the methods used by Watkins and Schevill (1972) and Spiesberger and Fristrup (1990). It has the advantage of giving the same mathematical form for 2D and 3D array systems, and for both minimum number of receivers arrays and over-determined arrays. Assuming that the first receiver is located at the origin of the coordinate system and subtracting Equation (2.28) for $i=0$ from Equation (2.28) for $i=1,2$ and 3, provides:

$$
2 \mathbf{R}^{T} \mathbf{S}+2 c^{2} \mathbf{t} T_{0}=\mathbf{b}
$$


where,

$$
\mathbf{R}=\left[\begin{array}{lll}
x_{1} & x_{2} & x_{3} \\
y_{1} & y_{2} & y_{3} \\
z_{1} & z_{2} & z_{3}
\end{array}\right], \mathbf{t}=\left(\begin{array}{l}
t_{1} \\
t_{2} \\
t_{3}
\end{array}\right), \mathbf{b}=\left(\begin{array}{l}
b_{1} \\
b_{2} \\
b_{3}
\end{array}\right) \text {, and } b_{i}=\left\|\mathbf{r}_{i}\right\|^{2}-c^{2} t_{i}^{2}
$$

From Equation (2.29),

$$
\mathbf{S}=\mathbf{R}^{-T}\left(\frac{1}{2} \mathbf{b}-c^{2} \mathbf{t} T_{0}\right)
$$

substituting Equation (2.31) to the relationship $\mathbf{S}^{T} \mathbf{S}=c^{2} T_{0}^{2}$ gives

$$
T_{0}=\frac{-p \pm \sqrt{p^{2}-a q}}{a}
$$

where,

$$
a=c^{4} \mathbf{t}^{T} \mathbf{R}^{-1} \mathbf{R}^{-T} \mathbf{t}-c^{2}, \quad p=-\frac{1}{2} c^{2} \mathbf{t}^{T} \mathbf{R}^{-1} \mathbf{R}^{-T} \mathbf{b}, \text { and } q=\frac{1}{4} \mathbf{b}^{T} \mathbf{R}^{-1} \mathbf{R}^{-T} \mathbf{b}
$$

After $T_{0}$ is determined, source position (S) is then obtained by Equation (2.31).

Note that there are two possible solutions for $T_{0}$. If they are both complex, then there is no exact solution for the given configuration and TOADs. A negative $T_{0}$ is nonphysical. When there are two real non-negative solutions, then both provide two possible locations for the source. In the JDA 2008 study, all hydrophones were installed at the dam face and were oriented upstream to detect sound emanating from upstream sources only, so estimated source location downstream of the dam face could not be real.

However, an exact solution may not be available due to the nonlinearity of the four distance equations and the errors in sound speed, time measurements, and hydrophone location uncertainties. Therefore the location of the sound source is estimated iteratively by minimizing the position errors. The most common methods are iterative Taylor-series methods or variant Newton-Gaussian methods, which linearize the equation using Taylor expansion and search for an approximate numerical solution iteratively by minimizing the least-square error (Foy 1976). Several other approaches have been developed: maximum likelihood algorithms (Chan 1994; Chan et al. 2006) that start from maximum likelihood functions instead of linearizing the equations first and derive a close-form approximation; the spherical interpolation approach (Torieri 1984); and linear-correction (Cheung et al. 2004). The codes for these approximation methods were developed but not applied to the JDA 2008 study because of the high success rates of exact solvers.

After the source location was obtained using 3D tracking, a set of artificial TOADs $\left(t_{1}^{\prime}, t_{2}^{\prime}, t_{3}^{\prime}\right)$ and $T_{0}^{\prime}$ was computed directly using the 3D-tracked source location for the given hydrophone locations and the speed of sound. The total time error was then defined as 


$$
\Delta T=\sqrt{\left(\mathrm{t}_{1}^{\prime}-\mathrm{t}_{1}\right)^{2}+\left(\mathrm{t}_{2}^{\prime}-\mathrm{t}_{2}\right)^{2}+\left(\mathrm{t}_{3}^{\prime}-\mathrm{t}_{3}\right)^{2}+\left(\mathrm{T}_{0}^{\prime}-\mathrm{T}_{0}\right)^{2}} .
$$

The detailed steps for 3D tracking are as follows:

- Pool together all detections of the same signal from different hydrophones. If more than four hydrophones detect the same tag signal, select the four with the best geometry configuration for 3D tracking (Wahlberg et al. 2001; Ehrenberg and Steig 2002). Compute the TOAD directly from detection time because all hydrophones are synchronized to a universal GPS clock with accuracy within $0.4 \mu$ s.

- Apply tracking solvers to estimate 3D locations and output solutions that are physical and within the pre-specified $\Delta T$ (10 $\mu$ s for the JDA 2008 study).

- Apply order 3 median filtering (Lim 1990) to remove spurious locations and smoothing fish tracks.

- Assign a route of passage based on the y component of the last tracked location.

- Assign another set of passage routes based on the detections on the last two hydrophones on different piers. For example, if the two hydrophones were at Pier 1 (numbering starting from the Oregon side) and Pier 2, then the passage route would be assigned to the first turbine unit.

- Compare the two sets of passage routes. If the difference for a fish is more than one bay, check its trajectory and detection history manually. 


\subsection{Results}

The study results related to environmental conditions, validation of JSATS performance, various survival estimates, fish passage, and fish behavior are presented in the following sections.

\subsection{Environmental Conditions}

This section contains a description of environmental conditions during the 2009 study, including river discharge and temperature relative to the 10-year average, the length frequencies of tagged and untagged fish that were collected at the JDA SMF, and results of the tag-life study.

\subsubsection{Dam Discharge and Temperature}

During times when tagged fish were arriving at JDA, mean daily dam discharge usually was above the previous 10-year average in spring and early summer and below average during most of July (Figure 3.1). Spill discharge was frequently above the previous 10-year average in spring and at or above the 10-year average from June 16 through July 29. Discharge was much higher than the 10-year average during the second half of the spring season. Forebay water temperatures were 1-2 degrees below the 10-year average most of spring and within 1 degree of the 10-year average most of summer, except for the last 1.5 weeks in July when they were $1-4$ degrees above average (Figure 3.2 ).

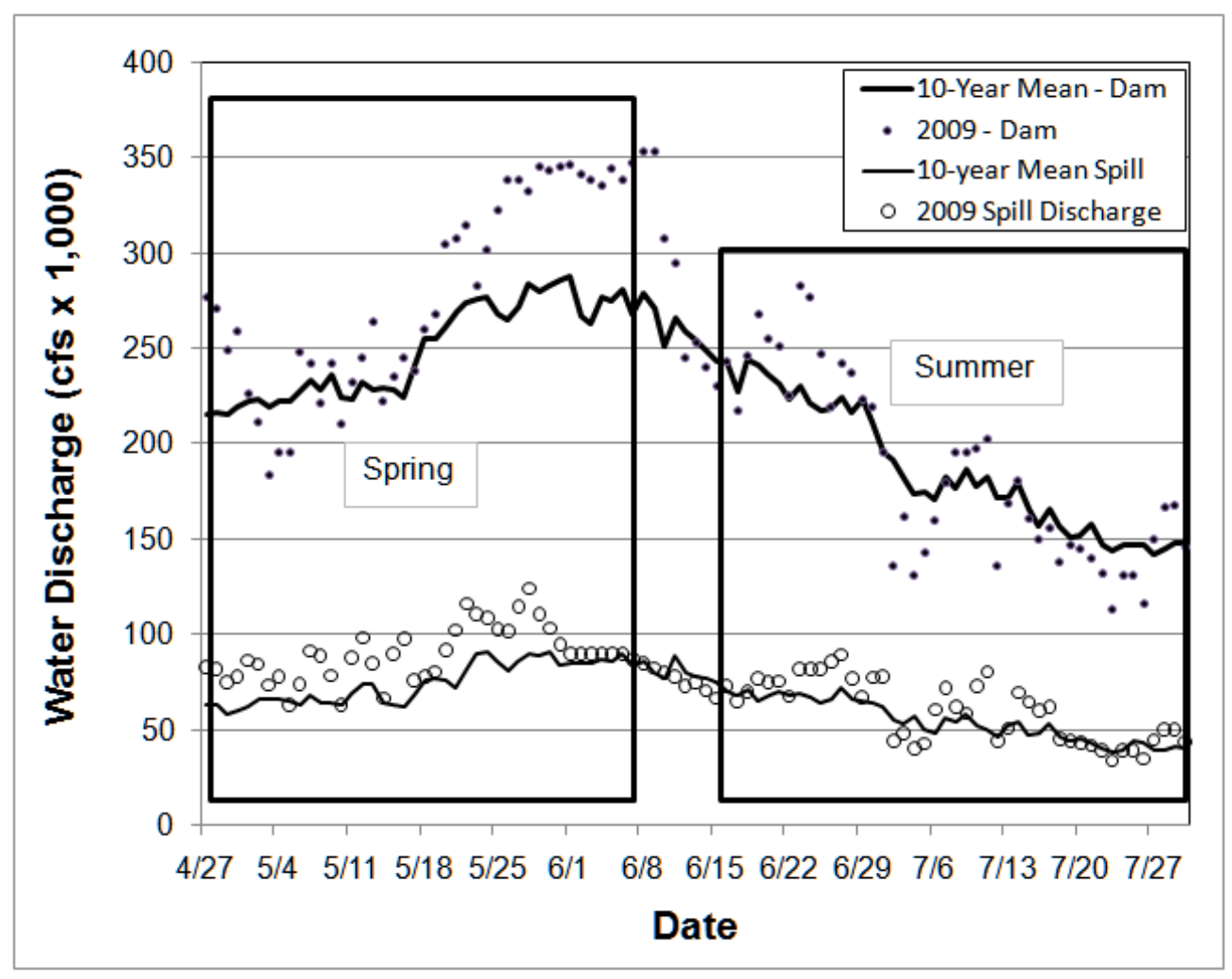

Figure 3.1. Estimated 2009 Daily Dam and Spillway Discharge Relative to the Previous 10-Year Average for JDA. Boxes bracket days when fish implanted with JSATS acoustic tags were arriving at the dam. 


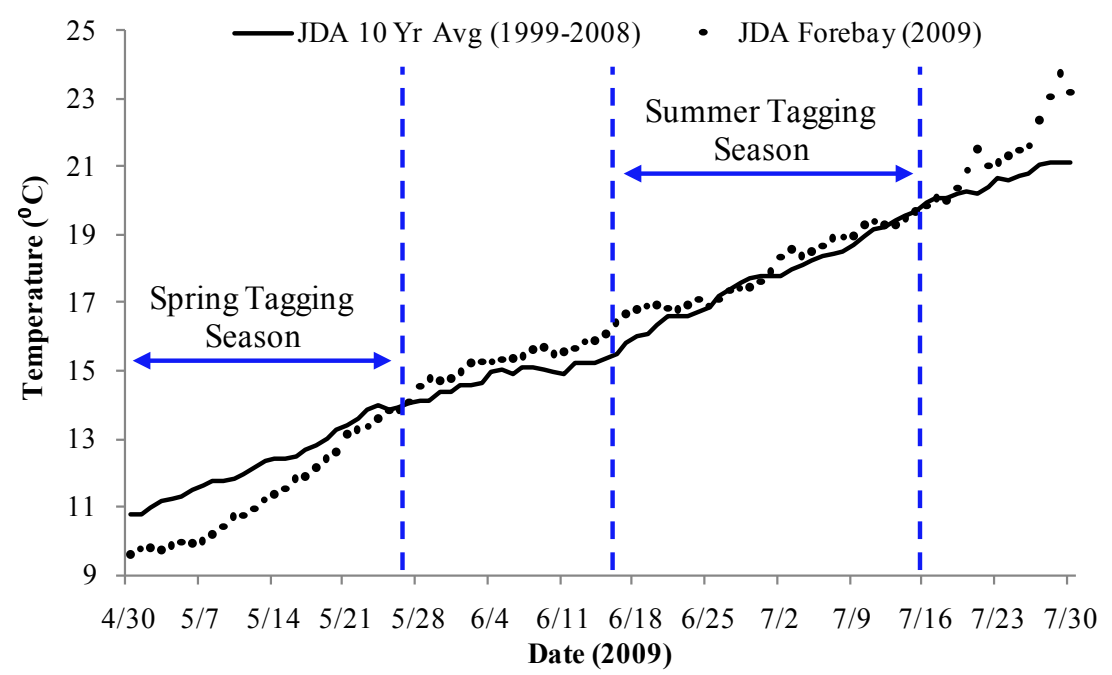

Figure 3.2. Ten-Year Average Forebay Water Temperature ( $\left.{ }^{\circ} \mathrm{C}\right)$ Versus 2009 Daily Estimates from April 30 through July 30 at JDA

\subsubsection{Realized Spill Treatment Conditions}

During spring 2009, treatment conditions were met for most of blocks 1 through 5, but percent spill varied from prescribed treatment conditions during the 40\% spill treatments in blocks 6 through 8 (Figure 3.3). During summer, the TSW and spillbays 17-20 were closed to due hydraulic conditions that resulted in increased bird predation on fish passing through these bays. All spill was passed through spillbays 2-14. Treatment conditions were not met for blocks 1,2 , and 3 , but were reasonably well met for in blocks 4 and 5 and very well for blocks 6 through 9 (Figure 3.4). Treatment conditions were not always met due to power-load issues and prevailing flow conditions.

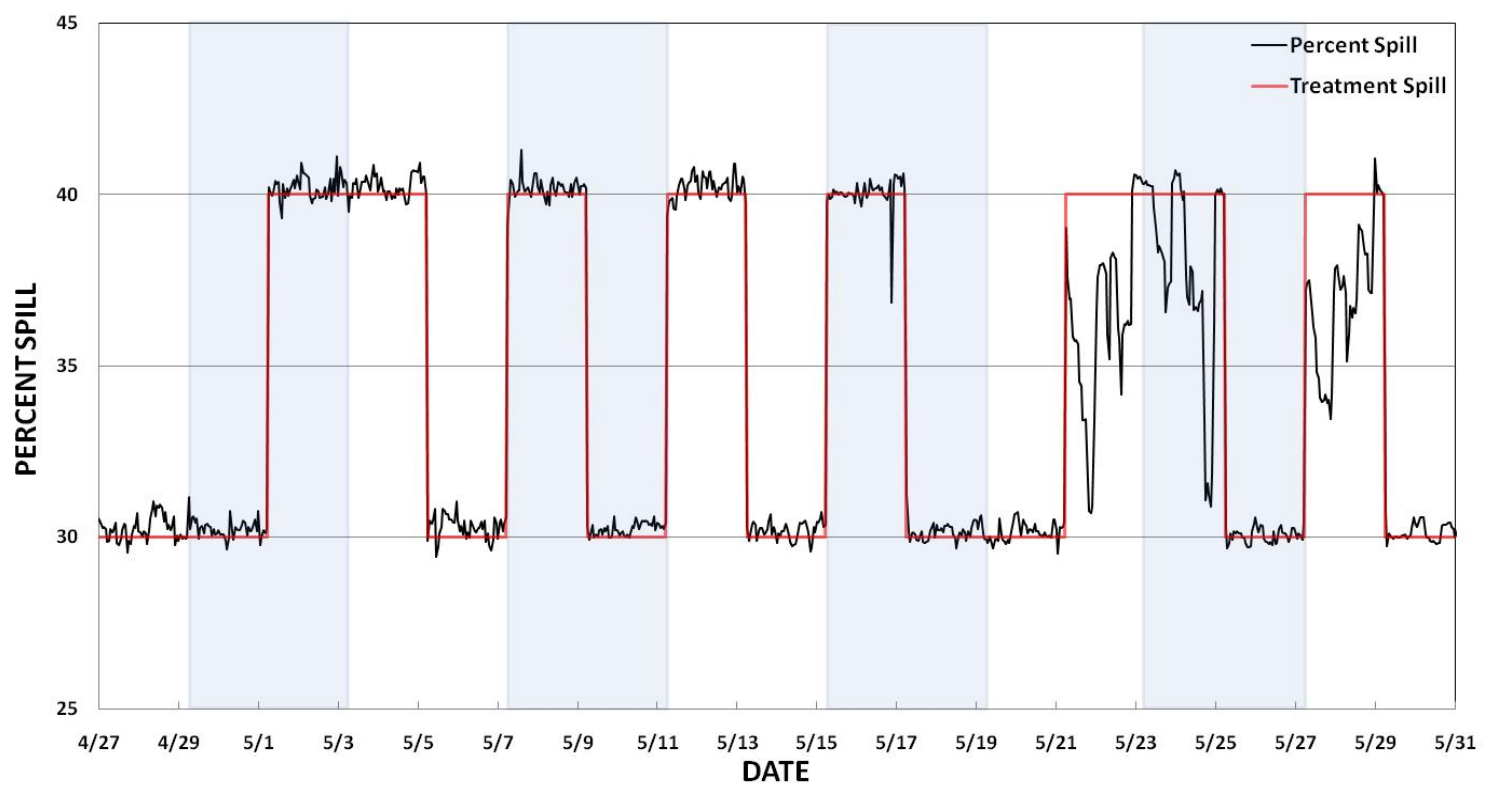

Figure 3.3. Realized Spill Treatments at JDA, April 29 Through May 31, 2009. There were eight 4-day treatment blocks with two 2-day treatments per block. 


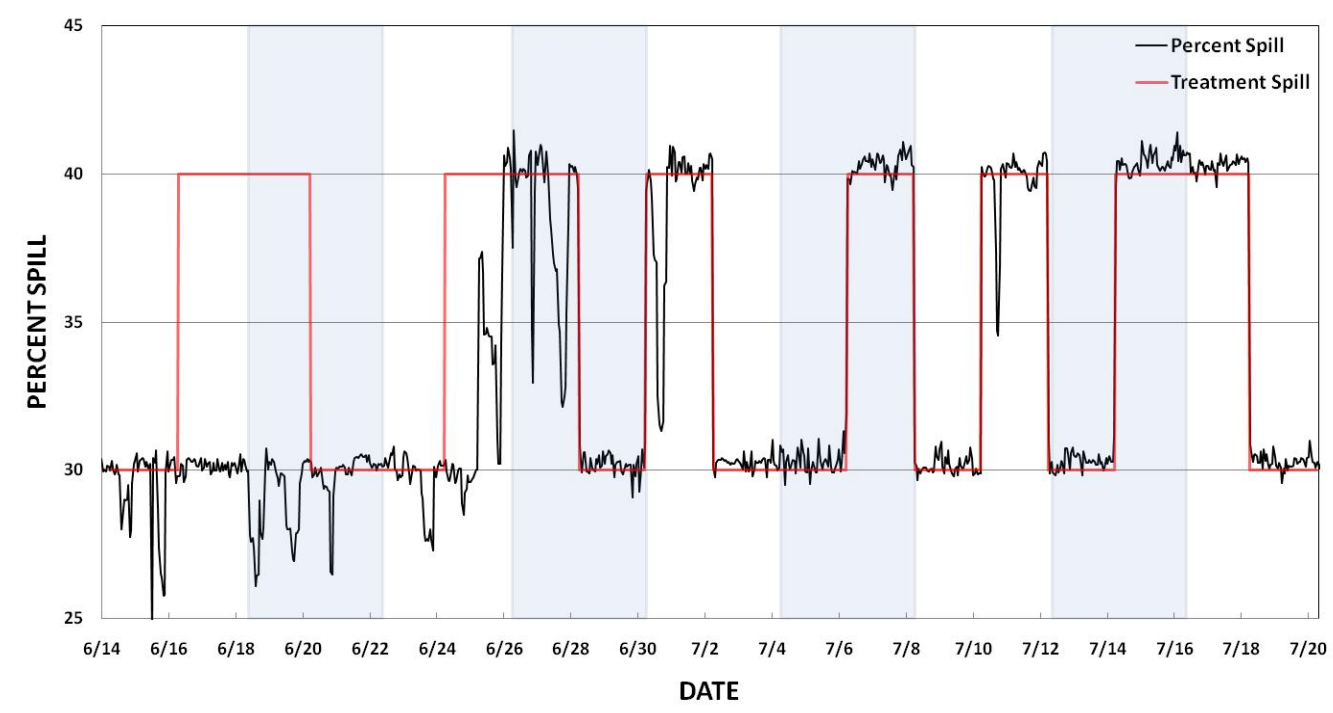

Figure 3.4. Realized Spill Treatments at JDA, June 14 Through July 20, 2009. There were nine 4-day treatment blocks with two 2-day treatments per block.

\subsubsection{Run Timing}

Run timing for the run-at-large of CH1 and STH both peaked in May 2009 with 50\% of the fish passing by May 17 and May 10, respectively (Figures 3.5 and 3.6; Table 3.1). Run timing for CH0 peaked in late June 2009 with $50 \%$ of the run-at-large passing by July 1 (Figure 3.7; Table 3.1). As planned, acoustic-tagging occurred for the most part during the central $80 \%$ of each run in 2009

(Figures 3.5, 3.6, and 3.7). The 10-year smolt index average was used as an indicator of run timing to determine the start date for tagging fish so that fish arrivals would approximate timing for the run-at-large for each stock (see Tables 3.2 through 3.4).

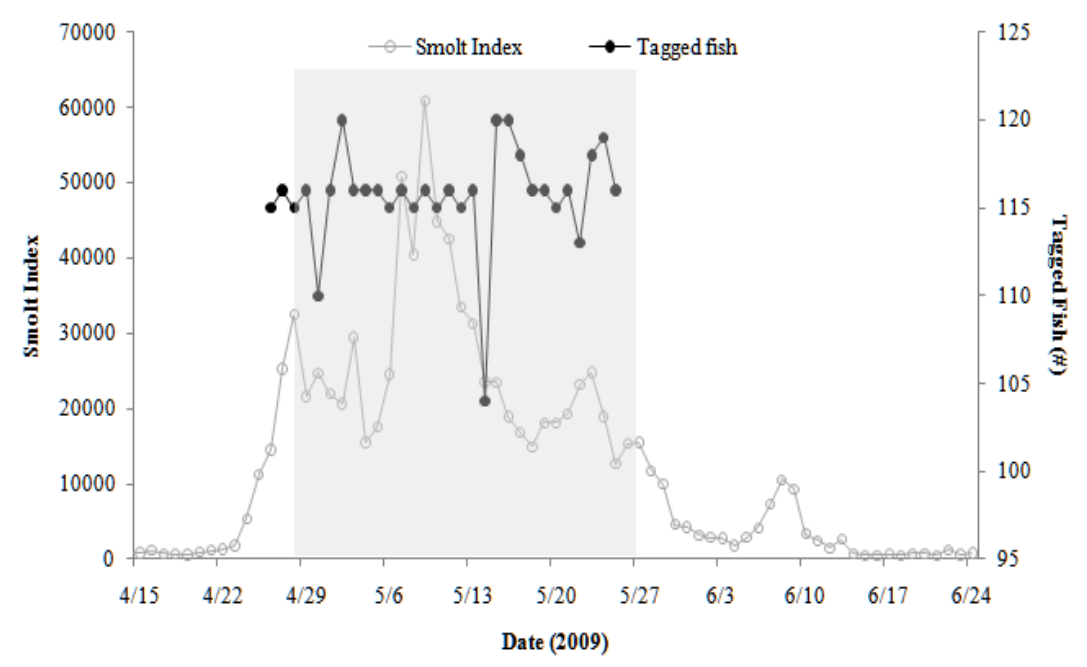

Figure 3.5. Smolt Monitoring Program Passage Index for April 15-June 24, 2009, and the Number of STH Tagged Per Day. Ten to 90 percent of the run passed JDA within the region shaded in gray, and STH arrived from 4/28 through 6/7 in spring. Passage index data were obtained from the DART website (Data Access in Real Time; www.cbr.washington/dart/dart.html). 


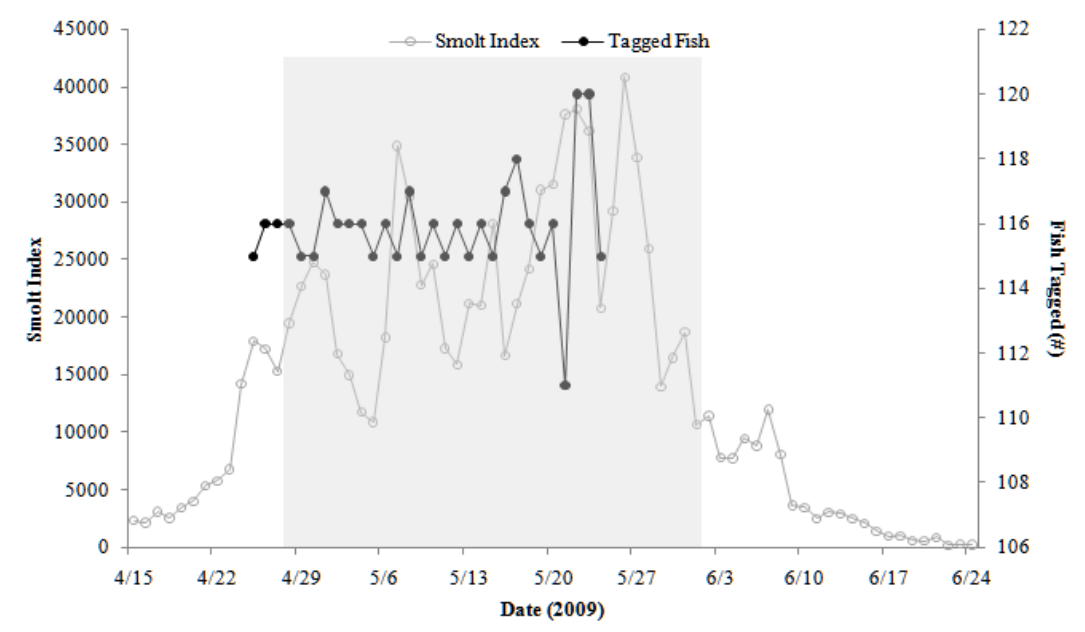

Figure 3.6. Smolt Monitoring Program Passage Index for April 15-June 24, 2009, and the Number of CH1 Tagged Per Day. Ten to 90 percent of the run passed JDA within the region shaded in gray, and yearlings arrived at the dam from 4/28 through 6/7 in spring. Data were obtained from the DART website (Data Access in Real Time; www.cbr.washington/dart/dart.html).

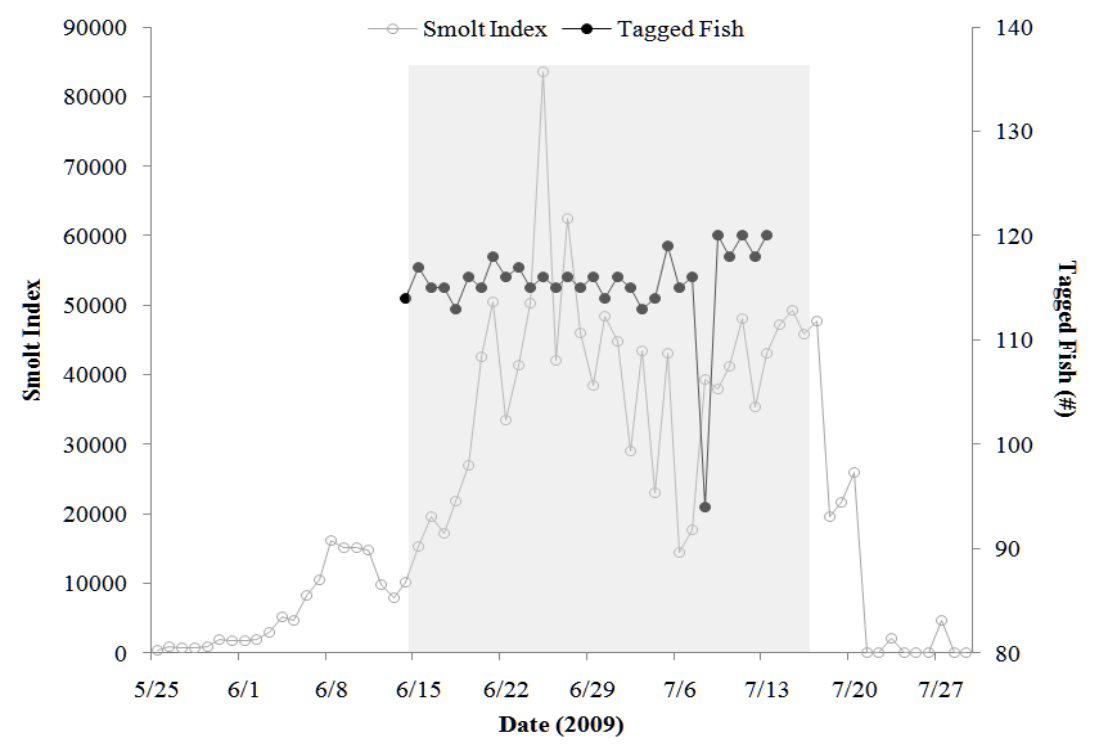

Figure 3.7. Smolt Monitoring Program Passage Index for May 25-July 30, 2009, and the Number of CH0 Tagged Per Day. Ten to 90 percent of the run passed JDA within the region shaded in gray, and subyearlings arrived at the dam from 6/16 through 7/29. Data were obtained from the DART website (Data Access in Real Time; www.cbr.washington/dart/dart.html).

Table 3.1. Yearly and Ten-Year Average of Run Timing for CH1 Sampled at the JDA SMF for Percentiles of the Passage Index

\begin{tabular}{cccccccccc}
\hline Year & First & $1 \%$ & $5 \%$ & $10 \%$ & $50 \%$ & $90 \%$ & $95 \%$ & Last & Middle $80 \%$ Days \\
\hline 1999 & $4 / 01$ & $4 / 10$ & $4 / 18$ & $4 / 22$ & $5 / 13$ & $5 / 31$ & $6 / 06$ & $8 / 30$ & 40 \\
2000 & $4 / 04$ & $4 / 10$ & $4 / 16$ & $4 / 21$ & $5 / 09$ & $5 / 28$ & $6 / 05$ & $9 / 18$ & 38 \\
2001 & $3 / 30$ & $4 / 21$ & $5 / 01$ & $5 / 06$ & $5 / 27$ & $6 / 20$ & $6 / 27$ & $9 / 17$ & 46 \\
2002 & $3 / 19$ & $4 / 18$ & $4 / 25$ & $5 / 01$ & $5 / 17$ & $6 / 01$ & $6 / 05$ & $8 / 30$ & 32
\end{tabular}


Table 3.1. (contd)

\begin{tabular}{cccccccccc}
\hline Year & First & $1 \%$ & $5 \%$ & $10 \%$ & $50 \%$ & $90 \%$ & $95 \%$ & Last & Middle $80 \%$ Days \\
\hline 2003 & $4 / 01$ & $4 / 14$ & $4 / 27$ & $5 / 03$ & $5 / 19$ & $6 / 02$ & $6 / 04$ & $9 / 15$ & 31 \\
2004 & $4 / 02$ & $4 / 09$ & $4 / 20$ & $4 / 28$ & $5 / 16$ & $5 / 30$ & $6 / 06$ & $9 / 15$ & 33 \\
2005 & $4 / 02$ & $4 / 05$ & $4 / 18$ & $4 / 25$ & $5 / 12$ & $5 / 22$ & $5 / 30$ & $9 / 15$ & 28 \\
2006 & $4 / 04$ & $4 / 14$ & $4 / 22$ & $4 / 25$ & $5 / 11$ & $5 / 24$ & $5 / 27$ & $9 / 14$ & 30 \\
2007 & $4 / 03$ & $4 / 16$ & $4 / 26$ & $5 / 02$ & $5 / 13$ & $5 / 25$ & $5 / 30$ & $9 / 13$ & 24 \\
2008 & $4 / 02$ & $4 / 12$ & $4 / 26$ & $5 / 04$ & $5 / 22$ & $6 / 01$ & $6 / 06$ & $9 / 15$ & 29 \\
10 -yr avg & $3 / 31$ & $4 / 12$ & $4 / 22$ & $4 / 28$ & $5 / 15$ & $5 / 30$ & $6 / 05$ & $9 / 12$ & 33 \\
2009 & $4 / 01$ & $4 / 15$ & $4 / 24$ & $4 / 27$ & $5 / 17$ & $6 / 01$ & $6 / 06$ & $8 / 07$ & 36 \\
\hline
\end{tabular}

Table 3.2. Yearly and Ten-Year Average of Run Timing for STH Sampled at the JDA SMF for Percentiles of the Passage Index

\begin{tabular}{cccccccccc}
\hline Year & First & $1 \%$ & $5 \%$ & $10 \%$ & $50 \%$ & $90 \%$ & $95 \%$ & Last & Middle $80 \%$ Days \\
\hline 1999 & $4 / 1$ & $4 / 2$ & $4 / 22$ & $4 / 28$ & $5 / 26$ & $6 / 6$ & $6 / 11$ & $9 / 9$ & 40 \\
2000 & $4 / 4$ & $4 / 12$ & $4 / 15$ & $4 / 16$ & $5 / 4$ & $5 / 26$ & $6 / 2$ & $9 / 18$ & 41 \\
2001 & $3 / 30$ & $4 / 16$ & $4 / 25$ & $4 / 30$ & $5 / 12$ & $6 / 2$ & $6 / 20$ & $9 / 17$ & 34 \\
2002 & $3 / 20$ & $4 / 14$ & $4 / 19$ & $4 / 22$ & $5 / 16$ & $6 / 7$ & $6 / 12$ & $9 / 16$ & 47 \\
2003 & $4 / 1$ & $4 / 11$ & $4 / 26$ & $5 / 2$ & $5 / 29$ & $6 / 4$ & $6 / 6$ & $9 / 15$ & 34 \\
2004 & $4 / 2$ & $4 / 12$ & $4 / 25$ & $5 / 3$ & $5 / 21$ & $5 / 31$ & $6 / 5$ & $9 / 15$ & 29 \\
2005 & $4 / 2$ & $4 / 17$ & $4 / 30$ & $5 / 2$ & $5 / 18$ & $5 / 25$ & $5 / 28$ & $9 / 15$ & 24 \\
2006 & $4 / 4$ & $4 / 17$ & $4 / 24$ & $4 / 27$ & $5 / 11$ & $5 / 29$ & $6 / 1$ & $9 / 12$ & 33 \\
2007 & $4 / 3$ & $4 / 17$ & $5 / 1$ & $5 / 4$ & $5 / 12$ & $5 / 26$ & $6 / 2$ & $9 / 13$ & 23 \\
2008 & $4 / 2$ & $4 / 25$ & $5 / 4$ & $5 / 7$ & $5 / 18$ & $5 / 31$ & $6 / 4$ & $9 / 15$ & 25 \\
10 -yr avg & $3 / 31$ & $4 / 14$ & $4 / 25$ & $4 / 29$ & $5 / 16$ & $5 / 31$ & $6 / 6$ & $9 / 14$ & 33 \\
2009 & $4 / 1$ & $4 / 21$ & $4 / 26$ & $4 / 28$ & $5 / 10$ & $5 / 27$ & $6 / 6$ & $8 / 21$ & 30 \\
\hline
\end{tabular}

Table 3.3. Yearly and Ten-Year Average of Run Timing for CH0 Sampled at the JDA SMF for Percentiles of the Passage Index

\begin{tabular}{cccccccccc}
\hline Year & First & $1 \%$ & $5 \%$ & $10 \%$ & $50 \%$ & $90 \%$ & $95 \%$ & Last & Middle $80 \%$ Days \\
\hline 1999 & $4 / 2$ & $6 / 3$ & $6 / 10$ & $6 / 18$ & $6 / 29$ & $7 / 25$ & $8 / 5$ & $10 / 26$ & 38 \\
2000 & $4 / 7$ & $6 / 1$ & $6 / 5$ & $6 / 6$ & $6 / 29$ & $8 / 3$ & $8 / 9$ & $9 / 18$ & 59 \\
2001 & $4 / 22$ & $6 / 10$ & $6 / 22$ & $6 / 27$ & $7 / 30$ & $8 / 22$ & $8 / 29$ & $9 / 17$ & 57 \\
2002 & $3 / 22$ & $6 / 3$ & $6 / 11$ & $6 / 20$ & $6 / 30$ & $7 / 21$ & $8 / 4$ & $9 / 16$ & 32 \\
2003 & $4 / 2$ & $5 / 30$ & $6 / 3$ & $6 / 6$ & $6 / 27$ & $7 / 30$ & $8 / 7$ & $9 / 15$ & 55 \\
2004 & $4 / 7$ & $5 / 30$ & $6 / 8$ & $6 / 14$ & $6 / 28$ & $7 / 23$ & $7 / 30$ & $9 / 15$ & 40 \\
2005 & $4 / 4$ & $5 / 25$ & $6 / 9$ & $6 / 19$ & $7 / 5$ & $7 / 27$ & $8 / 1$ & $9 / 15$ & 39 \\
2006 & $4 / 11$ & $5 / 25$ & $6 / 5$ & $6 / 12$ & $7 / 2$ & $7 / 17$ & $7 / 22$ & $9 / 14$ & 36 \\
2007 & $4 / 6$ & $5 / 28$ & $6 / 13$ & $6 / 25$ & $7 / 8$ & $7 / 17$ & $7 / 27$ & $9 / 13$ & 23 \\
2008 & $5 / 3$ & $5 / 28$ & $6 / 1$ & $6 / 14$ & $7 / 7$ & $7 / 30$ & $8 / 5$ & $9 / 15$ & 47 \\
10 -yr avg & $4 / 8$ & $5 / 30$ & $6 / 8$ & $6 / 16$ & $7 / 4$ & $7 / 27$ & $8 / 4$ & $9 / 19$ & 43 \\
2009 & $4 / 23$ & $6 / 4$ & $6 / 10$ & $6 / 16$ & $7 / 1$ & $7 / 17$ & $7 / 18$ & $9 / 15$ & 32 \\
\hline
\end{tabular}


Table 3.4. Percent of the Run Passing a the John Day Dam SMF on the First and Last Days of Tagging and the Dates That 10\%, 25\%, 50\%, 75\%, and 90\% of Each Run Passed the Dam in 2009 According to SMF Data

\begin{tabular}{lllllllll}
\hline & & \multicolumn{7}{c}{ Percent of Run Passage by Date } \\
\hline & Stock & First Arrival & $10 \%$ & $25 \%$ & $50 \%$ & $75 \%$ & $90 \%$ & \multicolumn{1}{c}{ Last Arrival } \\
\hline CH1 & $4 / 27(10 \%)$ & $4 / 27$ & $5 / 5$ & $5 / 17$ & $5 / 25$ & $6 / 1$ & $6 / 07(95 \%)$ \\
STH & $4 / 28(10 \%)$ & $4 / 28$ & $5 / 4$ & $5 / 10$ & $5 / 19$ & $6 / 06$ & $6 / 07(95 \%)$ \\
CH0 & $6 / 16(10 \%)$ & $6 / 16$ & $6 / 23$ & $7 / 1$ & $7 / 11$ & $7 / 17$ & $7 / 29(>90 \%)$ \\
\hline
\end{tabular}

\subsubsection{Length Frequency}

Length frequency distributions of tagged and run-of-river juvenile salmon populations were very similar for all three runs in 2009 (Figures 3.8, 3.9, and 3.10). Median lengths of tagged and untagged fish differed by just $2 \mathrm{~mm}$ for $\mathrm{CH} 1$ and $\mathrm{STH}$ and by less than $3 \mathrm{~mm}$ for $\mathrm{CH} 0$.

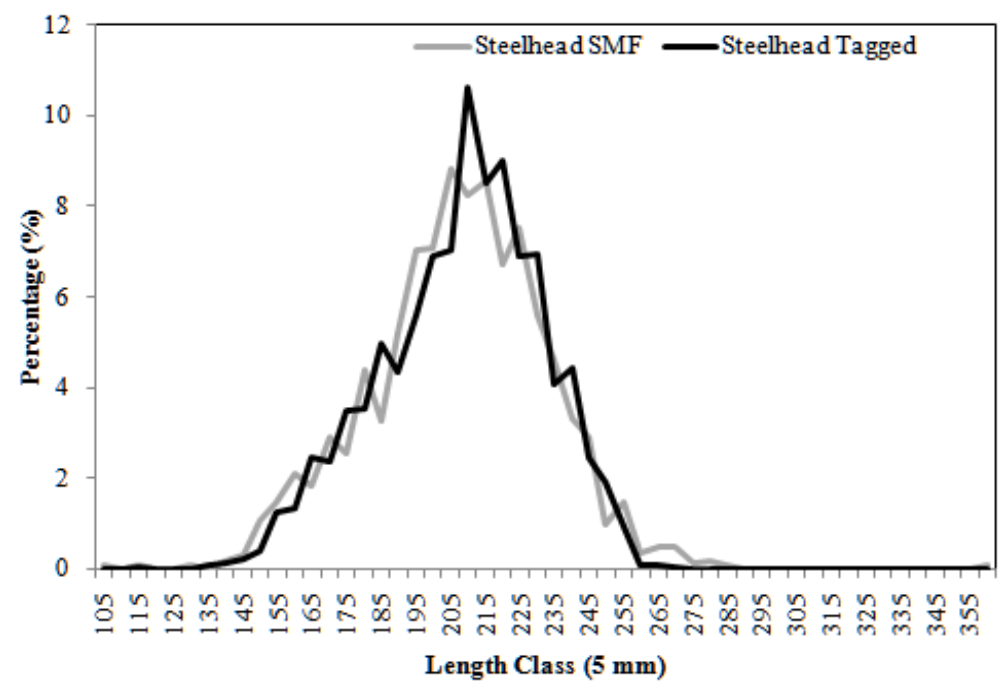

Figure 3.8. Length Frequency Distributions for Tagged and Run-of-River STH in 2009 


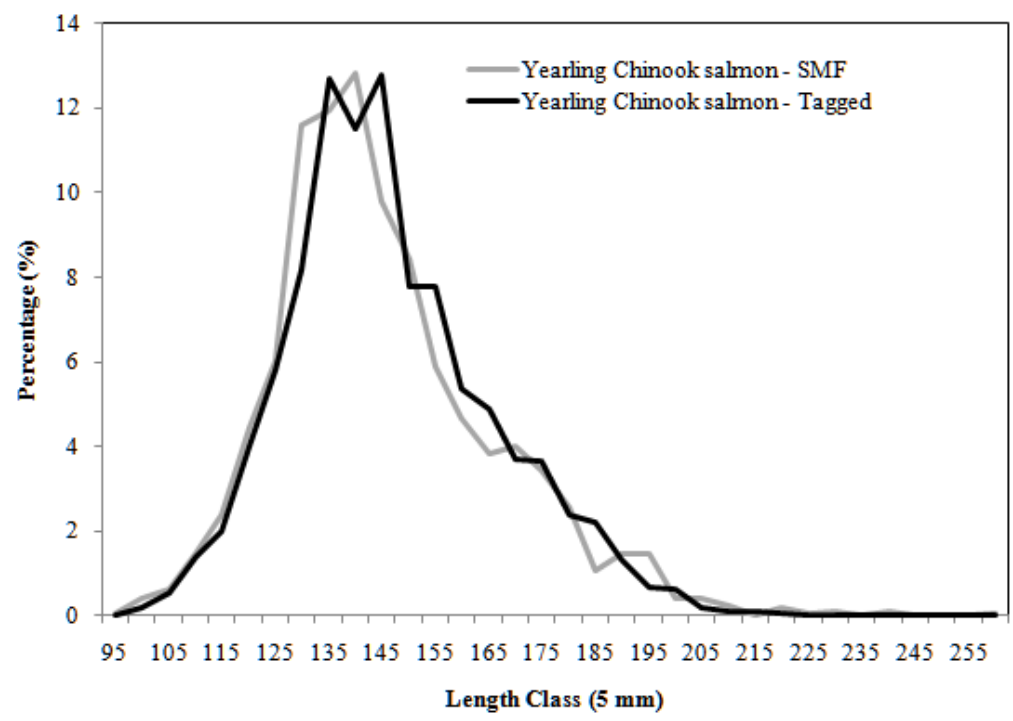

Figure 3.9. Length Frequency Distributions for Tagged and Run-of-River CH1 in 2009

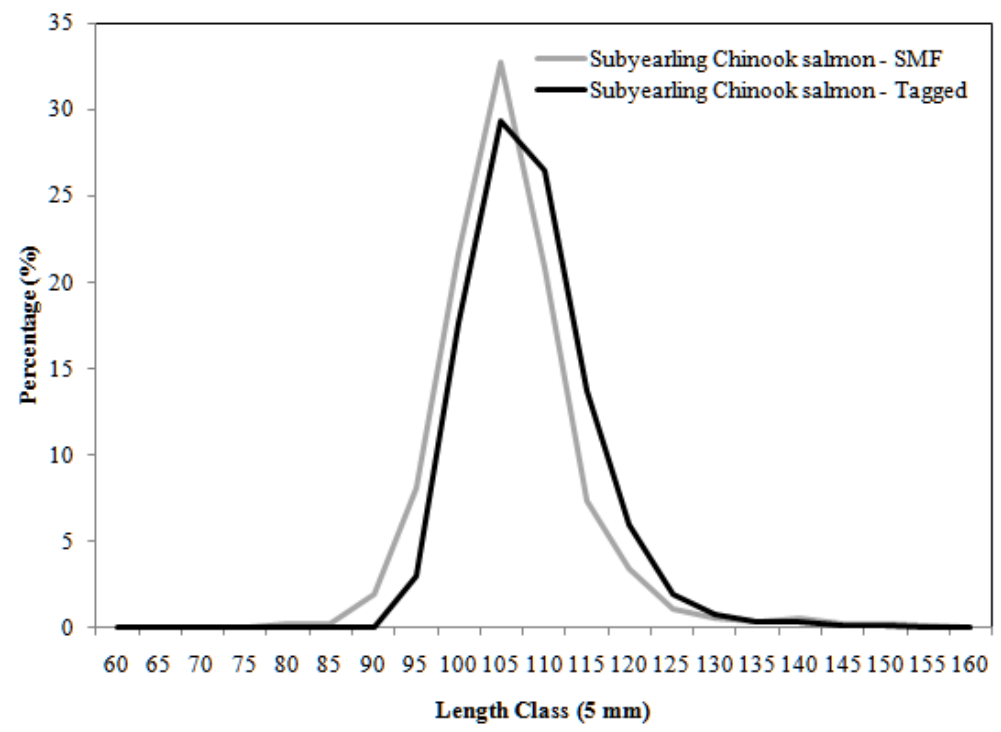

Figure 3.10. Length Frequency Distributions for Tagged and Run-of-River CH0 in 2009

\subsection{JSATS Performance}

JSATS performance was evaluated in terms of the detection of dead fish, detection probabilities at dam-face arrays, detection probabilities and fish distribution at autonomous nodes, and probabilities of implanted tags still working by the time they passed the survival-detection arrays. Detection probabilities are presented in Appendix C.

\subsubsection{Detection Probabilities at Dam-Face Arrays}

The combined detection probability of the dam-face array for each of three tagged fish runs exceeded 95\%: $95.6 \%$ for STH, $96.3 \%$ for $\mathrm{CH} 1$, and $97.9 \%$ for $\mathrm{CH} 0$ (Table 3.5 ). 
Table 3.5. Detection Probabilities for the Dam-Face Arrays at JDA During 2009. N11 = detected on both arrays; $\mathrm{N} 10=$ detected on array 1 but not array 2; N01 = detected on array 2 but not array 1 .

\begin{tabular}{|c|c|c|c|c|c|c|c|}
\hline Species & $\begin{array}{l}\text { Number } \\
\text { Released }\end{array}$ & N11 & N10 & N01 & $\begin{array}{c}\text { Detection } \\
\text { Probability } \\
\text { Array } 1\end{array}$ & $\begin{array}{c}\text { Detection } \\
\text { Probability } \\
\text { Array } 2\end{array}$ & $\begin{array}{l}\text { Combined } \\
\text { Probability }\end{array}$ \\
\hline $\mathrm{CH} 1$ & 3470 & 2259 & 467 & 622 & 0.784 & 0.829 & 0.963 \\
\hline STH & 3471 & 2121 & 523 & 603 & 0.779 & 0.802 & 0.956 \\
\hline $\mathrm{CH} 0$ & 3461 & 2239 & 340 & 437 & 0.837 & 0.868 & 0.979 \\
\hline
\end{tabular}

\subsubsection{Detection Probabilities and Fish Distributions at Autonomous Nodes}

Detection probabilities for survival arrays composed of autonomous nodes were over $99 \%$ for arrays deployed upstream of TDA each season and ranged from 92 to $95 \%$ for the BON forebay array, from 90 to $98 \%$ for the first tailwater reach below BON, and from 92 to $95 \%$ for the second tailwater reach (Figure 3.11). For the BON forebay and tailrace arrays, detection probabilities were consistently higher for $\mathrm{CH} 0$ passing in summer ( 95 to $98 \%$ ) than they were for $\mathrm{CH} 1(92 \%)$ and $\mathrm{STH}(90$ to $92 \%)$ passing in spring 2009.

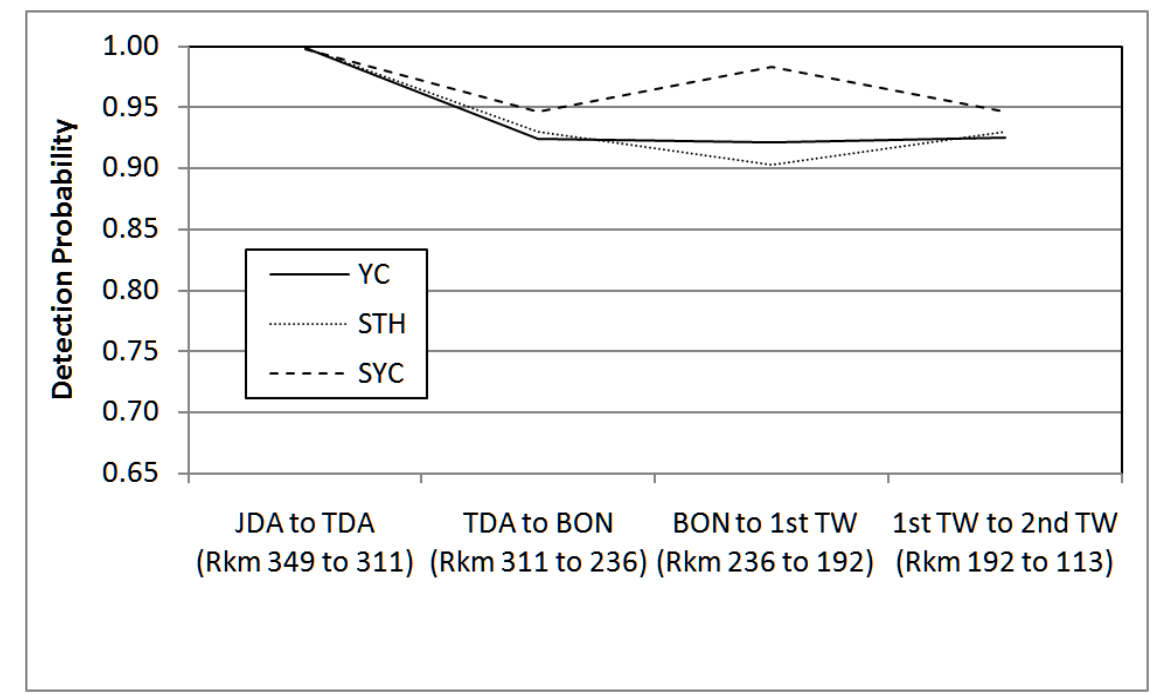

Figure 3.11. Detection Probabilities During 2009 by Reach for the Autonomous Arrays. Tailwater is abbreviated TW.

Most $\mathrm{CH} 1$ and $\mathrm{CH} 0$ smolts were detected on the spillway side of the JDA forebay entrance array; whereas the offshore distribution of STH smolts was uniform (top row of Figure 3.12). At TDA forebay entrance array (second row of Figure 3.12), more CH1 and STH smolts were detected on the north side than on the south side of the channel, but this northerly trend was not apparent for $\mathrm{CH} 0$ smolts. On the BON tailwater arrays, a higher percentage of tagged fish of each stock was detected on nodes deployed in the main channel than in side channels behind islands (Figure 3.12). 

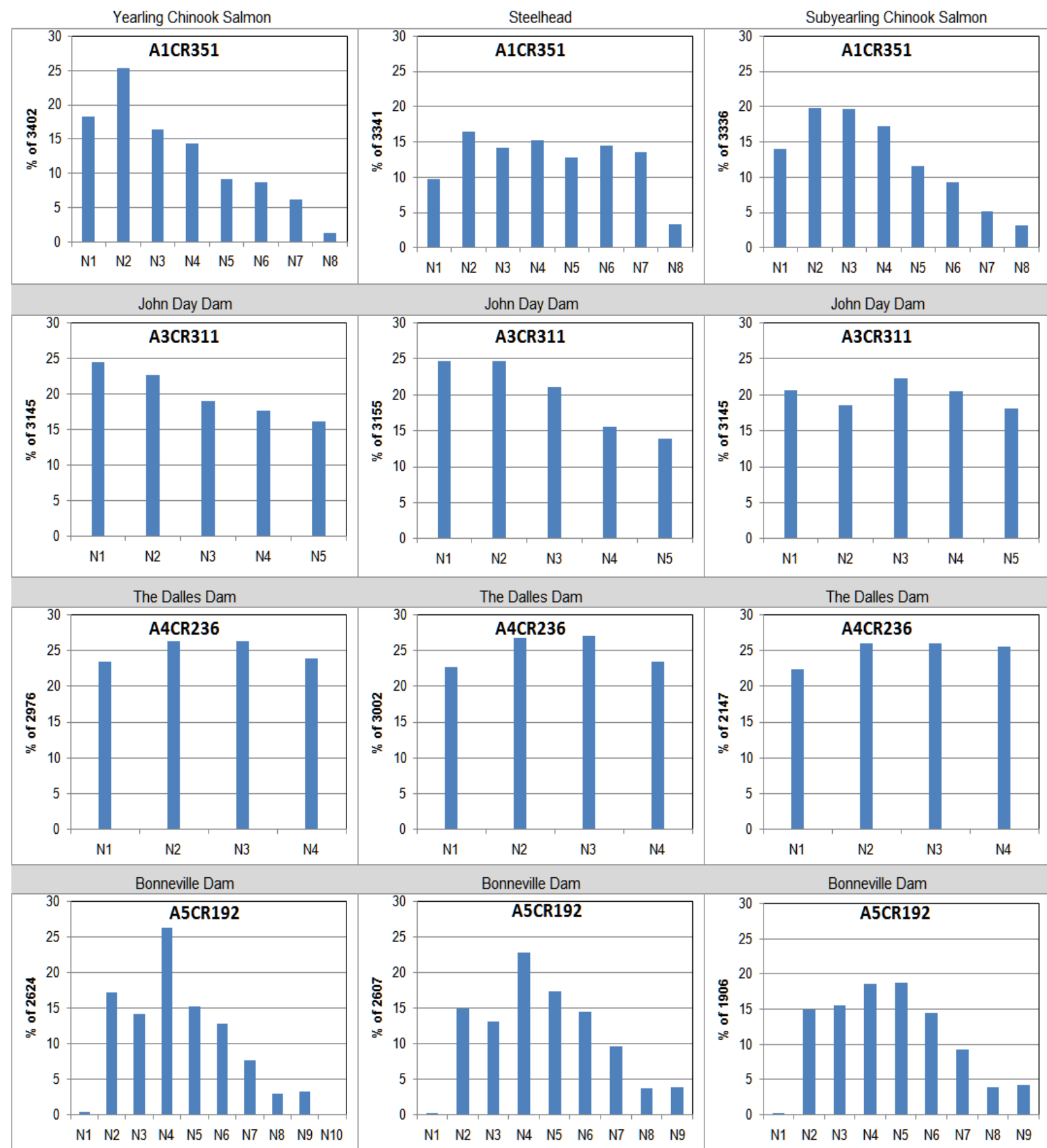

Figure 3.12. Percentage of Acoustic-Tag Detections by Fish Run (Columns) on Autonomous Nodes During 2009. Arrays were deployed in the JDA forebay (1st row), TDA forebay (2nd row), BON forebay (3rd row), and BON tailwater near Lady Island and Camas, Washington (4th row). In general, the Washington shore is on the left side of each panel and the Oregon shore is on the right as if the reader were looking upstream. Node N1 in Array A5CR192 was deployed north of Lady Island outside of the main navigation channel. All other nodes were deployed within the main navigation channel.

Another indicator of autonomous array performance is the frequency of simultaneous detections on multiple nodes within arrays, and the arrays upstream of BON clearly had more multi-node detections 
than did the first tailwater array downstream of BON (Figure 3.13). For example, the percent of simultaneous $\mathrm{CH} 1$ detections on two or more nodes ranged from 96 to $99 \%$ on the JDA forebay array, from 93 to $97 \%$ on TDA forebay array, and over $99 \%$ on the BON forebay array. In contrast, percent detection on two or more nodes of the BON primary array near Camas, Washington, was just $68 \%$ for $\mathrm{CH} 1$ and $\mathrm{STH}$ and $85 \%$ for $\mathrm{CH} 0$.

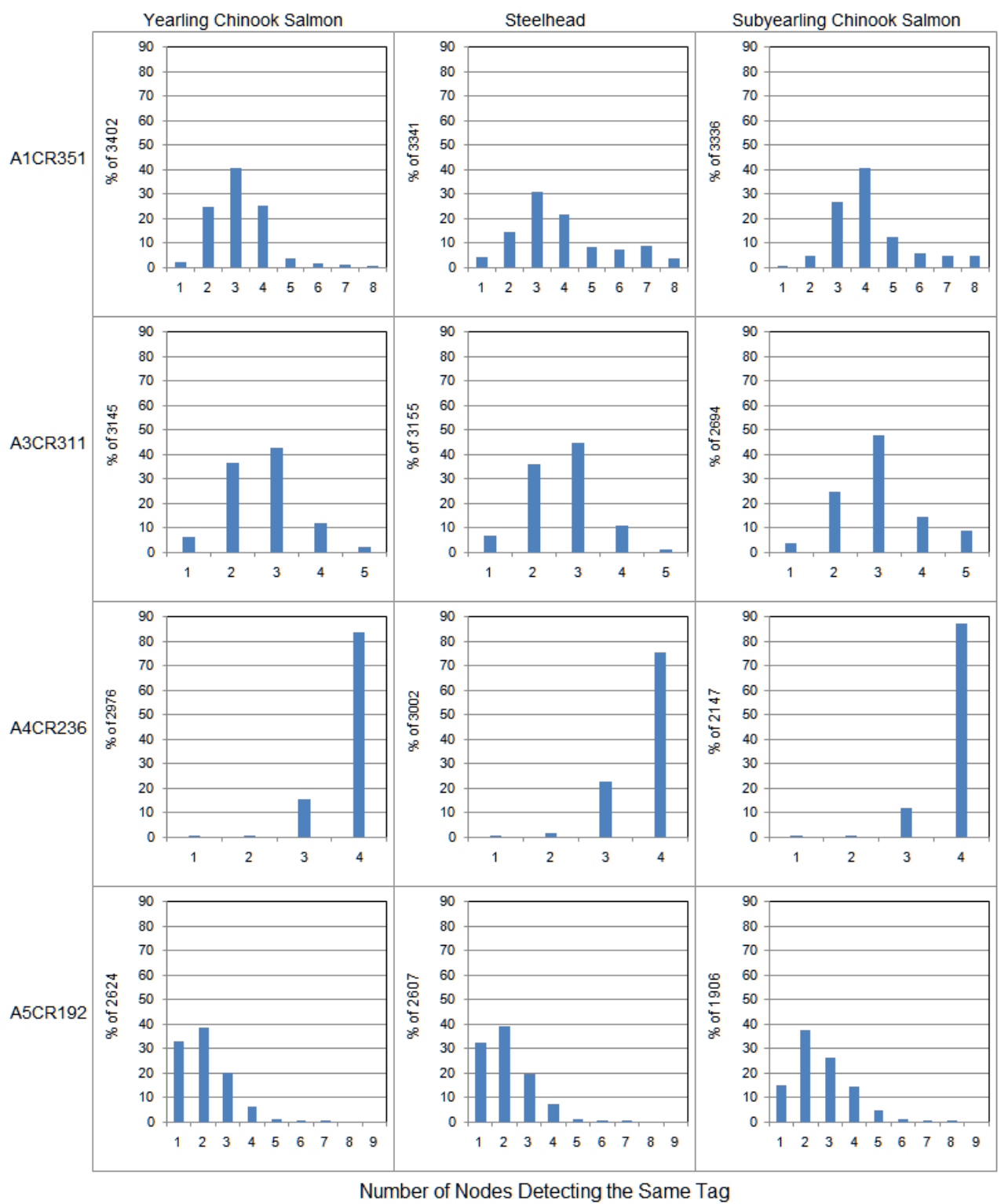

Figure 3.13. Frequency of Detections on Multiple Autonomous Nodes During 2009. Arrays were located in the JDA forebay entrance (A1CR351), TDA forebay entrance (A3CR311), BON forebay entrance (A4CR236), and BON tailwater (A5CR192).

Tagged-fish-detection probabilities for the array near Camas were inversely correlated with river discharge, meaning that detectability decreases and river discharge increases (Figure 3.14). The preferred situation is for detection probabilities to be independent of discharge, as observed for arrays in the TDA and BON forebays. The array near Camas, Washington, served as the tertiary array for the JDA study and as the primary survival array for a study at the BON B2. 


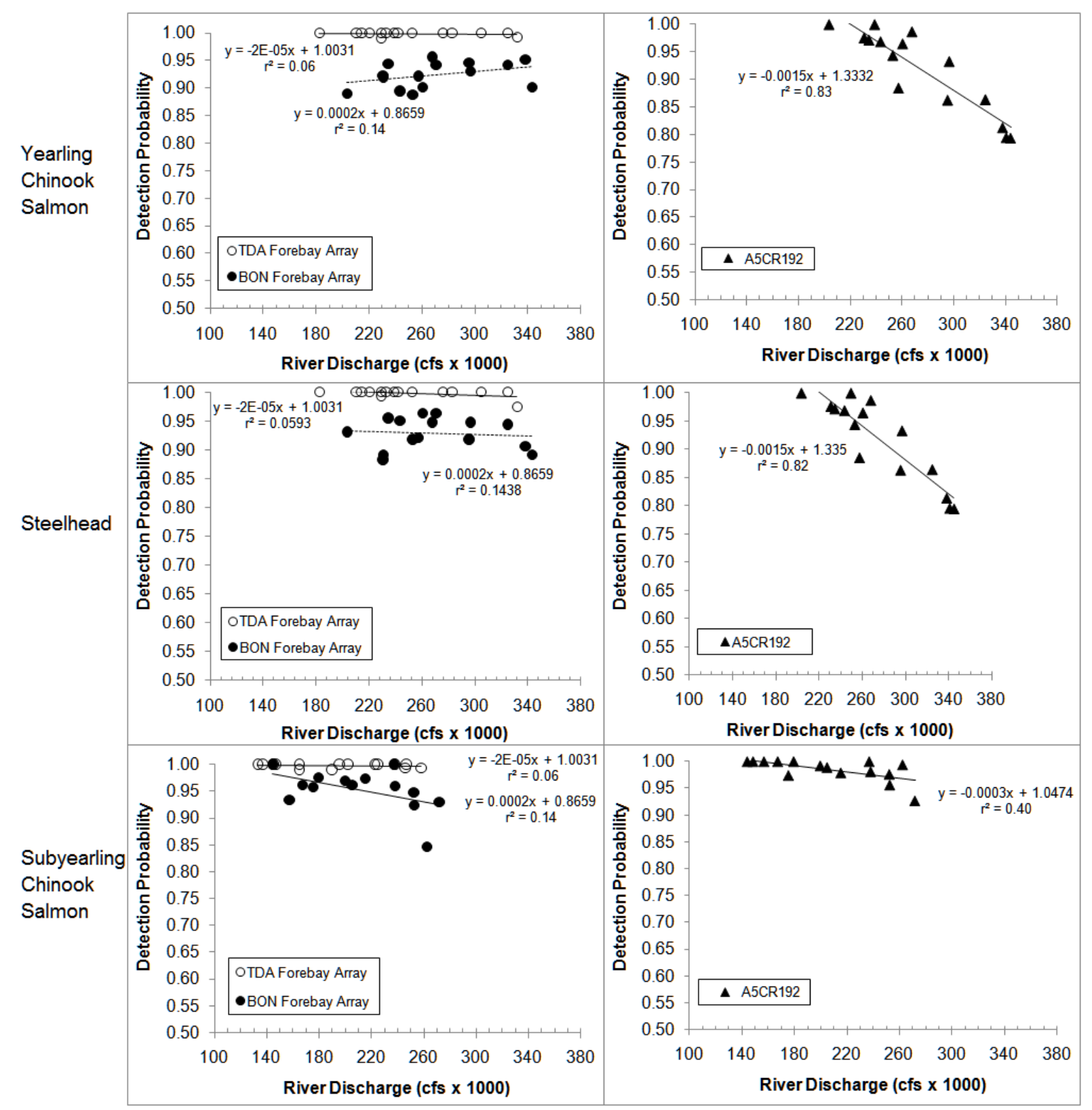

Figure 3.14. Detection Probabilities as a Function of Water Discharge in Three Detection Arrays During 2009. Array A5CR192 was located $42 \mathrm{~km}$ downstream of BON adjacent to Lady Island near Camas, Washington.

\subsubsection{Tag Life}

All acoustic tags in the tag-life study were active for the expected 23 days (Figure 3.15), and mean time to tag failure was $30 \pm 1.0$ (SE) days. The range in time until tag failure was from 24 to 49 days. All stocks of fish passed the tertiary survival-detection array before there was any significant tag failure (Figure 3.15), so it was not necessary to make tag-life corrections to any single-release survival estimate reported in this study. 


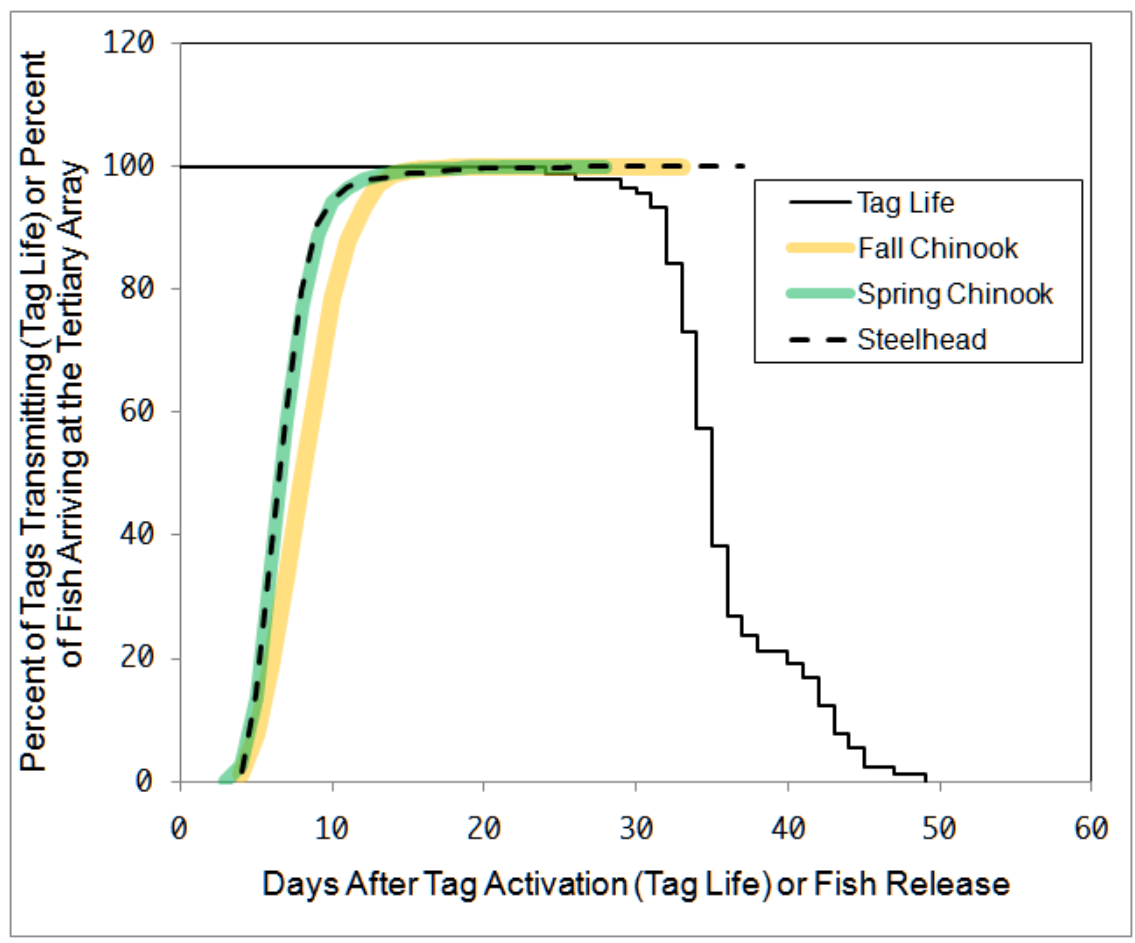

Figure 3.15. Percentage of Acoustic Tags Still Transmitting Versus Time Since Tag Activation During 2009. Expected nominal tag life was 23 days.

\subsubsection{Tests of Survival-Model Assumptions}

The length frequencies of tagged and untagged fish of each stock were compared in Section 3.1.4 to assess whether tagged fish were reasonably representative of the run at large. Results are examined using the following two types of model assumption tests:

- Burnham et al. (1987) Test 2 and Test 3 to assess the assumption that upstream and downstream detection and survival probabilities are independent.

- Comparison of the TOAs of tagged smolts at the primary survival array to verify that the releases mixed reasonably well in the common tailwater below a dam. The assumption is that treatment and reference releases of fish passed through the common tailwater at similar times of day and likely experienced similar survival processes.

\subsubsection{Burnham Test Results}

A major assumption of the survival models used in this study is that upstream detections do not affect downstream detection or survival probabilities, and this can be tested using Burnham Test 2 and Test 3. Appendix D presents the probabilities for Test 2 whether upstream detections affect downstream survival or detection, and Test 3 examines whether upstream capture histories affect downstream survival or capture for every release by fish stock and survival metric reported in this study.

Most of the Goodness-of-Fit analyses for the Burnham Test could not be calculated because of exceptionally high detection probabilities on JDA survival arrays (Appendix D). For CH1, none of the 
results for Test 2 were significant, and of 74 runs of Test 3 , six (8\%) were significant at $\alpha=0.1$. For STH, 4 of 69 runs $(6 \%)$ for Test 2 and 4 of 69 runs for Test $3(6 \%)$ were significant. For CH0, 2 of 53 results (4\%) for Test 2 were significant and, 2 of 53 (4\%) were significant at $\alpha=0.1$.

\subsubsection{Arrival Distribution Tests}

There were no tests of arrival distributions in 2009 because there were no reference releases of fish to compare to treatment releases.

\subsection{Yearling Chinook Salmon}

This section contains estimates of survival rates, travel times, passage metrics, and distributions for CH1 at JDA during spring 2009.

\subsubsection{Effect of Spill Conditions on Fish}

Two spill levels were compared in a randomized block design during spring and summer 2009 at JDA: $30 \%$ and $40 \%$ spill discharge out of total project discharge. The purpose of the comparison was to determine which spill level provides the most protection for downstream migrants at the dam.

Dam operators were able to meet spill treatment requirements for the first five of eight blocks in spring and provided treatments that were obviously different, although less consistent than the first five blocks after May 19 for blocks six through eight (Figure 3.16). Fish did not arrive in sufficient numbers during the eighth block so it was dropped as a treatment.

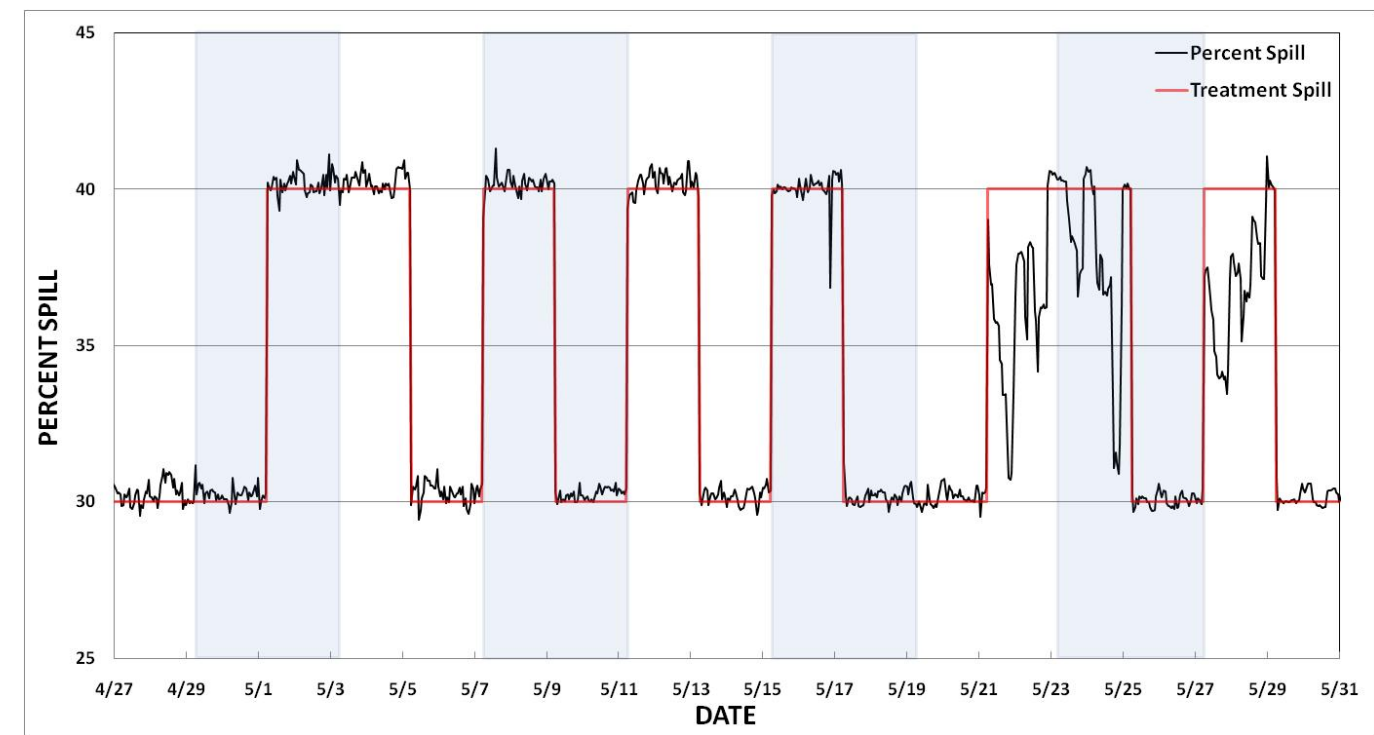

Figure 3.16. Spill Treatments as Prescribed (red line) and Actual Conditions (black line) in Spring 2009. The shaded areas represent odd numbered treatment blocks. (Repeated from Figure 3.3 for ease of reference.)

When comparing spill treatments that occurred during the first five blocks that closely met prescribed treatments, a one-tailed paired t-test showed that survival rates were significantly higher during the $30 \%$ 
spill treatment than they were during the $40 \%$ spill treatment (Table 3.6). Mean survival rates did not differ significantly when data from all seven blocks were analyzed. The mean survival rates for each block used in the analysis and the t-test results are provided for the five block in Tables 3.7 and 3.8 and seven block analysis in Tables 3.9 and 3.10 .

Table 3.6. Estimates of JDA Forebay-to-TDA Forebay Passage Survival Rates by Spill Treatment for CH1 During Spring 2009. A one-tailed, paired t-test produced the listed probabilities and those $<\alpha=0.05$ were considered to be significant.

\begin{tabular}{lccc}
\hline Spill Treatment & $\begin{array}{c}\text { Blocks } \\
\text { Analyzed }\end{array}$ & $\begin{array}{c}\text { Survival Rate } \\
( \pm 1 / 295 \% \mathrm{CI})\end{array}$ & $\begin{array}{c}\text { One Tailed } \\
\text { Probability (P) }\end{array}$ \\
\hline $30 \%$ Spill & 5 & $0.943 \pm 0.018$ & $0.0330^{*}$ \\
$40 \%$ Spill & 5 & $0.925 \pm 0.010$ & \\
$30 \%$ Spill & 7 & $0.930 \pm 0.027$ & 0.2873 \\
$40 \%$ Spill & 7 & $0.924 \pm 0.008$ & \\
\hline
\end{tabular}

Table 3.7. Estimates of JDA Forebay-to-TDA Forebay Passage Survival Rates by Two-Day Block and Spill Treatment for CH1, for First Five Blocks, During Spring 2009

\begin{tabular}{ccccc}
\hline Block & $30 \%$ Spill & $1 / 295 \%$ CI & $40 \%$ Spill & $1 / 295 \%$ CI \\
\hline 1 & 0.968 & 0.022 & 0.935 & 0.041 \\
2 & 0.935 & 0.029 & 0.926 & 0.037 \\
3 & 0.918 & 0.035 & 0.92 & 0.037 \\
4 & 0.947 & 0.029 & 0.932 & 0.029 \\
5 & 0.947 & 0.029 & 0.91 & 0.037 \\
\hline
\end{tabular}

Table 3.8. Results of a One-Tailed, Paired T-Test Comparing Estimates of JDA Forebay-to-TDA Forebay Passage Survival Rates by Two-Day Block and Spill Treatment for CH1, for First Five Blocks, During Spring 2009

\begin{tabular}{lrr}
\hline & $30 \%$ Spill & \multicolumn{1}{c}{$40 \%$ Spill } \\
\hline Mean & 0.943 & 0.9246 \\
Variance & 0.000336 & $9.98 \mathrm{E}-05$ \\
Observations & 5 & 5 \\
Pearson Correlation & 0.457011 & \\
Hypothesized Mean Difference & 0 & \\
$\mathrm{df}$ & 4 & \\
$\mathrm{t}$ Stat & 2.509506 & \\
$\mathrm{P}(\mathrm{T}<=\mathrm{t})$ one-tail & 0.033046 & \\
$\mathrm{t}$ Critical one-tail & 2.131847 & \\
$\mathrm{P}(\mathrm{T}<=\mathrm{t})$ two-tail & 0.066092 & \\
$\mathrm{t}$ Critical two-tail & 2.776445 & \\
\hline
\end{tabular}


Table 3.9. Estimates of JDA Forebay-to-TDA-Forebay-Passage Survival Rates by Two-Day Block and Spill Treatment for CH1, for Seven Blocks, During Spring 2009

\begin{tabular}{ccccc}
\hline Block & $30 \%$ Spill & $1 / 295 \%$ CI & $40 \%$ Spill & $1 / 295 \%$ CI \\
\hline 1 & 0.968 & 0.022 & 0.935 & 0.041 \\
2 & 0.935 & 0.029 & 0.926 & 0.037 \\
3 & 0.918 & 0.035 & 0.92 & 0.037 \\
4 & 0.947 & 0.029 & 0.932 & 0.029 \\
5 & 0.947 & 0.029 & 0.91 & 0.037 \\
6 & 0.912 & 0.033 & 0.926 & 0.031 \\
7 & 0.885 & 0.041 & 0.922 & 0.029 \\
\hline
\end{tabular}

Table 3.10. Results of a One-Tailed, Paired T-Test Comparing Estimates of JDA Forebay-to-TDA Forebay Passage Survival Rates by Two-Day Block and Spill Treatment for CH1, for Seven Blocks, During Spring 2009

\begin{tabular}{lrr}
\hline & $30 \%$ Spill & \multicolumn{1}{c}{$40 \%$ Spill } \\
\hline Mean & 0.930286 & 0.924429 \\
Variance & 0.000757 & $6.8 \mathrm{E}-05$ \\
Observations & 7 & 7 \\
Pearson Correlation & 0.313975 & \\
Hypothesized Mean Difference & 0 & \\
df & 6 & \\
t Stat & 0.593331 & \\
$\mathrm{P}(\mathrm{T}<=\mathrm{t})$ one-tail & 0.287314 & \\
$\mathrm{t}$ Critical one-tail & 1.94318 & \\
$\mathrm{P}(\mathrm{T}<=\mathrm{t})$ two-tail & 0.574628 & \\
$\mathrm{t}$ Critical two-tail & 2.446912 & \\
\hline
\end{tabular}

Spill-passage efficiency was significantly higher under the $40 \%$ spill treatment than under the $30 \%$ spill treatment, but the opposite was true for all other passage metrics except FPE, which did not differ between treatments (Table 3.11). Metrics that were higher during 30\% spill than during $40 \%$ spill included FGE at turbines (up 8.9\%), TSWE (up 8.9\%), JBSE (up 8\%), SPE (up 0.38), and TSW effectiveness (up 1.42). Combined with the survival results, this means that $9.6 \%$ more $\mathrm{CH} 1$ smolts are passing through the spillway during $40 \%$ spill than during $30 \%$ spill, but JDA-to-TDA forebay passage survival rate is $1.8 \%$ percentage points lower when spill is at $40 \%$ than when it is at $30 \%$. 
Table 3.11. Estimates of Major Passage Metrics by Spill Treatment for CH1 During Spring 2009. *A one-tailed, paired t-test produced the listed probabilities and those $<\alpha=0.05$ were considered to be significant.

\begin{tabular}{cccc}
\hline Metric & Spill Treatment & Estimate $( \pm 1 / 295 \%$ CI $)$ & T-Test Probability \\
\hline \multirow{2}{*}{ FPE } & $30 \%$ & $92.62 \pm 0.76 \%$ & 0.1193 \\
& $40 \%$ & $94.26 \pm 0.64 \%$ & $0.0048^{*}$ \\
SPE & $30 \%$ & $75.86 \pm 1.54 \%$ & \\
& $40 \%$ & $85.44 \pm 1.06 \%$ & $0.0264^{*}$ \\
FGE & $30 \%$ & $69.44 \pm 3.17 \%$ & \\
& $40 \%$ & $60.58 \pm 3.43 \%$ & $0.0100^{*}$ \\
TSWE & $30 \%$ & $31.46 \pm 1.30 \%$ & \\
& $40 \%$ & $22.60 \pm 1.43 \%$ & $0.0027^{*}$ \\
JBSE & $30 \%$ & $16.77 \pm 1.48 \%$ & \\
& $40 \%$ & $8.82 \pm 0.82 \%$ & $<0.0001^{*}$ \\
SEF & $30 \%$ & $2.51 \pm 0.05$ & $0.0060^{*}$ \\
& $40 \%$ & $2.21 \pm 0.03$ & \\
TSWEF & $30 \%$ & $4.35 \pm 0.18$ & \\
& $40 \%$ & $2.98 \pm 0.19$ & \\
\hline
\end{tabular}

\subsubsection{Survival Rates}

The survival and capture history of $\mathrm{CH} 1$ were evaluated for both JDA and TDA. Capture histories are presented in Appendix C.

\subsubsection{Seasonal Trends, JDA-to-TDA Forebay, and Route-Specific Survival Rates}

Estimates of single-release survival rates $[\hat{\mathrm{S}}( \pm 1 / 295 \% \mathrm{CI})]$ were calculated for $\mathrm{CH} 1$ released at Roosevelt, Washington ( $\mathrm{rkm} 390$ ), and regrouped at the JDA dam face to form virtual releases. The single-release, JDA-to-TDA forebay passage survival rate for JDA was $0.927( \pm 0.010)$, and there was no significant seasonal trend in estimates by virtual release (Figure 3.17). The highest route-specific survival rate (Table 3.12$)$ was for JBS-passed fish $(0.975 \pm 0.016)$ followed closely by the rate for TSW-passed fish $(0.951 \pm 0.014)$. The non-TSW spillway-passage survival rate was lower $0.912 \pm 0.014$ than the rate for TSW-passed fish. The lowest survival rate came from turbine-passed fish $(0.851 \pm 0.047)$. Detailed capture histories and survival estimates by release are in Appendix C. 


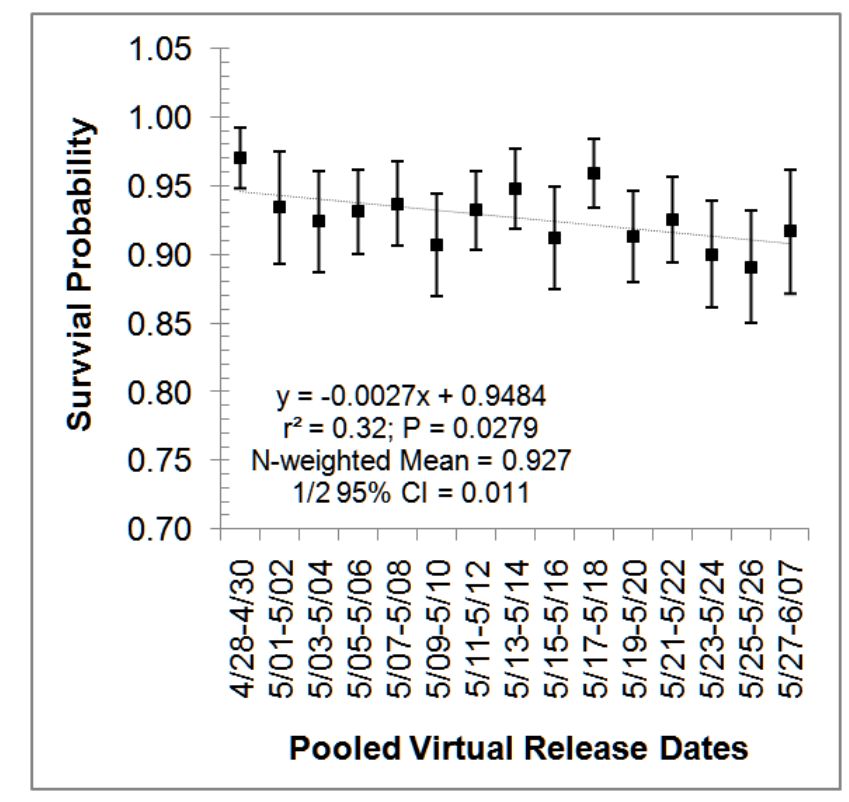

Figure 3.17. Seasonal Trend in Single-Release, JDA to TDA Forebay-Passage Survival Probability for CH1 at JDA in Spring 2009. Vertical bars indicate the extent of individual 95\% confidence intervals; the light gray regression line indicates a slight downward trend with a slope that did not differ significantly from zero; regression statistics, the $\mathrm{N}$-weighted mean, and associated $1 / 295 \%$ confidence intervals are for all data are listed below the points.

Table 3.12. Single-Release Estimates of Survival for CH1 Smolts in Virtual Releases at JDA During 2009 Based on Detections at Three Downstream Arrays (A3CR211, A4CR236, and A5CR192).

\begin{tabular}{lcc}
\hline \multicolumn{1}{c}{ Route } & Survival & $\pm 1 / 295 \%$ CI \\
\hline JDA-to-TDA forebay & 0.927 & 0.010 \\
Non-TSW & 0.913 & 0.014 \\
TSW & 0.951 & 0.014 \\
Turbine & 0.851 & 0.047 \\
JBS & 0.975 & 0.016 \\
\hline
\end{tabular}

\subsubsection{Day/Night Trends in Survival Rates}

For most routes, the survival rate estimate was higher for $\mathrm{CH} 1$ smolts that passed at night than it was for smolts that passed during the day (Figure 3.18). Only at spill bays $2-14$ was the daytime survival rate higher than that for nighttime, although the result is likely not statistically significant because of overlapping confidence intervals. Recall, during spring, day and night periods were defined as follows: day $=0600$ to $2159 \mathrm{~h}$ and night $=2200$ to $0559 \mathrm{~h}$. 


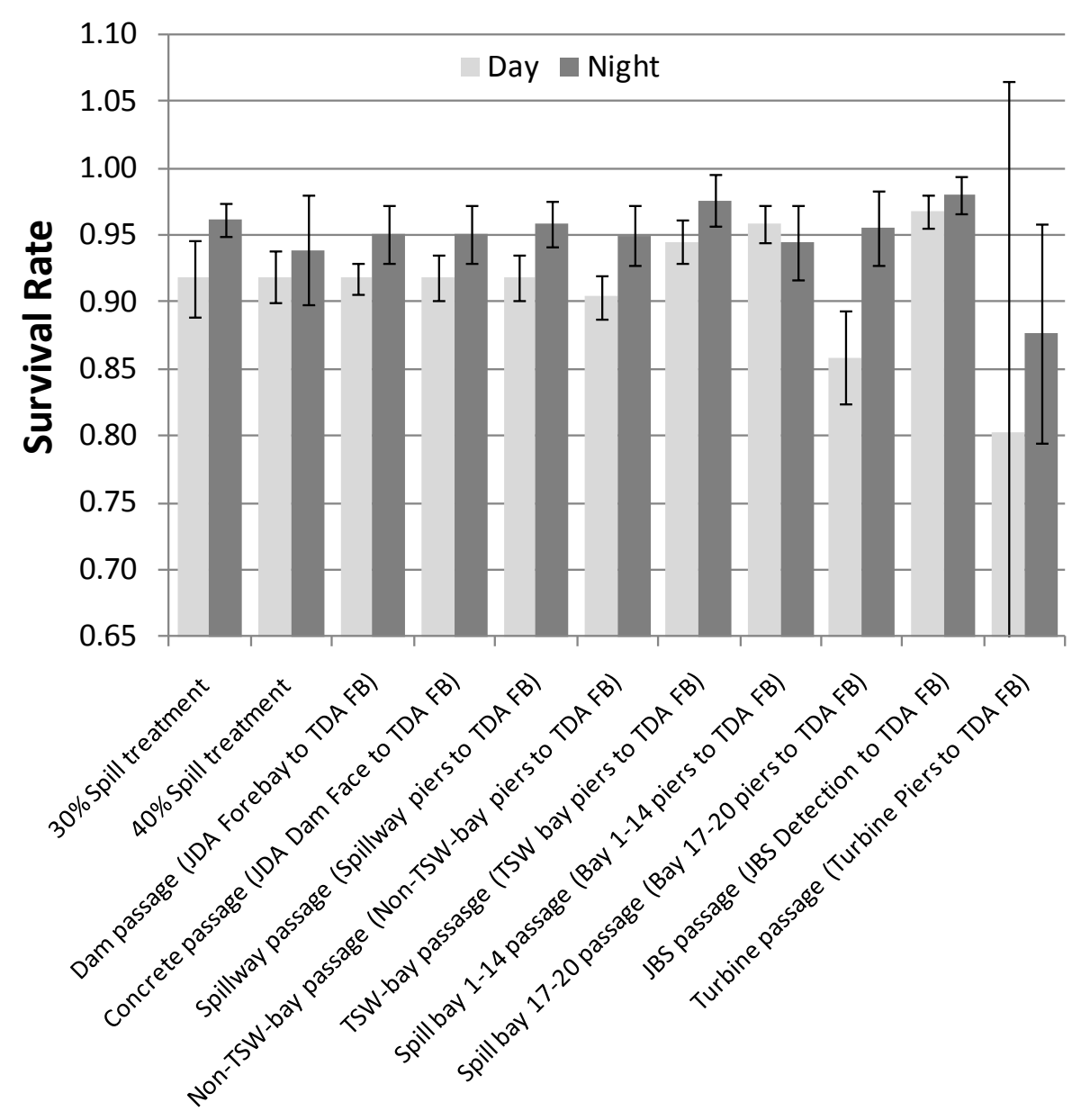

Figure 3.18. Day and Night Single-Release Estimates of CH1 Survival Rates by Route of Passage During Spring 2009

\subsubsection{Survival Rates at The Dalles Dam}

Yearling Chinook salmon released at Roosevelt, Washington ( $\mathrm{rkm} 390)$, were regrouped on the TDA forebay entrance array and used to estimate TDA forebay to BON forebay-passage survival rate based on subsequent detections on one array in the BON forebay and two arrays in the BON tailwater. The estimate of single-release passage survival rate for $\mathrm{CH} 1$ smolts traveling from TDA forebay entrance array to the BON forebay array was $0.890 \pm 0.012(1 / 295 \% \mathrm{CI})$, and estimates for individual virtual releases had no significant seasonal trend (Figure 3.19). Detailed capture history and survival results by release are in Appendix C. 


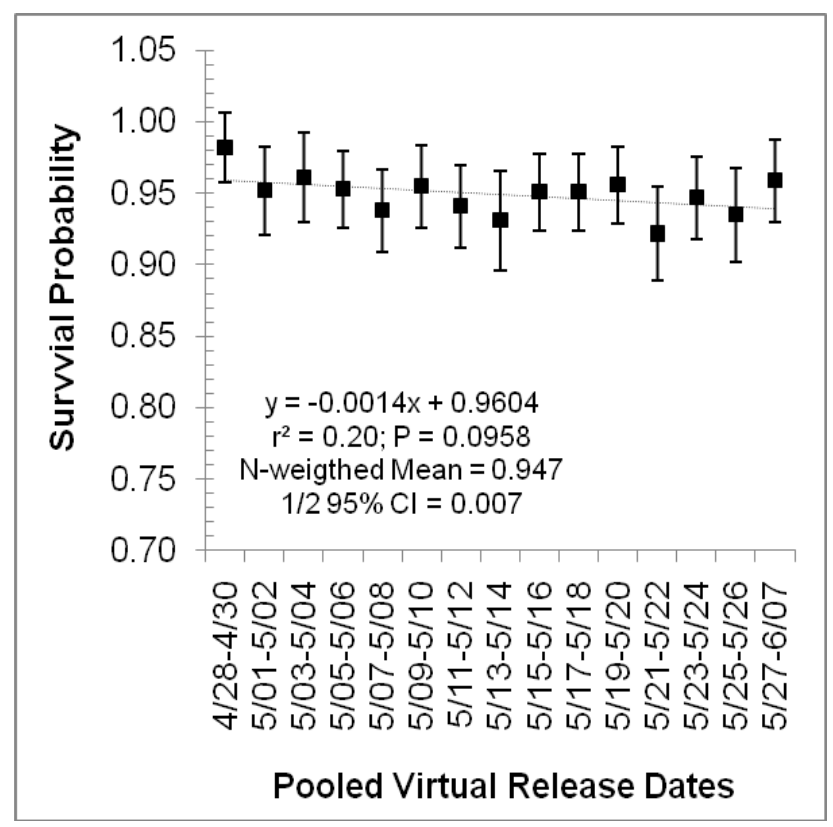

Figure 3.19. Seasonal Trend in Single-Release, Dam-Passage Survival Probability for CH1 at TDA in Spring 2009. Vertical bars indicate the extent of individual $95 \%$ confidence intervals; the light gray regression line indicates a slight downward trend with a slope that did not differ significantly from zero; regression statistics, the N-weighted mean, and associated $1 / 295 \%$ confidence intervals for all data are listed below the points.

No significant difference was observed in TDA passage survival for $\mathrm{CH} 1$ passing by four different routes through JDA based on overlap of $1 / 295 \%$ confidence intervals (Table 3.13 ).

Table 3.13. Single-Release Estimates of TDA Passage Survival for $\mathrm{CH} 1$ That Previously Passed Through Six Routes at JDA During 2009

\begin{tabular}{lll}
\hline \multicolumn{1}{c}{ JDA Passage Route } & TDA Survival & $1 / 295 \%$ CI \\
\hline Spillway (TSW bays 15 \& 16) & 0.874 & 0.024 \\
Spillway (All Non-TSW bays) & 0.894 & 0.016 \\
Non-TSW bays 2-14 & 0.881 & 0.024 \\
Non-TSW bays 17-20 & 0.908 & 0.020 \\
Turbines & 0.903 & 0.043 \\
JBS & 0.898 & 0.029 \\
\hline
\end{tabular}

Passage efficiency and effectiveness, powerhouse and spillway passage, the effect of spill conditions on dam-passage survival rate and passage proportions, and day/night trends in survival rates and passage efficiencies relative to $\mathrm{CH} 1$ at JDA during spring 2009 are described below. 


\subsubsection{Passage Metrics and Distributions}

In this section, passage and distribution data are presented for passage efficiency and effectiveness, powerhouse horizontal distribution, the relationship between powerhouse passage and discharge, spillway horizontal distribution, and day/night trends in passage.

\subsubsection{Passage Efficiency and Effectiveness}

For CH1 smolts in spring 2009, JDA FPE was 93.4 SPE was $80.6 \%$; and the two spill bays with TSWs passed $27.1 \%$ of all smolts in $7.4 \%$ of the water discharged through the dam (Table 3.14 ). The TSW was 1.54 times more effective than the entire spillway at passing $\mathrm{CH} 1$ smolts. Of the $24 \%$ of $\mathrm{CH} 1$ smolts passing into the powerhouse, $66.2 \%$ were diverted by the intake screens into the JBS, and JBSE, relative to total numbers passing through the dam, was $12.8 \%$. About $6.6 \%$ of all $\mathrm{CH} 1$ smolts passed through turbines.

Table 3.14. Estimates of Major Passage Metrics for CH1 During Spring 2009

\begin{tabular}{|c|c|}
\hline Metric & Estimate $( \pm 1 / 295 \% \mathrm{CI})$ \\
\hline FPE & $93.43 \pm 0.94 \%$ \\
\hline SPE & $80.59 \pm 1.75 \%$ \\
\hline FGE & $66.15 \pm 4.38 \%$ \\
\hline TSWE & $27.08 \pm 1.85 \%$ \\
\hline JBSE & $12.84 \pm 1.56 \%$ \\
\hline SEF & $2.37 \pm 0.05$ \\
\hline TSWEF & $3.66 \pm 0.25$ \\
\hline
\end{tabular}

\subsubsection{Powerhouse Horizontal Distribution and the Relationship between Passage and Discharge}

During spring, $66 \%$ of the $\mathrm{CH} 1$ smolts that passed through the dam at the powerhouse were guided through the JBS, and the remaining one-third passed through the turbines (Figure 3.20). Turbine discharge varied widely across the powerhouse and was lowest at units 6,10 , and 13 and highest at units $1-3,5,11$, and 14-16. A regression of number of tagged $\mathrm{CH} 1$ smolts passing each turbine in spring on unit-specific discharge was highly significant $(\mathrm{P}<0.0001)$ and discharge explained $70 \%$ of the variation in $\mathrm{CH} 1$ passage (Figure 3.21). 


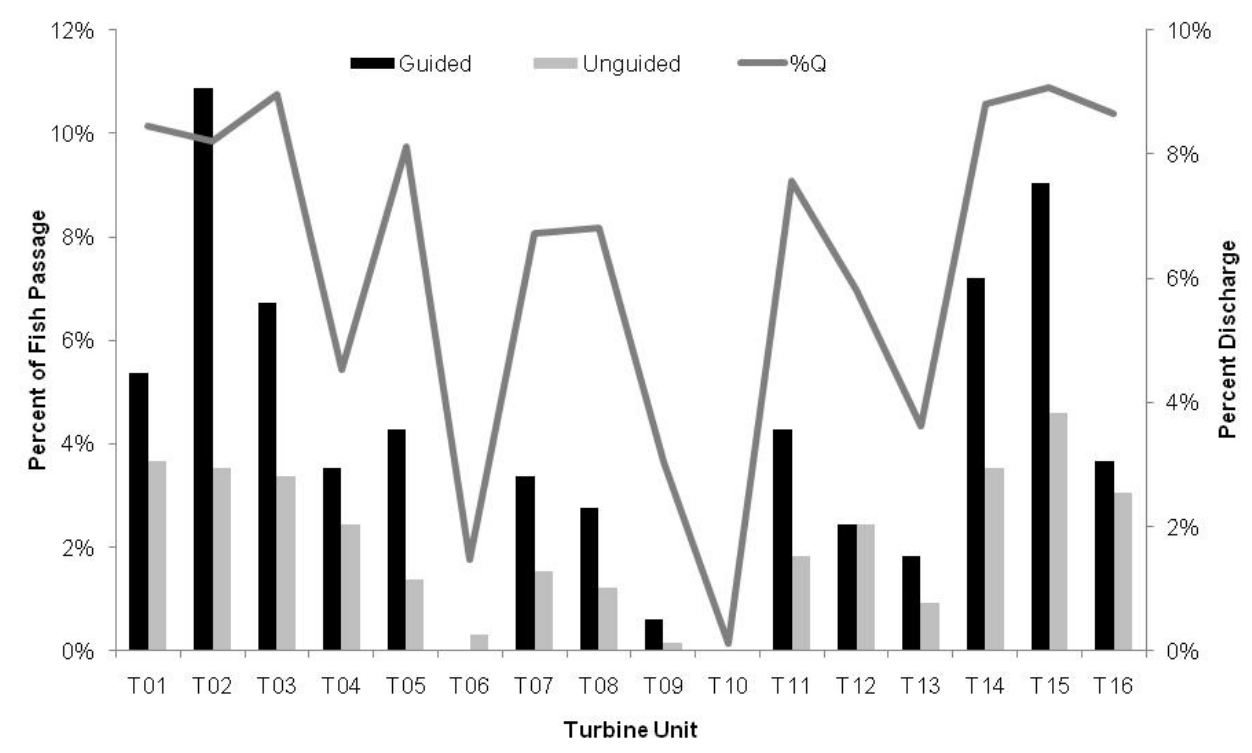

Figure 3.20. Percent Passage for Guided and Unguided CH1 and Percent Discharge by Turbine Unit for the John Day Powerhouse During Spring 2009

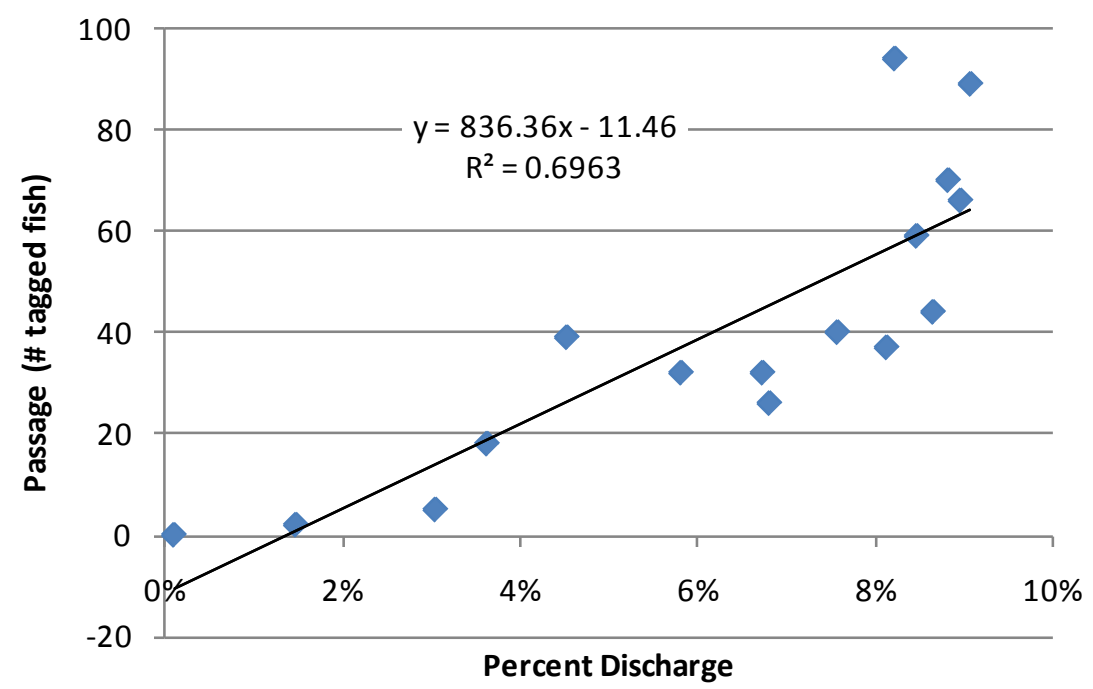

Figure 3.21. Regression of Fish-Passage on Percent Discharge for $\mathrm{CH} 1$ at the Powerhouse Turbine Units During Spring 2009

\subsubsection{Spillway Horizontal Distribution}

Of the $\mathrm{CH} 1$ smolts passing through the spillway, $73.2 \%$ passed through high-discharge bays, including TSW bays 15 and 16 and the nearby bays 14, 17, and 18 (Figure 3.22). Higher discharge at bays near the TSW bays was designed to provide training flow to speed tailrace egress for fish passing through the TSW bays. The average rate of passage at an average TSW spill bay was 7.4 times higher than the average rate for spill bays 1-14 and 1.9 times higher than the rate for bays 17-20 (Figure 3.23). 


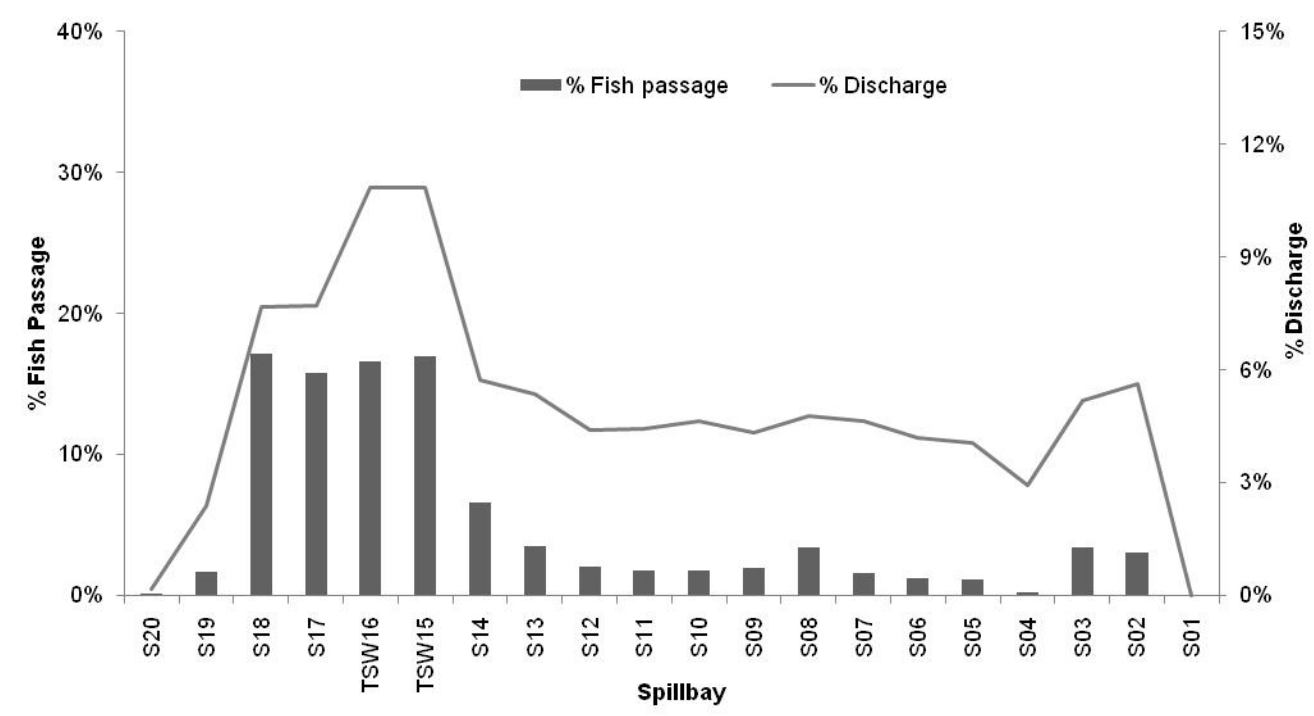

Figure 3.22. Percent CH1 Passage and Percent Discharge by Spill Bay During 2009

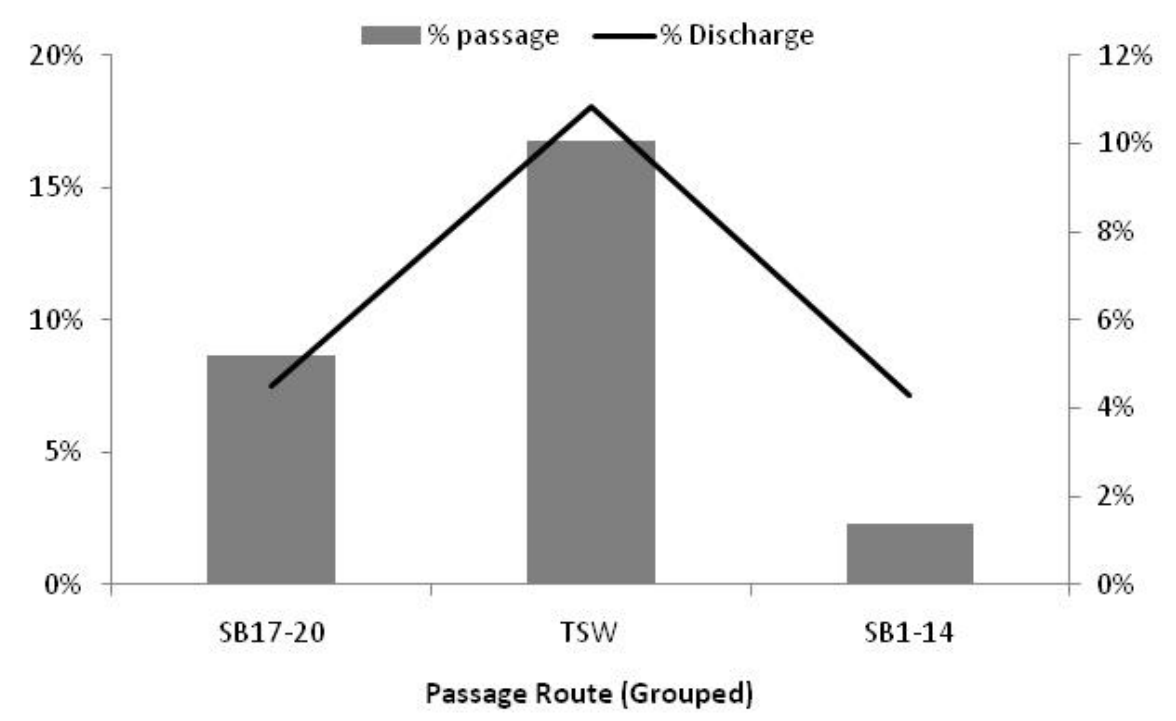

Figure 3.23. Average Percent Passage of CH1 Smolts and Percent Discharge Per Spill Bay Within Groups of Bays During 2009

\subsubsection{Day/Night Trends in Passage}

Total passage and spillway passage rates for $\mathrm{CH} 1$ were higher during the day than at night, while fish-passage rates for the powerhouse (JBS and turbines) were higher at night than during the day (Figure 3.24). The numbers of CH1 smolts passing through the dam were divided by total number of hours in "day" (464) and "night" (232) to come up with the number per hour. Hourly passage rates through spill bays 2-14, the TSW, and spill bays 17-20 were all higher during the day than they were at night, and both day and night passage rates per bay and hour were higher at TSW bays than they were at other spill bays (Figure 3.25). 


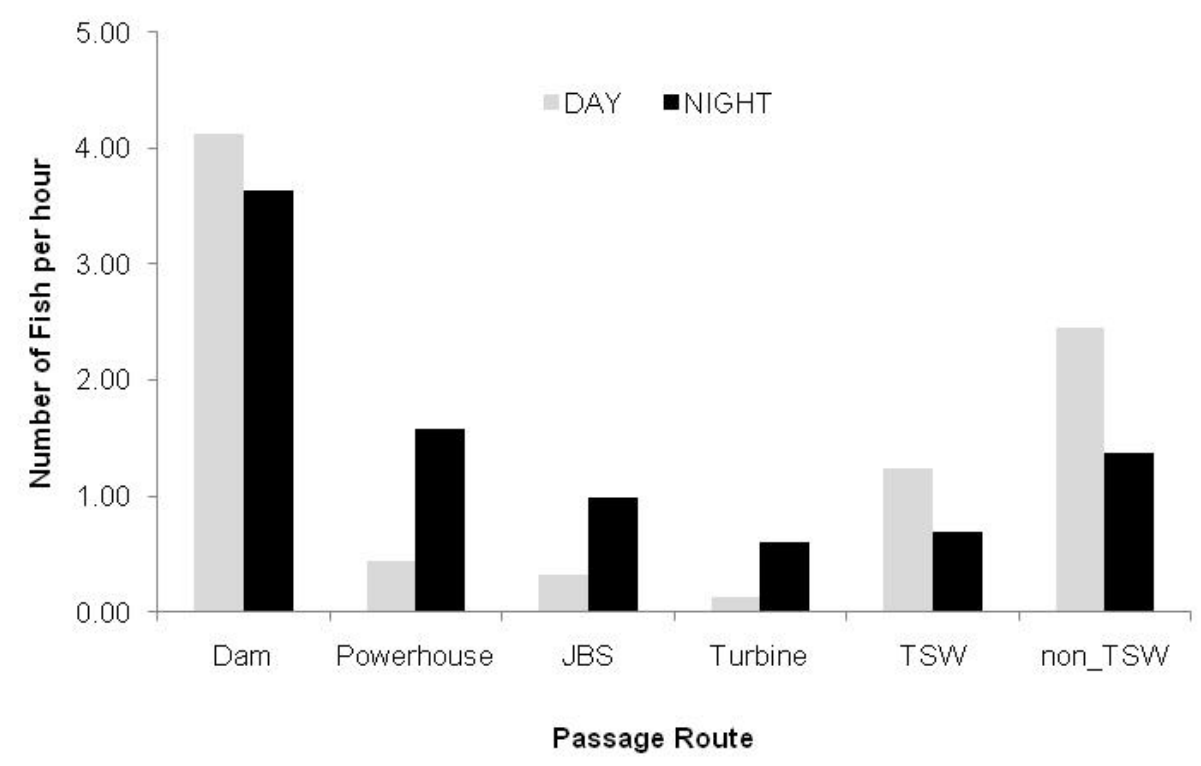

Figure 3.24. Day and Night Differences in Passage Rates for CH1 During 2009

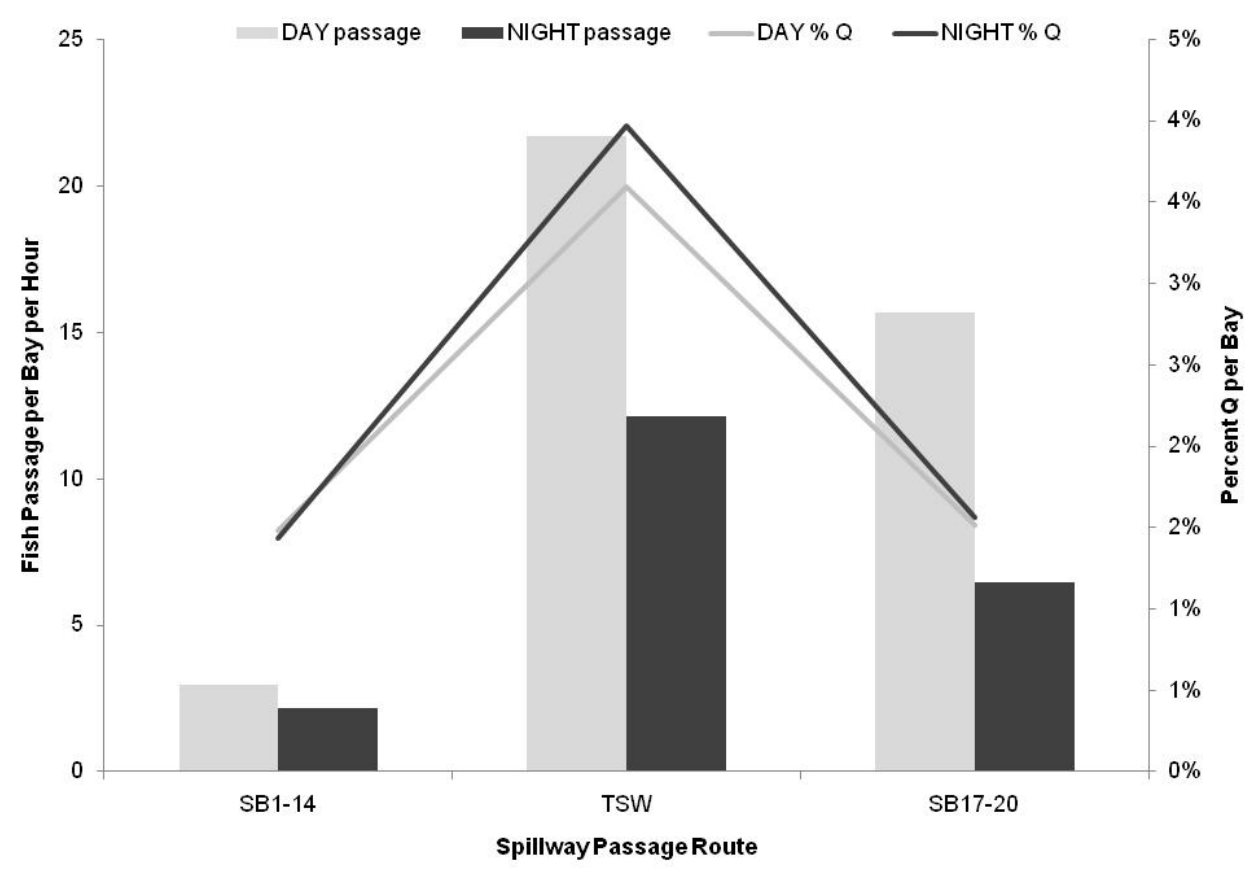

Figure 3.25. Day and Night Differences in Passage Rates (number/hour/bay) for $\mathrm{CH} 1$ and Percentage of Discharge (Q) for Groups of Spill Bays During 2009

\subsubsection{Fish Behavior}

This section contains a description of the arrival and passage patterns, day and night differences in behavior, vertical distributions, and travel and forebay residence times of fish, implanted with JSATS acoustic transmitters, in the forebay of JDA. The autonomous node array located $2 \mathrm{~km}$ upstream of JDA was used to assign approach locations and dam-mounted hydrophones were used to assign passage 
locations. Forebay residence times are described by passage route and for combinations of arrival and passage location. For analysis purposes, fish arriving at JDA were grouped into arrival blocks and passage-route blocks. The arrival blocks were assigned from autonomous nodes located in the JDA forebay, and passage-route blocks were assigned from detections on the dam-face arrays. These blocks included powerhouse units $1-8,9-16$, skeleton bays $17-20$, bays $1-14,15-16$ (TSW), and 17-20.

\subsubsection{Approach and Route of Passage}

The approach of $\mathrm{CH} 1$ at JDA during 2009 was as follows: $40 \%$ at the powerhouse, $13 \%$ at the skeleton bays, and $47 \%$ at the spillway (Figure 3.26). Of the tagged $\mathrm{CH} 1$ first detected approaching the powerhouse or skeleton bays, $66 \%$ eventually moved north and passed at the spillway. Fish approaching at the spillway were more likely to pass through the dam at the spillway ( $46 \%$ of total approach) than at the powerhouse (1.6\% of total approach).

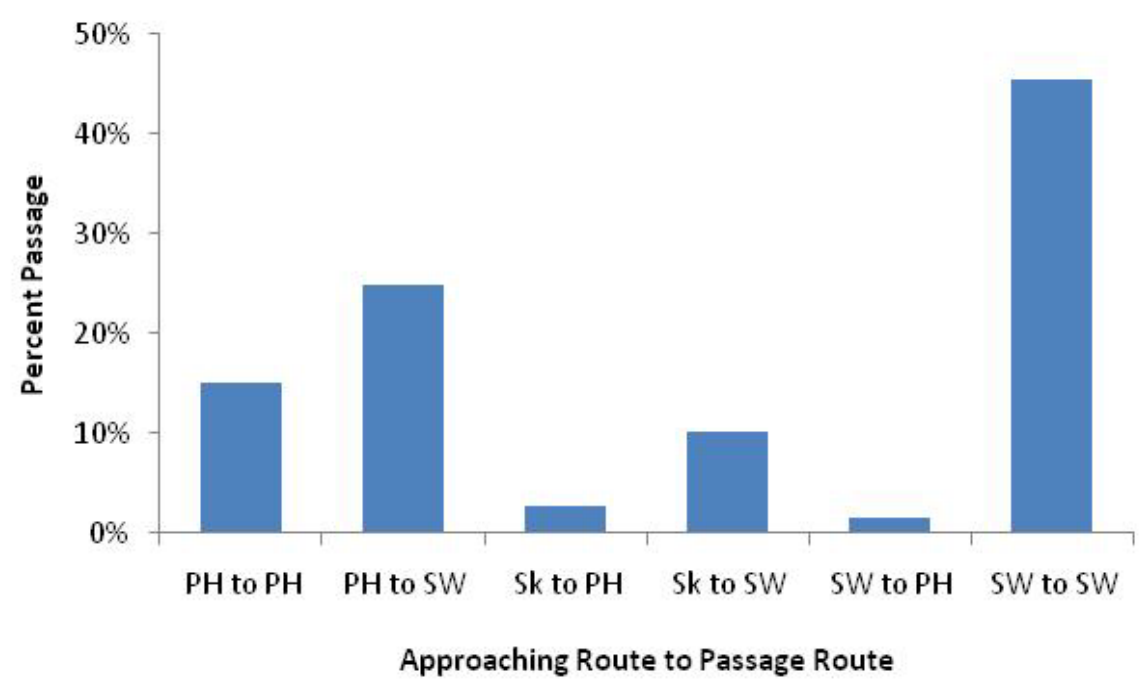

Figure 3.26. Yearling Chinook Salmon Approach and Passage Distributions at JDA During Spring 2009. The first abbreviation is for the approach location and the second is for the passage location. Abbreviations are: $\mathrm{PH}=$ powerhouse; $\mathrm{Sk}=$ skeleton bay; $\mathrm{SW}=$ spillway.

Of all fish passing the dam, $7 \%$ approached at the powerhouse but passed at the TSWs (spillway block 15-16) (Figure 3.27). In contrast, $\sim 13 \%$ of total passage occurring at the TSWs came from fish arriving at the powerhouse. More than half of the $\mathrm{CH} 1$ arriving at the powerhouse moved north to pass at the spillway. On the other hand, few fish approached the spillway and moved south to pass at the powerhouse. Only 5\% of the tagged $\mathrm{CH} 1$ approached the dam in the forebay of the TSWs (Figure 3.27), while $27 \%$ passed there (Table 3.14 ). 


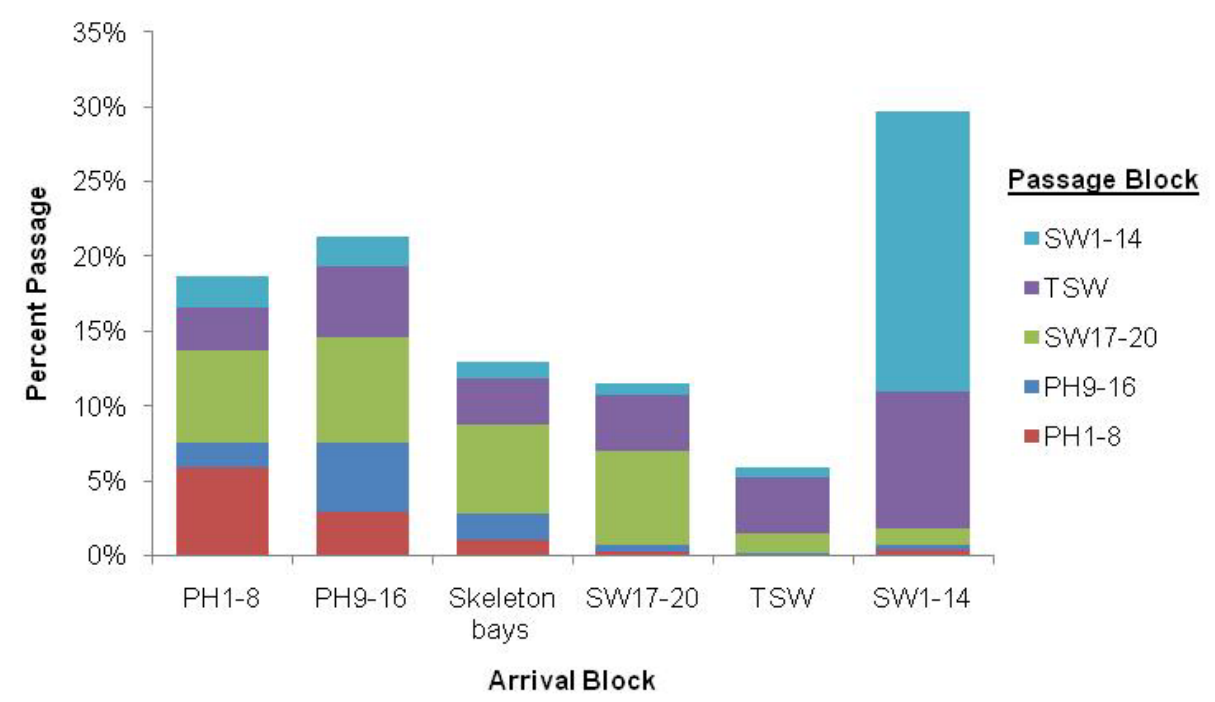

Figure 3.27. Yearling Chinook Salmon Approach and Passage Behavior Patterns at JDA During 2009

\subsubsection{Day/Night Behavior Patterns}

Yearling Chinook salmon passing the powerhouse at night tended to approach at the powerhouse (Figure 3.28). However, during daytime, $\mathrm{CH} 1$ approaching the powerhouse were more likely to migrate and pass through the spillway rather than pass at the powerhouse. A similar pattern was observed for fish approaching the skeleton bay area. Upon approaching the spillway, $\mathrm{CH} 1$ displayed a tendency to pass there during the day; this pattern was also evident at night, although less so.

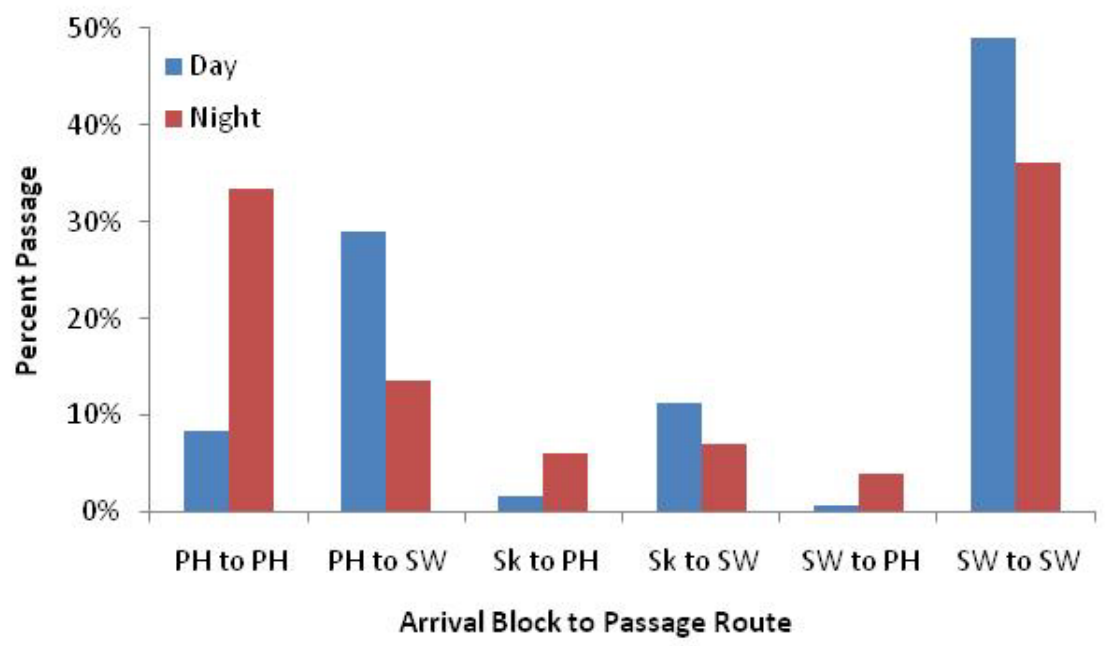

Figure 3.28. Yearling Chinook Salmon Approach and Passage Behavior Patterns During Day and Night, Spring 2009. Day/night allocation was defined by when the fish passed the dam.

Most $\mathrm{CH} 1$ arriving at the powerhouse eventually passed through spill bays 17-20 during the day (Figure 3.29). This was not the case at night; most $\mathrm{CH} 1$ arriving at the powerhouse passed there at night (Figure 3.30). Approach and passage behavioral patterns for the spillway were similar for day and night (Figures 3.29 and 3.30). 


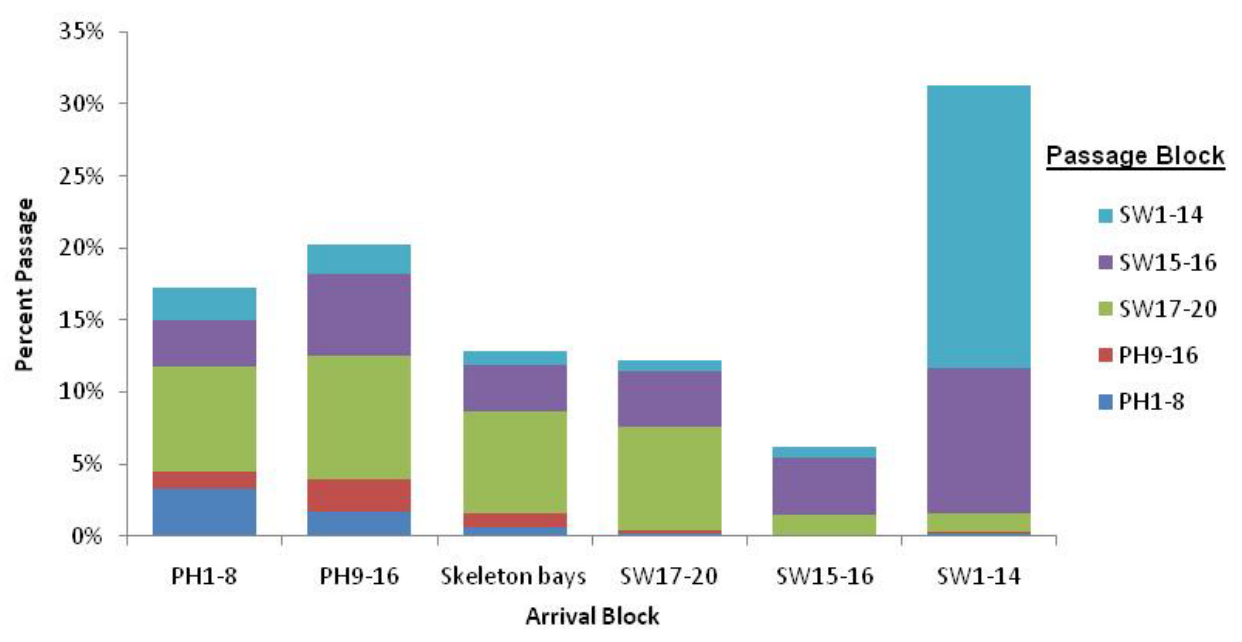

Figure 3.29. Approach and Passage Patterns for CH1 During Daytime at JDA, Spring 2009

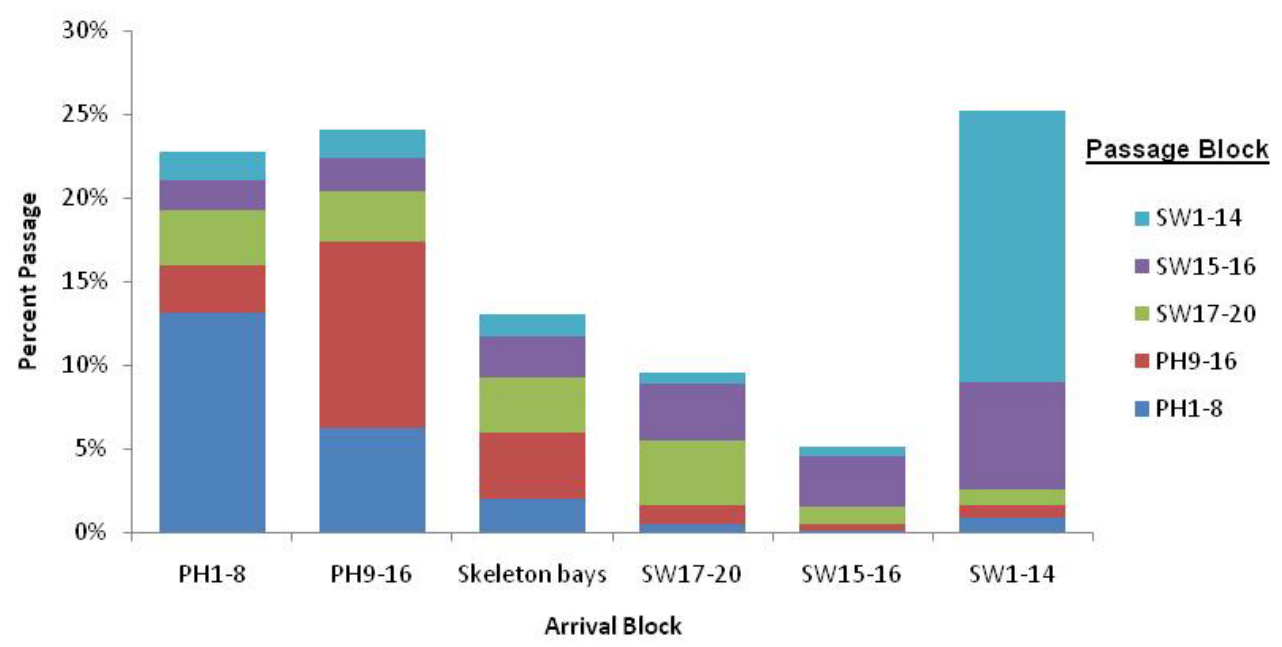

Figure 3.30. Approach and Passage Patterns for CH1 Passing JDA at Night During Spring 2009

\subsubsection{Vertical Distribution Behavior Patterns}

As $\mathrm{CH} 1$ approached the powerhouse, median depth of passage gradually decreased as distance from the dam decreased from $75 \mathrm{~m}$ to $10 \mathrm{~m}$ from the face of the powerhouse (Figure 3.31). However, $<5 \mathrm{~m}$ from the face of the powerhouse, median depth increased to over $20 \mathrm{~m}$ where the turbine intakes are located (Figure 3.31). At the spillway, $\mathrm{CH} 1$ approached at shallow depths $(\sim 2-3 \mathrm{~m})$. Any sudden increases in depth associated with passage under the tainter gates ( $\sim 15 \mathrm{~m}$ deep) were not detected because the dam-face hydrophones at the spillway were mounted on piers well upstream of the spill ogee. There were no day and night differences in vertical distributions for powerhouse- or spillway-passed fish. 


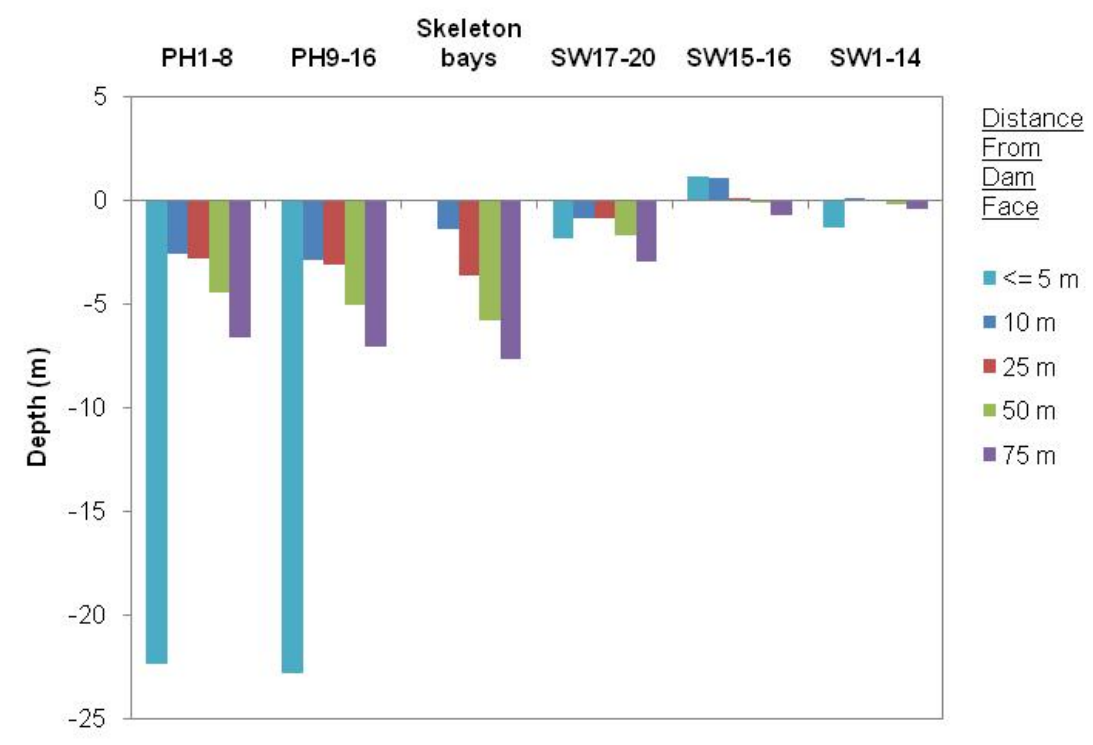

Figure 3.31. Median Depths of Last Detection of Tagged CH1 at JDA During 2009. Zero depth was referenced to the elevation of the shallow hydrophone deployed on the south side of Turbine Unit 1 at elevation $255.23 \mathrm{ft}$ above MSL. Mean forebay water surface elevation was $263.5 \mathrm{ft}$ above MSL.

Turbine- and JBS-passed CH1 smolts had median last-detection depths of $25 \mathrm{~m}$ and $20 \mathrm{~m}$, respectively (Figure 3.32). Fish that pass into the JBS at JDA are intercepted by screens in the upper part of the turbines, whereas deeper fish are not intercepted and pass into turbines. The difference in median last-detection depths of these two routes is consistent with the depths of submerged traveling screens.

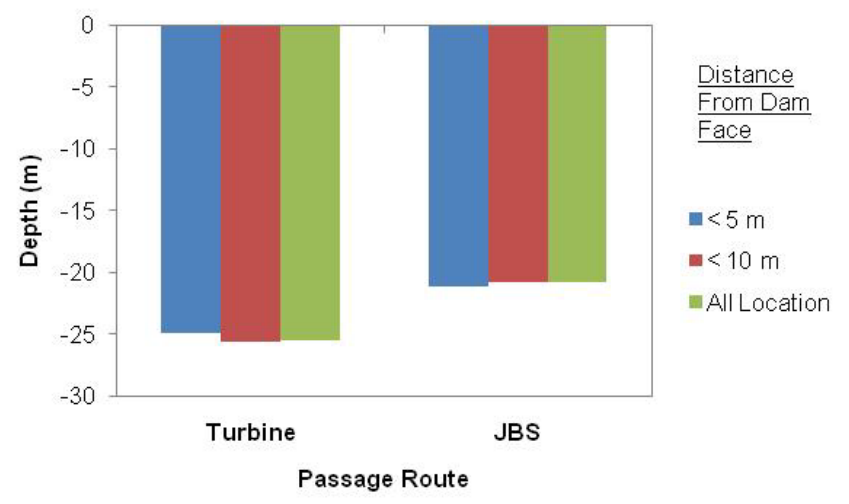

Figure 3.32. Median Depths of CH1 Passing into the JBS and Turbines, JDA 2009

\subsubsection{Travel Times and Forebay Residence Times}

During spring 2009, the median travel time for $\mathrm{CH} 1$ between the release station near Roosevelt, Washington, and the JDA forebay array was 33.0 hours (Table 3.15). For tagged CH1 detected on the forebay array, the median travel time until passage through JDA was 2.9 hours. Median travel time from the JDA face to the tailrace egress array $10 \mathrm{~km}$ downstream of the dam was 0.5 hours. From the JDA egress array to TDA forebay array, the median travel time was 14.6 hours. There was a median travel 
time of 29.0 hours to migrate from the TDA forebay to the BON forebay array. $\mathrm{CH} 1$ travel times were longest for the JBS route and shortest for the TSW at JDA during spring 2009.

Table 3.15. Distance of Travel and Median and Mean Travel Times ( $\pm 1 / 2$ 95\% CI) for Acoustic-Tagged CH1 Passing Through Specific River Reaches Between Roosevelt, Washington, and the BON Forebay

\begin{tabular}{|c|c|c|c|c|}
\hline Reach & $\begin{array}{c}\text { Distance } \\
(\mathrm{km})\end{array}$ & $\begin{array}{c}\text { Median } \\
\text { Travel } \\
\text { Time (h) }\end{array}$ & $\begin{array}{c}\text { Mean } \\
\text { Travel } \\
\text { Time (h) }\end{array}$ & $\begin{array}{c}1 / 2 \\
95 \% \\
\text { CI }\end{array}$ \\
\hline Roosevelt to JDA Forebay & 39.4 & 33.0 & 40.4 & 0.6 \\
\hline JDA Forebay to JDA Passage & 2 & & & \\
\hline Project & & 2.9 & 4.8 & 0.1 \\
\hline JBS & & 4.0 & 5.8 & 0.3 \\
\hline Turbine & & 2.7 & 4.6 & 0.2 \\
\hline TSW & & 2.6 & 4.5 & 0.2 \\
\hline NON-TSW & & 3.7 & 6.3 & 1.0 \\
\hline JDA Passage to JDA Tailwater & 2.6 & & & \\
\hline Project & & 0.5 & 2.3 & 0.2 \\
\hline JBS & & 6.9 & 14.6 & 1.5 \\
\hline Turbine & & 0.5 & 0.9 & 0.2 \\
\hline TSW & & 0.4 & 0.6 & 0.1 \\
\hline NON-TSW & & 0.7 & 1.5 & 0.3 \\
\hline JDA Passage to JDA Tailwater $30 \%$ Spill & 2.6 & & & \\
\hline Project & & 0.5 & 3.0 & 0.3 \\
\hline JBS & & 5.6 & 14.9 & 1.9 \\
\hline Turbine & & 0.5 & 0.9 & 0.2 \\
\hline TSW & & 0.4 & 0.7 & 0.1 \\
\hline NON-TSW & & 0.7 & 1.7 & 0.5 \\
\hline JDA Passage to JDA Tailwater $40 \%$ Spill & 2.6 & & & \\
\hline Project & & 0.5 & 1.8 & 0.3 \\
\hline JBS & & 8.4 & 14.1 & 2.0 \\
\hline Turbine & & 0.5 & 0.9 & 0.3 \\
\hline TSW & & 0.5 & 0.5 & 0.0 \\
\hline NON-TSW & & 0.8 & 0.8 & 0.1 \\
\hline JDA Tailwater to TDA Forebay & 34.6 & 14.6 & 15.6 & 0.1 \\
\hline TDA Forebay to BON Forebay & 75.4 & 29.0 & 31.0 & 0.2 \\
\hline
\end{tabular}

The $\mathrm{CH} 1$ approaching and passing at the spillway had a median residence time of 4 minutes, whereas fish arriving and passing through the powerhouse had a median residence time that was 10-fold higher (Figure 3.33). Fish arriving at the powerhouse and later passing through the spillway had a median residence time of over 2 hours, while fish approaching the spillway and passing through the powerhouse had median residence times of almost 3 hours. 


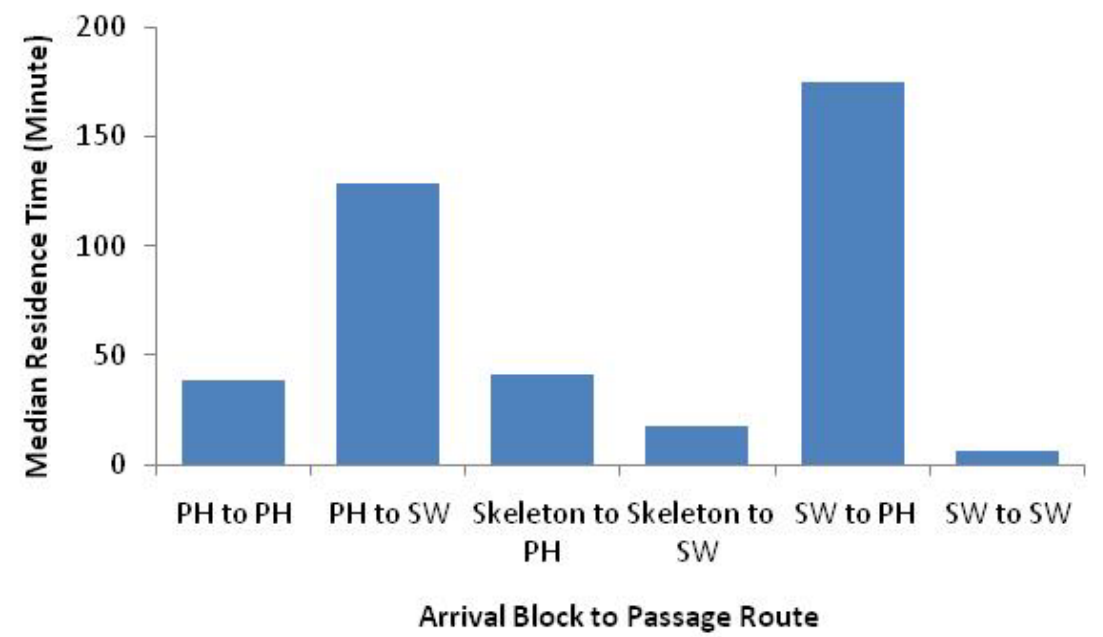

Figure 3.33. Yearling Chinook Salmon Median Passage Times During 2009

For $\mathrm{CH} 1$ approaching the powerhouse and passing the spillway, residence times were 2.5 times greater at night than during the day (Figure 3.34). In contrast, $\mathrm{CH} 1$ approaching the spillway and passing there had a median residence time of just 4 minutes whether during day or night. The longest residence time (over 4 hours) was for $\mathrm{CH} 1$ moving from approach at the powerhouse to passing at the spillway at night.

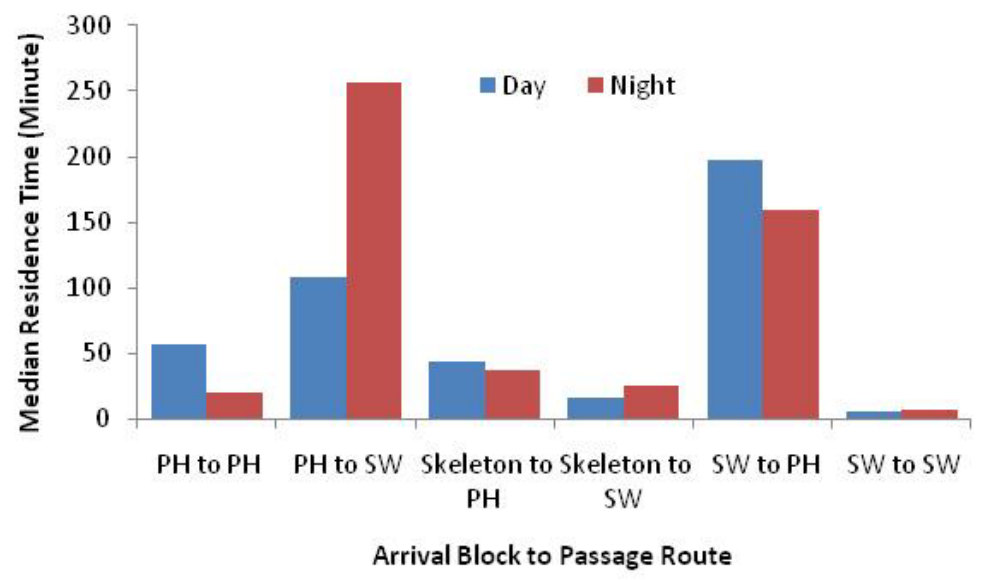

Figure 3.34. Yearling Chinook Salmon Day/Night Median Passage Times by Approach and Passage Blocks at JDA During 2009

\subsection{Steelhead}

This section contains estimates of survival rates, travel times, passage metrics, and distributions for STH at JDA during spring 2009. 


\subsubsection{Effect of Spill Conditions on Fish}

As mentioned previously, dam operators were able to meet the prescribed 30\%/40\% spill schedule for the first five blocks but were less consistent for blocks six through eight during spring 2009 (Figure 3.35). Fish did not arrive in sufficient numbers during the eighth block so it was dropped as a treatment.

Passage survival rates for STH were high for both the $30 \%$ and $40 \%$ spill treatments, although the rate was 0.8 and 1.2 percentage points higher for $30 \%$ than $40 \%$ spill for analysis of five and seven blocks, respectively (Table 3.16). The survival difference for STH was significant for the sevenblock test $(\mathrm{P}=0.0295)$, but not the five-block test $(\mathrm{P}=0.1430)$. The mean survival rates for each block used in the analysis and the t-test results are provided for the five-block analysis in Tables 3.17 and 3.18 and seven-block analysis in Tables 3.19 and 3.20.

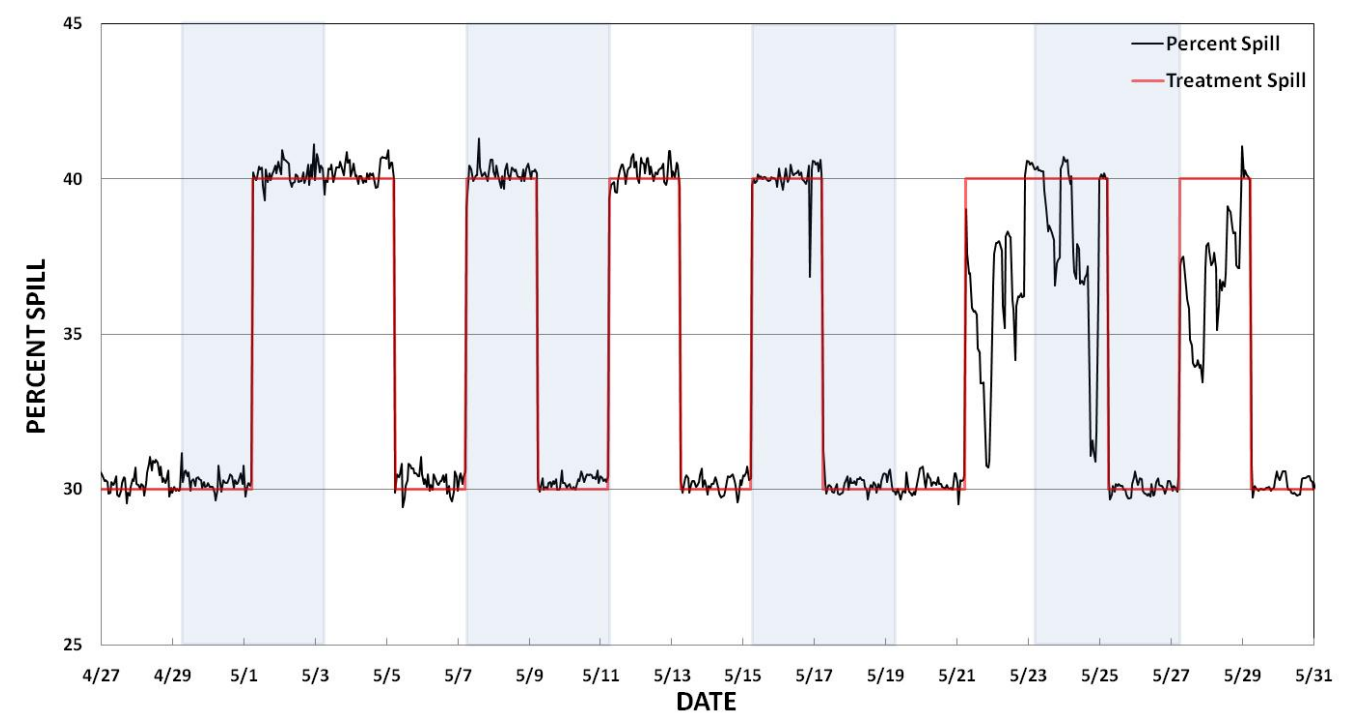

Figure 3.35. Spill Treatments as Prescribed (red line) and Actual Conditions (black line) in Spring During 2009. The shaded areas represent odd numbered treatment blocks. Repeated from Figure 3.3 for ease of reference.

Table 3.16. Estimates of JDA Forebay-to-TDA Forebay Passage Survival by Spill Condition for STH Smolts During Spring 2009. A one-tailed, paired t-test produced the listed probabilities and those $<\alpha=0.05$ were considered to be significant.

\begin{tabular}{lccc}
\hline Spill Treatment & $\begin{array}{c}\text { Blocks } \\
\text { Analyzed }\end{array}$ & $\begin{array}{c}\text { Survival Rate } \\
( \pm 1 / 295 \% \mathrm{CI})\end{array}$ & $\begin{array}{c}\text { One Tailed } \\
\text { Probability (P) }\end{array}$ \\
\hline $30 \%$ Spill & 5 & $0.955 \pm 0.019$ & 0.1430 \\
$40 \%$ Spill & 5 & $0.947 \pm 0.016$ & \\
\hline $30 \%$ Spill & 7 & $0.959 \pm 0.018$ & $0.0295^{*}$ \\
$40 \%$ Spill & 7 & $0.947 \pm 0.014$ & \\
\hline
\end{tabular}


Table 3.17. Estimates of JDA Forebay-to-TDA Forebay-Passage Survival Rates by Two-Day Block and Spill Treatment for STH, for First Five Blocks, During Spring 2009

\begin{tabular}{ccccc}
\hline Block & $30 \%$ Spill & $1 / 295 \%$ CI & $40 \%$ Spill & $1 / 295 \%$ CI \\
\hline 1 & 0.966 & 0.022 & 0.962 & 0.027 \\
2 & 0.975 & 0.018 & 0.943 & 0.035 \\
3 & 0.953 & 0.029 & 0.951 & 0.027 \\
4 & 0.958 & 0.027 & 0.96 & 0.025 \\
5 & 0.923 & 0.037 & 0.921 & 0.033 \\
\hline
\end{tabular}

Table 3.18. Results of a One-Tailed, Paired T-Test Comparing Estimates of JDA Forebay-to-TDA Forebay-Passage Survival Rates by Two-Day Block and Spill Treatment for STH, for First Five Blocks, During Spring 2009

\begin{tabular}{lrr}
\hline & $30 \%$ Spill & \multicolumn{1}{c}{$40 \%$ Spill } \\
\hline Mean & 0.955 & 0.9474 \\
Variance & 0.000389 & 0.000275 \\
Observations & 5 & 5 \\
Pearson Correlation & 0.723755 & \\
Hypothesized Mean Difference & 0 & \\
df & 4 & \\
t Stat & 1.230295 & \\
$\mathrm{P}(\mathrm{T}<=\mathrm{t})$ one-tail & 0.142996 & \\
t Critical one-tail & 2.131847 & \\
$\mathrm{P}(\mathrm{T}<=\mathrm{t})$ two-tail & 0.285992 & \\
$\mathrm{t}$ Critical two-tail & 2.776445 & \\
\hline
\end{tabular}

Table 3.19. Estimates of JDA Forebay-to-TDA Forebay Passage Survival Rates by Two-Day Block and Spill Treatment for STH, for Seven Blocks, During Spring 2009

\begin{tabular}{ccccc}
\hline Block & $30 \%$ Spill & $1 / 295 \%$ CI & $40 \%$ Spill & $1 / 295 \%$ CI \\
\hline 1 & 0.966 & 0.022 & 0.962 & 0.027 \\
2 & 0.975 & 0.018 & 0.943 & 0.035 \\
3 & 0.953 & 0.029 & 0.951 & 0.027 \\
4 & 0.958 & 0.027 & 0.96 & 0.025 \\
5 & 0.923 & 0.037 & 0.921 & 0.033 \\
6 & 0.975 & 0.02 & 0.955 & 0.025 \\
7 & 0.962 & 0.024 & 0.937 & 0.027 \\
\hline
\end{tabular}


Table 3.20. Results of a One-Tailed, Paired T-Test Comparing Estimates of JDA Forebay-to-TDA Forebay Passage Survival Rates by Two-Day Block and Spill Treatment for CH1, for Seven Blocks, During Spring 2009

\begin{tabular}{lrr}
\hline & $30 \%$ Spill & \multicolumn{1}{c}{$40 \%$ Spill } \\
\hline Mean & 0.958857 & 0.947 \\
Variance & 0.000317 & 0.000211 \\
Observations & 7 & 7 \\
Pearson Correlation & 0.668771 & \\
Hypothesized Mean Difference & 0 & \\
df & 6 & \\
t Stat & 2.324465 & \\
$\mathrm{P}(\mathrm{T}<=\mathrm{t})$ one-tail & 0.029543 & \\
$\mathrm{t}$ Critical one-tail & 1.94318 & \\
$\mathrm{P}(\mathrm{T}<=\mathrm{t})$ two-tail & 0.059087 & \\
$\mathrm{t}$ Critical two-tail & 2.446912 & \\
\hline
\end{tabular}

For STH during 2009, spill efficiency was significantly higher during the $40 \%$ spill than $30 \%$ spill treatment (Table 3.21). However, JBS efficiency and spill effectiveness were significantly higher during $30 \%$ spill than $40 \%$ spill. Point estimates for FPE were 1.23 percentage points higher during $40 \%$ than $30 \%$ spill.

Table 3.21. Estimates of Major Passage Metrics by Spill Treatment for STH During Spring 2009. *A one-tailed, paired t-test produced the listed probabilities and those $<\alpha=0.05$ were considered to be significant.

\begin{tabular}{|c|c|c|c|}
\hline Metric & Spill Treatment & Estimate $( \pm 1 / 295 \% \mathrm{CI})$ & T-Test Probability \\
\hline \multirow{2}{*}{ FPE } & $30 \%$ & $96.78 \pm 0.49 \%$ & \multirow{2}{*}{0.0612} \\
\hline & $40 \%$ & $98.01 \pm 0.38 \%$ & \\
\hline \multirow{2}{*}{ SPE } & $30 \%$ & $71.51 \pm 1.26 \%$ & \multirow{2}{*}{$0.0012 *$} \\
\hline & $40 \%$ & $81.18 \pm 1.20 \%$ & \\
\hline \multirow{2}{*}{ FGE } & $30 \%$ & $88.70 \pm 1.65 \%$ & \multirow{2}{*}{0.4644} \\
\hline & $40 \%$ & $89.40 \pm 1.92 \%$ & \\
\hline \multirow{2}{*}{ TSWE } & $30 \%$ & $48.48 \pm 1.38 \%$ & \multirow{2}{*}{0.2043} \\
\hline & $40 \%$ & $51.84 \pm 1.71 \%$ & \\
\hline \multirow{2}{*}{ JBSE } & $30 \%$ & $25.27 \pm 2.44 \%$ & \multirow{2}{*}{$0.0027 *$} \\
\hline & $40 \%$ & $16.82 \pm 2.31 \%$ & \\
\hline \multirow{2}{*}{ SFE } & $30 \%$ & $2.37 \pm 0.04$ & \multirow{2}{*}{$0.0020^{*}$} \\
\hline & $40 \%$ & $2.10 \pm 0.03$ & \\
\hline \multirow{2}{*}{ TSWEF } & $30 \%$ & $6.70 \pm 0.19$ & \multirow{2}{*}{0.4035} \\
\hline & $40 \%$ & $6.84 \pm 0.23$ & \\
\hline
\end{tabular}




\subsubsection{Survival Rates}

The survival and detection histories of STH in spring were evaluated for both JDA and TDA. Capture histories are presented in Appendix C.

\subsubsection{Seasonal Trends, JDA-to-TDA Forebay-Passage, and Route-Specific Survival Rates}

Survival estimates were calculated from JDA dam-face virtual releases of STH originally released at Roosevelt, Washington (rkm 390). The single-release estimate of survival rate for JDA, from the JDA dam-face to the TDA forebay, was $0.953 \pm 0.008(1 / 295 \% \mathrm{CI})$, and there was no significant temporal trend in spring (Figure 3.36). The single-release survival rate was highest for JBS-passed fish (0.966 \pm $0.014)$ followed closely by rates of $(0.963 \pm 0.010)$ for TSW-passed fish. The rate for non-TSW fish passed through the spillway $(0.936 \pm 0.016)$ was lower than that for TSW-passed fish, but the lowest rate was for turbine-passed fish $(0.824 \pm 0.080$; Table 3.22). Detailed capture history and survival results by release date are in Appendix C.

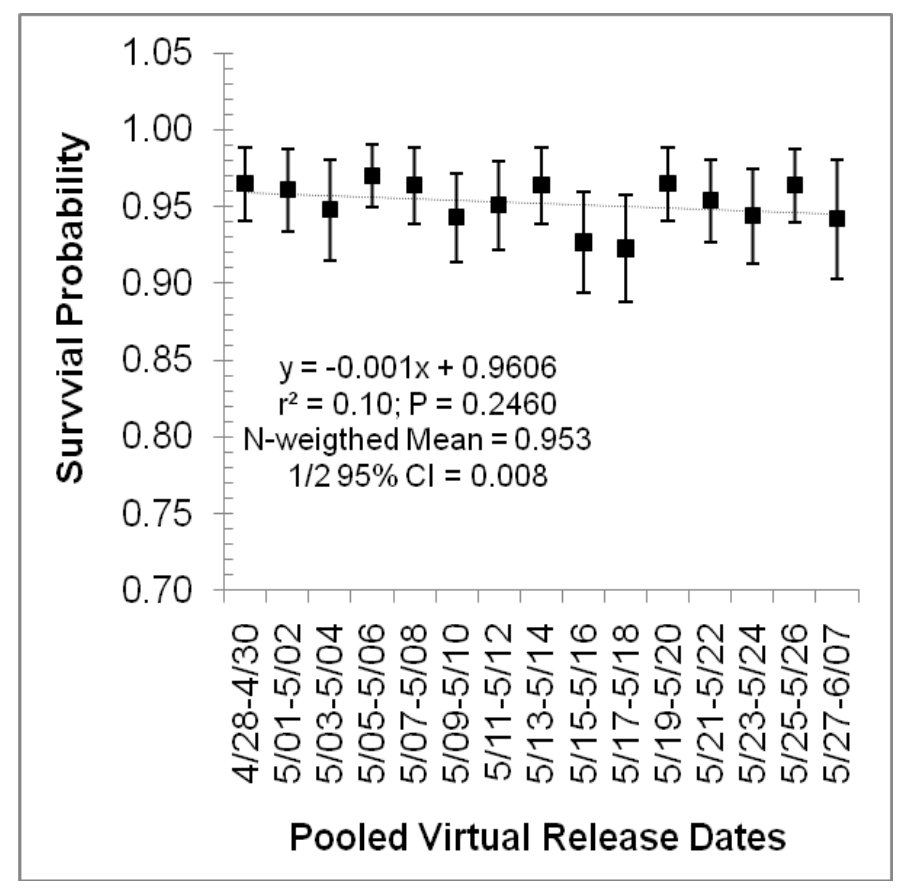

Figure 3.36. Seasonal Trend in Single-Release, JDA-to-TDA Forebay-Passage Survival Probability for STH at JDA in Spring 2009. Vertical bars indicate the extent of individual 95\% confidence intervals; the light gray regression line indicates a slight downward trend with a slope that did not differ significantly from zero; regression statistics, the N-weighted mean, and associated $1 / 295 \%$ confidence intervals are for all data are listed below the points. 
Table 3.22. Single Release Estimates of Survival for STH Smolts Regrouped at the Corresponding Routes at the Dam to Form Virtual Releases During 2009. Survival estimates were based on pooled data.

\begin{tabular}{lcc}
\hline \multicolumn{1}{c}{ Route } & Survival & $\pm 1 / 295 \%$ CI \\
\hline JDA-to-TDA forebay & 0.953 & 0.008 \\
Non-TSW & 0.936 & 0.016 \\
TSW & 0.963 & 0.010 \\
Turbine & 0.824 & 0.080 \\
JBS & 0.966 & 0.014 \\
\hline
\end{tabular}

\subsubsection{Day/Night Trends in Survival Rates}

Survival estimates for STH were generally higher during night than during day regardless of route or condition (Figure 3.37). The day and night difference in turbine passage survival was higher at night (84.1\%) than it was during day (75.0\%) (Figure 3.37).

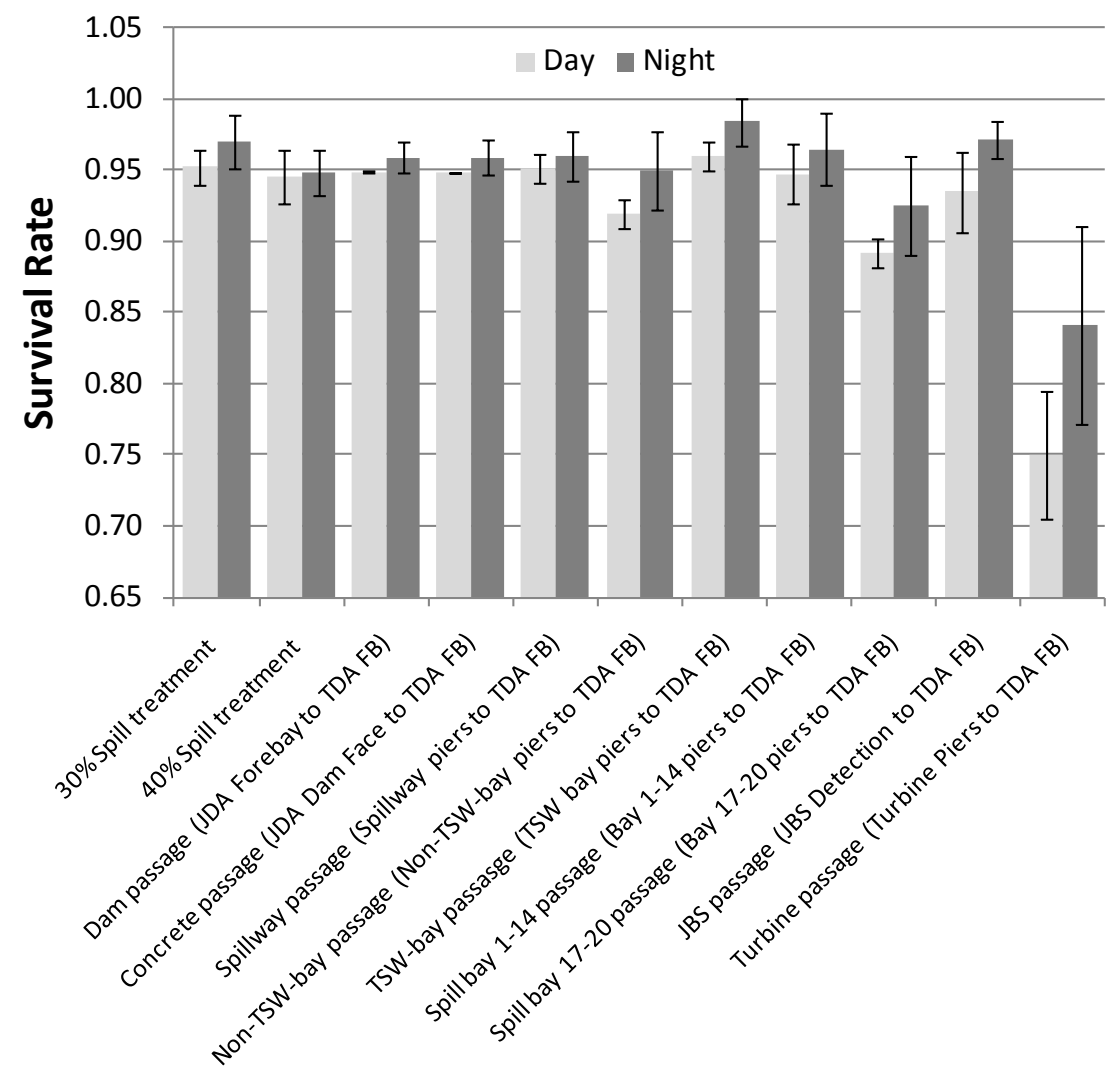

Figure 3.37. Day and Night Single-Release Estimates of STH Survival Rates by Route of Passage During Spring 2009 


\subsubsection{Survival Rates at The Dalles Dam}

Steelhead smolts were released near Roosevelt, Washington ( $\mathrm{rkm} 390$ ), and regrouped on TDA forebay entrance array to create virtual releases for estimating single-release TDA forebay to BON forebay-passage survival rates for TDA. The weighted mean passage survival rate from $2 \mathrm{~km}$ upstream of TDA to the BON forebay was $0.896 \pm 0.012(1 / 295 \% \mathrm{CI})$, and there was no significant temporal trend in rates among virtual releases (Figure 3.38). Detailed capture history and survival results by release are in Appendix C.

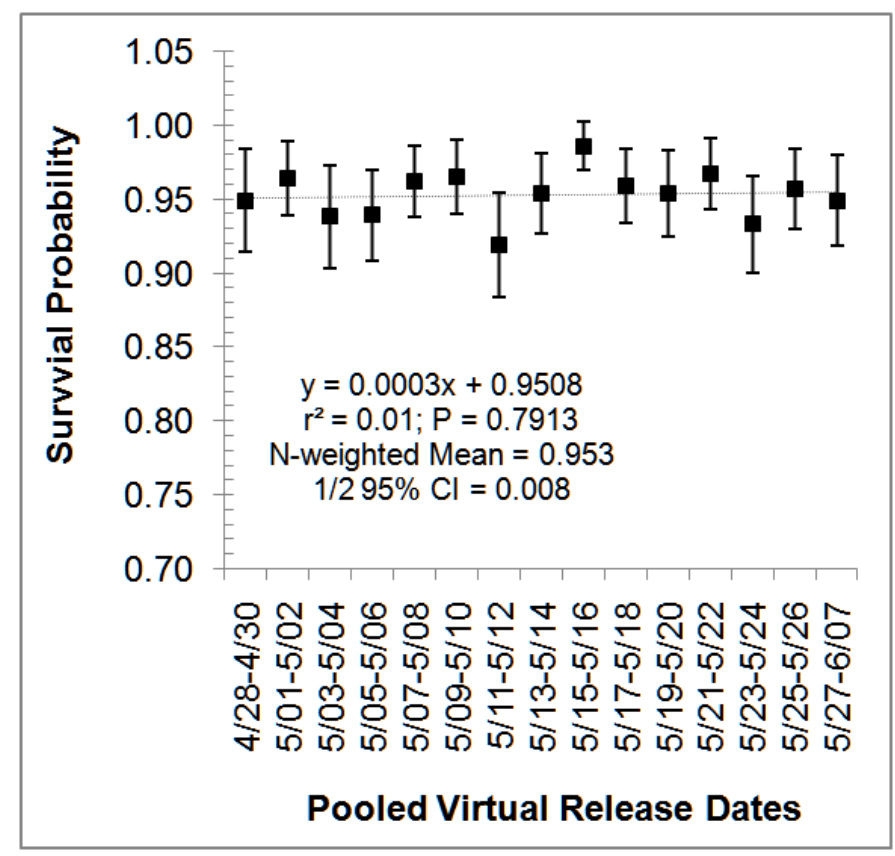

Figure 3.38. Seasonal Trend in Single-Release, TDA Forebay to BON Forebay-Passage Survival Probability for STH at TDA in Spring 2009. Vertical bars indicate the extent of individual 95\% confidence intervals; the light gray regression line indicates a slight upward trend with a slope that did not differ significantly from zero; regression statistics, the $\mathrm{N}$-weighted mean, and associated $1 / 295 \%$ confidence intervals are for all data are listed below the points.

No significant difference was observed in TDA-passage survival for STH smolts passing by six different routes through JDA based on overlap of $1 / 295 \%$ confidence intervals. However, the point estimate of the weighted mean TDA-passage survival estimate for STH smolts was 5\% lower for fish that passed through JDA turbines than it was for fish passing through any other route. The $1 / 295 \%$ confidence interval for turbine passed fish was 2.7 to 5.6 time higher for turbine passed STH than it was for STH passing through other routes (Table 3.23). 
Table 3.23. Single-Release Estimates of TDA-Passage Survival for STH Smolts That Previously Passed Through Six Routes at JDA During 2009

\begin{tabular}{|c|c|c|}
\hline JDA Passage Route & TDA Survival & $1 / 295 \% \mathrm{CI}$ \\
\hline Spillway (TSW bays $15 \& 16$ ) & 0.898 & 0.016 \\
\hline Spillway (All Non-TSW bays) & 0.904 & 0.022 \\
\hline Non-TSW bays 2-14 & 0.905 & 0.029 \\
\hline Non-TSW bays $17-20$ & 0.902 & 0.033 \\
\hline Turbines & 0.838 & 0.090 \\
\hline JBS & 0.888 & 0.025 \\
\hline
\end{tabular}

\subsubsection{Passage Metrics and Distribution}

Steelhead smolt, passage efficiency and effectiveness, powerhouse and spillway-passage, the effect of spill conditions on passage survival rates and passage proportions among routes, and day/night trends in survival rates and passage efficiencies at JDA during spring 2009 are described in the following sections.

\subsubsection{Passage Efficiency and Effectiveness}

During 2009, estimates of major passage metrics at JDA show that the TSWs passed $50 \%$ of all STH smolts that passed the dam (Table 3.24). The spillway routes passed $76.3 \%$ of all STH smolts that passed JDA. Of the STH smolts passing into the powerhouse, about $89 \%$ were diverted by the intake screens into the JBS. Of total dam passage, only about $3 \%$ of STH smolts passed through turbines. Non-TSW spill bays were only $52 \%$ as efficient as TSW spill bays for passing STH smolts. TSW passage effectiveness (6.8) was three times higher than spillway passage effectiveness (2.24; Table 3.24).

Table 3.24. Estimates of Major Passage Metrics for Yearling STH During Spring 2009

\begin{tabular}{lc}
\hline \multicolumn{1}{c}{ Metric } & Estimate $( \pm 1 / 295 \% \mathrm{CI})$ \\
\hline FPE & $97.39 \pm 0.59 \%$ \\
SPE & $76.28 \pm 1.69 \%$ \\
FGE & $88.98 \pm 2.40 \%$ \\
TSWE & $50.14 \pm 1.99 \%$ \\
JBSE & $21.10 \pm 1.63 \%$ \\
SPEF & $2.24 \pm 0.05$ \\
TSWEF & $6.78 \pm 0.27$ \\
\hline
\end{tabular}

\subsubsection{Powerhouse Horizontal Distribution and the Relationship between Passage and Discharge}

During spring, $89 \%$ of all STH smolts passing into the powerhouse were guided by screens into the JBS (Figure 3.39). A regression of number of tagged STH smolts passing each turbine on unit-specific discharge was highly significant $(\mathrm{P}<0.0001)$ with discharge explaining $64 \%$ of the variation in STH passage (Figure 3.40). 


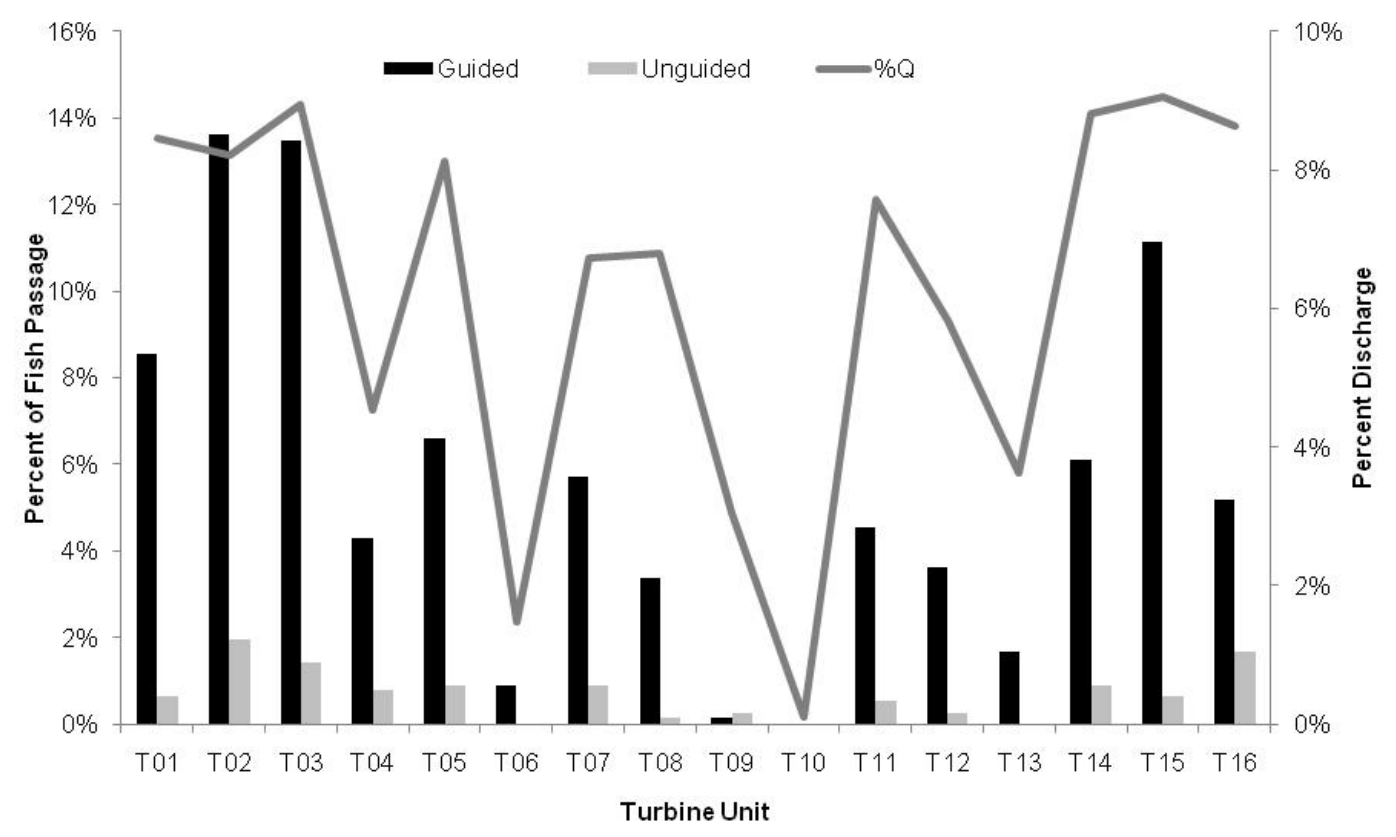

Figure 3.39. Percent Passage for Guided and Unguided STH Smolts and Percent Discharge by Turbine Unit for the John Day Powerhouse During Spring 2009

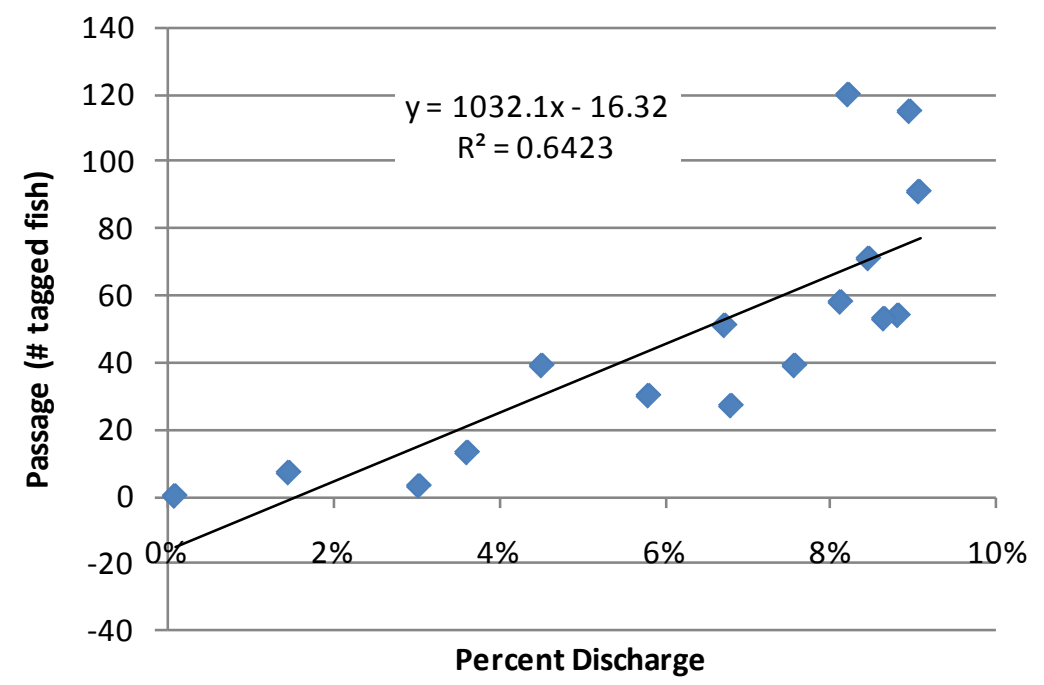

Figure 3.40. Percent Passage for Guided and Unguided STH and Percent Discharge by Turbine Unit for the John Day Powerhouse During Spring 2009

\subsubsection{Spillway Horizontal Distribution}

Among routes through the spillway, TSW spill bays 15 and 16 passed $66.6 \%$ of STH smolts (Figure 3.41). On a per-bay basis, percent passage through an average TSW bay was 33 times higher than that through an average spill bay from spill bays 1 through 14 and 8.3 times higher than that through an average bay from spill bays 17 through 20 (Figure 3.42). 


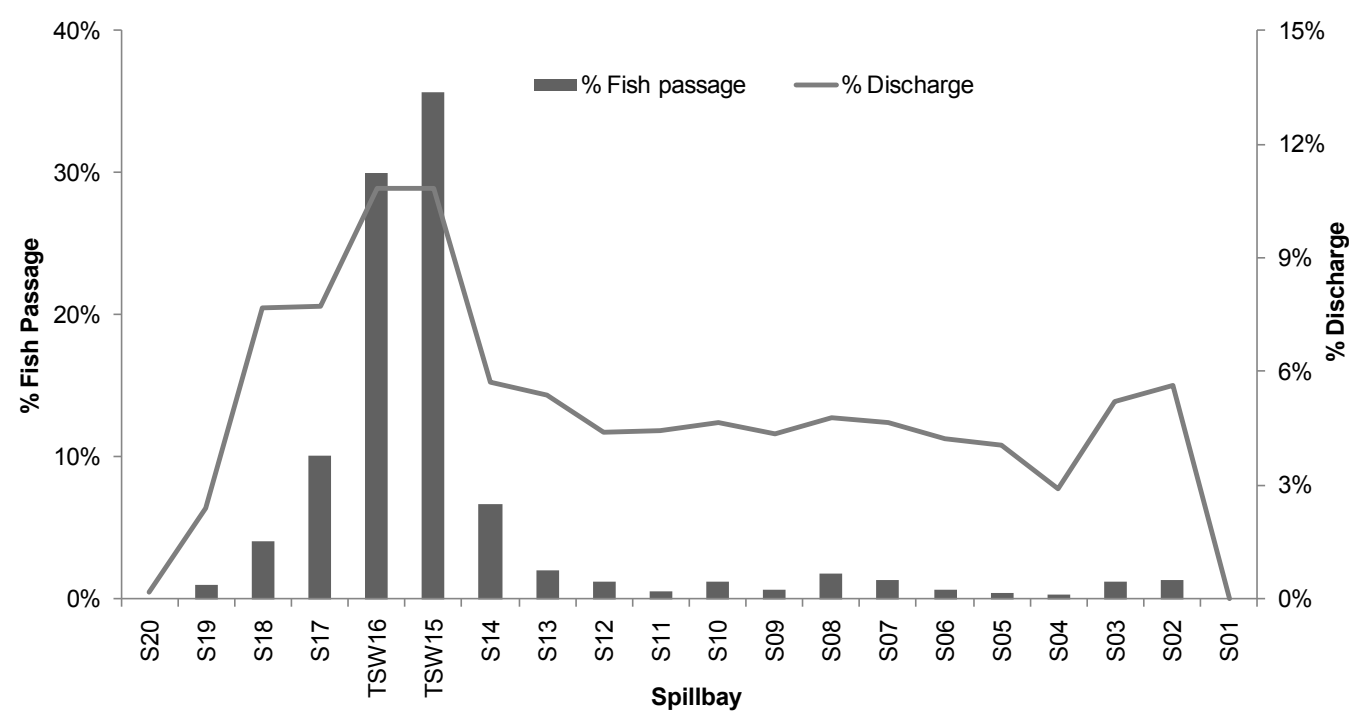

Figure 3.41. Steelhead Passage and Percent Discharge by Spill Bay During 2009

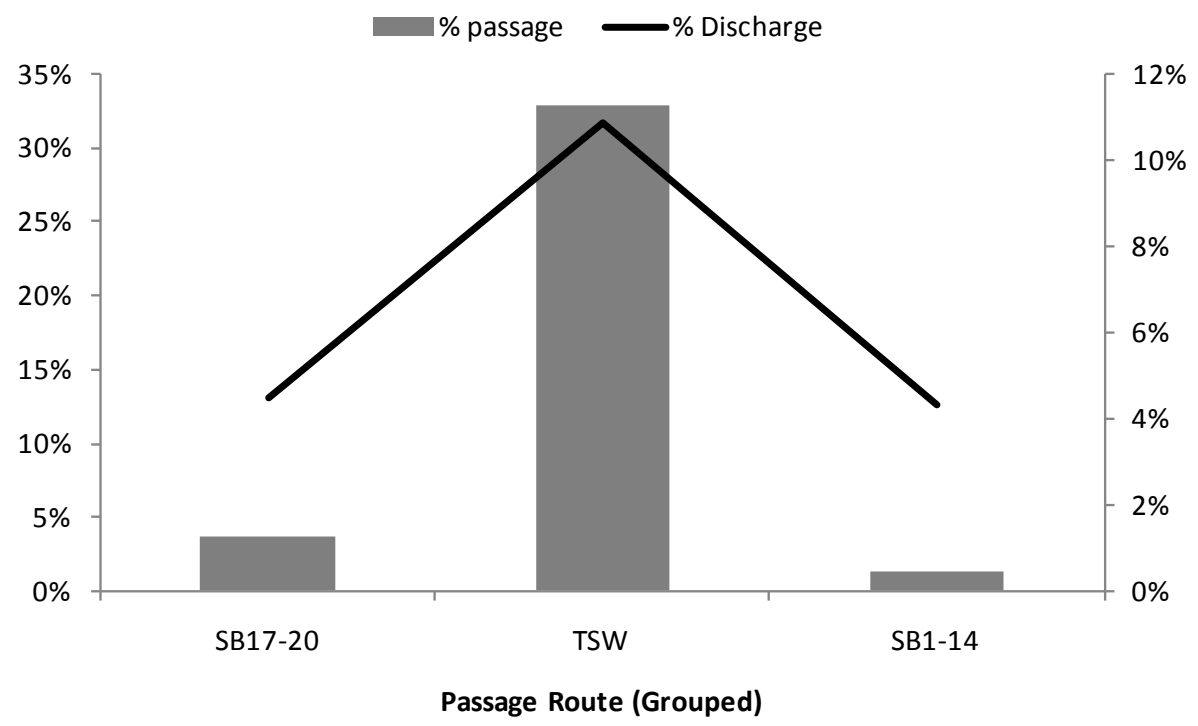

Figure 3.42. Percent Passage of STH Smolts and Discharge for an Average Spill Bay Within Groups of Bays During 2009

\subsubsection{Day/Night Trends in Passage}

The rates of passage of STH smolts were higher at night than during the day at the powerhouse, turbines, and JBS, whereas day passage rates were higher than night passage rates for the entire spillway (Figure 3.43). On a per-bay basis, the TSW had a higher passage rate than other locations within the spillway, and the rate was much higher during the day than it was at night (Figure 3.44). The night passage rate was slightly higher than the day passage rate at non-TSW bays, and differences in day-night trends for TSW and non-TSW spill bays indicate that the predominance of day passage for the entire spillway (Figure 3.43) was mostly due to high daytime passage at TSW bays (Figure 3.44). 


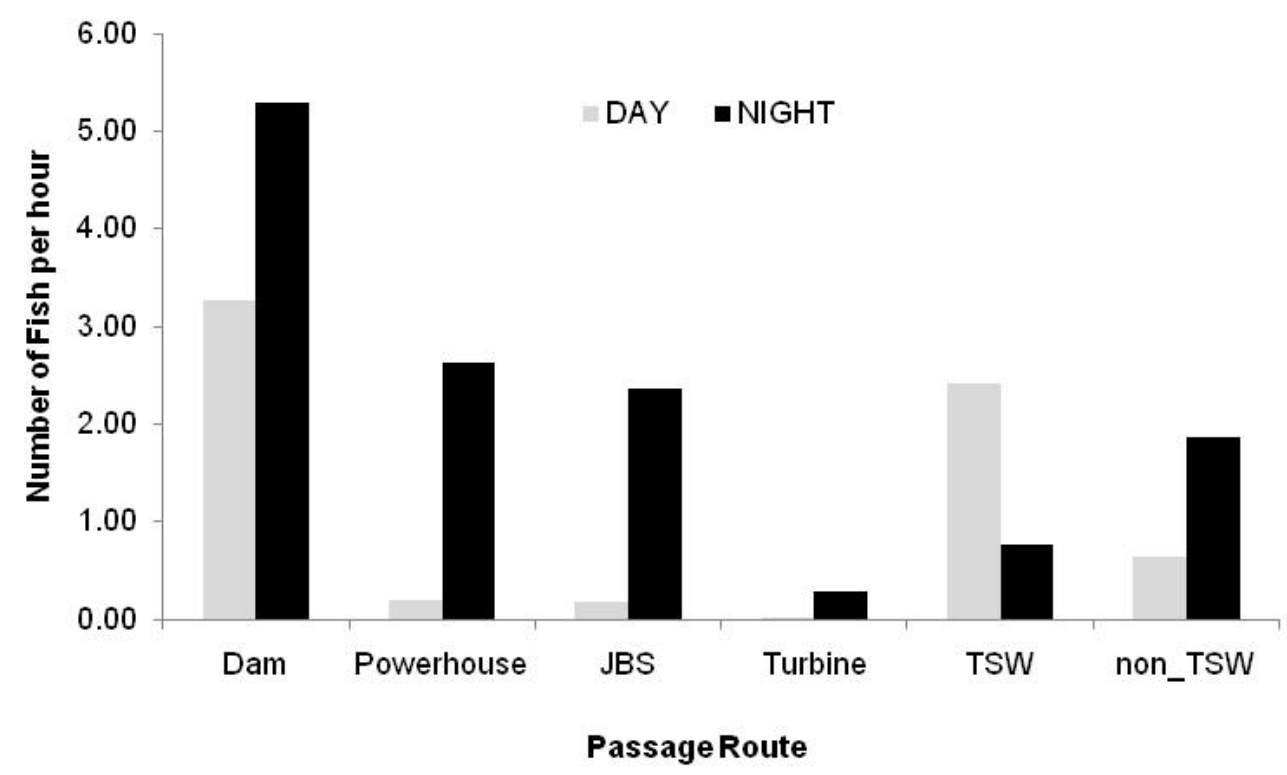

Figure 3.43. Day and Night Passage Rates (number/hour) of STH by Route During Spring 2009

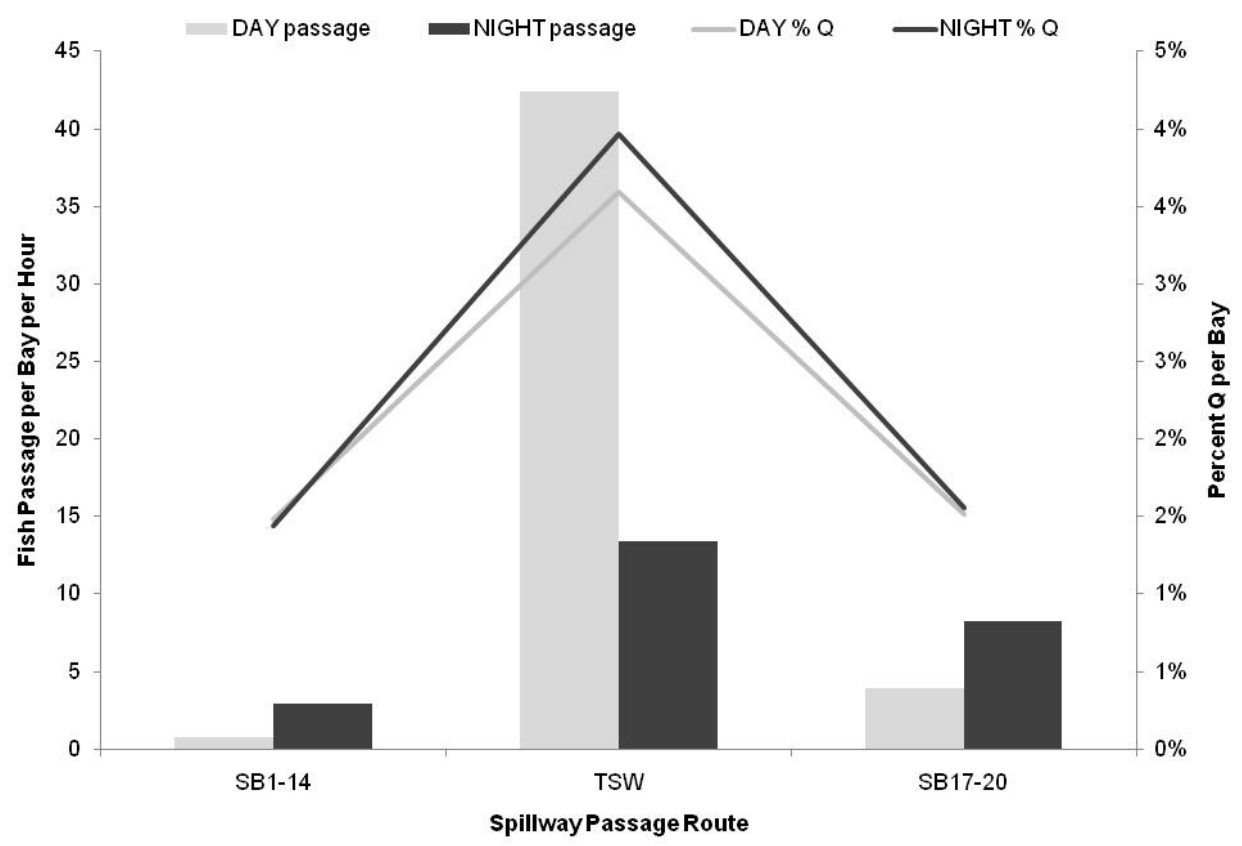

Figure 3.44. Day and Night Passage Rates (number/hour/bay) for STH and Percent Discharge for Groups of Spill Bays

\subsubsection{Fish Behavior}

\subsubsection{Approach and Route of Passage}

The forebay approach pattern for STH was $46 \%$ at the powerhouse, $11 \%$ at the skeleton bays, and $43 \%$ at the spillway (Figure 3.45). Of the tagged STH first detected approaching the powerhouse or 
skeleton bays, 65\% moved north and passed at the spillway. As with CH1, STH approaching at the spillway were more likely to pass through the dam at the spillway (39\% of total approach) than at the powerhouse (3.8\% of total approach).

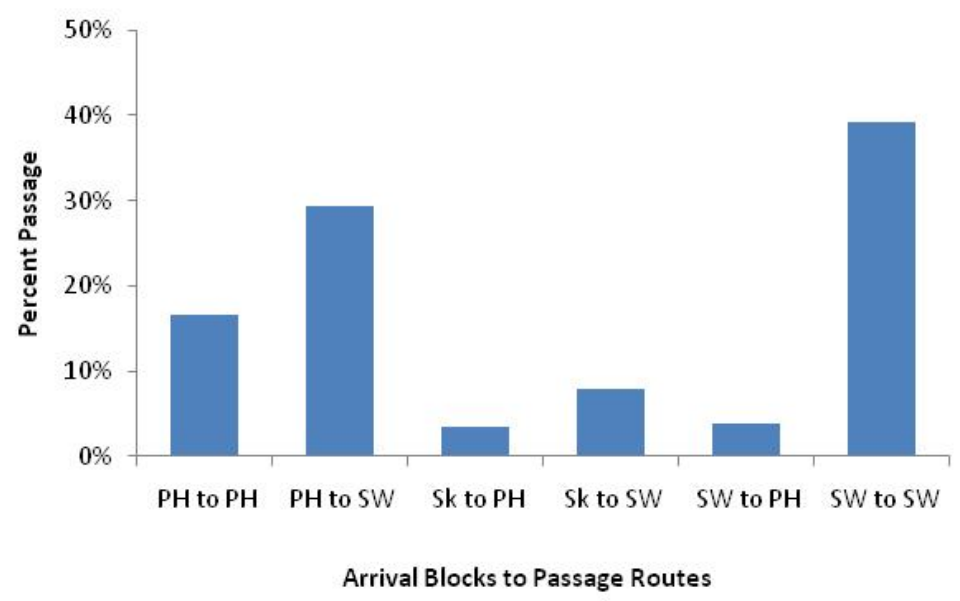

Figure 3.45. Steelhead Percent Passage by Approach and Passage Blocks at JDA During 2009. Abbreviations are as follows: $\mathrm{PH}=$ powerhouse; $\mathrm{Sk}=$ skeleton bay; $\mathrm{SW}=$ spillway.

Of the STH approaching at the powerhouse and skeleton bays in spring, $46 \%$ eventually pass the TSW in spill bays 15 and 16 (Figure 3.46). In contrast, only 12\% of the STH approaching on the powerhouse side passed at spill bays 17-20 even though spill bays 17-20 were between the powerhouse and TSW. Only 6\% of the tagged STH approached the dam in the forebay of the TSWs (Figure 3.46), while $50 \%$ passed there (Table 3.25 ).

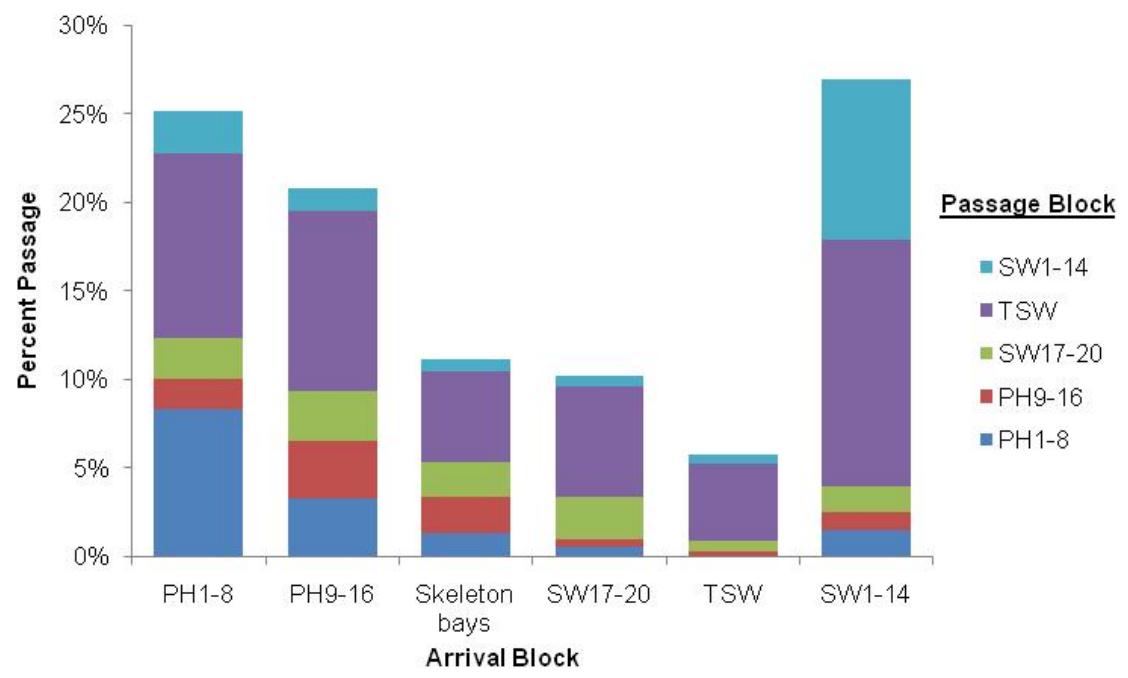

Figure 3.46. Steelhead Approach and Passage Behavior Patterns at JDA During 2009

\subsubsection{Day/Night Behavior Patterns}

Steelhead approaching the powerhouse had a much greater tendency to pass the spillway during the day than they did at night; $55 \%$ during day and $18 \%$ at night (Figure 3.47). The powerhouse was much 
more effective at passing STH that arrived at night, as seen previously with $\mathrm{CH} 1$. The spillway was more effective at retaining approaching STH with 38\% passage during the day and 25\% passage at night.

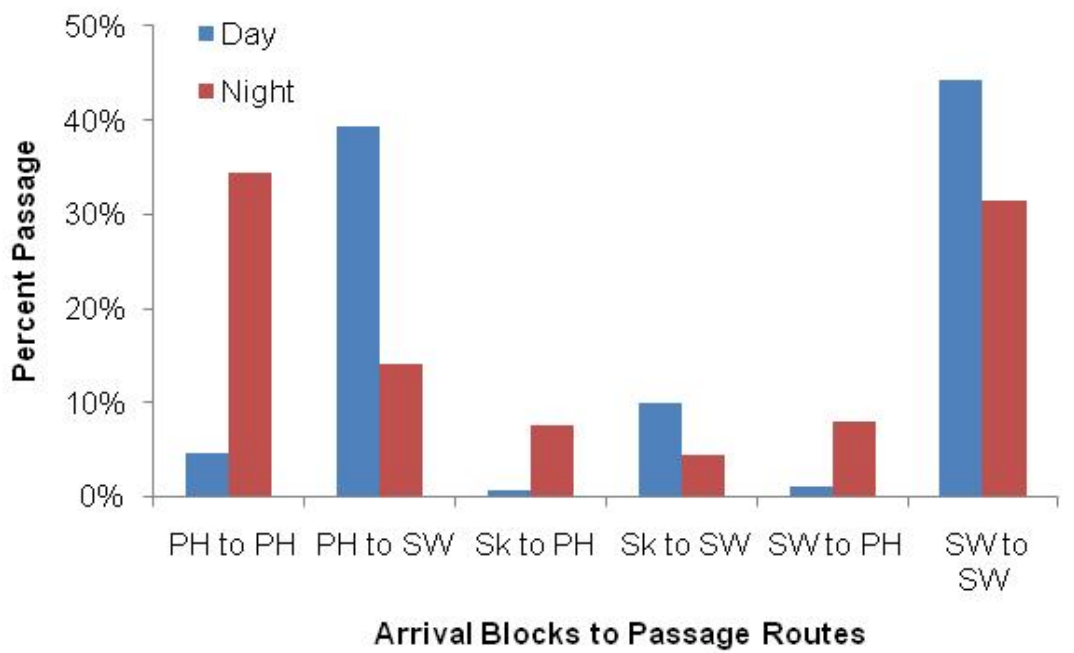

Figure 3.47. Steelhead Approach and Passage Patterns During Day and Night at JDA, 2009. Day/night allocation was defined by when the fish passed the dam.

Most STH arriving at the powerhouse eventually passed through the TSWs during the day (Figure 3.48). This was not the case at night; most $\mathrm{CH} 1$ arriving at the powerhouse also passed there at night (Figure 3.49). Approach and passage behavioral patterns for the spillway were different for day and night; during day, TSW passage predominated while passage at SW1-14 upon approach at the spillway was the common behavior at night (Figures 3.48 and 3.49).

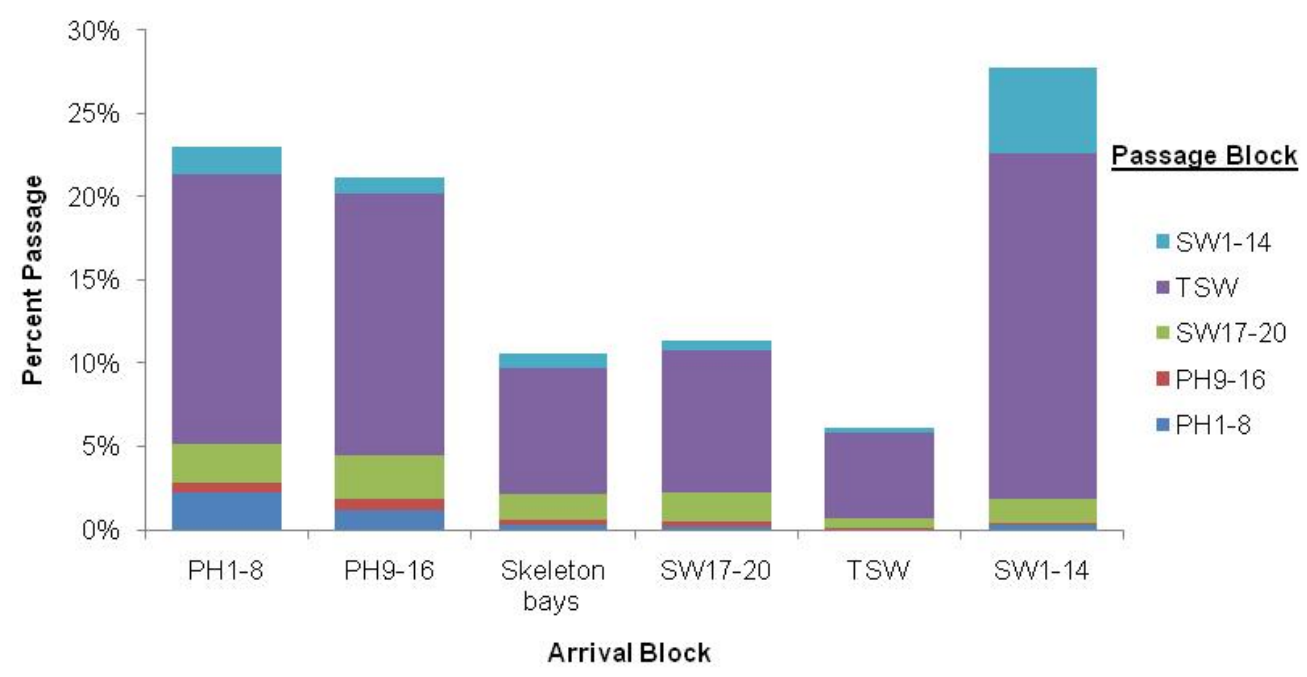

Figure 3.48. Approach and Passage Patterns for STH During Daytime, Spring 2009 


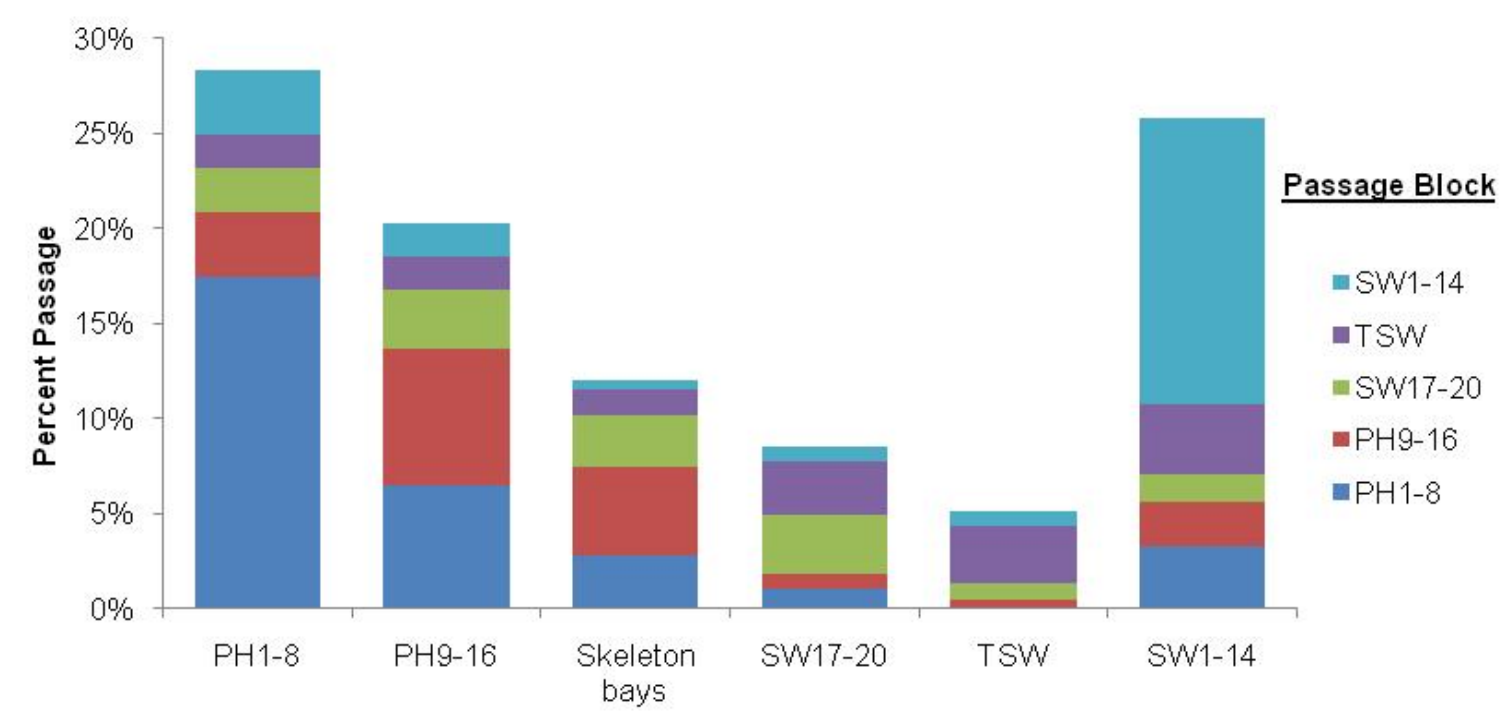

Arrival Block

Figure 3.49. Approach and Passage Patterns for STH During Nighttime, Spring 2009

\subsubsection{Vertical Distribution Behavior Patterns}

The median depths of STH approaching within $75 \mathrm{~m}$ of the powerhouse or skeleton bays were less than $7 \mathrm{~m}$ (Figure 3.50). As with $\mathrm{CH} 1$, median depth decreased as distance to the powerhouse decreased, until the fish were within $5 \mathrm{~m}$ of the dam where depth abruptly increased in front of the powerhouse turbine intakes. For tagged STH approaching the spillway, median depths of detection were within the surface $2 \mathrm{~m}$ of the water column (Figure 3.50).

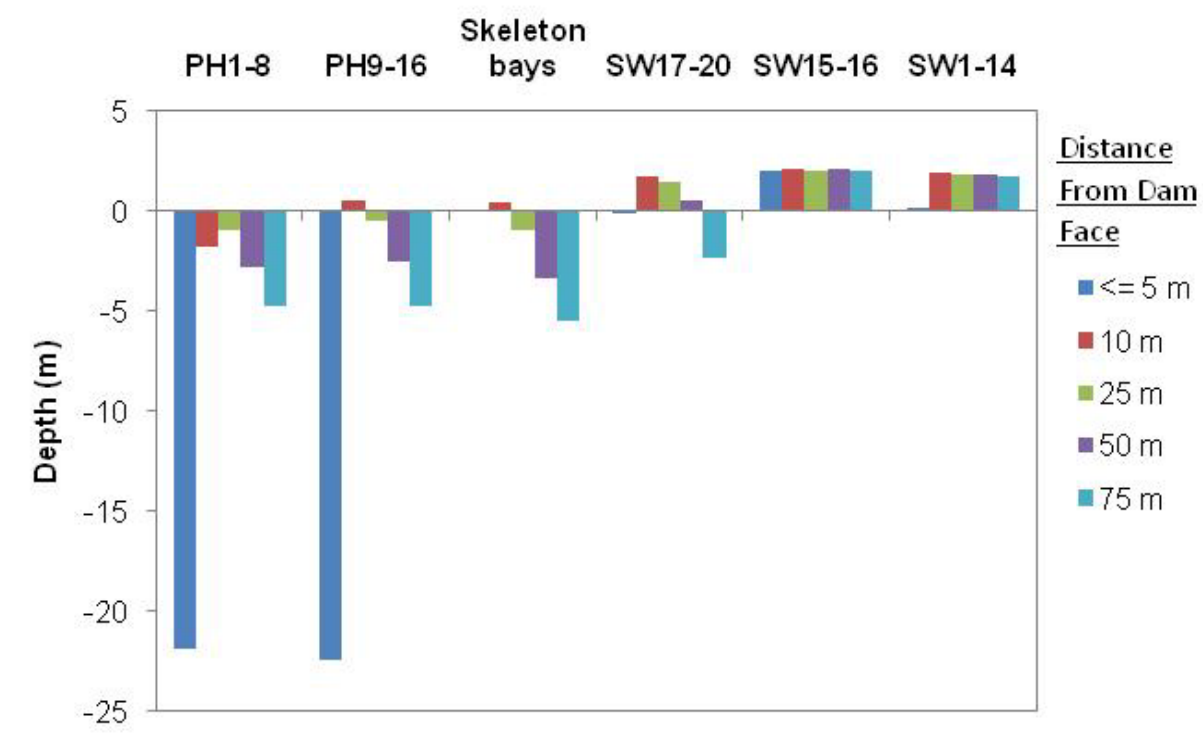

Figure 3.50. Median Depths of Last Detection of Tagged STH at JDA During 2009. Zero depth was referenced to the elevation of the shallow hydrophone deployed on the south side of Turbine Unit 1 at elevation $255.23 \mathrm{ft}$ above MSL. Mean forebay water surface elevation was $263.5 \mathrm{ft}$ above MSL. 
The vertical distribution of STH was 3-5 m deeper during night than day (Figures 3.51 and 3.52). The depths of STH ultimately passing through turbines was about $5 \mathrm{~m}$ greater than the depth of STH routed into the JBS (Figure 3.53).

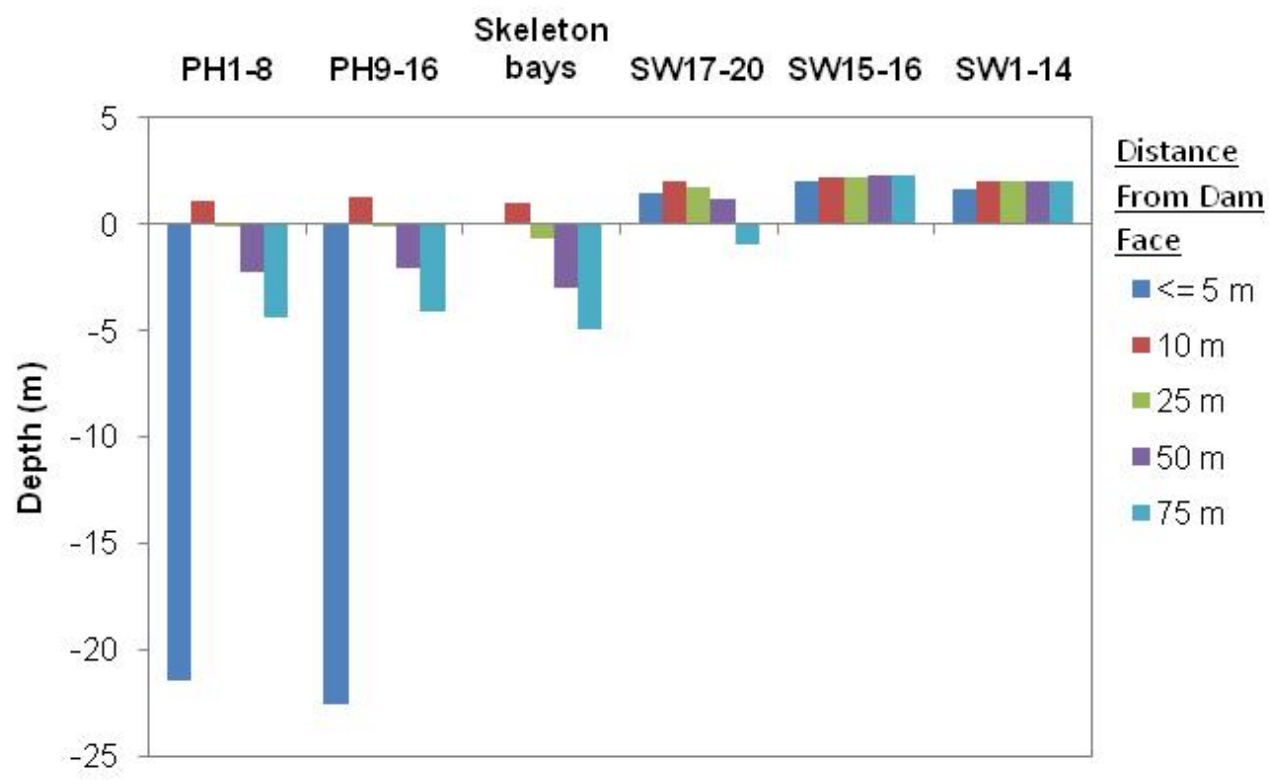

Figure 3.51. Median Depths of Last Detection of Tagged STH Smolts at JDA During the Day.

Zero depth was referenced to the elevation of the shallow hydrophone deployed on the south side of Turbine Unit 1 at elevation $255.23 \mathrm{ft}$ above MSL, and mean forebay water surface elevation was $263.5 \mathrm{ft}$ above MSL.

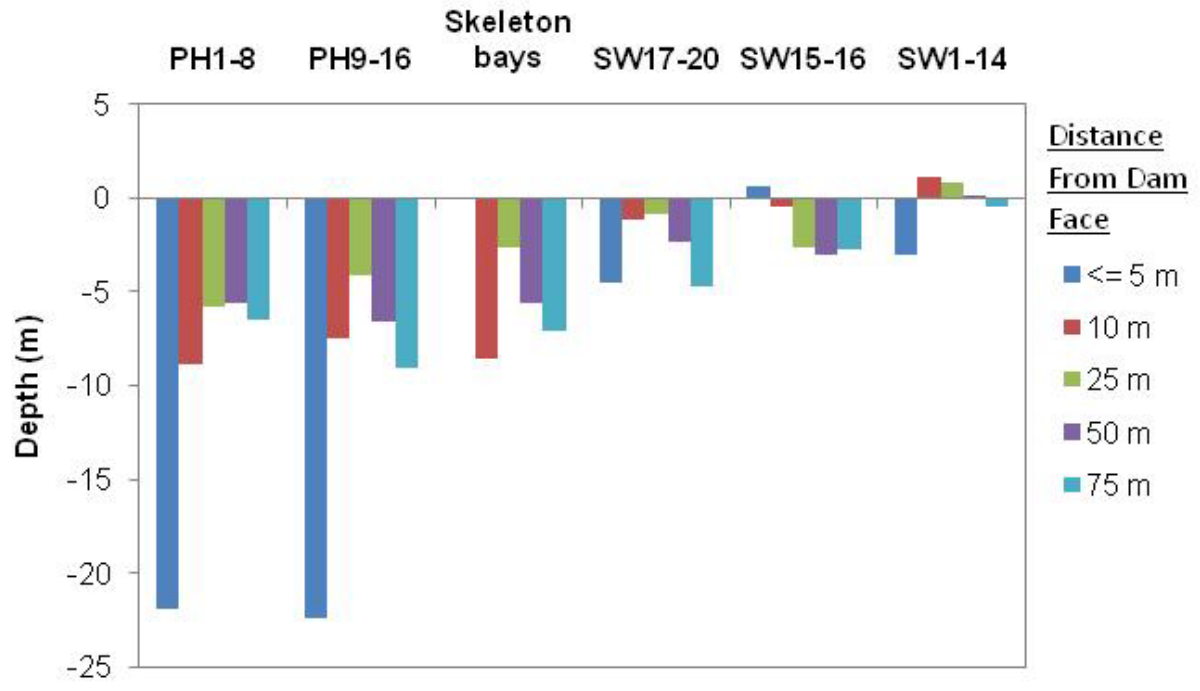

Figure 3.52. Median Depths of Last Detection of Tagged STH Smolts at JDA at Night. Zero depth was referenced to the elevation of the shallow hydrophone deployed on the south side of Turbine Unit 1 at elevation $255.23 \mathrm{ft}$ above MSL, and mean forebay water surface elevation was $263.5 \mathrm{ft}$ above MSL. 


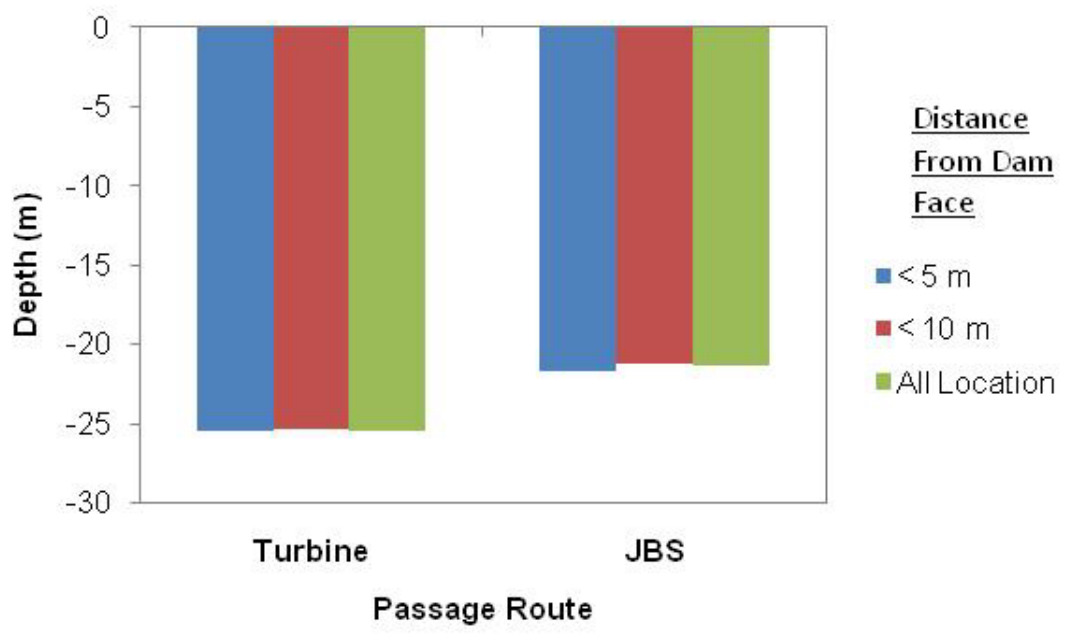

Figure 3.53. Steelhead Median Last-Detection Depths for Turbine- and JBS-Passed Fish

\subsubsection{Travel Times and Forebay Residence Times}

The median travel time between the release station and the JDA forebay array was 29.2 hours for STH implanted with JSATS acoustic transmitters during spring 2009 (Table 3.25). The median travel time until passage through JDA was 5.5 hours for tagged STH detected on the forebay array. Median travel time from the JDA face to the tailrace egress array $10 \mathrm{~km}$ downstream of the dam was 0.5 hours. The median travel time was 10.2 hours from the JDA egress array to TDA forebay array. The median travel time from the TDA forebay to the BON forebay array was 24.6 hours. As with CH1, STH travel times were longest for the JBS route and shortest for the TSW at JDA during spring 2009.

Table 3.25. Distance of Travel and Median and Mean Travel Times ( $\pm 1 / 295 \%$ CI) for Acoustic-Tagged STH Passing Through Specific River Reaches Between Roosevelt, Washington, and the BON Forebay

\begin{tabular}{lrrrr}
\hline & Reach & Median Travel & Mean Travel & \multicolumn{2}{c}{$1 / 295 \%$} \\
& Distance $(\mathrm{km})$ & \multicolumn{1}{c}{ Time $(\mathrm{h})$} & \multicolumn{1}{c}{ Time $(\mathrm{h})$} & \multicolumn{2}{c}{ CI } \\
\hline Roosevelt to JDA Forebay & 39.4 & 29.2 & 32.2 & 0.3 \\
JDA Forebay to JDA Passage & 2 & & & \\
Project & & 5.5 & 8.9 & 0.2 \\
JBS & & 7.5 & 10.2 & 0.4 \\
Turbine & & 6.1 & 13.3 & 2.7 \\
TSW & & 4.8 & 8.2 & 0.2 \\
NON-TSW & & 5.5 & 8.8 & 0.4 \\
JDA Passage to JDA Tailwater & 2.6 & & & \\
Project & & 0.5 & 4.6 & 0.4 \\
JBS & & 4.2 & 19.8 & 1.7 \\
Turbine & & 0.9 & 12.2 & 5.1 \\
TSW & & 0.4 & 0.6 & 0.1 \\
NON-TSW & & 0.4 & 0.6 & 0.0
\end{tabular}


Table 3.25. (contd)

\begin{tabular}{|c|c|c|c|c|}
\hline Reach & Distance $(\mathrm{km})$ & $\begin{array}{c}\text { Median Travel } \\
\text { Time (h) }\end{array}$ & $\begin{array}{c}\text { Mean Travel } \\
\text { Time (h) }\end{array}$ & $\begin{array}{c}1 / 295 \% \\
\text { CI }\end{array}$ \\
\hline JDA Passage to JDA Tailwater $30 \%$ Spill & 2.6 & & & \\
\hline Project & & 0.5 & 5.2 & 0.6 \\
\hline JBS & & 4.1 & 19.2 & 2.1 \\
\hline Turbine & & 0.9 & 15.0 & 7.0 \\
\hline TSW & & 0.4 & 0.5 & 0.0 \\
\hline NON-TSW & & 0.5 & 0.6 & 0.0 \\
\hline JDA Passage to JDA Tailwater $40 \%$ Spill & 2.6 & & & \\
\hline Project & & 0.4 & 3.9 & 0.5 \\
\hline JBS & & 4.8 & 20.8 & 3.1 \\
\hline Turbine & & 0.8 & 5.6 & 4.5 \\
\hline TSW & & 0.4 & 0.7 & 0.3 \\
\hline NON-TSW & & 0.4 & 0.6 & 0.0 \\
\hline JDA Tailwater to TDA Forebay & 34.6 & 10.2 & 11.1 & 0.2 \\
\hline TDA Forebay to BON Forebay & 75.4 & 24.6 & 26.4 & 0.3 \\
\hline
\end{tabular}

Steelhead approaching the spillway but eventually passing through the dam at the powerhouse had a median residence time that was slightly less than 7 hours (Figure 3.54). In contrast, STH approaching the powerhouse but passing at the spillway had a median residence time of about 3 hours (Figure 3.54). This was especially true for STH approaching the spillway but eventually passing the powerhouse during the night (median $\sim 7$ hours) (Figure 3.55). The STH approaching the spillway and passing there had the lowest residence time ( 8 minutes).

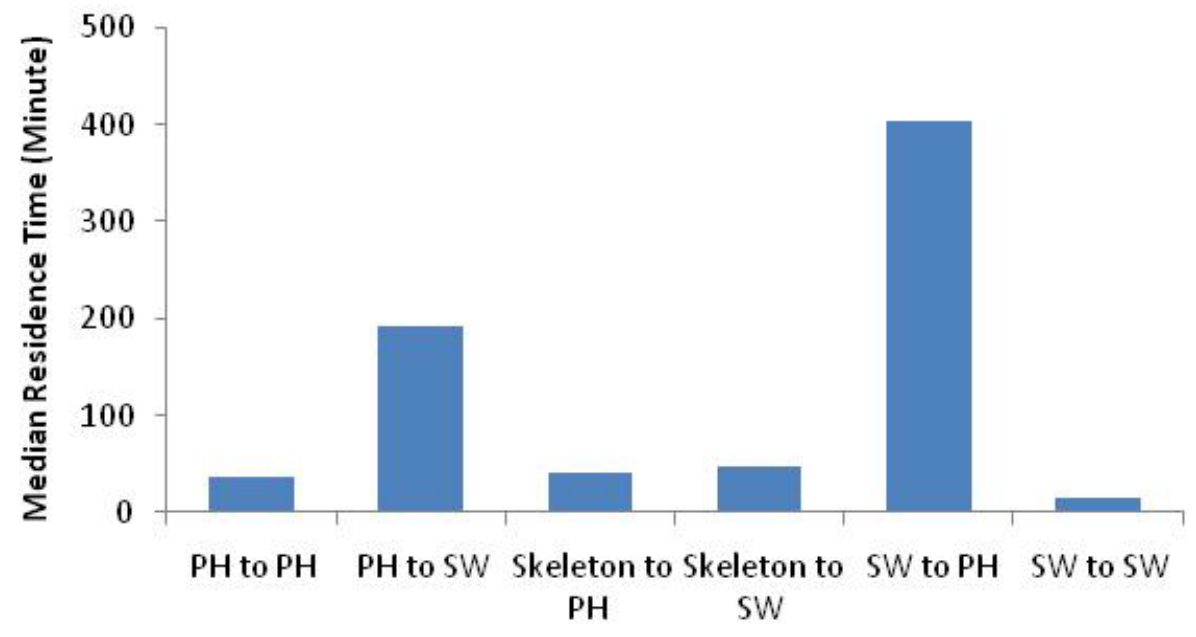

Arrival Block to Passage Route

Figure 3.54. Steelhead Median Passage Times by Approach and Passage Routes During 2009 


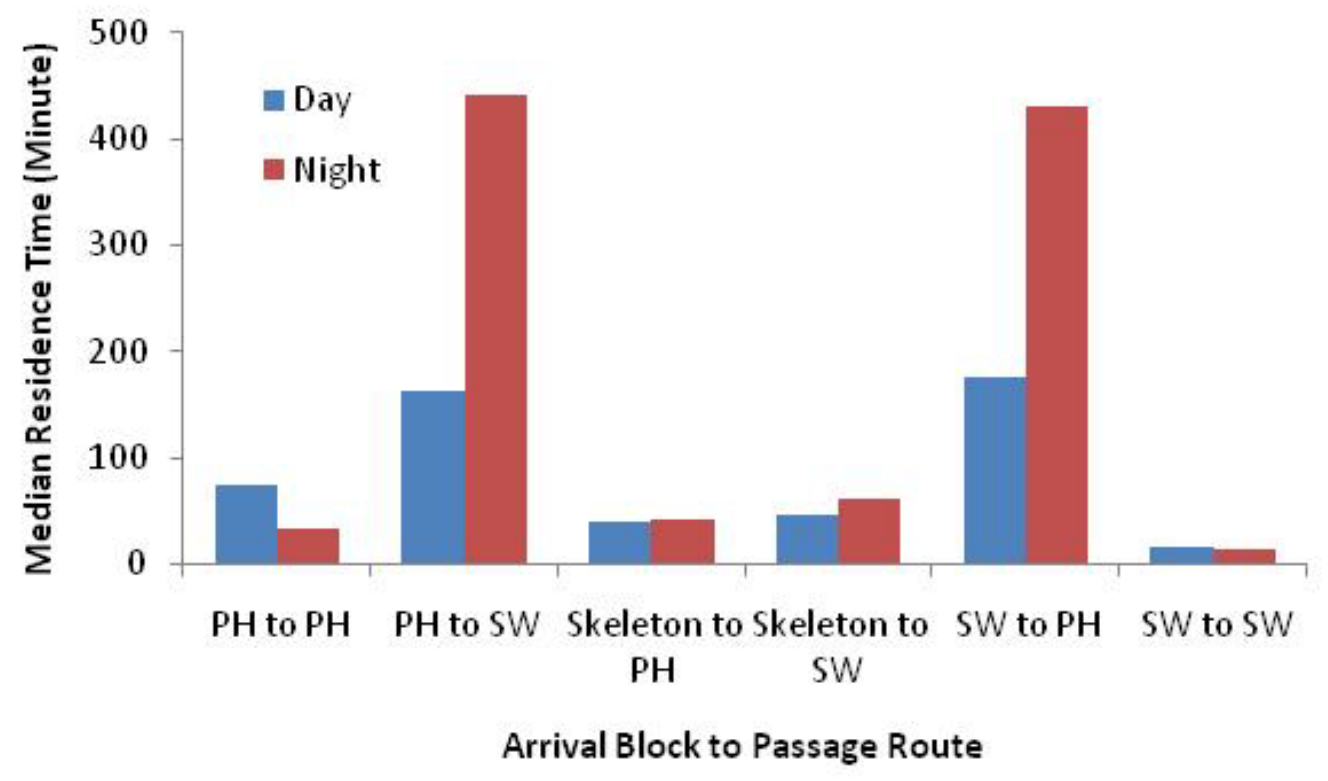

Figure 3.55. Steelhead Diel Median Passage Times at JDA

\subsection{Subyearling Chinook Salmon}

This section contains estimates of survival rates, travel times, passage metrics, and distributions for $\mathrm{CH} 0$ at JDA during spring 2009.

\subsubsection{Effect of Spill Conditions on Fish}

Dam operations met the prescribed spill treatments reasonably well during the last seven blocks and very well during the last five blocks of the summer test (Figure 3.56). Passage survival rates for CH0 were about $84-85 \%$ for both the $30 \%$ and $40 \%$ spill treatments and were not statistically different (Table 3.26). The survival rates were comparable whether five or seven blocks were analyzed. The mean survival rates for each block used in the analysis and the t-test results are provided for the five-block analysis in Tables 3.27 and 3.28 and seven-block analysis in Tables 3.29 and 3.30. 


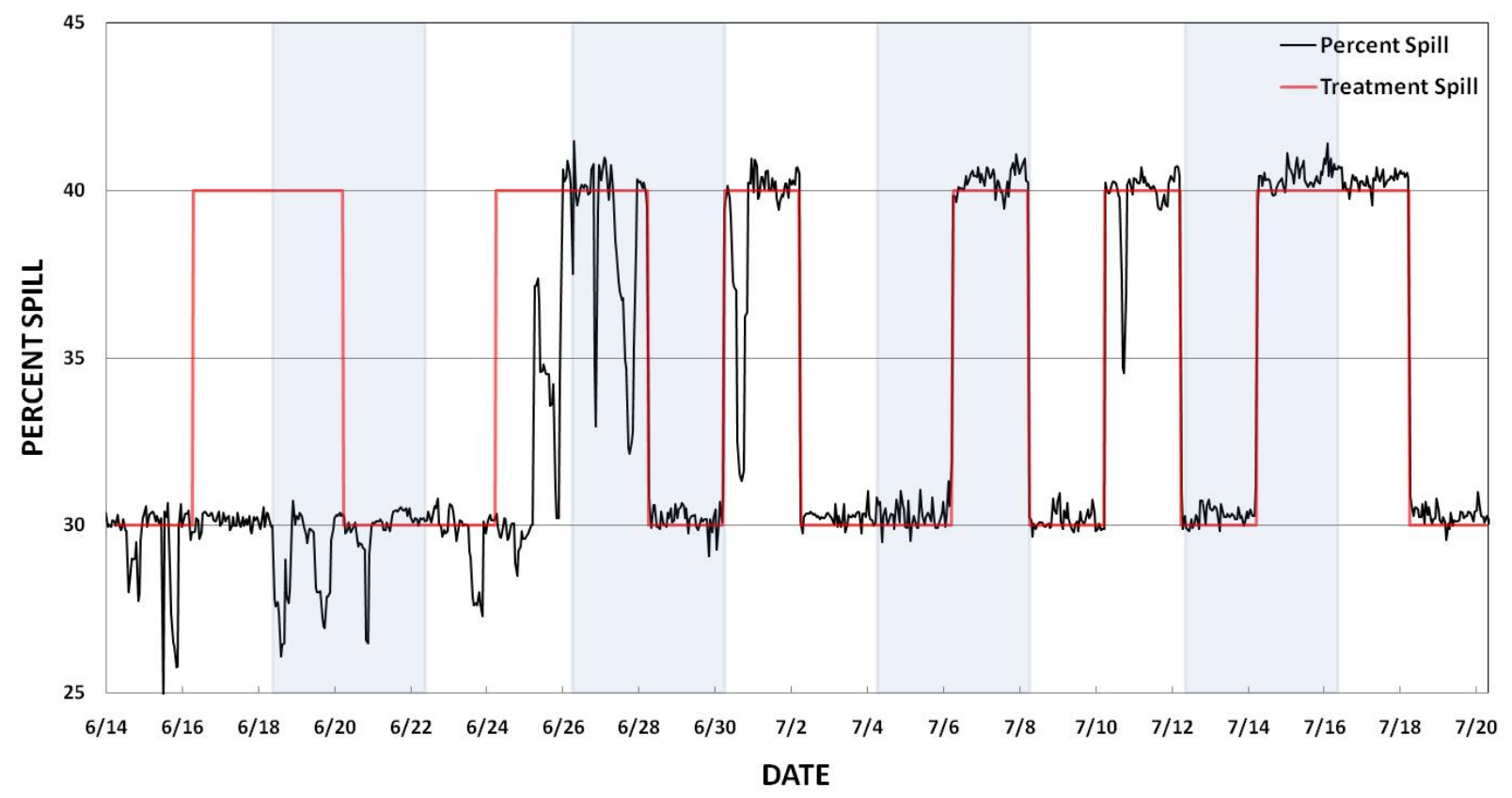

Figure 3.56. Spill Treatments as Prescribed (red line) and Actual Conditions (black line) in Summer

Table 3.26. Single Release Estimates of JDA Forebay-to-TDA Forebay Survival by Spill Condition for CH0 During Summer 2009. A one-tailed, paired t-test produced the listed probabilities and those $<\alpha=0.05$ were considered to be significant.

\begin{tabular}{lccc}
\hline Spill Treatment & $\begin{array}{c}\text { Blocks } \\
\text { Analyzed }\end{array}$ & $\begin{array}{c}\text { Survival Rate } \\
( \pm 1 / 295 \% \mathrm{CI})\end{array}$ & $\begin{array}{c}\text { One Tailed } \\
\text { Probability (P) }\end{array}$ \\
\hline 30\% Spill & 5 & $0.851 \pm 0.042$ & 0.4269 \\
$40 \%$ Spill & 5 & $0.855 \pm 0.048$ & \\
$30 \%$ Spill & 7 & $0.842 \pm 0.040$ & 0.4535 \\
$40 \%$ Spill & 7 & $0.840 \pm 0.051$ & \\
\hline
\end{tabular}

Table 3.27. Estimates of JDA Forebay-to-TDA Forebay-Passage Survival Rates by Two-Day Block and Spill Treatment for CH0, for First Five Blocks, During Spring 2009

\begin{tabular}{ccccc}
\hline Block & $30 \%$ Spill & $1 / 295 \%$ CI & $40 \%$ Spill & $1 / 295 \%$ CI \\
\hline 1 & 0.840 & 0.055 & 0.905 & 0.045 \\
2 & 0.832 & 0.061 & 0.888 & 0.039 \\
3 & 0.801 & 0.067 & 0.779 & 0.049 \\
4 & 0.847 & 0.053 & 0.838 & 0.047 \\
5 & 0.793 & 0.061 & 0.763 & 0.049 \\
\hline
\end{tabular}


Table 3.28. Results of a One-Tailed, Paired T-Test Comparing Estimates of JDA Forebay-to-TDA Forebay-Passage Survival Rates by Two-Day Block and Spill Treatment for CH0, for First Five Blocks, During Spring 2009

\begin{tabular}{lrr}
\hline & $30 \%$ Spill & \multicolumn{1}{c}{$40 \%$ Spill } \\
\hline Mean & 0.8226 & 0.8346 \\
Variance & 0.000582 & 0.004009 \\
Observations & 5 & 5 \\
Pearson Correlation & 0.839395 & \\
Hypothesized Mean Difference & 0 & \\
df & 4 & \\
t Stat & -0.59606 & \\
$\mathrm{P}(\mathrm{T}<=\mathrm{t})$ one-tail & 0.291612 & \\
$\mathrm{t}$ Critical one-tail & 2.131847 & \\
$\mathrm{P}(\mathrm{T}<=\mathrm{t})$ two-tail & 0.583224 & \\
$\mathrm{t}$ Critical two-tail & 2.776445 & \\
\hline
\end{tabular}

Table 3.29. Estimates of JDA Forebay to TDA Forebay-Passage Survival Rates by Two-Day Block and Spill Treatment for CH0, for Seven Blocks, During Spring 2009

\begin{tabular}{ccccc}
\hline Block & $30 \%$ Spill & $1 / 295 \%$ CI & $40 \%$ Spill & $1 / 295 \%$ CI \\
\hline 1 & 0.914 & 0.037 & 0.850 & 0.039 \\
2 & 0.866 & 0.045 & 0.855 & 0.047 \\
3 & 0.840 & 0.055 & 0.905 & 0.045 \\
4 & 0.832 & 0.061 & 0.888 & 0.039 \\
5 & 0.801 & 0.067 & 0.779 & 0.049 \\
6 & 0.847 & 0.053 & 0.838 & 0.047 \\
7 & 0.793 & 0.061 & 0.763 & 0.049 \\
\hline
\end{tabular}

Table 3.30. Results of a One-Tailed, Paired T-Test Comparing Estimates of JDA Forebay to TDA Forebay-Passage Survival Rates by Two-Day Block and Spill Treatment for CH0, for Seven Blocks, During Spring 2009

\begin{tabular}{lrr}
\hline & $30 \%$ Spill & \multicolumn{1}{r}{$40 \%$ Spill } \\
\hline Mean & 0.841857 & 0.839714 \\
Variance & 0.001662 & 0.002751 \\
Observations & 7 & 7 \\
Pearson Correlation & 0.524866 & \\
Hypothesized Mean Difference & 0 & \\
df & 6 &
\end{tabular}


Table 3.30. (contd)

\begin{tabular}{lrr}
\hline & $30 \%$ Spill & $40 \%$ Spill \\
\hline $\mathrm{t}$ Stat & 0.121749 & \\
$\mathrm{P}(\mathrm{T}<=\mathrm{t})$ one-tail & 0.453537 \\
$\mathrm{t}$ Critical one-tail & 1.94318 \\
$\mathrm{P}(\mathrm{T}<=\mathrm{t})$ two-tail & 0.907073 \\
$\mathrm{t}$ Critical two-tail & 2.446912 \\
\hline
\end{tabular}

Estimates of the major fish-passage metrics for CH0 during 2009 were not statistically different between $30 \%$ and $40 \%$ spill treatments, except for JBSE, which was significantly higher during $30 \%$ spill than $40 \%$ spill (Table 3.31). Fish-passage efficiency and SPE were 2.54 and 6.36 percentage points higher for $40 \%$ than $30 \%$ spill, respectively.

Table 3.31. Estimates of Major Passage Metrics by Spill Treatment for CH0 During Summer 2009. *A one-tailed, paired t-test produced the listed probabilities and those $<\alpha=0.05$ were considered to be significant.

\begin{tabular}{lccc}
\hline Metric & Spill Treatment & Estimate $( \pm 1 / 295 \% \mathrm{CI})$ & T-Test Probability \\
\hline \multirow{2}{*}{ FPE } & $30 \%$ & $83.07 \pm 2.22 \%$ & 0.2485 \\
& $40 \%$ & $85.61 \pm 2.15 \%$ & \\
SPE & $30 \%$ & $69.68 \pm 2.92 \%$ & 0.1212 \\
& $40 \%$ & $76.04 \pm 2.44 \%$ & \\
FGE & $30 \%$ & $45.09 \pm 6.95 \%$ & 0.2185 \\
& $40 \%$ & $39.68 \pm 6.46 \%$ & \\
TSWE & $30 \%$ & $\mathrm{NA}$ & $\mathrm{NA}$ \\
& $40 \%$ & $\mathrm{NA}$ & \multirow{2}{*}{$0.0225^{*}$} \\
JBSE & $30 \%$ & $13.77 \pm 1.72 \%$ & \\
& $40 \%$ & $9.61 \pm 1.06 \%$ & 0.1308 \\
SEF & $30 \%$ & $2.32 \pm 0.10$ & \\
& $40 \%$ & $2.11 \pm 0.07$ & $\mathrm{NA}$ \\
\multirow{2}{*}{ TSWEF } & $30 \%$ & $\mathrm{NA}$ & \\
\hline
\end{tabular}

\subsubsection{Survival Rates}

The JDA and TDA estimated survival rates and detection histories for $\mathrm{CH} 0$ are described in the following sections. Capture histories are presented in Appendix C. 


\subsubsection{Seasonal Trends, JDA to TDA Forebay-Passage, and Route-Specific Survival Rates}

The single-release estimate of the JDA to TDA forebay-passage survival / residualization rate for $\mathrm{CH} 0$ smolts was $0.839 \pm 0.014(1 / 295 \% \mathrm{CI})$, and there was a significant decrease in the combined rate during the summer migration (Figure 3.57). The highest route-specific point estimate was for JBS-passed smolts at $0.908 \pm 0.031(1 / 295 \% \mathrm{CI})$ followed by smolts passing through the spillway through non-TSW bays $0.847 \pm 0.016(1 / 295 \% \mathrm{CI})$ and smolts passing through turbines $(0.749 \pm 0.039$; Table 3.32$)$. Detailed capture history and survival results by release date are in Appendix C.

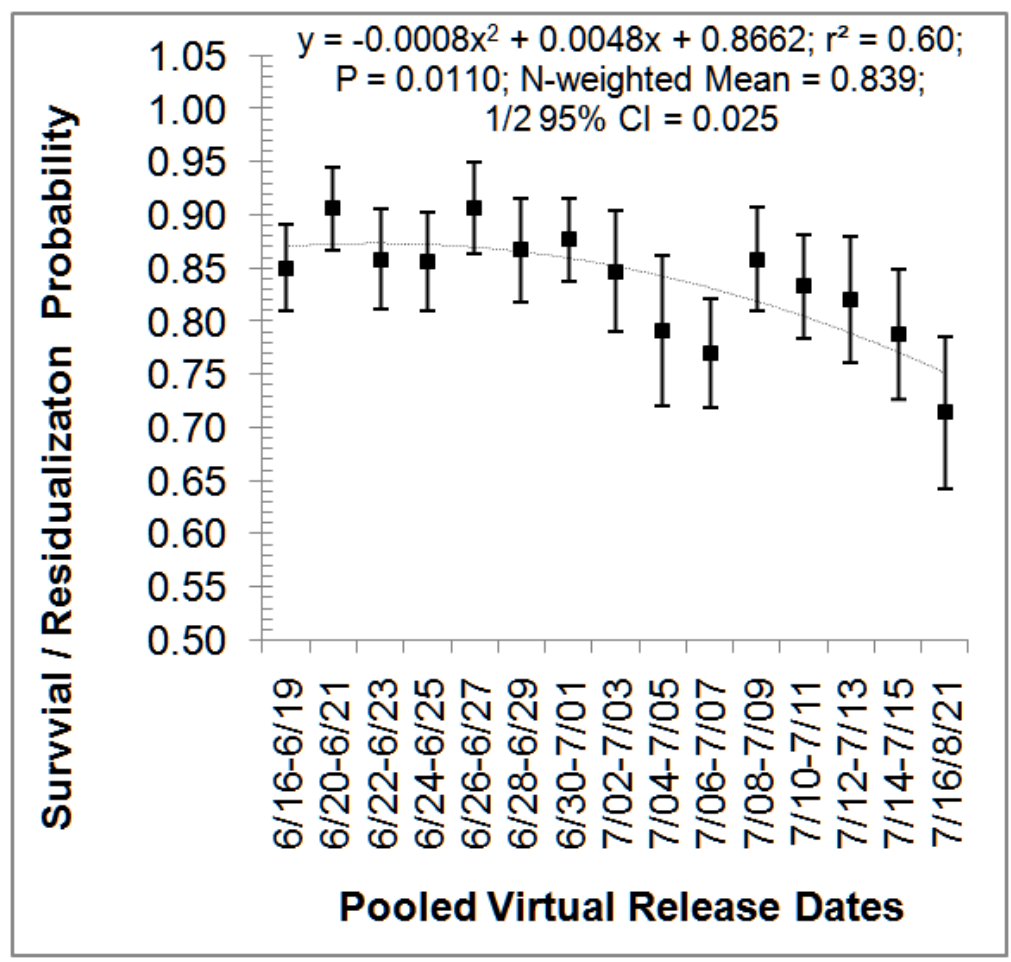

Figure 3.57. Seasonal Trend in Single-Release, Combined JDA to TDA Forebay-Passage Survival and Residualization Probability for CH0 at JDA in Summer 2009. Vertical bars indicate the extent of individual 95\% confidence intervals; the light gray regression line indicates a significant downward trend; regression statistics, the N-weighted mean, and associated $1 / 295 \%$ confidence intervals are for all data are listed above the points.

Table 3.32. Single-Release Estimates of Survival for Subyearling Chinook Smolts in Virtual Release at JDA Based on Three Downstream Arrays During 2009. Survival estimates were based on pooled data.

\begin{tabular}{lcc}
\hline \multicolumn{1}{c}{ Route } & Survival & $\pm 1 / 295 \% \mathrm{CI}$ \\
\hline JDA to TDA forebay & 0.839 & 0.014 \\
Non-TSW & 0.847 & 0.016 \\
TSW & NA & NA \\
Turbine & 0.749 & 0.039 \\
JBS & 0.908 & 0.031 \\
\hline
\end{tabular}




\subsubsection{Day/Night Trends in Survival Rates}

The survival rate of $\mathrm{CH} 0$ was higher at night than during the day for smolts passing JDA, turbines, JBS, spillway to the TDA forebay (Figure 3.58). In fact, the high day/night survival rate was for CH0 passing the JBS during night, while the lowest was for daytime turbine passage.

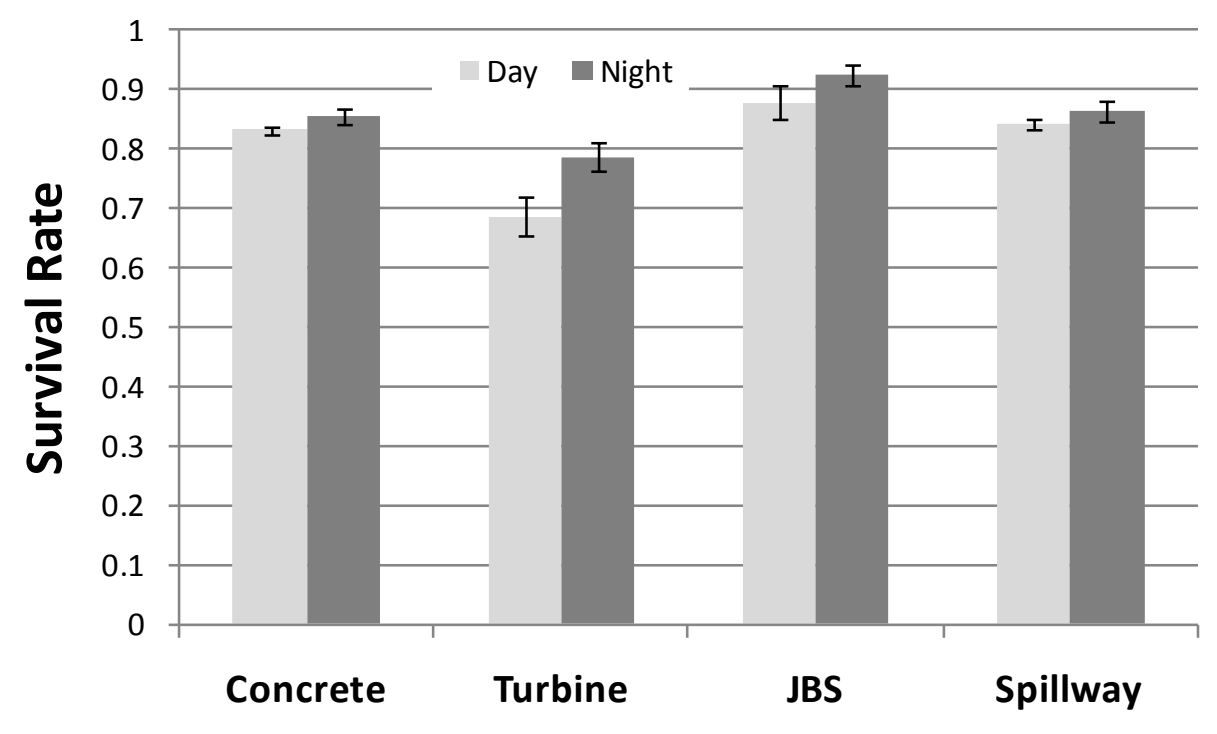

Figure 3.58. Day and Night Single-Release Estimates of CH0 Survival Rates by Route of Passage During Summer 2009

\subsubsection{Survival Rates at The Dalles Dam}

Subyearling Chinook salmon smolts were released near Roosevelt, Washington (rkm 390), in summer, and regrouped on TDA forebay entrance array to create virtual releases for estimating passage survival rates from TDA forebay to BON forebay. The weighted mean dam-passage survival and residualization rate from $2 \mathrm{~km}$ upstream of TDA to the BON forebay was $0.639 \pm 0.020(1 / 295 \% \mathrm{CI})$, and there was a highly significant decline in survival rates among virtual releases as summer progressed (Figure 3.59). Detailed capture history and survival results by release are in Appendix C. 


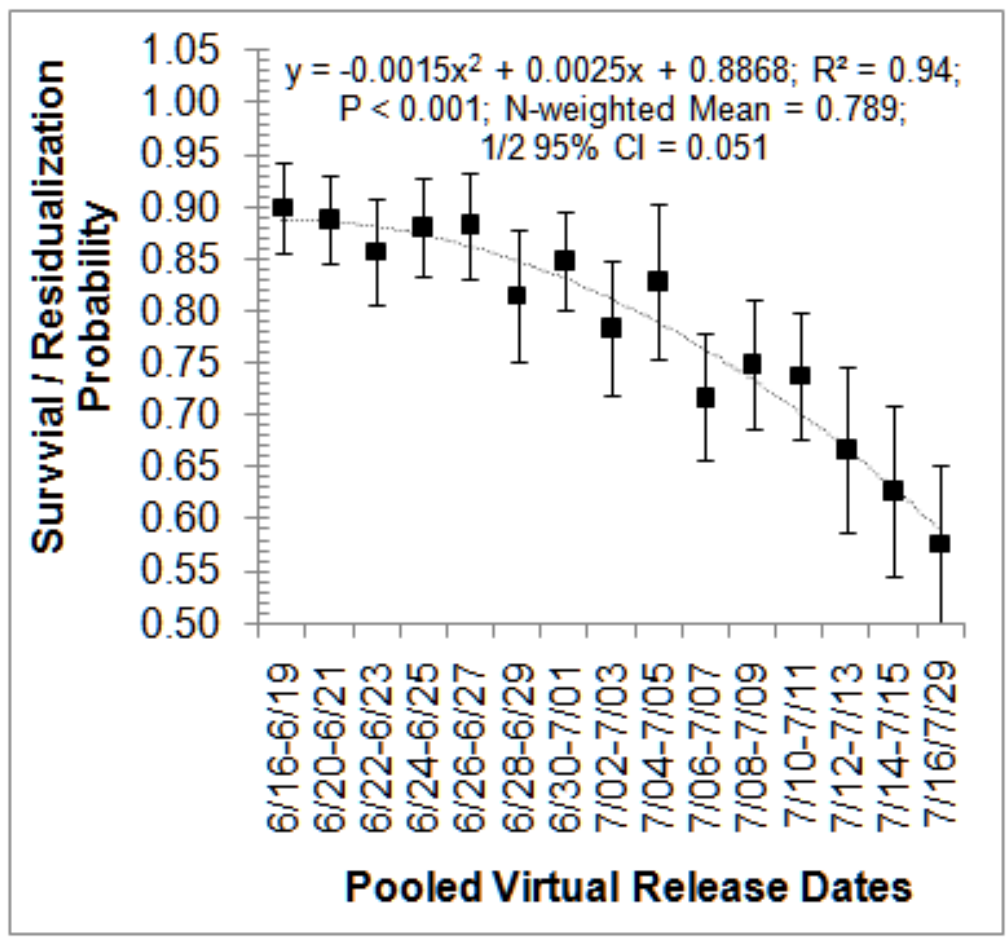

Figure 3.59. Seasonal Trend in Single-Release, Passage Survival/Residualization Probability for CH0 at TDA in Summer 2009. Vertical bars indicate the extent of individual 95\% confidence intervals; the light gray regression line indicates a significant downward trend; the Nweighted mean and associated $1 / 295 \%$ confidence intervals are for all data collected during this migration.

The TDA-passage survival / residualization for $\mathrm{CH0}$ smolts that previously passed through turbines at JDA was significantly lower than the TDA-passage survival for $\mathrm{CH} 0$ smolts that previously passed through the JDA spillway or JBS (Table 3.33).

Table 3.33. Single-Release Estimates of TDA-Passage Survival/Residualization for CH0 That Passed Through Three Available Routes at JDA in Summer 2009

\begin{tabular}{lll}
\hline \multicolumn{1}{c}{ JDA Passage Route } & TDA Survival/Residualization & $1 / 295 \%$ CI \\
\hline Spillway (All Non-TSW bays) & 0.650 & 0.022 \\
Turbines & 0.555 & 0.053 \\
JBS & 0.670 & 0.053 \\
\hline
\end{tabular}

\subsubsection{Passage Metrics and Distribution}

Passage efficiency and effectiveness, powerhouse and spillway passage, the effect of spill conditions on passage survival rate and fish-passage proportions among routes, and diel trends in survival rates and passage efficiencies for acoustic tagged $\mathrm{CHO}$ at JDA during 2009 are described below. 


\subsubsection{Passage Efficiency and Effectiveness}

During 2009, FPE for $\mathrm{CH} 0$ was $84.5 \%$, with $11.3 \%$ of total dam passage guided by in-turbine screens to the JBS and $73.2 \%$ passing through the spillway (Table 3.34). Fish guidance efficiency of the inturbine screen system was $42.2 \%$ for $\mathrm{CH} 0$ during 2009 . The proportion of total dam passage through the spillway was 2.2 times higher than the proportion of total discharge through the spillway.

Table 3.34. Estimates of Major Passage Metrics for $\mathrm{CH} 0$. *The TSWs were not operated during summer 2009.

\begin{tabular}{lc}
\hline \multicolumn{1}{c}{ Metric } & Estimate $( \pm 1 / 295 \% \mathrm{CI})$ \\
\hline FPE & $84.51 \pm 1.33 \%$ \\
SPE & $73.20 \pm 1.63 \%$ \\
FGE & $42.20 \pm 4.12 \%$ \\
TSWE & NA \\
JBSE & $11.31 \pm 0.82 \%$ \\
SEF & $2.21 \pm 0.05$ \\
TSWEF & NA \\
\hline
\end{tabular}

\subsubsection{Powerhouse Horizontal Distribution and the Relationship Between Passage and Discharge}

During summer, only $42 \%$ of the $\mathrm{CH} 0$ that passed through the dam at the powerhouse were guided through the JBS, and the remaining 58\% passed through turbines. Guided passage exceeded unguided passage at turbine units 11 and 12, but was less than unguided passage at the other 14 units (Figure 3.60). A regression of number of tagged $\mathrm{CH} 0$ smolts passing each turbine on unit-specific discharge was highly significant $(\mathrm{P}<0.0001)$ with discharge explaining $81 \%$ of the variation in STH passage (Figure 3.61).

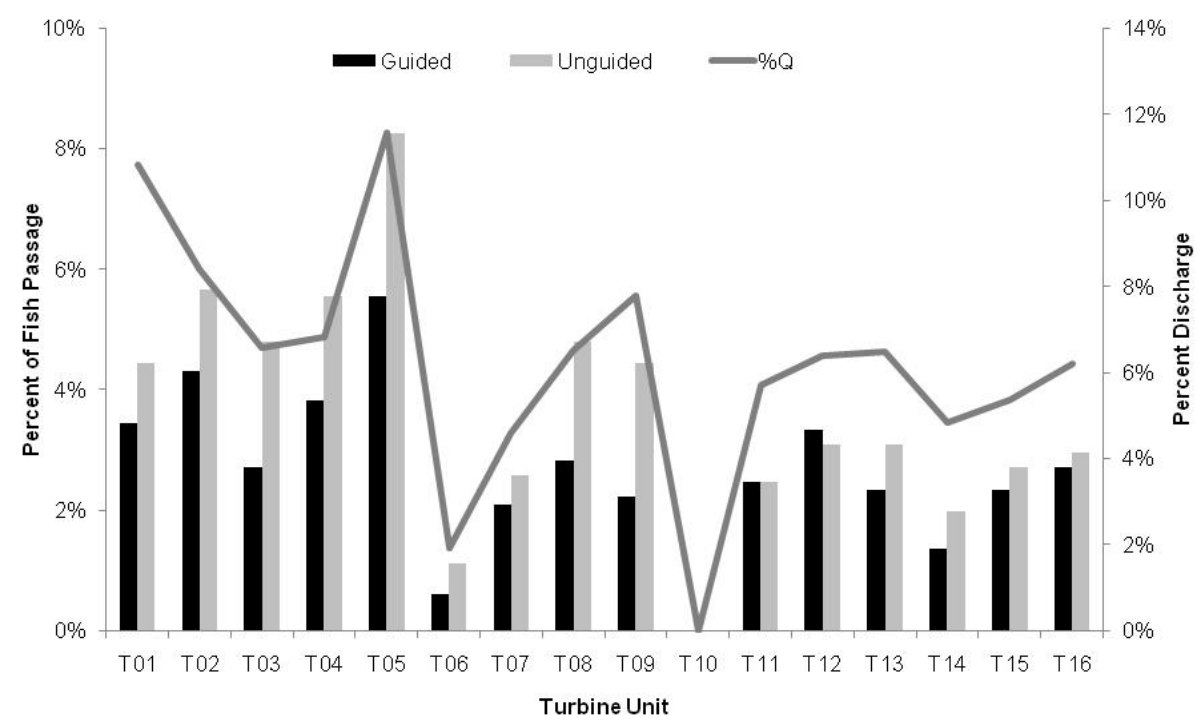

Figure 3.60. Percent Passage for Guided and Unguided $\mathrm{CH} 0$ and Percent Discharge by Turbine Unit for the John Day Powerhouse During Summer 2009 


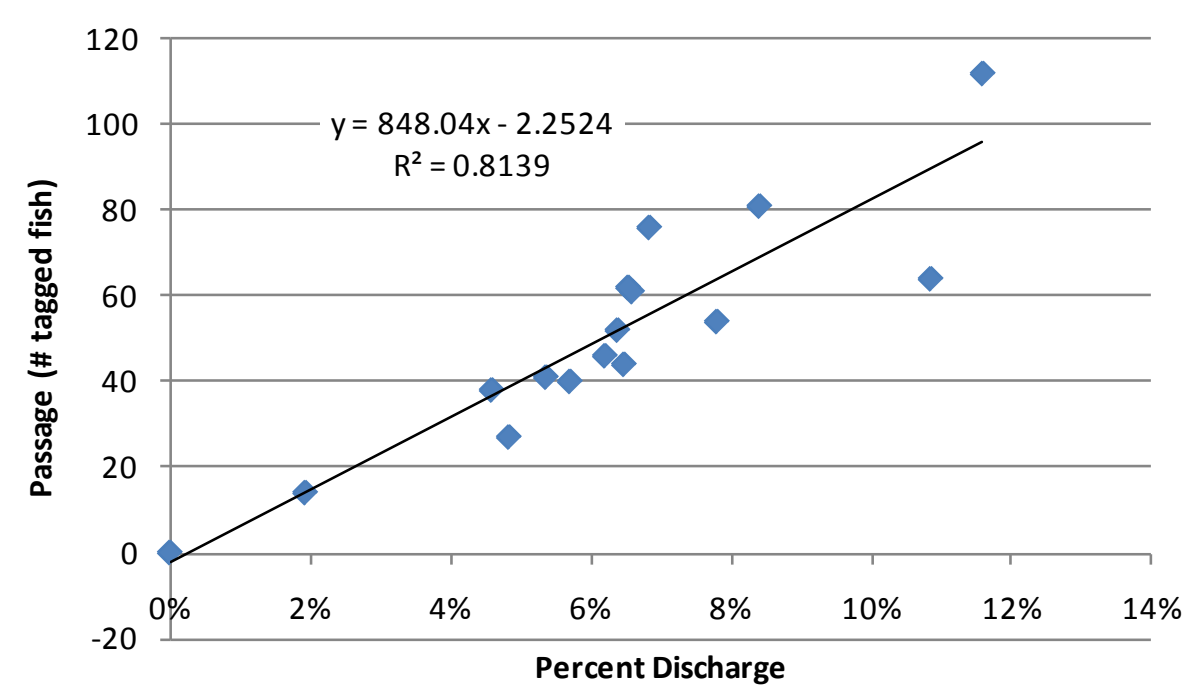

Figure 3.61. Percent Passage for Guided and Unguided $\mathrm{CH} 0$ and Percent Discharge by Turbine Unit for the John Day Powerhouse During Summer 2009

\subsubsection{Spillway Horizontal Distribution}

Of the $\mathrm{CH} 0$ smolts passing through the spillway, $73.2 \%$ passed through the operating bays $2-14$ (Figure 3.62). Spillway passage peaked at bay 14, although was otherwise fairly uniform.

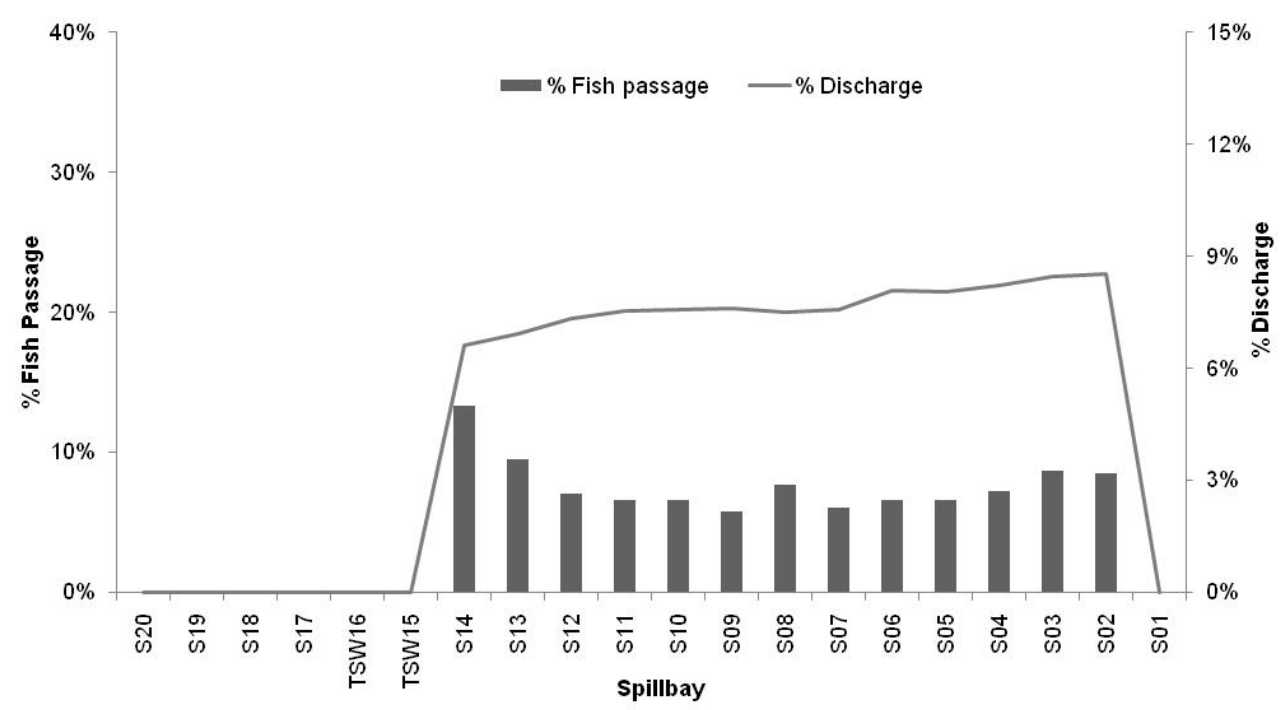

Figure 3.62. Percent Discharge and Passage of CH0 Smolts by Spill Bay During Summer 2009

\subsubsection{Day/Night Trends in Passage}

The hourly rate of passage of $\mathrm{CH} 0$ through the dam, powerhouse, turbines, and JBS was higher at night than during the day (Figure 3.63). Only the spillway passed more $\mathrm{CHO}$ during the day (2.2 fish/h) than it did at night (1.9 fish/h). The TSWs were not operational in summer 2009. 


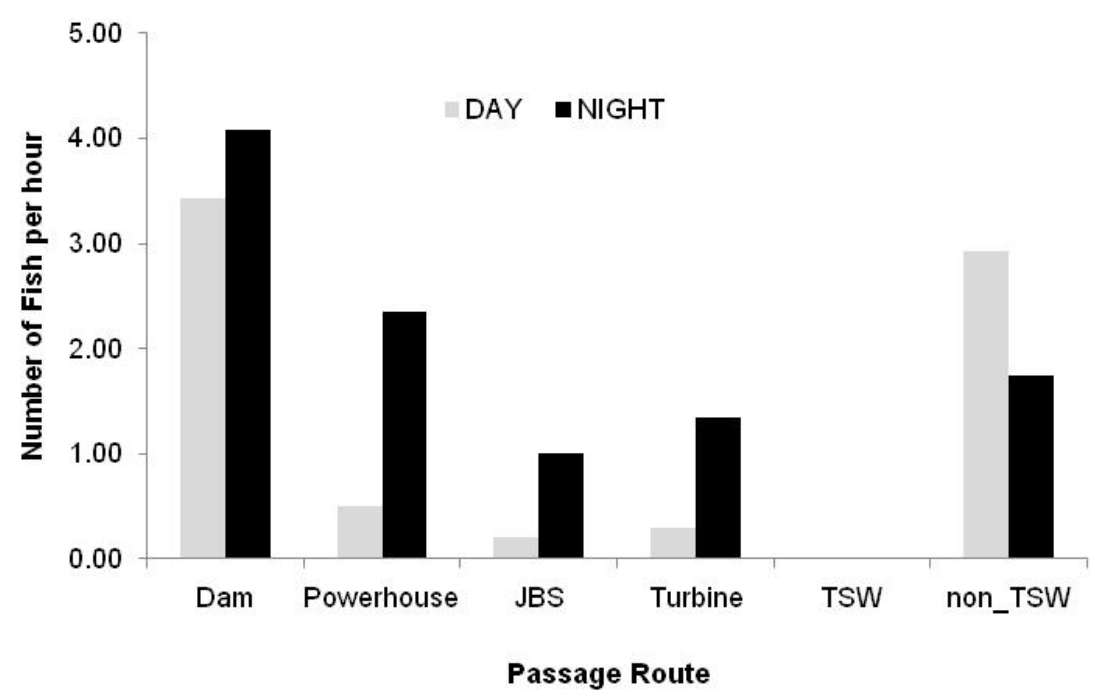

Figure 3.63. Day and Night Passage Rates by Route for CH0 During Summer 2009

\subsubsection{Fish Behavior}

Fish behavior relative to approach and rate of passage, day and night, vertical distribution, and travel and forebay residence times are described in the following sections.

\subsubsection{Approach and Route of Passage}

The $\mathrm{CH} 0$ approach to JDA was similar to spring with over $50 \%$ of first detections at the powerhouse and skeleton bays (Figure 3.64). Of the $\mathrm{CH} 0$ approaching the dam in the powerhouse forebay, over $20 \%$ eventually move north to pass at the spillway. The $\mathrm{CH} 0$ approaching the spillway were more than 8 times as likely to pass at the spillway than at the powerhouse.

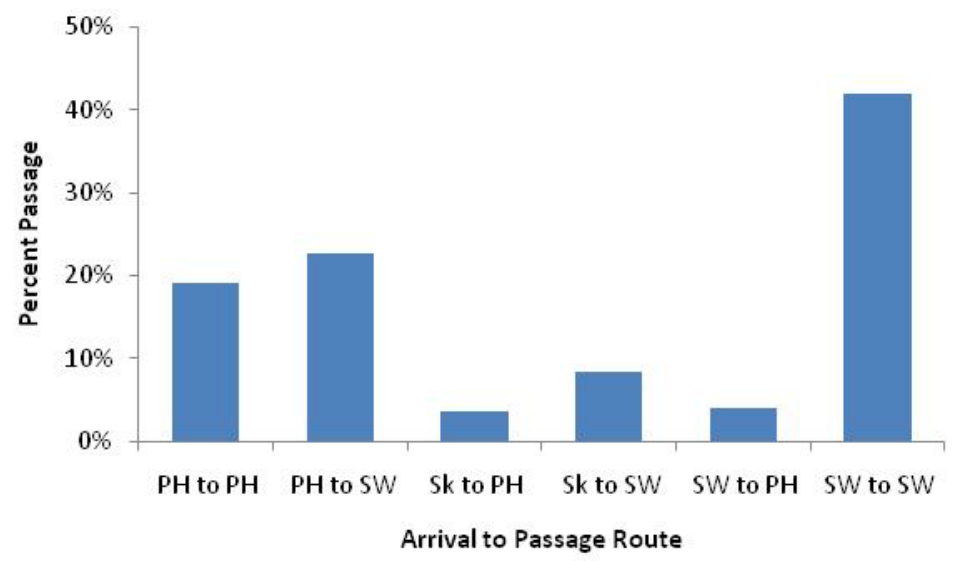

Figure 3.64. Subyearling Chinook Salmon Percent Passage by Approach and Passage Blocks at JDA During 2009. Abbreviations are as follows: $\mathrm{PH}=$ powerhouse; $\mathrm{Sk}=$ skeleton bay; $\mathrm{SW}=$ spillway. 
For $\mathrm{CH} 0,42 \%$ approached in the forebay of the powerhouse, $12 \%$ at the skeleton bays, and $46 \%$ at the spillway forebay (Figure 3.65). Of the $\mathrm{CHO}$ approaching at the powerhouse and skeleton bays, $58 \%$ ended up passing at the spillway even with the TSWs closed. Few $\mathrm{CH} 0$ approaching the spillway moved south to pass at the powerhouse ( $4.1 \%$ of total approach).

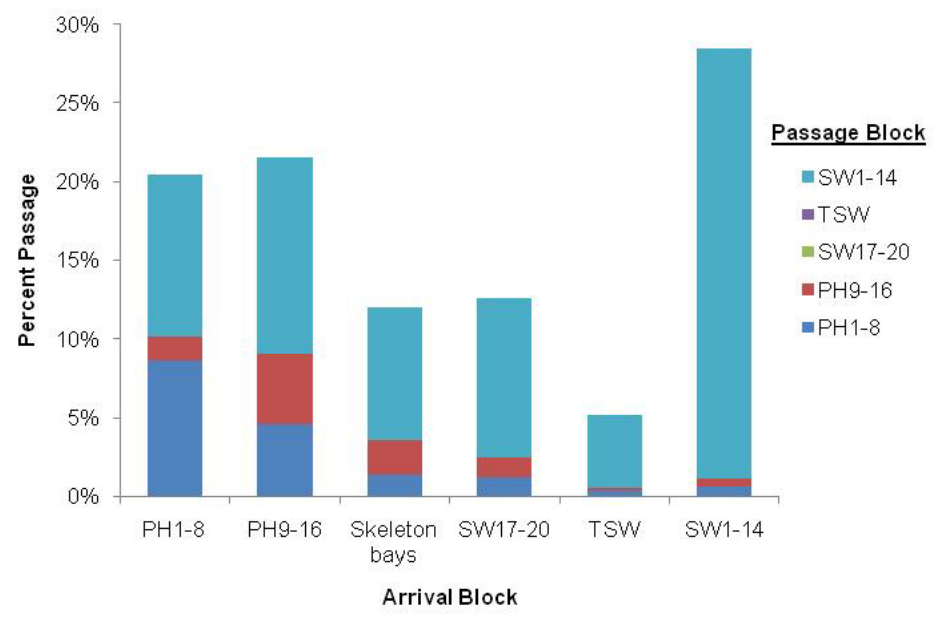

Figure 3.65. Subyearling Chinook Salmon Approach and Passage Behavior Patterns at JDA During 2009. Note, the TSWs were closed during summer 2009.

\subsubsection{Day/Night Behavior Patterns}

SubyearlingChinook salmon approaching the powerhouse had a much greater tendency to move south to pass the spillway during the day than they did at night; $28 \%$ during day and $8 \%$ at night (Figure 3.66). The powerhouse was more effective at passing $\mathrm{CH} 0$ that arrived at night, as seen previously with $\mathrm{CH} 1$ and STH. Upon approach to the spillway, $\mathrm{CH} 0$ behavior was to pass there, especially during day (42\%) as compared to night $(30 \%)$.

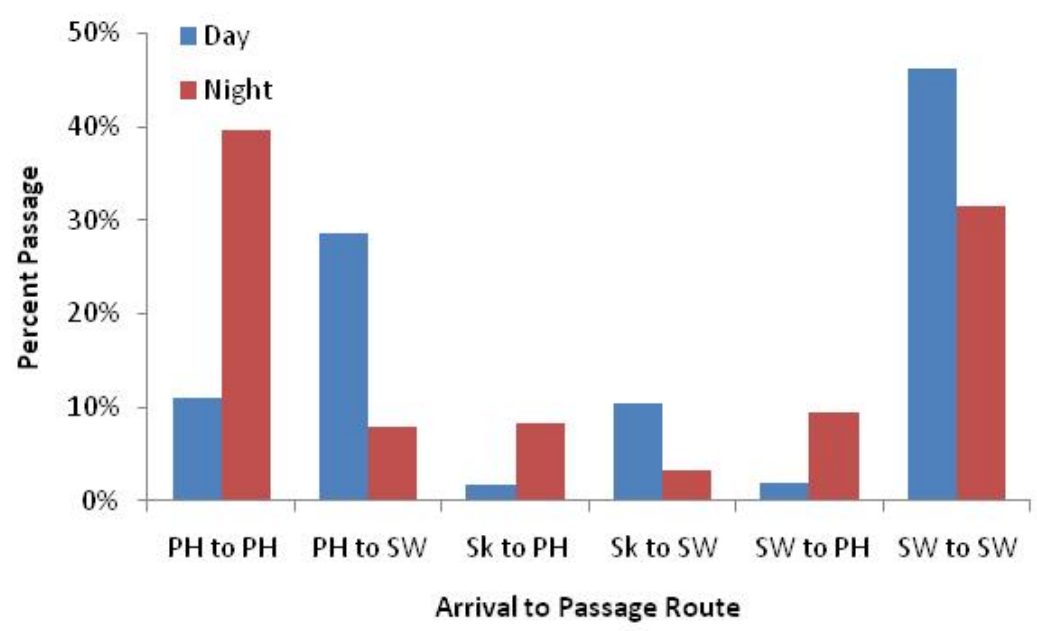

Figure 3.66. Subyearling Chinook Salmon Approach and Passage Patterns at JDA During Day and Night, 2009. Day/night allocation was defined by when the fish passed the dam.

Passage distributions for $\mathrm{CH} 0$ during the day were similar to the pooled distributions for day and night periods, with a tendency for powerhouse-arriving fish to move laterally along the powerhouse and 
pass at the spillway (Figure 3.67). This trend was not as evident at night (Figure 3.68). At night, CH0 tended to pass through the same block that they first approached. A majority of fish arriving at the powerhouse passed there while fish arriving at the spillway passed at the spillway. Fish arriving at the skeleton bays favored the spillway over the powerhouse.

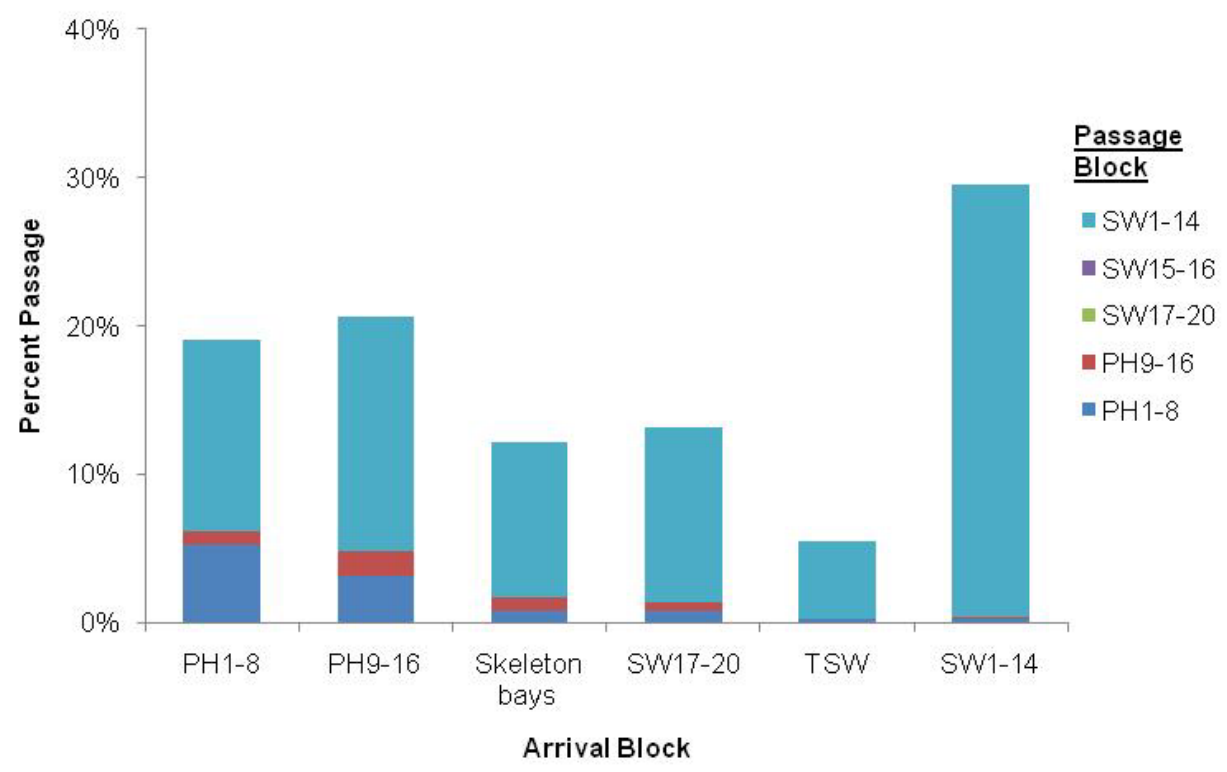

Figure 3.67. Approach and Passage Patterns for CH0 During Daytime at JDA, Summer 2009

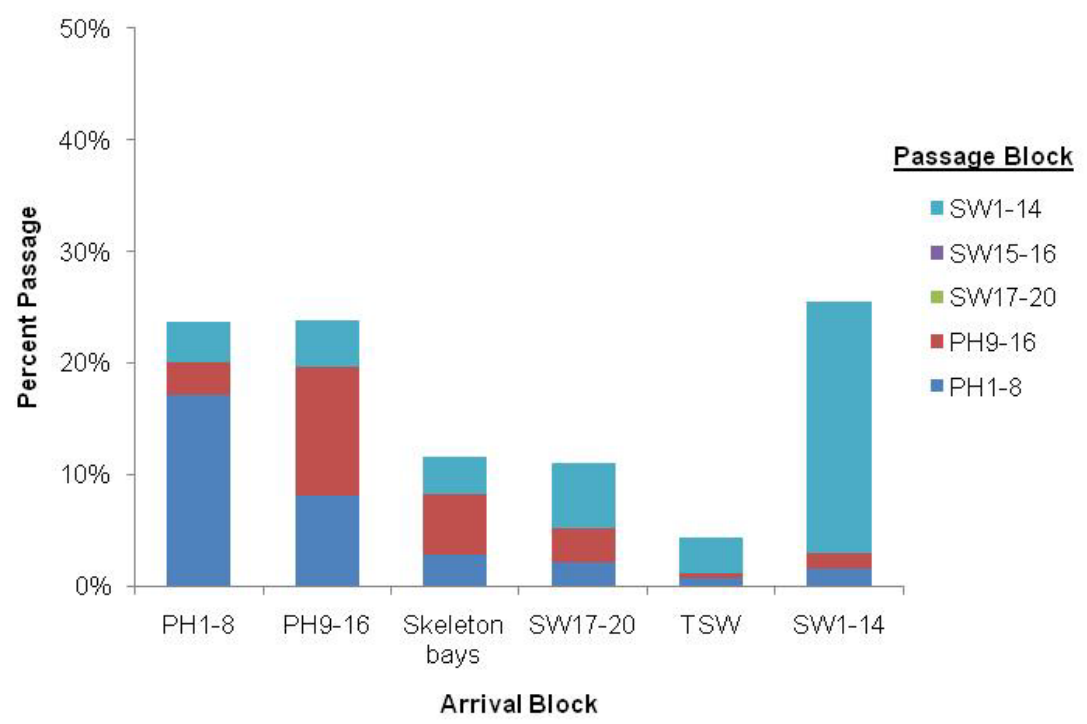

Figure 3.68. Approach and Passage Patterns for CH0 During Nighttime at JDA, Summer 2009

\subsubsection{Vertical Distribution Behavior Patterns}

The median depths of $\mathrm{CH} 0$ approaching within $75 \mathrm{~m}$ of the powerhouse or skeleton bays were less than $12 \mathrm{~m}$ (Figure 3.69). As with $\mathrm{CH} 1$ and STH, median depth decreased as distance to the powerhouse decreased, until the fish were within $5 \mathrm{~m}$ of the dam where depth abruptly increased in front of the powerhouse turbine intakes. For tagged $\mathrm{CHO}$ approaching the spillway, median depths of detection were 
within the surface $7 \mathrm{~m}$ of the water column, the deepest of the three tagged stocks (Figure 3.69). The $\mathrm{CH} 0$ that passed turbines were approximately $5 \mathrm{~m}$ deeper than those that were screened into the JBS (Figure 3.70).

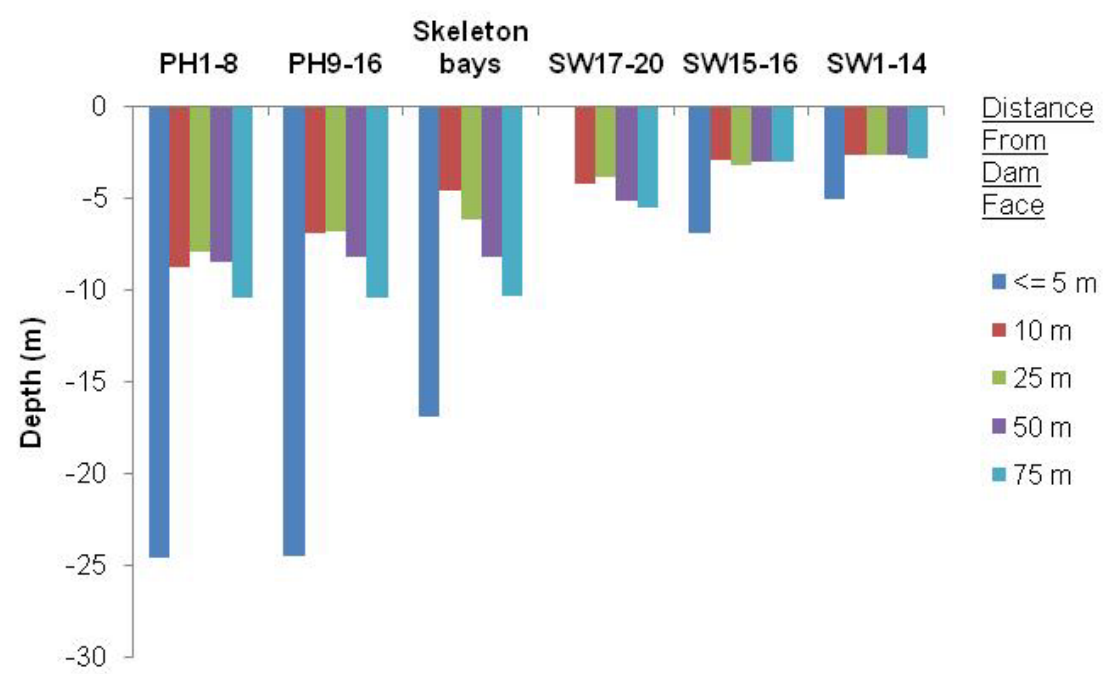

Figure 3.69. Median Depths of the Last Detection of Tagged CH0 Smolts at JDA. Zero depth was referenced to the elevation of the shallow hydrophone deployed on the south side of Turbine Unit 1 at elevation $255.23 \mathrm{ft}$ above MSL, and mean forebay water surface elevation was $263.5 \mathrm{ft}$ above MSL.

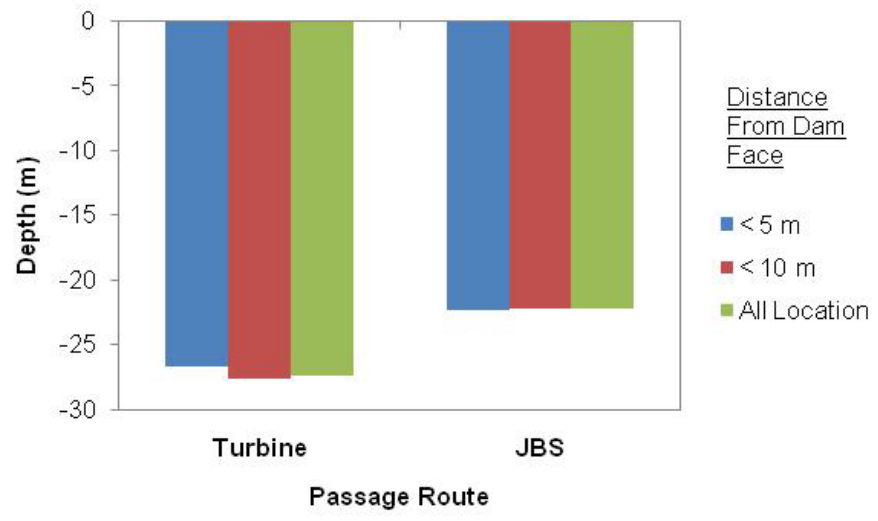

Figure 3.70. Subyearling Chinook Salmon Median Last-Detection Depths for Turbine- and JBS-Passed Fish

\subsubsection{Travel Times and Forebay Residence Times}

During summer 2009, acoustic-tagged $\mathrm{CH} 0$ had a median travel time between the release station and the JDA forebay array of 31.3 hours (Table 3.35). For tagged $\mathrm{CH} 0$ detected on the forebay array, the median travel time until passage through JDA was 3.8 hours. Median travel time from the JDA face to the tailrace egress array $10 \mathrm{~km}$ downstream of the dam was 0.5 hours. The median travel time from the JDA egress array to TDA forebay array was 15.4 hours. The median travel time from the TDA forebay to the Bonneville Dam forebay array was 33.1 hours. Subyearling Chinook salmon travel times were longest for powerhouse routes and shortest for the spillway (bays 2-14) at JDA during summer 2009. 
Table 3.35. Distance of Travel and Median Travel Time ( $\pm 1 / 2$ 95\% CI) for CH0 Smolts Passing Through Specific River Reaches Between Roosevelt, Washington, and the BON Forebay

\begin{tabular}{|c|c|c|c|c|}
\hline Reach & $\begin{array}{l}\text { Distance } \\
(\mathrm{km})\end{array}$ & $\begin{array}{l}\text { Median Travel } \\
\text { Time (h) }\end{array}$ & $\begin{array}{l}\text { Mean Travel } \\
\text { Time (h) }\end{array}$ & $1 / 295 \% \mathrm{CI}$ \\
\hline Roosevelt to JDA Forebay & 39.4 & 31.3 & 36.2 & 0.3 \\
\hline JDA Forebay to JDA Passage & 2 & & & \\
\hline Project & & 3.8 & 7.2 & 0.2 \\
\hline JBS & & 3.8 & 8.2 & 0.8 \\
\hline Turbine & & 4.6 & 9.0 & 0.6 \\
\hline Spill2-14 & & 3.6 & 6.7 & 0.2 \\
\hline JDA Passage to JDA Tailwater & 2.6 & & & \\
\hline Project & & 0.5 & 1.4 & 0.1 \\
\hline JBS & & 3.1 & 7.3 & 0.6 \\
\hline Turbine & & 1.0 & 1.1 & 0.1 \\
\hline Spill2-14 & & 0.4 & 0.5 & 0.0 \\
\hline JDA Passage to JDA Tailwater $30 \%$ Spill & 2.6 & & & \\
\hline Project & & 0.5 & 1.7 & 0.1 \\
\hline JBS & & 3.9 & 7.4 & 0.7 \\
\hline Turbine & & 0.9 & 1.2 & 0.1 \\
\hline Spill2-14 & & 0.4 & 0.5 & 0.0 \\
\hline JDA Passage to JDA Tailwater $40 \%$ Spill & 2.6 & & & \\
\hline Project & & 0.5 & 1.1 & 0.1 \\
\hline JBS & & 2.1 & 7.1 & 1.2 \\
\hline Turbine & & 1.1 & 1.1 & 0.0 \\
\hline Spill2-14 & & 0.4 & 0.5 & 0.0 \\
\hline JDA Tailwater to TDA Forebay & 34.6 & 15.4 & 15.9 & 0.1 \\
\hline TDA Forebay to BON Forebay & 75.4 & 33.1 & 35.6 & 0.3 \\
\hline
\end{tabular}

The median residence times of $\mathrm{CH} 0$ were similar to those of $\mathrm{CH} 1$ and $\mathrm{STH}$. Fish approaching and passing through the dam at the spillway had the shortest residence times $(<10$ minutes $)$ (Figure 3.71). Tagged $\mathrm{CH} 0$ approaching the spillway but passing at the powerhouse had the longest residence times ( $\sim 130$ minutes). Fish approaching and passing at the powerhouse had a short residence times ( $<20$ minutes). On the other hand, fish approaching the powerhouse but passing at the spillway had residence times of over 100 minutes. 


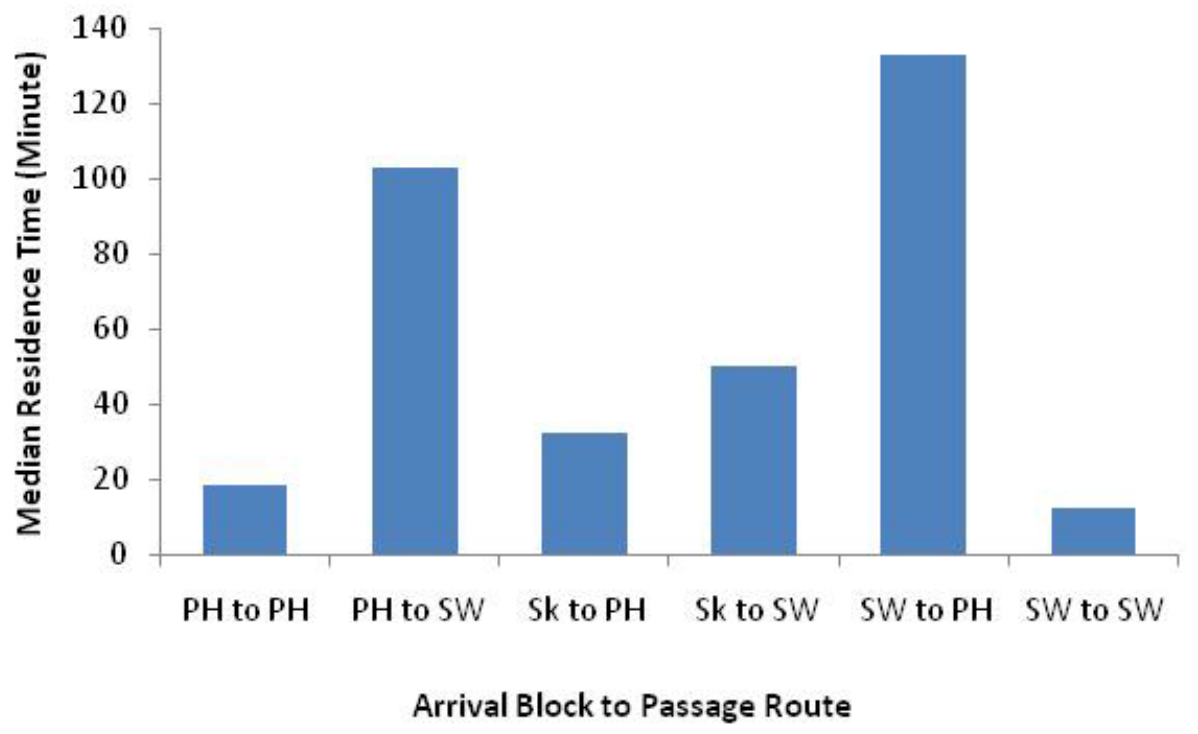

Figure 3.71. Median Residence Times of $\mathrm{CHO}$ at JDA, 2009

The median residence time of smolts arriving at the powerhouse but passing through the dam at the spillway at night was over four times longer than that of smolts exhibiting the same behavior during the day (Figure 3.72). Day/night differences for other behavior patterns were not distinct.

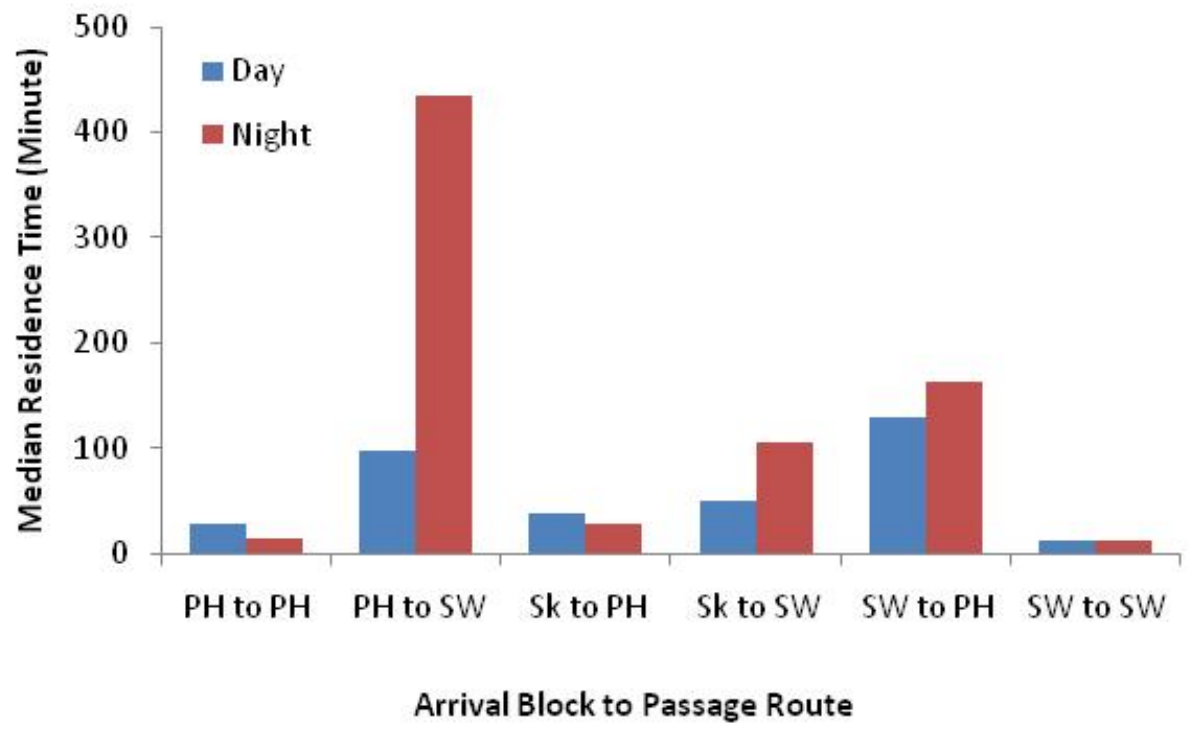

Figure 3.72. Subyearling Chinook Salmon Day/Night Median Passage Times at JDA, 2009. Abbreviations are as follows: $\mathrm{PH}=$ powerhouse; $\mathrm{SW}=$ spillway; Skeleton = skeleton bays. 


\subsection{Discussion, Conclusions, and Recommendations}

In this section, we assess study integrity, compare 2009 results with previous survival and passage studies at JDA, and discuss the performance of the prototype TSW SFO. The section closes with 2009 study conclusions and recommendations.

\subsection{Study Integrity}

The 2009 acoustic telemetry study at JDA provided reliable data on fish survival rates, passage rates, and behavior, as substantiated by the following facts.

The tagged fish populations reasonably represented the respective runs-at-large in terms of run timing and length frequency. The goal of tagging the middle $80 \%$ of each of the $\mathrm{CH} 1, \mathrm{STH}$, and CH0 runs was well met (Figures 3.5, 3.6, and 3.7). The median length of tagged fish was slightly longer than that of untagged fish of the same stock ( $2 \mathrm{~mm}$ for $\mathrm{CH} 1$ and STH; $3 \mathrm{~mm}$ for $\mathrm{CH} 0$ ) (Figures 3.8, 3.9, and 3.10). The $95-\mathrm{mm}$ minimum length requirement on candidate fish for tagging did not restrict the lengths of fish that could be tagged in the spring and excluded only about $6.7 \%$ of the run-of-river subyearlings from tagging in 2009. In 2007, $40 \%$ of subyearlings could not be tagged because they were too small (Ploskey et al. 2008), presumably because growth was slower that year. In 2008, about $9 \%$ of the CH0 run-at-large was too small to be tagged (Weiland et al. 2009).

Detection probabilities for the dam-face cable arrays were excellent. The combined probability of detection for the two independent arrays was $96 \%$ for $\mathrm{CH} 1$ and STH and $98 \%$ for $\mathrm{CHO}$ (Table 3.5).

Detection probabilities for autonomous arrays above and below BON were acceptable. Detection rates for $\mathrm{CH} 1$, STH, and $\mathrm{CH} 0$ were greater than $90 \%$ for the autonomous arrays (Figure 3.11). Multinode detections for arrays above BON were greater than $93 \%$ (Figure 3.13). Below BON, percent detection on two or more nodes of the BON primary array near Camas, Washington, was just $68 \%$ for $\mathrm{CH} 1$ and $\mathrm{STH}$ and $85 \%$ for $\mathrm{CH} 0$. This improved performance over 2008 is a result of increased node densities in the arrays below BON.

Tag life did not affect study results. All acoustic tags in the tag-life study were active for the required 23 days (Figure 3.15). Mean tag life was 30 days and ranged from 24 to 49 days.

Two testable assumptions of the survival models were met. There were few significant results of Burnham et al. (1987) Test 2 or Test 3. In fact, most of the Burnham Test could not be calculated because of exceptionally high detection probabilities on JDA survival arrays, and of those that could be calculated, none was significant at $\alpha=0.1$. Note, there were no tests of arrival distributions in 2009 because there were no reference releases of fish to compare to treatment releases.

\subsection{Comparison of Survival Rates and Passage Efficiencies for $30 \%$ versus $40 \%$ Spill Operations}

Estimates of survival rates and passage efficiencies for the $30 \%$ and $40 \%$ spill treatments were reasonably consistent between 2008 and 2009 (Figure 4.1). One distinction was that SPE was higher for 
the $200940 \%$ treatment than the other treatment/year combinations. As a result, FPE was highest for this treatment/year. In contrast, however, dam survival rates were lower for $40 \%$ spill during 2009 compared to the others. TSWE for CH1 was 5-10 percentage points higher for 30\% than $40 \%$ spill during both years; the opposite was true for STH. The $40 \%$ spill condition did not significantly increase survival rates or passage efficiencies for $\mathrm{CH} 1, \mathrm{STH}$, or $\mathrm{CH} 0$ over $30 \%$ spill.

Even though the $40 \%$ treatment provided one-third more spilled water than the $30 \%$ condition, perhaps a bigger difference in the treatment condition would reveal any relationship between survival and spill percentage. For example, a comparison of $20 \%$ vs $40 \%, 10 \%$ vs $30 \%$, or $30 \%$ vs $50 \%$ spill might be considered for future studies, after due diligence examination of the tailrace hydraulics in a physical scale model.

Survival rates were likely also influenced by the large number of predatory birds feeding on fish passing through the spillway, mainly the TSW and adjacent bays in spring. In summer when the TSW and spillbays 17-20 were closed, in an attempt to reduce the hydraulic influence that was making access to the fish easier, the birds shifted their feeding north to spillbays $2-14$. This resulted in lower spillway survival in 2009 relative to 2008.

\subsection{Performance of the Prototype TSW Surface Flow Outlet}

The prototype TSW SFO tested at JDA during 2009 performed comparably to other SFOs on the main stem Columbia and Snake rivers (Table 4.1). In fact, SFO passage efficiency and effectiveness for the JDA TSW were similar to those of the McNary TSW. Neither SFOperformed as well as the SFOs at Wells Dam or the BON B2. The JDA TSW out-performed the Lower Granite Dam and Ice Harbor Dam removable spillway weirs for STH, but not for $\mathrm{CH} 1$ or $\mathrm{CH}$. The SFOs at Wells Dam and B2 benefit from a pronounced horizontal concentration of juvenile salmonid emigrants due to physical features of the dam structure and forebay circulation patterns (Sweeney et al. 2007). Lower Granite and Ice Harbor dams have a horizontal concentrating mechanism due to relatively small forebay widths in the Snake River compared to main stem dams downstream in the Columbia River.

Because JDA does not have a pre-existing mechanism to concentrate fish horizontally, the SFO design relied on relatively high SFO discharge and a correspondingly large flow net in the forebay to attract or intercept downstream migrants, which are naturally surface-oriented and reluctant to sound during emigration (Andrew and Geen 1960). Accordingly, the intent of the JDA TSW and associated spill operation was to pass fish that approached the spillway at the spillway and pass an appreciable number of fish approaching the powerhouse at the spillway. Researchers wanted to know whether fish approaching the powerhouse would move to the north to pass through the spillway. The forebay behavior data showed that this was the case for about one-half to two-thirds of the tagged fish. This is an important finding given the huge size of the JDA powerhouse. This effect possibly could be enhanced by locating the TSWs closer to the powerhouse, perhaps at spill bays 18 and 19. 

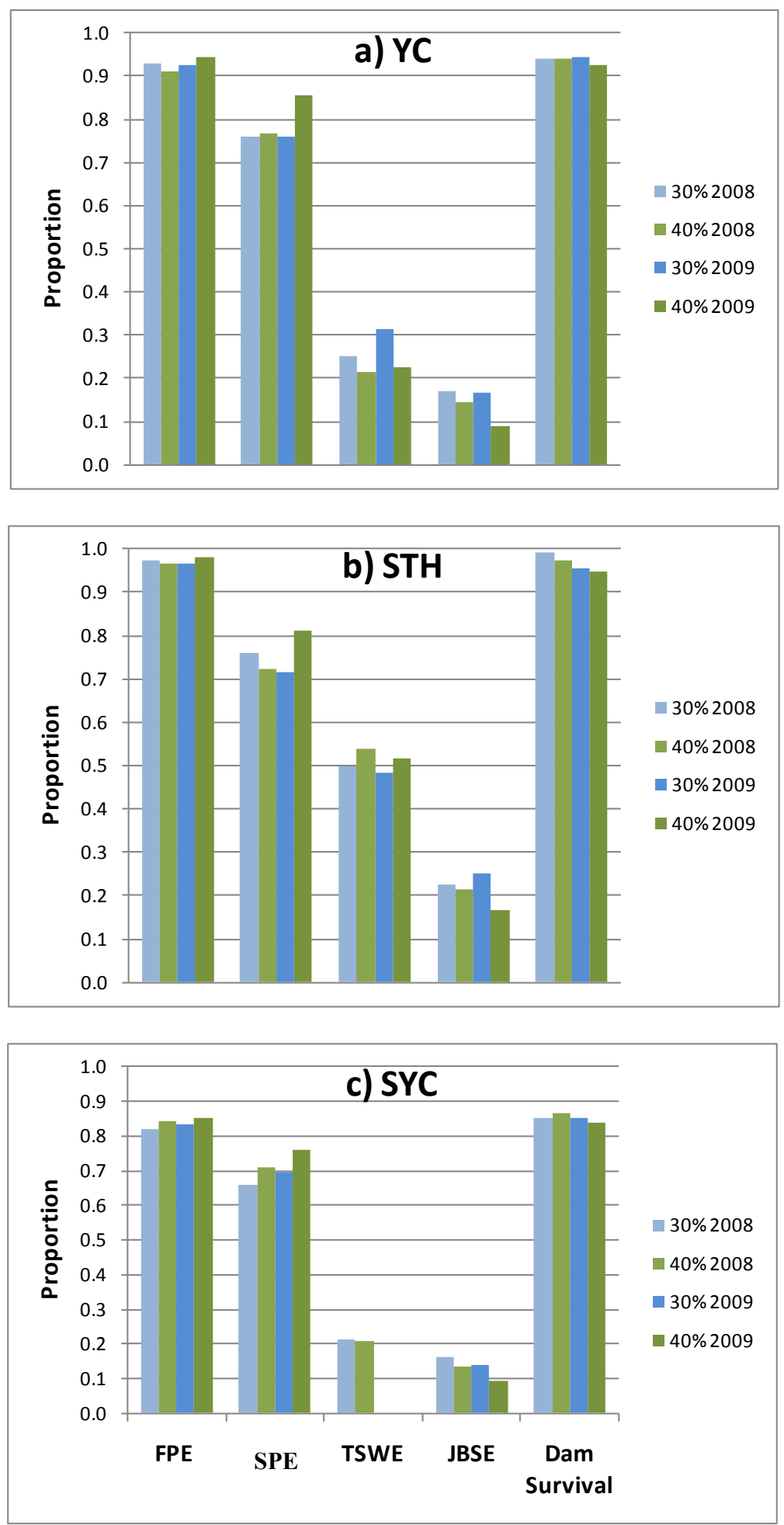

Figure 4.1. Comparison of Passage and Survival Proportions for $30 \%$ and $40 \%$ Spill Conditions During 2008 and 2009. Data for 2008 are from Weiland et al. (2009). FPE is fish-passage efficiency; SPE is spillpassage efficiency; TSWE is Top-spill weir efficiency; JBSE is juvenile bypass system-passage efficiency. Dam survival from the single-release model with virtual release at the dam-face arrays includes mortality during passage and in the tailwater to the first downstream detection array. 
A primary goal of the TSW SFOs at JDA is to reduce turbine passage, the worst survival route at the dam, and thereby improve overall survival rates for downstream migrants. This report provides estimates of survival rates and passage efficiencies that indicate the goal is being met. For the purpose of further discussion of this topic, the effect of the TSWs on turbine passage was enhanced by synthesizing data from pre- and post-TSW studies at JDA. The proportion of fish passing the turbines is about $50 \%$ lower post-TSW than pre-TSW (Figure 4.2). It is possible other factors influenced this result. However, the $30-40 \%$ spill proportions during post-TSW years (2008 and 2009) were higher than some pre-TSW years $(1999,2000,2002$, and 2003) but lower than others. Outflow post-TSW was not distinctly higher or lower than pre-TSW. Extended-length submersible screens were in place each year. One piece of evidence, though, does not support the contention that the TSWs reduce turbine passage - the turbine passage proportion for $\mathrm{CH} 0$ during summer 2008 when the TSWs were operated was only 1 percentage point lower than during summer 2009 when the TSWs were off. Further research during 2010 will be applied to this matter.
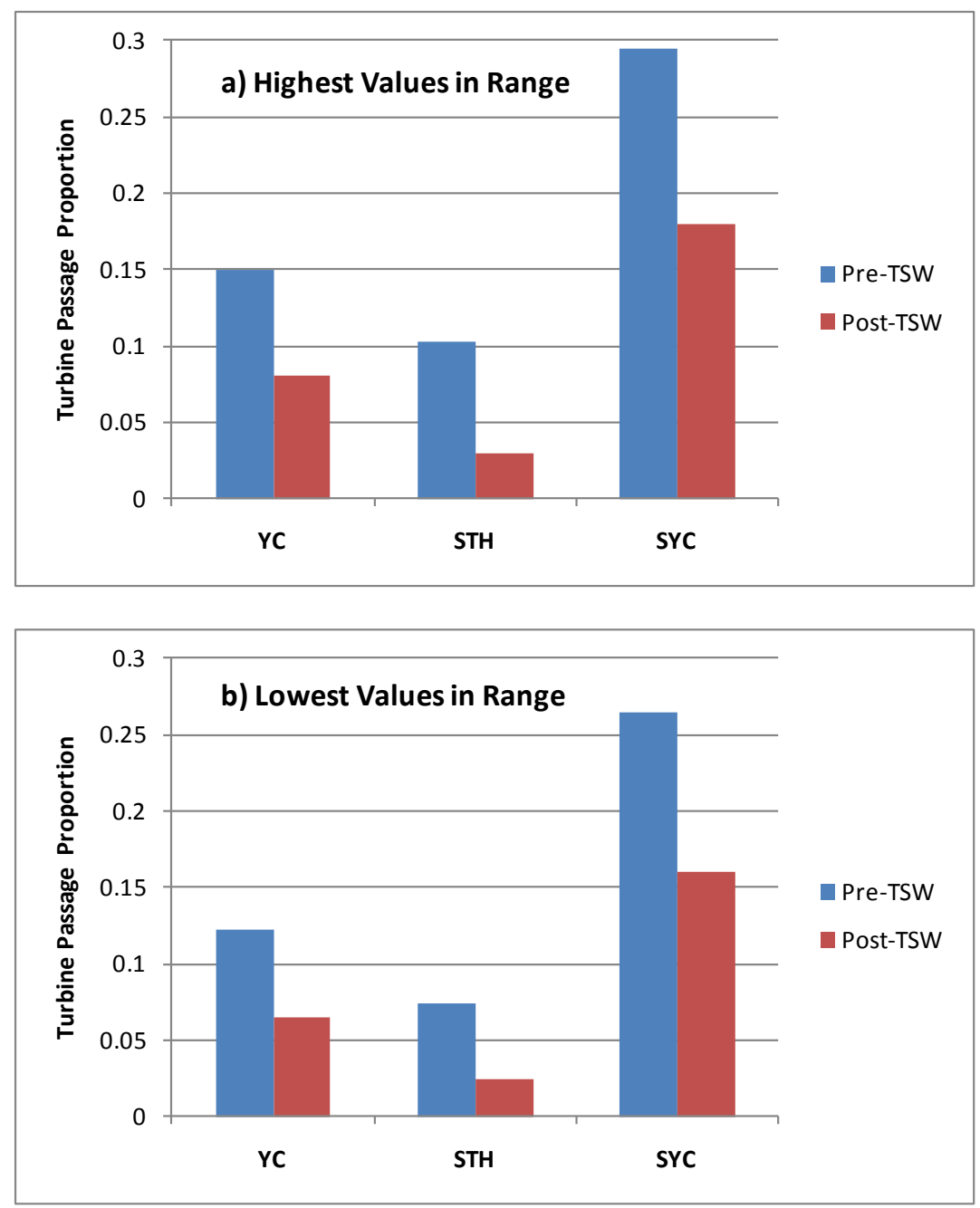

Figure 4.2. Turbine Passage Proportions Pre- and Post-TSW. Data are average across years of telemetry studies: pre-TSW during 1999, 2000, 2002, 2003 and post-TSW during 2008 and 2009 (Tables 1.2, 3.14, 3.25, and 3.35). 
In addition to assessing the fish collection efficiency and effectiveness of SFOs, SFO performance must also be assessed in terms of survival rates (Johnson and Dauble 2006; Sweeney et al. 2007). Routespecific survivals (dam face through the tailrace) for the TSW were high (95\% and $96 \%$ for $\mathrm{CH} 1$ and STH, respectively; the TSW was not operated during the $2009 \mathrm{CH} 0$ migration), indicating that conveyance and outfall conditions for the TSW were satisfactory. Non-TSW spill improves tailrace passage conditions for TSW-passed fish by inhibiting eddy formation and providing fast water velocities to deter predation.

Table 4.1. Comparison of Performance for Various Surface-Flow Outlets in the Pacific Northwest

\begin{tabular}{ccllccccc}
\hline & & & \multicolumn{3}{c}{ SFO Efficiency } & \multicolumn{3}{c}{ SFO Effectiveness } \\
\cline { 5 - 9 } Year & Dam & SFO Type & CH1 & STH & CH0 & CH1 & STH & CH0 \\
\hline $1990-1992^{(\text {(a) }}$ & WEL & Retrofit baffle & $0.89^{(\mathrm{b})}$ & & 0.89 & $17.9^{(\mathrm{b})}$ & & 17.8 \\
$2004-2005^{(\mathrm{c})}$ & B2 & Sluice Chute & 0.33 & 0.70 & 0.39 & $6.5^{(\mathrm{d})}$ & $13.7^{(\mathrm{d})}$ & $5.8^{(\mathrm{d})}$ \\
$2006^{(\mathrm{e})}$ & LGR & RSW & 0.30 & 0.26 & 0.57 & 6.0 & 5.4 & 4.6 \\
$2006^{(\mathrm{f})}$ & IHR & RSW & 0.42 & 0.34 & 0.68 & 6.9 & 5.6 & 4.6 \\
$2007^{(\mathrm{g})}$ & MCN & Temp. SW & 0.25 & 0.66 & 0.28 & 3.4 & 8.9 & 3.1 \\
$2008^{(\mathrm{h})}$ & JDA & TSW & 0.24 & 0.50 & 0.21 & 3.4 & 7.2 & 3.1 \\
$2009^{(\mathrm{i})}$ & JDA & TSW & 0.23 & 0.44 & 0.21 & 3.7 & 6.8 & NA \\
\hline
\end{tabular}

(a) Skalski et al. 1996.

(b) Run-at-large in spring comprised of $\mathrm{CH} 1$ and $\mathrm{STH}$.

(c) Counihan et al. 2006a and 2006b.

(d) Re: Total B2 Q, not the entire Bonneville complex.

(e) Beeman et al. (2007); the two values are for spring and summer periods.

(f) Data for spring are from Axel et al. (2007); values are averages of data for the BiOp and $30 \% / 40 \%$ spill treatments. Data for summer are from Ogden et al. (2008).

(g) Adams and Counihan (2009); the two values are for spring and summer periods.

(h) Weiland et al. (2009)

(i) This study

$\mathrm{B} 2=$ Bonneville Dam second powerhouse.

IHR $=$ Ice Harbor Dam.

JDA $=$ John Day Dam.

LGR $=$ Lower Granite Dam.

$\mathrm{MCN}=$ McNary Dam.

$\mathrm{SFO}=$ surface-flow outlet.

STH $=$ steelhead

$\mathrm{CHO}=$ subyearling Chinook salmon.

$\mathrm{WEL}=$ Wells Dam

$\mathrm{CH} 1=$ yearling Chinook salmon.

\subsection{Conclusions}

The main conclusions from the acoustic telemetry evaluation of survival rates, fish-passage efficiencies and distributions, fish behavior, and effects of spill condition for $\mathrm{CH} 1, \mathrm{STH}$, and $\mathrm{CH} 0$ at JDA during 2009 are as follows. 
- Survival Rates

- For 2009, single-release estimates of JDA-to-TDA forebay-passage survival rates for CH1 $\left(0.927 \pm 0.010^{1}\right)$ and STH $(0.953 \pm 0.008)$ in spring and estimates for CH0 were $(0.839 \pm 0.014)$ in summer. Due to the study design being single release estimates and encompassing TDA pool down to the TDA forebay the performance standards outlined in the $2008 \mathrm{BiOp}$ could not be applied here.

- The passage route with the highest survival rate is the JBS (0.908 to 0.975). In terms of survival, the turbines are the worst route (0.749 to 0.851$)$.

- Bird predation, especially at the spillway, affected survival estimates.

- Passage Efficiencies and Distributions

- Fish-passage efficiency was generally highest for STH and lowest for CH0. Proportionately more $\mathrm{CH} 0$ than $\mathrm{CH} 1$ or STH pass the dam via turbines.

- Fish-passage rates at individual turbine units are strongly, positively correlated with unit-specific discharge.

- Fish Behavior

- Spill and TSW operations attracted downstream migrant juvenile salmonids to the spillway. About half of the tagged fish arriving in the forebay of the powerhouse and skeleton bays moved toward and passed at the spillway. In contrast, relatively few smolts approaching the spillway passed at the powerhouse.

- Fish approaching the spillway had the shortest median residence time of all approach paths (4 to 20 minutes, depending on fish run). The longest residence time was for fish approaching the powerhouse and then passing through the dam at the spillway or vice versa ( 2 to 7 hours).

- Downstream migrants are surface-oriented, being distributed in the upper portion of the water column $(<5-7 \mathrm{~m})$ on approach to the dam.

- Effect of Spill Condition (30\% versus $40 \%$ spill)

- Survival was significantly higher for $\mathrm{CH} 1$ at $30 \%$ spill for the five blocks meeting the treatment spill rates and at 30\% spill for STH when all seven blocks were tested. There is no statistically significant increase in survival for the $40 \%$ spill treatments. Survival estimates, passage efficiencies, and fish behaviors are similar between the two spill conditions. The increase in spill discharge from $30 \%$ to $40 \%$ of total water discharged through the dam basically serves to pass incrementally more fish at non-TSW bays and incrementally fewer fish at the TSW bays.

- TSW Performance

- In terms of fish collection, the TSWs perform well when they are operated. At about $20 \mathrm{kcfs}$, the TSW bays passed half of the STH and a quarter of the $\mathrm{CH} 1$ of the respective totals passing through JDA.

\footnotetext{
${ }^{1} \pm 1 / 295 \%$ confidence interval.
} 
- As intended in the TSW design and operation, the TSW surface flows appeared to attract, or provide a surface outlet opportunity, for fish that had originally arrived at the dam in the powerhouse forebay. Passage at the TSW bays was much higher during the day than at night, which is consistent with observations at many other SFOs (Johnson and Dauble 2006; Sweeney et al. 2007).

\subsection{Recommendations}

Based on the 2009 results, recommendations include the following:

- Assuming there would be no adverse impact on tailrace passage conditions, the TSWs should be moved closer to the powerhouse to maximize the collection of fish approaching and passing through the powerhouse and thereby minimizing turbine passage.

- To date, there is only 1 year (2008) of TSW evaluation for CH0. Performance of the TSW during summer for $\mathrm{CH} 0$ should be addressed in future studies.

- After due diligence examination of tailrace hydraulics in a physical scale model, a comparison of $20 \%$ versus $40 \%$ or $10 \%$ versus $30 \%$ spill might be considered for future studies. 


\subsection{References}

Adams NS and TD Counihan. 2008. Survival and Migration Behavior of Juvenile Salmonids at McNary Dam, 2007. Draft Report of Research prepared by the U.S. Geological Survey, Cook, Washington, for the U.S. Army Corps of Engineers, Walla Walla, Washington.

Adams, NS and TD Counihan (eds.). 2009. Survival and Migration Behavior of Juvenile Salmonids at McNary Dam, 2007. U.S. Geological Survey Report to the U.S. Army Corps of Engineers, Contract W68SBV70178419, Walla Walla, Washington.

Andrew FJ and GH Geen. 1960. Sockeye and Pink Salmon Production in Relation to Proposed Dams in the Fraser River System. International Pacific Salmon Fisheries Commission Bulletin, XI, New Westminster, British Columbia, Canada.

Anglea S, T Poe, and A Giorgi. 2001. Synthesis of Radio Telemetry, Hydroacoustic, and Survival Studies of Juvenile Salmon at John Day Dam (1980-2000). Prepared for the U.S. Army Corps of Engineers District, Portland, Oregon by Pacific Northwest National Laboratory, Richland, Washington.

Axel GA, EE Hockersmith, DA Ogden, BJ Burke, KE Frick, BP Sandford, and WD Muir. 2007. Passage Behavior and Survival of Radio-Tagged Yearling Chinook Salmon and Steelhead at Ice Harbor Dam, 2006. Report of research by Northwest Fisheries Science Center, National Marine Fisheries Service submitted to the U.S. Army Corps of Engineers, Walla Walla District.

Beeman JW, HC Hansel, PV Haner, K Hardiman, D Hardiman, and J Hardiman. 2003. Estimates of Fish and Spill Passage Efficiency of Radio-Tagged Juvenile Steelhead, and Yearling and Subyearling Chinook Salmon at John Day Dam, 2000. Final Report of Research prepared by the U.S. Geological Survey, Cook, Washington, for the U.S. Army Corps of Engineers, Portland, Oregon.

Beeman JW, L Dingmon, S Juhnke, HC Hansel, B Hausmann, and P Haner. 2006. Estimates of Fish, Spill, and Juvenile Fish Bypass Passage Efficiencies of Radio-Tagged Juvenile Salmonids Relative to Spring and Summer Spill Treatments at John Day Dam in 2002. Final Report of Research prepared by the U.S. Geological Survey, Cook, Washington, for the U.S. Army Corps of Engineers, Portland, Oregon.

Beeman JW, SD Fielding, AC Braatz, TS Wilkerson, AC Pope, CE Walker, JM Hardiman, RW Perry, and TD Counihan. 2007. Survival and Migration Behavior of Juvenile Salmonids at Lower Granite Dam, 2006. Final Report of Research by the U.S. Geological Survey to the U.S. Army Corps of Engineers, Walla Walla District, Contract W68SBV60378208, Walla Walla, Washington.

BioSonics, Inc. 1999. Hydroacoustic Evaluation and Studies at the John Day Dam, 1997. Final Report. BioSonics, Inc., Seattle, Washington.

Burnham KP, DR Anderson, GC White, C Brownie, and KH Pollock. 1987. "Design and Analysis Methods for Fish Survival Estimates Based on Release-Recapture." American Fisheries Society Monograph No. 5. 
Cash KM, DM Faber, TW Hatton, EC Jones, RJ Magie, NM Swyers, RK Burns, MD Sholtis, SA Zimmerman, JS Hughes, TL Gilbride, NS Adams, and DW Rondorf. 2005. Three Dimensional Behavior and Passage of Juvenile Salmonids at The Dalles Dam, 2004. Final Report of Research prepared by the U.S. Geological Survey and Pacific Northwest National Laboratory to the U.S. Army Corps of Engineers, Portland, Oregon.

Chan YT and KC Ho. 1994. "A Simple and Efficient Estimator for Hyperbolic Location." IEEE Trans. Signal Process. 42(8):1905-1915.

Chan YT, HYC Hang, and P-C Ching. 2006. "Exact and Approximate Maximum Likelihood Localization Algorithms." IEEE Transactions on Vehicular Technology 55(1).

Cheung KW, HC So, WK Ma, and YT Chan. 2004. "Least Squares Algorithms for Time-of-ArrivalBased Mobile Location.” IEEE Trans. Signal Process. 52:1121-1128.

Counihan TD, JH Petersen, NS Adams, RS Shively, and HC Hansel. 2002a. Feasibility of Extracting Survival Information from Radio-Telemetry Studies at the John Day Dam, 1999. Final Report of Research prepared by the U.S. Geological Survey, Cook, Washington, for the U.S. Army Corps of Engineers, Portland District, Portland, Oregon.

Counihan T D, JH Petersen, and KJ Felton. 2002b. Survival Estimates of Migrant Juvenile Salmonids in the Columbia River from John Day Dam through Bonneville Dam using Radio-Telemetry, 2000. Final Report of Research prepared by the U.S. Geological Survey, Cook, Washington, for the U.S. Army Corps of Engineers, Portland, Oregon.

Counihan TD, GS Holmberg, and JH Peterson. 2006a Survival Estimates of Migrant Juvenile Salmonids in the Columbia River through John Day Dam using Radio Telemetry, 2002. Final Report of Research prepared by the U.S. Geological Survey, Columbia River Research Laboratory, Cook, Washington, for the U.S. Army Engineer District, Portland, Oregon.

Counihan TD, GS Holmberg, CE Walker, and JM Hardiman. 2006b. Survival Estimates of Migrant Juvenile Salmonids in the Columbia River through John Day Dam using Radio- Telemetry, 2003. Final Report of Research prepared by the U.S. Geological Survey, Columbia River Research Laboratory, Cook, Washington, for the U.S. Army Engineer District, Portland, Oregon.

Counihan TD, AL Puls, CE Walker, JM Hardiman, and GS Holmberg. 2006c. Survival Estimates of Migrant Juvenile Salmonids through The Dalles Dam Using Radiotelemetry, 2004. Final Report of Research prepared by the U.S. Geological Survey, Cook, Washington, for the U.S. Army Corps of Engineers, Portland, Oregon.

Counihan TD, AL Puls, CE Walker, JM Hardiman, and GS Holmberg. 2006d. Survival Estimates of Migrant Juvenile Salmonids through The Dalles Dam Using Radiotelemetry, 2005. Final Report of Research prepared by the U.S. Geological Survey, Cook, Washington, for the U.S. Army Corps of Engineers, Portland, Oregon.

Efron B and RJ Tibshirani. 1993. An Introduction to the Bootstrap. Chapman \& Hall, New York. 
Ehgrenberg JE and TW Steig. 2002. "A Method for Estimating the Position Accuracy of Acoustic Fish Tags.” ICES Journal of Marine Science 59:140-149.

Endangered Species Act of 1973. 1973. Public Law 93-205, as amended, 16 USC 1531 et seq.

Hansel, HC, JW Beeman, TD Counihan, BD Liedtke, MS Novick, and JM Plumb. 2000. Estimates of Fish and Spill Passage Efficiency for Radio-Tagged Juvenile Steelhead and Yearling Chinook Salmon at John Day Dam, 1999. Annual report of research to U.S. Army Corps of Engineers, Portland District, Portland, Oregon. U.S. Geological Survey, Biological Resources Division, 5501A Cook-Underwood Rd., Cook, Washington

Faber DM, MA Weiland, RA Moursund, TJ Carlson, N Adams, and D Rhondorf. 2001. Evaluation of the Fish Passage Effectiveness of the Bonneville I Prototype Surface Collector using Three-Dimensional Ultrasonic Fish Tracking. Final Report, PNNL-13526, prepared by Pacific Northwest National Laboratory and U.S. Geological Survey, Biological Resources Division, for the U.S. Army Corps of Engineers, Portland District, Portland, Oregon.

Faber DM, GR Ploskey, MA Weiland, Z Deng, JS Hughes, RL McComas, J Kim, RL Townsend, T Fu, JR Skalski, and ES Fischer. 2010. Evaluation of a Behavioral Guidance Structure at Bonneville Dam Second Powerhouse including Passage Survival of Juvenile Salmon and Steelhead using Acoustic Telemetry, 2008. PNNL-18753, prepared for U.S. Army Corps of Engineers District, Portland, Oregon, by Pacific Northwest National Laboratory, Richland, Washington.

Fang BT. 1990. "Simple Solutions for Hyperbolic and Related Position Fixes." IEEE Trans. Aerosp. Electron. Syst. 26:748-753.

Foy WH. 1976. "Position-Location Solutions by Taylor-Series Estimation." IEEE Trans. Aerosp. Electron. Syst. AES-12:187-194.

Giorgi AE and JR Stevenson. 1995. A Review of Biological Investigations Describing Smolt Passage Behavior at Portland District Corps of Engineer Projects: Implications to Surface Collection Systems. Draft, Don Chapman Consultants, Inc., Boise, Idaho.

Hansel HC, JW Beeman, BJ Hausmann, SD Juhnke, PV Haner, and JL Phelps. 2004. Estimates of Fish, Spill, and Juvenile Fish Bypass Passage Efficiencies of Radio-Tagged Juvenile Salmonids Relative to Spring and Summer Spill Treatments at John Day Dam in 2003. Final Report of Research prepared by the U.S. Geological Survey, Cook, Washington, for the U.S. Army Corps of Engineers, Portland, Oregon.

Hansel HC, NS Adams, TD Counihan, BD Liedtke, MS Novick, JM Plumb, and TP Poe. 2000. Independent Scientific Group. Return to the River 2000: Restoration of Salmonid Fishes in the Columbia River Ecosystem. NWPPC 2000-12, Northwest Power Planning Council, Portland, Oregon.

Johnson GE and DD Dauble. 2006. "Surface Flow Outlets to Protect Juvenile Salmonids Passing Through Hydropower Dams." Reviews in Fisheries Science 14:213-244.

Juell J-E and H Westerberg. 1993. "An Ultrasonic Telemetric System for Automatic Positioning of Individual Fish Used to Track Atlantic Salmon (Salmo salar L.) in a Sea Cage.” Aquacultural Eng. 12:1-18. 
Lady J, P Westhagen, and J Skalski. 2001. SURPH 2.1 Survival under proportional hazards. Report prepared by the University of Washington School of Aquatic and Fisheries Sciences for the U.S. Department of Energy, Bonneville Power Administration.

Lim JS. 1990. Two-Dimensional Signal and Image Processing. Prentice Hall, Englewood Cliffs, New Jersey, pp. 469-476.

McComas RL, JW Ferguson, SG Smith, GA McMichael, TJ Carlson, JA Vucelick, and KD Ham. 2005. "A Study to Estimate Salmonid Survival Through the Columbia River Estuary Using Acoustic Tags." Abstract in the 2005 Anadromous Fish Evaluation Program, U.S. Army Corps of Engineer District, Portland, Oregon.

McComas RL, JW Ferguson, SG Smith, GA McMichael, and TJ Carlson. 2004. "A Study to Estimate Salmonid Survival Through the Columbia River Estuary Using Acoustic Tags." Abstract in the 2004 Anadromous Fish Evaluation Program, U.S. Army Corps of Engineer District, Portland, Oregon.

McComas RL, L Gilbreath, E Hockersmith, SG Smith, GA McMichael, TJ Carlson, JA Vucelick, and KD Ham. 2006. "A Study to Estimate Salmonid Survival Through the Columbia River Estuary Using Acoustic Tags, 2006." Abstract in the 2006 Anadromous Fish Evaluation Program, U.S. Army Corps of Engineer District, Portland, Oregon.

McComas RL, JP Everett, GA McMichael, GE Johnson, GM Matthews, and JW Ferguson. 2007. "Field Evaluation of a Three-Dimensional Mobile System for Tracking Acoustically-Tagged Smolts in the Columbia River and Estuary." Abstract in the 2007 Anadromous Fish Evaluation Program, U.S. Army Corps of Engineers District, Portland, Oregon.

McComas RL, JP Everett, GA McMichael, and J Carter. 2008. "A Study to Estimate Salmonid Survival Through the Columbia River Estuary Using Acoustic Tags, Mobile Tracking Efforts." Abstract in the 2008 Anadromous Fish Evaluation Program, U.S. Army Corps of Engineers District, Portland, Oregon.

Montgomery Watson, NHC, Glosten Associates, and I. Civil Tech. 2000. John Day Dam Surface Bypass Removable Spillway Weir Physical Model Alternatives Report. Technical report prepared for the U.S. Army Corps of Engineer District, Portland, Oregon.

Moursund RA, KD Ham, and PS Titzler. 2003. Hydroacoustic Evaluation of Downstream Fish Passage at John Day Dam in 2002. PNWD-3236, prepared for U.S. Army Corps of Engineers District, Portland, Oregon, by Pacific Northwest National Laboratory, Richland, Washington.

National Marine Fisheries Service (NMFS). 2008. Biological Opinion-Consultation on Remand for Operation of the Federal Columbia River Power System, 11 Bureau of Reclamation Projects in the Columbia Basin and ESA Section 10(a)(1)(A) Permit for Juvenile Fish Transportation Program. National Oceanic and Atmospheric Administration Fisheries, Northwest Region, Seattle, Washington.

Ogden DA, EE Hockersmith, GA Axel, BJ Burke, KE Frick, RF Absolon, and BP Sandford. 2008. Passage Behavior and Survival for River-run Subyearling Chinook Salmon at Ice Harbor Dam, 2006. Report of research by Northwest Fisheries Science Center, National Marine Fisheries Service, submitted the U.S. Army Corps of Engineers, Walla Walla District. 
Peven C, A Giorgi, J Skalski, M Langeslay, A Grassell, SG Smith, T Counihan, R Perry, and S Bickford. 2005. Guidelines and Recommended Protocols for Conducting, Analyzing, and Reporting Juvenile Salmonid Survival Studies in the Columbia River Basin. Published electronically; available in PDF electronic format from chuckp@chelanpud.org.

Ploskey GR, MA Weiland, JS Hughes, SR Zimmerman, RE Durham, ES Fischer, J Kim, RL Townsend, JR Skalski, and RL McComas. 2007. Acoustic Telemetry Studies of Juvenile Chinook Salmon Survival at the Lower Columbia Projects in 2006. PNNL-16560, prepared for U.S. Army Corps of Engineers District, Portland, Oregon, by Pacific Northwest National Laboratory, Richland, Washington.

Ploskey GR, MA Weiland, JS Hughes, SR Zimmerman, RE Durham, ES Fischer, J Kim, RL Townsend, JR Skalski, RA Buchanan, and RL McComas. 2008. Survival of Juvenile Chinook Salmon Passing the Bonneville Dam Spillway in 2007. PNNL-18113, prepared for U.S. Army Corps of Engineers District, Portland, Oregon, by Pacific Northwest National Laboratory, Richland, Washington.

Ploskey GR, MA Weiland, DM Faber, Z Deng, GE Johnson, JS Hughes, SA Zimmerman, TJ Monter,AW Cushing, MC Wilberding, RE Durham, RL Townsend, JR Skalski, RA Buchanan, J Kim, ES Fischer,MM Meyer, RL McComas, and JP Everett. 2009. Survival Rates of Juvenile Salmonids Passing Through the Bonneville Dam and Spillway in 2008. PNNL-18748, prepared for U.S. Army Corps of Engineers District, Portland, Oregon, by Pacific Northwest National Laboratory, Richland, Washington. Seber GAF. 1982. The Estimation of Animal Abundance. MacMillan, New York.

Skalski JR, GE Johnson, CM Sullivan, EA Kudera, and MW Erho. 1996. "Statistical Evaluation of Turbine Bypass Efficiency at Wells Dam on the Columbia River, Washington." Can. J. Fish. Aquat. Sci. 53:2188-2198.

Skalski JR, SG Smith, RN Iwamoto, JF Williams, and A Hoffmann. 1998. "Use of PIT-Tags to Estimate Survival of Migrating Juvenile Salmonids in the Snake and Columbia Rivers." Canadian Journal of Fisheries and Aquatic Sciences 55:1484-1493.

Spiesberger JL and KM Fristrup. 1990. "Passive Location of Calling Animals and Sensing of Their Acoustic Environment Using Acoustic Tomography.” Am. Nat. 135:107-153.

Sweeney CE, R Hall, AE Giorgi, M Miller, and GE Johnson. 2007. Surface Bypass Program Comprehensive Review Report. ENSR Document No. 09000-399-0409, prepared for the U.S. Army Corps of Engineers, Portland District, Portland, Oregon, by ENSR/AECOM, BioAnalysts, Inc., and Pacific Northwest National Laboratory, published by ENSR, Redmond, Washington.

Torieri DJ. 1984. "Statistical Theory of Passive Location Systems." IEEE Trans. Aerospace Electronic Systems 20:183-198.

Townsend RL, JR Skalski, P Dillingham, and TW Steig. 2006. "Correcting Bias in Survival Estimation Resulting from Tag Failure in Acoustic and Radiotelemetry Studies." Journal of Agricultural Biology and Environmental Statistics 11(2):183-196.

U.S. Army Corps of Engineers (USACE). 1995. "Lower Snake and Columbia Rivers Surface Bypass and Collection Systems Prototype Development Program." Portland and Walla Walla Districts, USACE, Walla Walla, Washington. 
U.S. Army Corps of Engineers (USACE) Portland District. 2007. John Day Lock and Dam Configuration and Operation Plan. USACE, Portland District, Portland, Oregon.

Wahlberg M, B Mohl, and PT Madsen. 2001. "Estimating Source Position Accuracy of a LargeAperture Hydrophone Array for Bioacoustics." Jour. Acoust. Soc. Am. 109(1):397-406.

Watkins WA and WE Schevill. 1972. "Sound Source Location by Arrival-Times on a Non-Rigid ThreeDimensional Hydrophone Array." Deep-Sea Res. 19:691-706.

Weiland MA, GR Ploskey, JS Hughes, Z Deng, T Fu, TJ Monter, GE Johnson, F Khan, MC Wilberding, AW Cushing, SA Zimmerman, DM Faber, RE Durham, RL Townsend, JR Skalski, J Kim, ES Fischer, and MM Meyer. 2009. Acoustic Telemetry Evaluation of Juvenile Salmonid Passage and Survival at John Day Dam with Emphasis on the Prototype Surface Flow Outlet, 2008. PNNL-18890, prepared for U.S. Army Corps of Engineers District, Portland, Oregon, by Pacific Northwest National Laboratory, Richland, Washington. 
Appendix A

\section{Tagging Tables}




\section{Appendix A}

\section{Tagging Tables}

Table A.1. Yearling Chinook Salmon and Steelhead Tagged at the JDA SMF and Released near Roosevelt, Washington, in Spring 2009

\begin{tabular}{|c|c|c|c|c|}
\hline Tag Date & Release Date & Number Tagged & Species & Number Released \\
\hline \multirow{2}{*}{$4 / 26 / 2009$} & \multirow{2}{*}{$4 / 27 / 2009$} & \multirow{2}{*}{229} & Steelhead & 115 \\
\hline & & & Yearling Chinook & 114 \\
\hline \multirow{2}{*}{$4 / 27 / 2009$} & \multirow{2}{*}{$4 / 28 / 2009$} & \multirow{2}{*}{232} & Steelhead & 116 \\
\hline & & & Yearling Chinook & 116 \\
\hline \multirow{2}{*}{$4 / 28 / 2009$} & \multirow{2}{*}{$4 / 29 / 2009$} & \multirow{2}{*}{231} & Steelhead & 115 \\
\hline & & & Yearling Chinook & 116 \\
\hline \multirow{2}{*}{$4 / 29 / 2009$} & \multirow{2}{*}{$4 / 30 / 2009$} & \multirow{2}{*}{231} & Steelhead & 116 \\
\hline & & & Yearling Chinook & 115 \\
\hline \multirow{2}{*}{$4 / 30 / 2009$} & \multirow{2}{*}{$5 / 1 / 2009$} & \multirow{2}{*}{225} & Steelhead & 110 \\
\hline & & & Yearling Chinook & 115 \\
\hline \multirow{2}{*}{$5 / 1 / 2009$} & \multirow{2}{*}{$5 / 2 / 2009$} & \multirow{2}{*}{231} & Steelhead & 116 \\
\hline & & & Yearling Chinook & 115 \\
\hline \multirow{2}{*}{$5 / 2 / 2009$} & \multirow{2}{*}{$5 / 3 / 2009$} & \multirow{2}{*}{237} & Steelhead & 120 \\
\hline & & & Yearling Chinook & 117 \\
\hline \multirow{2}{*}{$5 / 3 / 2009$} & \multirow{2}{*}{$5 / 4 / 2009$} & \multirow{2}{*}{232} & Steelhead & 116 \\
\hline & & & Yearling Chinook & 116 \\
\hline \multirow{2}{*}{$5 / 4 / 2009$} & \multirow{2}{*}{$5 / 5 / 2009$} & \multirow{2}{*}{232} & Steelhead & 116 \\
\hline & & & Yearling Chinook & 116 \\
\hline \multirow{2}{*}{$5 / 5 / 2009$} & \multirow{2}{*}{$5 / 6 / 2009$} & 232 & Steelhead & 116 \\
\hline & & 232 & Yearling Chinook & 116 \\
\hline & & & Steelhead & 115 \\
\hline $5 / 6 / 2009$ & $5 / 7 / 2009$ & 229 & Yearling Chinook & 114 \\
\hline $5 / 7 / 2009$ & $5 / 8 / 2000$ & 231 & Steelhead & 116 \\
\hline $5 / 1 / 2009$ & $5 / 8 / 2009$ & 231 & Yearling Chinook & 115 \\
\hline & & & Steelhead & 115 \\
\hline $5 / 8 / 2009$ & $5 / 9 / 2009$ & 230 & Yearling Chinook & 115 \\
\hline $5 / 0 / 2000$ & $5 / 10 / 2000$ & 233 & Steelhead & 116 \\
\hline $5 / 9 / 2009$ & $5 / 10 / 2009$ & 233 & Yearling Chinook & 117 \\
\hline $5 / 10 / 2000$ & & 230 & Steelhead & 115 \\
\hline $5 / 10 / 2009$ & $5 / 11 / 2009$ & 230 & Yearling Chinook & 115 \\
\hline $5 / 11 / 2000$ & $5 / 12 / 2000$ & & Steelhead & 116 \\
\hline $5 / 11 / 2009$ & $5 / 12 / 2009$ & 232 & Yearling Chinook & 116 \\
\hline & & & Steelhead & 115 \\
\hline $5 / 12 / 2009$ & $5 / 13 / 2009$ & 230 & Yearling Chinook & 115 \\
\hline
\end{tabular}


Table A.1. (contd)

\begin{tabular}{|c|c|c|c|c|}
\hline Tag Date & Release Date & Number Tagged & Species & Number Released \\
\hline \multirow{2}{*}{$5 / 13 / 2009$} & \multirow{2}{*}{$5 / 14 / 2009$} & \multirow{2}{*}{232} & Steelhead & 116 \\
\hline & & & Yearling Chinook & 116 \\
\hline \multirow{2}{*}{$5 / 14 / 2009$} & \multirow{2}{*}{$5 / 15 / 2009$} & \multirow{2}{*}{219} & Steelhead & 104 \\
\hline & & & Yearling Chinook & 115 \\
\hline \multirow{2}{*}{$5 / 15 / 2009$} & \multirow{2}{*}{$5 / 16 / 2009$} & \multirow{2}{*}{235} & Steelhead & 120 \\
\hline & & & Yearling Chinook & 115 \\
\hline \multirow{2}{*}{$5 / 16 / 2009$} & \multirow{2}{*}{$5 / 17 / 2009$} & \multirow{2}{*}{234} & Steelhead & 120 \\
\hline & & & Yearling Chinook & 114 \\
\hline \multirow{2}{*}{$5 / 17 / 2009$} & \multirow{2}{*}{$5 / 18 / 2009$} & \multirow{2}{*}{235} & Steelhead & 118 \\
\hline & & & Yearling Chinook & 117 \\
\hline \multirow{2}{*}{$5 / 18 / 2009$} & \multirow{2}{*}{$5 / 19 / 2009$} & \multirow{2}{*}{234} & Steelhead & 116 \\
\hline & & & Yearling Chinook & 118 \\
\hline \multirow{2}{*}{$5 / 19 / 2009$} & \multirow{2}{*}{$5 / 20 / 2009$} & \multirow{2}{*}{232} & Steelhead & 116 \\
\hline & & & Yearling Chinook & 116 \\
\hline \multirow{2}{*}{$5 / 20 / 2009$} & \multirow{2}{*}{$5 / 21 / 2009$} & \multirow{2}{*}{230} & Steelhead & 115 \\
\hline & & & Yearling Chinook & 115 \\
\hline \multirow{2}{*}{$5 / 21 / 2009$} & \multirow{2}{*}{$5 / 22 / 2009$} & \multirow{2}{*}{231} & Steelhead & 116 \\
\hline & & & Yearling Chinook & 115 \\
\hline \multirow{2}{*}{$5 / 22 / 2009$} & \multirow{2}{*}{$5 / 23 / 2009$} & \multirow{2}{*}{224} & Steelhead & 113 \\
\hline & & & Yearling Chinook & 111 \\
\hline \multirow{2}{*}{$5 / 23 / 2009$} & \multirow{2}{*}{$5 / 24 / 2009$} & 238 & Steelhead & 118 \\
\hline & & 250 & Yearling Chinook & 120 \\
\hline $5 / 24 / 2009$ & $5 / 25 / 2009$ & 239 & Steelhead & 119 \\
\hline לטסט ודים ות & 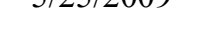 & (2) & Yearling Chinook & 120 \\
\hline $5 / 25 / 2000$ & $5 / 26 / 2000$ & 231 & Steelhead & 116 \\
\hline 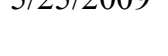 & 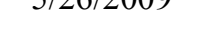 & 231 & Yearling Chinook & 115 \\
\hline Totals & Totals & 6941 & Steelhead & 3471 \\
\hline 10tato & 10tais & (דונט & Yearling Chinook & 3470 \\
\hline
\end{tabular}


Table A.2. Subyearling Chinook Salmon Tagged at the JDA SMF and Released near Roosevelt, Washington, in Summer 2009

\begin{tabular}{|c|c|c|c|}
\hline Tag Date & Release Date & Number Tagged & Number Released \\
\hline $6 / 15 / 2009$ & $6 / 16 / 2009$ & 114 & 114 \\
\hline $6 / 16 / 2009$ & $6 / 17 / 2009$ & 117 & 117 \\
\hline $6 / 17 / 2009$ & $6 / 18 / 2009$ & 115 & 115 \\
\hline $6 / 18 / 2009$ & $6 / 19 / 2009$ & 115 & 115 \\
\hline $6 / 19 / 2009$ & $6 / 20 / 2009$ & 113 & 113 \\
\hline $6 / 20 / 2009$ & $6 / 21 / 2009$ & 116 & 116 \\
\hline $6 / 21 / 2009$ & $6 / 22 / 2009$ & 115 & 115 \\
\hline $6 / 22 / 2009$ & $6 / 23 / 2009$ & 118 & 118 \\
\hline $6 / 23 / 2009$ & $6 / 24 / 2009$ & 116 & 116 \\
\hline $6 / 24 / 2009$ & $6 / 25 / 2009$ & 117 & 117 \\
\hline $6 / 25 / 2009$ & $6 / 26 / 2009$ & 115 & 115 \\
\hline $6 / 26 / 2009$ & $6 / 27 / 2009$ & 116 & 116 \\
\hline $6 / 27 / 2009$ & $6 / 28 / 2009$ & 115 & 115 \\
\hline $6 / 28 / 2009$ & $6 / 29 / 2009$ & 116 & 116 \\
\hline $6 / 29 / 2009$ & $6 / 30 / 2009$ & 115 & 115 \\
\hline $6 / 30 / 2009$ & $7 / 1 / 2009$ & 116 & 116 \\
\hline $7 / 1 / 2009$ & $7 / 2 / 2009$ & 114 & 114 \\
\hline 7/2/2009 & $7 / 3 / 2009$ & 116 & 116 \\
\hline $7 / 3 / 2009$ & $7 / 4 / 2009$ & 115 & 115 \\
\hline $7 / 4 / 2009$ & $7 / 5 / 2009$ & 113 & 113 \\
\hline $7 / 5 / 2009$ & 7/6/2009 & 114 & 114 \\
\hline $7 / 6 / 2009$ & 7/7/2009 & 119 & 119 \\
\hline 7/7/2009 & 7/8/2009 & 115 & 115 \\
\hline 7/8/2009 & 7/9/2009 & 116 & 116 \\
\hline 7/9/2009 & $7 / 10 / 2009$ & 94 & 94 \\
\hline $7 / 10 / 2009$ & $7 / 11 / 2009$ & 120 & 120 \\
\hline $7 / 11 / 2009$ & $7 / 12 / 2009$ & 118 & 118 \\
\hline $7 / 12 / 2009$ & $7 / 13 / 2009$ & 120 & 120 \\
\hline $7 / 13 / 2009$ & $7 / 14 / 2009$ & 118 & 118 \\
\hline $7 / 14 / 2009$ & $7 / 15 / 2009$ & 120 & 120 \\
\hline Totals & Totals & 3461 & 3461 \\
\hline
\end{tabular}


Appendix B

Hydrophone and Autonomous Node Deployment Tables 


\section{Appendix B}

\section{Hydrophone and Autonomous Node Deployment Tables}

Table B.1. 2009 John Day Dam-Face Hydrophone Deployment

\begin{tabular}{|c|c|c|c|c|c|c|c|c|c|c|c|c|}
\hline System & Pier Nose & $\begin{array}{l}\text { Elevation } \\
\text { Category }\end{array}$ & Trailer & $\begin{array}{l}\text { Y-Block } \\
\text { Color }\end{array}$ & Channel & $\begin{array}{l}\text { Y-Block } \\
\text { Location }\end{array}$ & $\begin{array}{l}\text { Beldon } \\
\text { Cable (ft) }\end{array}$ & $\begin{array}{c}\text { Deck } \\
\text { Cable (ft) }\end{array}$ & $\begin{array}{l}\text { Nod } \\
\text { e SN }\end{array}$ & Northing & Easting & $\begin{array}{c}\text { Elevation } \\
\text { (MSL) }\end{array}$ \\
\hline \multirow[t]{4}{*}{ P0 } & 0 & $\mathrm{~S}$ & PH South & Green & 1 & 0 & 150 & 250 & 12 & 745714.97 & 8153831.93 & 259.64 \\
\hline & 0 & $\mathrm{~S}$ & & Blue & 2 & & 150 & & 100 & 745762.90 & 8153797.32 & 259.50 \\
\hline & $\mathrm{C} 1$ & FOREBAY & & Yellow & 3 & & 150 & & 183 & 746016.31 & 8153759.87 & \\
\hline & $\mathrm{C} 2$ & FOREBAY & & Red & 4 & & 150 & & 209 & 746352.82 & 8153513.46 & \\
\hline \multirow[t]{4}{*}{ P1 } & $0-1$ & $\mathrm{~S}$ & PH South & Green & 1 & $1-2$ & 150 & 250 & 18 & 745814.84 & 8153758.42 & 255.23 \\
\hline & $1-2$ & $\mathrm{D}$ & & Blue & 2 & & 150 & & 19 & 745890.46 & 8153711.93 & 169.54 \\
\hline & $2-3$ & $\mathrm{~S}$ & & Yellow & 3 & & 150 & & 39 & 745959.26 & 8153654.16 & 255.34 \\
\hline & $3-4$ & $\mathrm{D}$ & & Red & 4 & & 350 & & 20 & 746036.31 & 8153606.67 & 169.46 \\
\hline \multirow[t]{4}{*}{ P2 } & $0-1$ & $\mathrm{D}$ & PH South & Green & 1 & $2-3$ & 350 & 250 & 24 & 745819.01 & 8153763.51 & 169.42 \\
\hline & $1-2$ & $\mathrm{~S}$ & & Blue & 2 & & 150 & & 13 & 745886.29 & 8153706.83 & 255.34 \\
\hline & $2-3$ & $\mathrm{D}$ & & Yellow & 3 & & 150 & & 152 & 745963.43 & 8153659.25 & 169.54 \\
\hline & $3-4$ & $\mathrm{~S}$ & & Red & 4 & & 150 & & 15 & 746032.14 & 8153601.58 & 255.27 \\
\hline \multirow[t]{4}{*}{ P3 } & $4-5$ & $\mathrm{~S}$ & PH South & Green & 1 & $5-6$ & 150 & 500 & 130 & 746104.93 & 8153548.78 & 255.26 \\
\hline & $5-6$ & $\mathrm{D}$ & & Blue & 2 & & 150 & & 174 & 746182.24 & 8153501.22 & 169.40 \\
\hline & $6-7$ & $\mathrm{~S}$ & & Yellow & 3 & & 150 & & 226 & 746251.01 & 8153443.52 & 255.62 \\
\hline & $7-8$ & $\mathrm{D}$ & & Red & 4 & & 350 & & 239 & 746328.24 & 8153395.89 & 169.43 \\
\hline \multirow[t]{4}{*}{ P4 } & $4-5$ & $\mathrm{D}$ & PH Unit 8 & Green & 1 & $6-7$ & 350 & 350 & 137 & 746109.10 & 8153553.88 & 169.45 \\
\hline & $5-6$ & $\mathrm{~S}$ & & Blue & 2 & & 150 & & 17 & 746178.07 & 8153496.13 & 255.21 \\
\hline & $6-7$ & D & & Yellow & 3 & & 150 & & 241 & 746255.18 & 8153448.61 & 169.56 \\
\hline & $7-8$ & S & & Red & 4 & & 150 & & 142 & 746324.07 & 8153390.80 & 255.49 \\
\hline \multirow[t]{4}{*}{ P5 } & $8-9$ & $\mathrm{~S}$ & PH Unit 8 & Green & 1 & $9-10$ & 150 & 250 & 42 & 746397.01 & 8153338.14 & 255.39 \\
\hline & $9-10$ & $\mathrm{D}$ & & Blue & 2 & & 150 & & 155 & 746473.96 & 8153290.39 & 169.49 \\
\hline & $10-11$ & $\mathrm{~S}$ & & Yellow & 3 & & 150 & & 223 & 746542.78 & 8153232.56 & 255.56 \\
\hline & $11-12$ & $\mathrm{D}$ & & Red & 4 & & 350 & & 233 & 746620.13 & 8153184.99 & 169.46 \\
\hline
\end{tabular}


Table B.1. (contd)

\begin{tabular}{|c|c|c|c|c|c|c|c|c|c|c|c|c|}
\hline System & Pier Nose & $\begin{array}{l}\text { Elevation } \\
\text { Category }\end{array}$ & Trailer & $\begin{array}{l}\text { Y-Block } \\
\text { Color }\end{array}$ & Channel & $\begin{array}{l}\text { Y-Block } \\
\text { Location }\end{array}$ & $\begin{array}{l}\text { Beldon } \\
\text { Cable (ft) }\end{array}$ & $\begin{array}{c}\text { Deck } \\
\text { Cable (ft) }\end{array}$ & $\begin{array}{l}\text { Nod } \\
\text { e SN }\end{array}$ & Northing & Easting & $\begin{array}{c}\text { Elevation } \\
\text { (MSL) }\end{array}$ \\
\hline \multirow[t]{4}{*}{ P6 } & $8-9$ & $\mathrm{D}$ & PH Unit 8 & Green & 1 & $10-11$ & 350 & 500 & 238 & 746401.18 & 8153343.24 & 169.33 \\
\hline & $9-10$ & $\mathrm{~S}$ & & Blue & 2 & & 150 & & 154 & 746469.79 & 8153285.30 & 255.54 \\
\hline & $10-11$ & $\mathrm{D}$ & & Yellow & 3 & & 150 & & 240 & 746546.95 & 8153237.66 & 169.50 \\
\hline & $11-12$ & $\mathrm{~S}$ & & Red & 4 & & 150 & & 151 & 746615.96 & 8153179.90 & 255.51 \\
\hline \multirow[t]{4}{*}{ P7 } & $12-13$ & $\mathrm{~S}$ & PH Unit 8 & Green & 1 & $13-14$ & 150 & 750 & 227 & 746688.83 & 8153127.26 & 255.59 \\
\hline & $13-14$ & $\mathrm{D}$ & & Blue & 2 & & 150 & & 243 & 746766.00 & 8153079.59 & 169.35 \\
\hline & $14-15$ & $\mathrm{~S}$ & & Yellow & 3 & & 150 & & 157 & 746834.78 & 8153022.15 & 255.41 \\
\hline & $15-16$ & $\mathrm{D}$ & & Red & 4 & & 350 & & 218 & 746911.90 & 8152974.45 & 169.43 \\
\hline \multirow[t]{4}{*}{ P8 } & $12-13$ & $\mathrm{D}$ & PH Unit 8 & Green & 1 & $14-15$ & 350 & & 234 & 746693.00 & 8153132.36 & 169.53 \\
\hline & $13-14$ & $\mathrm{~S}$ & & Blue & 2 & & 150 & 750 & 175 & 746761.83 & 8153074.49 & 255.40 \\
\hline & $14-15$ & $\mathrm{D}$ & & Yellow & 3 & & 150 & & 242 & 746838.95 & 8153027.24 & 169.36 \\
\hline & $15-16$ & $\mathrm{~S}$ & & Red & 4 & & 150 & & 188 & 746907.73 & 8152969.35 & 255.49 \\
\hline \multirow[t]{4}{*}{ P9 } & $16-17$ & $\mathrm{~S}$ & PH Unit 19 & Green & 1 & $17-18$ & 150 & 850 & 115 & 746980.62 & 8152916.49 & 255.60 \\
\hline & $17-18$ & $\mathrm{D}$ & & Blue & 2 & & 150 & & 177 & 747057.69 & 8152868.87 & 169.36 \\
\hline & $18-19$ & $\mathrm{~S}$ & & Yellow & 3 & & 150 & & 123 & 747126.39 & 8152811.13 & 255.47 \\
\hline & $19-20$ & $\mathrm{D}$ & & Red & 4 & & 350 & & 138 & 747203.50 & 8152763.54 & 169.46 \\
\hline \multirow[t]{4}{*}{ P10 } & $16-17$ & $\mathrm{D}$ & PH Unit 19 & Green & 1 & $18-19$ & 350 & 500 & 140 & 746984.79 & 8152921.59 & 169.54 \\
\hline & $17-18$ & $\mathrm{~S}$ & & Blue & 2 & & 150 & & 111 & 747053.52 & 8152863.77 & 255.42 \\
\hline & $18-19$ & $\mathrm{D}$ & & Yellow & 3 & & 150 & & 136 & 747130.56 & 8152816.22 & 169.41 \\
\hline & $19-20$ & $\mathrm{~S}$ & & Red & 4 & & 150 & & 126 & 747199.33 & 8152758.45 & 255.52 \\
\hline \multirow[t]{4}{*}{ PS11 } & 20-ph & $\mathrm{S}$ & PH Unit 19 & Green & 1 & $20-20$ & 150 & 250 & 128 & 747273.24 & 8152705.03 & 255.52 \\
\hline & $20 \mathrm{sp}$ & D & & Blue & 2 & & 150 & & 48 & 747297.22 & 8152677.93 & 232.53 \\
\hline & $19-20 \mathrm{sp}$ & S & & Yellow & 3 & & 150 & & 30 & 747346.71 & 8152641.53 & 259.78 \\
\hline & $18-19 \mathrm{sp}$ & $\mathrm{D}$ & & Red & 4 & & 246 & & 217 & 747397.02 & 8152605.21 & 232.61 \\
\hline \multirow[t]{4}{*}{ PS12 } & 20-ph & $\mathrm{D}$ & PH Unit 19 & Green & 1 & $19-20 \mathrm{SP}$ & 350 & 600 & 135 & 747277.41 & 8152710.12 & 169.46 \\
\hline & $20 \mathrm{sp}$ & $\mathrm{S}$ & & Blue & 2 & & 150 & & 36 & 747297.22 & 8152677.93 & 259.70 \\
\hline & $19-20 \mathrm{sp}$ & $\mathrm{D}$ & & Yellow & 3 & & 150 & & 213 & 747346.71 & 8152641.53 & 232.61 \\
\hline & $18-19 \mathrm{sp}$ & $\mathrm{S}$ & & Red & 4 & & 150 & & 112 & 747397.02 & 8152605.21 & 259.78 \\
\hline
\end{tabular}


Table B.1. (contd)

\begin{tabular}{|c|c|c|c|c|c|c|c|c|c|c|c|c|}
\hline System & Pier Nose & $\begin{array}{l}\text { Elevation } \\
\text { Category }\end{array}$ & Trailer & $\begin{array}{l}\text { Y-Block } \\
\text { Color }\end{array}$ & Channel & $\begin{array}{l}\text { Y-Block } \\
\text { Location }\end{array}$ & $\begin{array}{c}\text { Beldon } \\
\text { Cable (ft) }\end{array}$ & $\begin{array}{c}\text { Deck } \\
\text { Cable (ft) }\end{array}$ & $\begin{array}{l}\text { Nod } \\
\text { e SN }\end{array}$ & Northing & Easting & $\begin{array}{c}\text { Elevation } \\
\text { (MSL) }\end{array}$ \\
\hline \multirow[t]{4}{*}{ S13 } & $17-18$ & $\mathrm{~S}$ & PH Unit 19 & Green & 1 & $16-17$ & 150 & 500 & 23 & 747447.22 & 8152568.92 & 259.93 \\
\hline & $16-17$ & $\mathrm{D}$ & & Blue & 2 & & 150 & & 127 & 747497.65 & 8152532.55 & 232.45 \\
\hline & $15-16$ & $\mathrm{~S}$ & & Yellow & 3 & & 150 & & 187 & 747548.01 & 8152496.25 & 259.35 \\
\hline & $14-15$ & D & & Red & 4 & & 250 & & 216 & 747598.24 & 8152459.90 & 232.35 \\
\hline \multirow[t]{4}{*}{ S14 } & $17-18$ & D & PH Unit 19 & Green & 1 & $15-16$ & 250 & 500 & 29 & 747447.22 & 8152568.92 & 232.76 \\
\hline & $16-17$ & $\mathrm{~S}$ & & Blue & 2 & & 150 & & 45 & 747497.65 & 8152532.55 & 259.62 \\
\hline & $15-16$ & $\mathrm{D}$ & & Yellow & 3 & & 100 & & 228 & 747548.01 & 8152496.25 & 232.18 \\
\hline & $14-15$ & $\mathrm{~S}$ & & Red & 4 & & 150 & & 178 & 747598.24 & 8152459.90 & 259.52 \\
\hline \multirow[t]{4}{*}{ S15 } & $13-14$ & $\mathrm{~S}$ & PH Unit 19 & Green & 1 & $12-13$ & 150 & 750 & 133 & 747648.47 & 8152423.58 & 259.71 \\
\hline & $12-13$ & $\mathrm{D}$ & & Blue & 2 & & 100 & & 225 & 747698.84 & 8152387.29 & 232.44 \\
\hline & $11-12$ & $\mathrm{~S}$ & & Yellow & 3 & & 150 & & 28 & 747748.83 & 8152350.94 & 259.87 \\
\hline & $10-11$ & D & & Red & 4 & & 250 & & 119 & 747799.16 & 8152314.60 & 232.38 \\
\hline \multirow[t]{4}{*}{ S16 } & $13-14$ & D & PH Unit 19 & Green & 1 & $11-12$ & 250 & 750 & 134 & 747648.47 & 8152423.58 & 232.54 \\
\hline & $12-13$ & $\mathrm{~S}$ & & Blue & 2 & & 150 & & 180 & 747698.84 & 8152387.29 & 259.61 \\
\hline & $11-12$ & $\mathrm{D}$ & & Yellow & 3 & & 100 & & 164 & 747748.83 & 8152350.94 & 232.70 \\
\hline & $10-11$ & S & & Red & 4 & & 150 & & 60 & 747799.16 & 8152314.60 & 259.55 \\
\hline \multirow[t]{4}{*}{ S17 } & $9-10$ & S & SP North & Green & 1 & $8-9$ & 150 & 600 & 47 & 747849.50 & 8152278.53 & 259.81 \\
\hline & $8-9$ & D & & Blue & 2 & & 100 & & 229 & 747899.71 & 8152242.06 & 232.70 \\
\hline & $7-8$ & $\mathrm{~S}$ & & Yellow & 3 & & 150 & & 109 & 747949.84 & 8152205.89 & 259.86 \\
\hline & $6-7$ & $\mathrm{D}$ & & Red & 4 & & 250 & & 231 & 748000.70 & 8152169.33 & 232.62 \\
\hline \multirow[t]{4}{*}{ S18 } & $9-10$ & D & SP North & Green & 1 & $7-8$ & 250 & 558 & 132 & 747849.50 & 8152278.53 & 232.64 \\
\hline & $8-9$ & S & & Blue & 2 & & 150 & & 32 & 747899.71 & 8152242.06 & 259.87 \\
\hline & $7-8$ & $\mathrm{D}$ & & Yellow & 3 & & 100 & & 237 & 747949.84 & 8152205.89 & 232.69 \\
\hline & $6-7$ & $\mathrm{~S}$ & & Red & 4 & & 150 & & 148 & 748000.70 & 8152169.33 & 259.79 \\
\hline \multirow[t]{4}{*}{ S19 } & $5-6$ & S & SP North & Green & 1 & $4-5$ & 150 & 500 & 16 & 748050.73 & 8152133.20 & 259.81 \\
\hline & $4-5$ & $\mathrm{D}$ & & Blue & 2 & & 100 & & 46 & 748101.13 & 8152097.00 & 232.30 \\
\hline & $3-4$ & S & & Yellow & 3 & & 150 & & 45 & 748151.05 & 8152060.87 & 259.76 \\
\hline & $2-3$ & $\mathrm{D}$ & & Red & 4 & & 250 & & 179 & 748201.45 & 8152024.74 & 232.38 \\
\hline
\end{tabular}


Table B.1. (contd)

\begin{tabular}{|c|c|c|c|c|c|c|c|c|c|c|c|c|}
\hline System & Pier Nose & $\begin{array}{l}\text { Elevation } \\
\text { Category }\end{array}$ & Trailer & $\begin{array}{l}\text { Y-Block } \\
\text { Color }\end{array}$ & Channel & $\begin{array}{l}\text { Y-Block } \\
\text { Location }\end{array}$ & $\begin{array}{l}\text { Beldon } \\
\text { Cable (ft) }\end{array}$ & $\begin{array}{c}\text { Deck } \\
\text { Cable (ft) }\end{array}$ & $\begin{array}{l}\text { Nod } \\
\text { e SN }\end{array}$ & Northing & Easting & $\begin{array}{c}\text { Elevation } \\
\text { (MSL) }\end{array}$ \\
\hline \multirow[t]{4}{*}{ S20 } & $5-6$ & $\mathrm{D}$ & SP North & Green & 1 & $3-4$ & 250 & 500 & 21 & 748050.73 & 8152133.20 & 232.64 \\
\hline & $4-5$ & S & & Blue & 2 & & 150 & & 26 & 748101.13 & 8152097.00 & 259.47 \\
\hline & $3-4$ & $\mathrm{D}$ & & Yellow & 3 & & 100 & & 153 & 748151.05 & 8152060.87 & 232.59 \\
\hline & $2-3$ & S & & Red & 4 & & 150 & & 49 & 748201.45 & 8152024.74 & 259.55 \\
\hline \multirow[t]{4}{*}{ S21 } & $1-2$ & $\mathrm{D}$ & SP North & Green & 1 & 1 & 150 & 250 & 244 & 748251.90 & 8151988.45 & 232.73 \\
\hline & $1-2$ & $\mathrm{~S}$ & & Blue & 2 & & 150 & & 118 & 748251.90 & 8151988.45 & 259.90 \\
\hline & 1 & South & SP North & Yellow & 3 & & 150 & & 102 & 748306.74 & 8151947.97 & 259.32 \\
\hline & 1 & North & & Red & 4 & & 150 & & 105 & 748379.55 & 8151915.63 & 259.72 \\
\hline P0 & $\mathrm{C} 1$ & FOREBAY & PH South & Yellow & 3 & & 500 & 500 & 183 & 746016.31 & 8153759.87 & \\
\hline P0 & $\mathrm{C} 2$ & FOREBAY & PH South & Red & 4 & & 500 & & 209 & 746352.82 & 8153513.46 & \\
\hline $\mathrm{C} 2$ & $\mathrm{C} 3$ & FOREBAY & PH Unit 19 & Green & 1 & & 1000 & 820 & 110 & 746676.78 & 8153280.25 & \\
\hline $\mathrm{C} 2$ & $\mathrm{C} 4$ & FOREBAY & PH Unit 19 & Blue & 2 & & 500 & & 232 & 747007.46 & 8153040.23 & \\
\hline $\mathrm{C} 2$ & $\mathrm{C} 5$ & FOREBAY & PH Unit 19 & Yellow & 3 & & 500 & & 235 & 747338.71 & 8152798.69 & \\
\hline $\mathrm{C} 2$ & C6 & FOREBAY & PH Unit 19 & Green & 4 & & 1000 & 1250 & 104 & 747630.17 & 8152583.15 & \\
\hline $\mathrm{C} 3$ & $\mathrm{C} 7$ & FOREBAY & SP North & Green & 1 & & 500 & 500 & 51 & 747916.39 & 8152377.01 & \\
\hline $\mathrm{C} 3$ & $\mathrm{C} 8$ & FOREBAY & SP North & Blue & 2 & & 500 & & 144 & 748244.91 & 8152142.27 & \\
\hline
\end{tabular}


Table B.2. Approximate Global Positioning System Coordinates of Autonomous Nodes Deployed in 2009 by Array. Array node is a concatenation of the array name and autonomous node number, which incremented with increasing distance from the Washington shore toward Oregon. Array name is a concatenation of " $\mathrm{A}$ " for autonomous, a single digit indicating the successive array number from Roosevelt, Washington, downstream to Oak Point, Washington, and "CR" for Columbia River.

\begin{tabular}{|c|c|c|c|c|}
\hline Array_Node & Array Function & $\begin{array}{l}\text { Latitude in } \\
\text { decimal deg. (neg. } \\
\text { is south) }\end{array}$ & $\begin{array}{c}\text { Longitude in } \\
\text { decimal deg. (neg. } \\
\text { is west) }\end{array}$ & $\begin{array}{l}\text { Approximate } \\
\text { Depth (m) }\end{array}$ \\
\hline A1CR351_01 & JDA FB Entrance & 45.731319 & -120.67719 & 85 \\
\hline A1CR351_02 & & 45.730279 & -120.67585 & 133 \\
\hline A1CR351_03 & & 45.729167 & -120.67479 & 100 \\
\hline A1CR351_04 & & 45.728181 & -120.67370 & 115 \\
\hline A1CR351_05 & & 45.727194 & -120.67252 & 115 \\
\hline A1CR351_06 & & 45.726136 & -120.67133 & 115 \\
\hline A1CR351_07 & & 45.725114 & -120.67004 & 180 \\
\hline A1CR351_08 & & 45.724074 & -120.66888 & 100 \\
\hline A2CR346_01 & JDA TW Egress & 45.708464 & -120.72577 & 20 \\
\hline A2CR346_02 & & 45.707495 & -120.72507 & 24 \\
\hline A2CR346_03 & & 45.706436 & -120.72420 & 42 \\
\hline A2CR346_04 & & 45.705772 & -120.72368 & 67 \\
\hline A3CR311_01 & JDA Primary & 45.629886 & -121.11286 & 50 \\
\hline A3CR311_02 & & 45.629148 & -121.11175 & 130 \\
\hline A3CR311_03 & & 45.628338 & -121.11035 & 45 \\
\hline A3CR311_04 & & 45.627708 & -121.10929 & 42 \\
\hline A3CR311_05 & & 45.627024 & -121.10810 & 50 \\
\hline A4CR236_01 & BON FB Entrance \& JDA Secondary & 45.649388 & -121.92339 & 55 \\
\hline A4CR236_02 & & 45.648956 & -121.92282 & 73 \\
\hline A4CR236_03 & & 45.648417 & -121.92226 & 80 \\
\hline A4CR236_04 & & 45.647985 & -121.92174 & 56 \\
\hline A5CR192_01 & JDA Tertiary; BON Primary & 45.576289 & -122.42849 & 32 \\
\hline A5CR192_02 & & 45.568721 & -122.42088 & 72 \\
\hline A5CR192_03 & & 45.568105 & -122.42180 & 64 \\
\hline A5CR192_04 & & 45.567490 & -122.42083 & 59 \\
\hline A5CR192_05 & & 45.566874 & -122.42186 & 48 \\
\hline A5CR192_06 & & 45.566294 & -122.42078 & 42 \\
\hline A5CR192_07 & & 45.565751 & -122.42186 & 32 \\
\hline A5CR192_08 & & 45.565208 & -122.42088 & 29 \\
\hline A5CR192_09 & & 45.564519 & -122.42186 & 26 \\
\hline A6CR113_01 & BON Secondary & 46.063202 & -122.86923 & 36 \\
\hline A6CR113_02 & & 46.070685 & -122.88697 & 56 \\
\hline A6CR113_03 & & 46.070067 & -122.88733 & 53 \\
\hline A6CR113_05 & & 46.069387 & -122.88876 & 52 \\
\hline A6CR113_06 & & 46.069583 & -122.88973 & 50 \\
\hline
\end{tabular}


Table B.2. (contd)

\begin{tabular}{|c|c|c|c|c|}
\hline Array_Node & Array Function & $\begin{array}{c}\text { Latitude in } \\
\text { decimal deg. (neg. } \\
\text { is south) }\end{array}$ & $\begin{array}{c}\text { Longitude in } \\
\text { decimal deg. (neg. } \\
\text { is west) }\end{array}$ & $\begin{array}{l}\text { Approximate } \\
\text { Depth (m) }\end{array}$ \\
\hline A6CR113_07 & & 46.068892 & -122.89035 & 43 \\
\hline A6CR113_08 & & 46.068988 & -122.89151 & 32 \\
\hline A6CR113_09 & & 46.068473 & -122.89226 & 32 \\
\hline A6CR113_10 & & 46.068938 & -122.89403 & 27 \\
\hline A7CR086_01 & BON Tertiary & 46.186095 & -123.18056 & 72 \\
\hline A7CR086_02 & & 46.185952 & -123.17930 & 73 \\
\hline A7CR086_03 & & 46.185175 & -123.17980 & 60 \\
\hline A7CR086_04 & & 46.184390 & -123.17908 & 60 \\
\hline A7CR086_05 & & 46.184080 & -123.17789 & 43 \\
\hline A7CR086_06 & & 46.183470 & -123.17853 & 55 \\
\hline
\end{tabular}




\section{Appendix C}

\section{Survival and Detection Probabilities for Single Releases}




\section{Appendix C}

\section{Survival and Detection Probabilities for Single Releases}

Table C.1. List of Excel Files on an Accompanying Compact Disc*

\begin{tabular}{|c|c|}
\hline File & Description \\
\hline Appendix C1.xlsx & $\begin{array}{l}\text { Yearling Chinook Single-Release Survival Capture Histories and Detection Probabilities and } \\
\text { Histories at JDA }\end{array}$ \\
\hline Appendix C2.xlsx & Steelhead Single Releases Survival and Detection Probabilities and Histories at JDA \\
\hline Appendix C3.xlsx & $\begin{array}{l}\text { Subyearling Chinook Single Releases Survival and Detection Probabilities and Histories at } \\
\text { JDA }\end{array}$ \\
\hline Appendix C4.xlsx & $\begin{array}{l}\text { Single Releases Survival and Detection Probabilities and Histories at TDA ( } 1 \text { Tab per fish } \\
\text { run) }\end{array}$ \\
\hline \multicolumn{2}{|c|}{$\begin{array}{l}\text { *A compact disc accompanying the report has _files: A Portable Document File (PDF) of this report and comma- } \\
\text { separated-variable files and Excel files with tagging, release, virtual release, capture-history data and Survival and } \\
\text { Detection Probabilities for Single releases results. }\end{array}$} \\
\hline
\end{tabular}


Appendix D

\section{Burnham Test Results}




\section{Appendix D}

\section{Burnham Test Results}

Burnham Test 2 examines whether upstream detections affect downstream survival or detection, and Test 3 examines whether upstream capture histories affect downstream survival or capture (Burnham et al. 1987). In the following tables, cells containing "NC" could not be calculated because of high detection rates on the primary and secondary arrays. Shaded cells that have P-values $<0.10$ indicate a violation of model assumptions.

\section{D.1 Yearling Chinook Salmon}

Table D.1. Burnham et al. (1987) Test 2 and Test 3 P-Values for Goodness-of-Fit to the Single ReleaseRecapture Data for Spring Chinook Salmon Smolts Passing John Day Dam Concrete

\begin{tabular}{ccc}
\hline & \multicolumn{2}{c}{ P-Values from Fisher's Exact Test } \\
\cline { 2 - 3 } Virtual Release Date & Test 2.2 & Test 3.1 \\
\hline $4 / 28-4 / 31$ & $\mathrm{NC}$ & $\mathrm{NC}$ \\
$5 / 01-5 / 02$ & $\mathrm{NC}$ & $\mathrm{NC}$ \\
$5 / 03-5 / 04$ & $\mathrm{NC}$ & $\mathrm{NC}$ \\
$5 / 05-5 / 06$ & $\mathrm{NC}$ & $\mathrm{NC}$ \\
$5 / 07-5 / 08$ & $\mathrm{NC}$ & $\mathrm{NC}$ \\
$5 / 09-5 / 10$ & $\mathrm{NC}$ & $\mathrm{NC}$ \\
$5 / 11-5 / 12$ & 0.4964 & 0.0005 \\
$5 / 13-5 / 14$ & $\mathrm{NC}$ & $\mathrm{NC}$ \\
$5 / 15-5 / 16$ & $\mathrm{NC}$ & $\mathrm{NC}$ \\
$5 / 17-5 / 18$ & $\mathrm{NC}$ & $\mathrm{NC}$ \\
$5 / 19-5 / 20$ & $\mathrm{NC}$ & $\mathrm{NC}$ \\
$5 / 21-5 / 22$ & $\mathrm{NC}$ & $\mathrm{NC}$ \\
$5 / 23-5 / 24$ & $\mathrm{NC}$ & $\mathrm{NC}$ \\
$5 / 25-5 / 26$ & $\mathrm{NC}$ & $\mathrm{NC}$ \\
$5 / 27-6 / 07$ & 0.1530 & 0.1528 \\
\hline
\end{tabular}


Table D.2. Burnham et al. (1987) Test 2 and Test 3 P-Values for Goodness-of-Fit to the Single ReleaseRecapture Data for Spring Chinook Salmon Smolts Passing John Day Dam

\begin{tabular}{ccc}
\hline & \multicolumn{2}{c}{ P-Values from Fisher's Exact Test } \\
\cline { 2 - 3 } Virtual Release Date & Test 2.2 & Test 3.1 \\
\hline $4 / 28-4 / 31$ & $\mathrm{NC}$ & $\mathrm{NC}$ \\
$5 / 01-5 / 02$ & $\mathrm{NC}$ & $\mathrm{NC}$ \\
$5 / 03-5 / 04$ & $\mathrm{NC}$ & $\mathrm{NC}$ \\
$5 / 05-5 / 06$ & $\mathrm{NC}$ & $\mathrm{NC}$ \\
$5 / 07-5 / 08$ & $\mathrm{NC}$ & $\mathrm{NC}$ \\
$5 / 09-5 / 10$ & $\mathrm{NC}$ & $\mathrm{NC}$ \\
$5 / 11-5 / 12$ & 0.4498 & 0.0004 \\
$5 / 13-5 / 14$ & $\mathrm{NC}$ & $\mathrm{NC}$ \\
$5 / 15-5 / 16$ & $\mathrm{NC}$ & $\mathrm{NC}$ \\
$5 / 17-5 / 18$ & $\mathrm{NC}$ & $\mathrm{NC}$ \\
$5 / 19-5 / 20$ & $\mathrm{NC}$ & $\mathrm{NC}$ \\
$5 / 21-5 / 22$ & $\mathrm{NC}$ & $\mathrm{NC}$ \\
$5 / 23-5 / 24$ & $\mathrm{NC}$ & $\mathrm{NC}$ \\
$5 / 25-5 / 26$ & $\mathrm{NC}$ & $\mathrm{NC}$ \\
$5 / 27-6 / 07$ & 0.1583 & 0.1868 \\
\hline
\end{tabular}

Table D.3. Burnham et al. (1987) Test 2 and Test 3 P-Values for Goodness-of-Fit to the Single ReleaseRecapture Data for Spring Chinook Salmon Smolts Passing the John Day Dam Turbines

\begin{tabular}{ccc}
\hline & \multicolumn{2}{c}{ P-Values from Fisher's Exact Test } \\
\cline { 2 - 3 } Virtual Release Date & Test 2.2 & Test 3.1 \\
\hline $4 / 27-4 / 31$ & $\mathrm{NC}$ & $\mathrm{NC}$ \\
$5 / 01-5 / 05$ & $\mathrm{NC}$ & $\mathrm{NC}$ \\
$5 / 06-5 / 10$ & $\mathrm{NC}$ & $\mathrm{NC}$ \\
$5 / 11-5 / 15$ & $\mathrm{NC}$ & $\mathrm{NC}$ \\
$5 / 16-5 / 20$ & $\mathrm{NC}$ & $\mathrm{NC}$ \\
$5 / 21-5 / 25$ & $\mathrm{NC}$ & $\mathrm{NC}$ \\
$5 / 21-6 / 07$ & $\mathrm{NC}$ & $\mathrm{NC}$ \\
\hline
\end{tabular}


Table D.4. Burnham et al. (1987) Test 2 and Test 3 P-Values for Goodness-of-Fit to the Single ReleaseRecapture Data for Spring Chinook Salmon Smolts Passing the John Day Dam JBS

\begin{tabular}{ccc}
\hline & \multicolumn{2}{c}{ P-Values from Fisher's Exact Test } \\
\cline { 2 - 3 } Virtual Release Date & Test 2.2 & Test 3.1 \\
\hline $4 / 27-4 / 31$ & $\mathrm{NC}$ & $\mathrm{NC}$ \\
$5 / 01-5 / 05$ & $\mathrm{NC}$ & $\mathrm{NC}$ \\
$5 / 06-5 / 10$ & $\mathrm{NC}$ & $\mathrm{NC}$ \\
$5 / 11-5 / 15$ & 0.1383 & 0.0316 \\
$5 / 16-5 / 20$ & $\mathrm{NC}$ & $\mathrm{NC}$ \\
$5 / 21-5 / 25$ & $\mathrm{NC}$ & $\mathrm{NC}$ \\
$5 / 21-6 / 07$ & $\mathrm{NC}$ & $\mathrm{NC}$ \\
\hline
\end{tabular}

Table D.5. Burnham et al. (1987) Test 2 and Test 3 P-Values for Goodness-of-Fit to the Single ReleaseRecapture Data for Spring Chinook Salmon Smolts Passing the John Day Spillways

\begin{tabular}{ccc}
\hline & \multicolumn{2}{c}{ P-Values from Fisher's Exact Test } \\
\cline { 2 - 3 } Virtual Release Date & Test 2.2 & Test 3.1 \\
\hline $4 / 28-4 / 31$ & $\mathrm{NC}$ & $\mathrm{NC}$ \\
$5 / 01-5 / 02$ & $\mathrm{NC}$ & $\mathrm{NC}$ \\
$5 / 03-5 / 04$ & $\mathrm{NC}$ & $\mathrm{NC}$ \\
$5 / 05-5 / 06$ & $\mathrm{NC}$ & $\mathrm{NC}$ \\
$5 / 07-5 / 08$ & $\mathrm{NC}$ & $\mathrm{NC}$ \\
$5 / 09-5 / 10$ & $\mathrm{NC}$ & $\mathrm{NC}$ \\
$5 / 11-5 / 12$ & 0.1858 & 0.0000 \\
$5 / 13-5 / 14$ & $\mathrm{NC}$ & $\mathrm{NC}$ \\
$5 / 15-5 / 16$ & $\mathrm{NC}$ & $\mathrm{NC}$ \\
$5 / 17-5 / 18$ & $\mathrm{NC}$ & $\mathrm{NC}$ \\
$5 / 19-5 / 20$ & $\mathrm{NC}$ & $\mathrm{NC}$ \\
$5 / 21-5 / 22$ & $\mathrm{NC}$ & $\mathrm{NC}$ \\
$5 / 23-5 / 24$ & $\mathrm{NC}$ & $\mathrm{NC}$ \\
$5 / 25-5 / 26$ & $\mathrm{NC}$ & $\mathrm{NC}$ \\
$5 / 27-6 / 07$ & 0.1632 & 0.1612 \\
\hline
\end{tabular}


Table D.6. Burnham et al. (1987) Test 2 and Test 3 P-Values for Goodness-of-Fit to the Single ReleaseRecapture Data for Spring Chinook Salmon Smolts Passing the John Day Dam TSW

\begin{tabular}{ccc}
\hline & \multicolumn{2}{c}{ P-Values from Fisher's Exact Test } \\
\cline { 2 - 3 } Virtual Release Date & Test 2.2 & Test 3.1 \\
\hline $4 / 28-4 / 31$ & $\mathrm{NC}$ & $\mathrm{NC}$ \\
$5 / 01-5 / 02$ & $\mathrm{NC}$ & $\mathrm{NC}$ \\
$5 / 03-5 / 04$ & $\mathrm{NC}$ & $\mathrm{NC}$ \\
$5 / 05-5 / 06$ & $\mathrm{NC}$ & $\mathrm{NC}$ \\
$5 / 07-5 / 08$ & $\mathrm{NC}$ & $\mathrm{NC}$ \\
$5 / 09-5 / 10$ & $\mathrm{NC}$ & $\mathrm{NC}$ \\
$5 / 11-5 / 12$ & 0.1666 & 0.0008 \\
$5 / 13-5 / 14$ & $\mathrm{NC}$ & $\mathrm{NC}$ \\
$5 / 15-5 / 16$ & $\mathrm{NC}$ & $\mathrm{NC}$ \\
$5 / 17-5 / 18$ & $\mathrm{NC}$ & $\mathrm{NC}$ \\
$5 / 19-5 / 20$ & $\mathrm{NC}$ & $\mathrm{NC}$ \\
$5 / 21-5 / 22$ & $\mathrm{NC}$ & $\mathrm{NC}$ \\
$5 / 23-5 / 24$ & $\mathrm{NC}$ & $\mathrm{NC}$ \\
\hline
\end{tabular}

\section{D.2 Steelhead}

Table D.7. Burnham et al. (1987) Test 2 and Test 3 P-Values for Goodness-of-Fit to the Single ReleaseRecapture Data for Steelhead Smolts Passing John Day Dam Concrete

\begin{tabular}{ccc}
\hline & \multicolumn{2}{c}{ P-Values from Fisher's Exact Test } \\
\cline { 2 - 3 } Virtual Release Date & Test 2.2 & Test 3.1 \\
\hline $4 / 28-4 / 31$ & $\mathrm{NC}$ & $\mathrm{NC}$ \\
$5 / 01-5 / 02$ & $\mathrm{NC}$ & $\mathrm{NC}$ \\
$5 / 03-5 / 04$ & $\mathrm{NC}$ & $\mathrm{NC}$ \\
$5 / 05-5 / 06$ & $\mathrm{NC}$ & $\mathrm{NC}$ \\
$5 / 07-5 / 08$ & $\mathrm{NC}$ & $\mathrm{NC}$ \\
$5 / 09-5 / 10$ & $\mathrm{NC}$ & $\mathrm{NC}$ \\
$5 / 11-5 / 12$ & 0.0314 & 0.0508 \\
$5 / 13-5 / 14$ & $\mathrm{NC}$ & $\mathrm{NC}$ \\
$5 / 15-5 / 16$ & $\mathrm{NC}$ & $\mathrm{NC}$ \\
$5 / 17-5 / 18$ & $\mathrm{NC}$ & $\mathrm{NC}$ \\
$5 / 19-5 / 20$ & $\mathrm{NC}$ & $\mathrm{NC}$ \\
$5 / 21-5 / 22$ & $\mathrm{NC}$ & $\mathrm{NC}$ \\
$5 / 23-5 / 24$ & $\mathrm{NC}$ & $\mathrm{NC}$ \\
$5 / 25-5 / 26$ & $\mathrm{NC}$ & $\mathrm{NC}$ \\
$5 / 27-6 / 07$ & 0.6875 & 0.7457 \\
\hline
\end{tabular}


Table D.8. Burnham et al. (1987) Test 2 and Test 3 P-Values for Goodness-of-Fit to the Single ReleaseRecapture Data for Steelhead Smolts Passing John Day Dam

\begin{tabular}{ccc}
\hline & \multicolumn{2}{c}{ P-Values from Fisher's Exact Test } \\
\cline { 2 - 3 } Virtual Release Date & Test 2.2 & Test 3.1 \\
\hline $4 / 28-4 / 31$ & $\mathrm{NC}$ & $\mathrm{NC}$ \\
$5 / 01-5 / 02$ & $\mathrm{NC}$ & $\mathrm{NC}$ \\
$5 / 03-5 / 04$ & $\mathrm{NC}$ & $\mathrm{NC}$ \\
$5 / 05-5 / 06$ & $\mathrm{NC}$ & $\mathrm{NC}$ \\
$5 / 07-5 / 08$ & $\mathrm{NC}$ & $\mathrm{NC}$ \\
$5 / 09-5 / 10$ & $\mathrm{NC}$ & $\mathrm{NC}$ \\
$5 / 11-5 / 12$ & 0.0337 & 0.0189 \\
$5 / 13-5 / 14$ & $\mathrm{NC}$ & $\mathrm{NC}$ \\
$5 / 15-5 / 16$ & $\mathrm{NC}$ & $\mathrm{NC}$ \\
$5 / 17-5 / 18$ & $\mathrm{NC}$ & $\mathrm{NC}$ \\
$5 / 19-5 / 20$ & $\mathrm{NC}$ & $\mathrm{NC}$ \\
$5 / 21-5 / 22$ & $\mathrm{NC}$ & $\mathrm{NC}$ \\
$5 / 23-5 / 24$ & $\mathrm{NC}$ & 0.3223 \\
$5 / 25-5 / 26$ & 0.0996 & 0.2994 \\
$5 / 27-6 / 07$ & 0.1612 & 0.2582 \\
\hline
\end{tabular}

Table D.9. Burnham et al. (1987) Test 2 and Test 3 P-Values for Goodness-of-Fit to the Single ReleaseRecapture Data for Steelhead Smolts Passing the John Day Dam Turbines

\begin{tabular}{ccc}
\hline & \multicolumn{2}{c}{ P-Values from Fisher's Exact Test } \\
\cline { 2 - 3 } Virtual Release Date & Test 2.2 & Test 3.1 \\
\hline $4 / 27-5 / 15$ & $\mathrm{NC}$ & $\mathrm{NC}$ \\
$5 / 16-6 / 07$ & $\mathrm{NC}$ & $\mathrm{NC}$ \\
\hline
\end{tabular}

Table D.10. Burnham et al. (1987) Test 2 and Test 3 P-Values for Goodness-of-Fit to the Single ReleaseRecapture Data for Steelhead Smolts Passing the John Day Dam JBS

\begin{tabular}{ccc}
\hline & \multicolumn{2}{c}{ P-Values from Fisher's Exact Test } \\
\cline { 2 - 3 } Virtual Release Date & Test 2.2 & Test 3.1 \\
\hline $4 / 27-4 / 31$ & $\mathrm{NC}$ & $\mathrm{NC}$ \\
$5 / 01-5 / 05$ & $\mathrm{NC}$ & $\mathrm{NC}$ \\
$5 / 06-5 / 10$ & $\mathrm{NC}$ & $\mathrm{NC}$ \\
$5 / 11-5 / 15$ & $\mathrm{NC}$ & $\mathrm{NC}$ \\
$5 / 16-5 / 20$ & $\mathrm{NC}$ & $\mathrm{NC}$ \\
$5 / 21-5 / 25$ & $\mathrm{NC}$ & $\mathrm{NC}$ \\
$5 / 21-6 / 07$ & $\mathrm{NC}$ & $\mathrm{NC}$ \\
\hline
\end{tabular}


Table D.11. Burnham et al. (1987) Test 2 and Test 3 P-Values for Goodness-of-Fit to the Single ReleaseRecapture Data for Steelhead Smolts Passing the John Day Dam Spillways

\begin{tabular}{ccc}
\hline & \multicolumn{2}{c}{ P-Values from Fisher's Exact Test } \\
\cline { 2 - 3 } Virtual Release Date & Test 2.2 & Test 3.1 \\
\hline $4 / 28-4 / 31$ & $\mathrm{NC}$ & $\mathrm{NC}$ \\
$5 / 01-5 / 02$ & $\mathrm{NC}$ & $\mathrm{NC}$ \\
$5 / 03-5 / 04$ & $\mathrm{NC}$ & $\mathrm{NC}$ \\
$5 / 05-5 / 06$ & $\mathrm{NC}$ & $\mathrm{NC}$ \\
$5 / 07-5 / 08$ & $\mathrm{NC}$ & $\mathrm{NC}$ \\
$5 / 09-5 / 10$ & $\mathrm{NC}$ & $\mathrm{NC}$ \\
$5 / 11-5 / 12$ & 0.0229 & 0.0812 \\
$5 / 13-5 / 14$ & $\mathrm{NC}$ & $\mathrm{NC}$ \\
$5 / 15-5 / 16$ & $\mathrm{NC}$ & $\mathrm{NC}$ \\
$5 / 17-5 / 18$ & $\mathrm{NC}$ & $\mathrm{NC}$ \\
$5 / 19-5 / 20$ & $\mathrm{NC}$ & $\mathrm{NC}$ \\
$5 / 21-5 / 22$ & $\mathrm{NC}$ & $\mathrm{NC}$ \\
$5 / 23-5 / 24$ & $\mathrm{NC}$ & $\mathrm{NC}$ \\
$5 / 25-5 / 26$ & $\mathrm{NC}$ & $\mathrm{NC}$ \\
$5 / 27-6 / 07$ & 0.7333 & 0.7429 \\
\hline
\end{tabular}

Table D.12. Burnham et al. (1987) Test 2 and Test 3 P-Values for Goodness-of-Fit to the Single ReleaseRecapture Data for Steelhead Smolts Passing the John Day Dam TSW

\begin{tabular}{ccc}
\hline & \multicolumn{2}{c}{ P-Values from Fisher's Exact Test } \\
\cline { 2 - 3 } Virtual Release Date & Test 2.2 & Test 3.1 \\
\hline $4 / 28-4 / 31$ & $\mathrm{NC}$ & $\mathrm{NC}$ \\
$5 / 01-5 / 02$ & $\mathrm{NC}$ & $\mathrm{NC}$ \\
$5 / 03-5 / 04$ & $\mathrm{NC}$ & $\mathrm{NC}$ \\
$5 / 05-5 / 06$ & $\mathrm{NC}$ & $\mathrm{NC}$ \\
$5 / 07-5 / 08$ & $\mathrm{NC}$ & $\mathrm{NC}$ \\
$5 / 09-5 / 10$ & $\mathrm{NC}$ & $\mathrm{NC}$ \\
$5 / 11-5 / 12$ & $\mathrm{NC}$ & $\mathrm{NC}$ \\
$5 / 13-5 / 14$ & $\mathrm{NC}$ & $\mathrm{NC}$ \\
$5 / 15-5 / 16$ & $\mathrm{NC}$ & $\mathrm{NC}$ \\
$5 / 17-5 / 18$ & $\mathrm{NC}$ & $\mathrm{NC}$ \\
$5 / 19-5 / 20$ & $\mathrm{NC}$ & $\mathrm{NC}$ \\
$5 / 21-5 / 22$ & $\mathrm{NC}$ & $\mathrm{NC}$ \\
$5 / 23-5 / 24$ & $\mathrm{NC}$ & $\mathrm{NC}$ \\
$5 / 25-5 / 26$ & $\mathrm{NC}$ & $\mathrm{NC}$ \\
$5 / 27-6 / 07$ & 0.1890 & 0.0554 \\
\hline
\end{tabular}




\section{D.3 Subyearling Chinook Salmon}

Table D.13. Burnham et al. (1987) Test 2 and Test 3 P-Values for Goodness-of-Fit to the Single ReleaseRecapture Data for Fall Chinook Salmon Smolts Passing John Day Dam Concrete

\begin{tabular}{ccc}
\hline & \multicolumn{2}{c}{ P-Values from Fisher's Exact Test } \\
\cline { 2 - 3 } Virtual Release Date & Test 2.2 & Test 3.1 \\
\hline $6 / 16-6 / 19$ & $\mathrm{NC}$ & $\mathrm{NC}$ \\
$6 / 20-6 / 21$ & $\mathrm{NC}$ & $\mathrm{NC}$ \\
$6 / 22-6 / 23$ & 0.0652 & 0.4717 \\
$6 / 24-6 / 25$ & 0.0515 & $\mathrm{NC}$ \\
$6 / 26-6 / 27$ & $\mathrm{NC}$ & $\mathrm{NC}$ \\
$6 / 28-6 / 29$ & $\mathrm{NC}$ & $\mathrm{NC}$ \\
$6 / 30-7 / 01$ & $\mathrm{NC}$ & $\mathrm{NC}$ \\
$7 / 02-7 / 03$ & $\mathrm{NC}$ & $\mathrm{NC}$ \\
$7 / 04-7 / 05$ & $\mathrm{NC}$ & $\mathrm{NC}$ \\
$7 / 06-7 / 07$ & 0.0165 & 0.1833 \\
$7 / 08-7 / 09$ & 0.0051 & 0.0642 \\
$7 / 10-7 / 11$ & $\mathrm{NC}$ & $\mathrm{NC}$ \\
$7 / 12-7 / 13$ & $\mathrm{NC}$ & $\mathrm{NC}$ \\
$7 / 14-7 / 15$ & $\mathrm{NC}$ & $\mathrm{NC}$ \\
$7 / 16 / 8 / 21$ & $\mathrm{NC}$ & $\mathrm{NC}$ \\
\hline
\end{tabular}

Table D.14. Burnham et al. (1987) Test 2 and Test 3 P-Values for Goodness-of-Fit to the Single ReleaseRecapture Data for Fall Chinook Salmon Smolts Passing John Day Dam

\begin{tabular}{lcc}
\hline & \multicolumn{2}{c}{ P-Values from Fisher's Exact Test } \\
Virtual Release Date & Test 2.2 & Test 3.1 \\
\hline $6 / 16-6 / 19$ & $\mathrm{NC}$ & $\mathrm{NC}$ \\
$6 / 20-6 / 21$ & $\mathrm{NC}$ & $\mathrm{NC}$ \\
$6 / 22-6 / 23$ & 0.0515 & 0.4822 \\
$6 / 24-6 / 25$ & 0.0487 & $\mathrm{NC}$ \\
$6 / 26-6 / 27$ & $\mathrm{NC}$ & $\mathrm{NC}$ \\
$6 / 28-6 / 29$ & $\mathrm{NC}$ & $\mathrm{NC}$ \\
$6 / 30-7 / 01$ & $\mathrm{NC}$ & $\mathrm{NC}$ \\
$7 / 02-7 / 03$ & $\mathrm{NC}$ & $\mathrm{NC}$ \\
$7 / 04-7 / 05$ & $\mathrm{NC}$ & $\mathrm{NC}$ \\
$7 / 06-7 / 07$ & 0.1075 & 0.4064 \\
$7 / 08-7 / 09$ & $\mathrm{NC}$ & $\mathrm{NC}$ \\
$7 / 10-7 / 11$ & $\mathrm{NC}$ & $\mathrm{NC}$ \\
$7 / 12-7 / 13$ & $\mathrm{NC}$ & $\mathrm{NC}$ \\
$7 / 14-7 / 15$ & $\mathrm{NC}$ & $\mathrm{NC}$ \\
$7 / 16 / 7 / 29$ & $\mathrm{NC}$ & $\mathrm{NC}$ \\
\hline
\end{tabular}

D.7 
Table D.15. Burnham et al. (1987) Test 2 and Test 3 P-Values for Goodness-of-Fit to the Single ReleaseRecapture Data for Fall Chinook Salmon Smolts Passing the John Day Turbines

\begin{tabular}{ccc}
\hline & \multicolumn{2}{c}{ P-Values from Fisher's Exact Test } \\
\cline { 2 - 3 } Virtual Release Date & Test 2.2 & Test 3.1 \\
\hline $6 / 17-6 / 23$ & $\mathrm{NC}$ & $\mathrm{NC}$ \\
$6 / 24-6 / 31$ & 0.0031 & $\mathrm{NC}$ \\
$7 / 01-7 / 08$ & $\mathrm{NC}$ & $\mathrm{NC}$ \\
$7 / 09-8 / 11$ & $\mathrm{NC}$ & $\mathrm{NC}$ \\
\hline
\end{tabular}

Table D.16. Burnham et al. (1987) Test 2 and Test 3 P-Values for Goodness-of-Fit to the Single ReleaseRecapture Data for Fall Chinook Salmon Smolts Passing the John Day Dam JBS

\begin{tabular}{ccc}
\hline & \multicolumn{2}{c}{ P-Values from Fisher's Exact Test } \\
\cline { 2 - 3 } Virtual Release Date & Test 2.2 & Test 3.1 \\
\hline $6 / 17-6 / 23$ & 0.1197 & 0.5151 \\
$6 / 24-6 / 31$ & $\mathrm{NC}$ & $\mathrm{NC}$ \\
$7 / 01-7 / 08$ & $\mathrm{NC}$ & $\mathrm{NC}$ \\
$7 / 09-7 / 20$ & $\mathrm{NC}$ & $\mathrm{NC}$ \\
\hline
\end{tabular}

Table D.17. Burnham et al. (1987) Test 2 and Test 3 P-Values for Goodness-of-Fit to the Single ReleaseRecapture Data for Fall Chinook Salmon Smolts Passing the John Day Spillways

\begin{tabular}{ccc}
\hline & \multicolumn{2}{c}{ P-Values from Fisher's Exact Test } \\
\cline { 2 - 3 } Virtual Release Date & Test 2.2 & Test 3.1 \\
\hline $6 / 16-6 / 19$ & $\mathrm{NC}$ & $\mathrm{NC}$ \\
$6 / 20-6 / 21$ & $\mathrm{NC}$ & $\mathrm{NC}$ \\
$6 / 22-6 / 23$ & $\mathrm{NC}$ & $\mathrm{NC}$ \\
$6 / 24-6 / 25$ & $\mathrm{NC}$ & $\mathrm{NC}$ \\
$6 / 26-6 / 27$ & $\mathrm{NC}$ & $\mathrm{NC}$ \\
$6 / 28-6 / 29$ & $\mathrm{NC}$ & $\mathrm{NC}$ \\
$6 / 30-7 / 01$ & $\mathrm{NC}$ & $\mathrm{NC}$ \\
$7 / 02-7 / 03$ & $\mathrm{NC}$ & $\mathrm{NC}$ \\
$7 / 04-7 / 05$ & $\mathrm{NC}$ & $\mathrm{NC}$ \\
$7 / 06-7 / 07$ & 0.0253 & 0.1903 \\
$7 / 08-7 / 09$ & 0.0011 & 0.0542 \\
$7 / 10-7 / 11$ & $\mathrm{NC}$ & $\mathrm{NC}$ \\
$7 / 12-7 / 13$ & $\mathrm{NC}$ & $\mathrm{NC}$ \\
$7 / 14-7 / 15$ & $\mathrm{NC}$ & $\mathrm{NC}$ \\
$7 / 16 / 8 / 21$ & $\mathrm{NC}$ & $\mathrm{NC}$ \\
\hline
\end{tabular}




\section{Distribution}

No. of

Copies

OFFSITE

5 Paper \& CD with PDF

Brad Eppard

USACE District, Portland

CENWP-PM-E

333 SW 1st Avenue (R. Duncan Plaza)

Portland, OR 97204-3495

1 Paper \& CD with PDF

John Skalski

Univeristy of Washington

$13254^{\text {th }}$ Ave

Seattle, WA 98101

20 Paper \& CD with PDF

Mark Weiland and coauthors

PNNL for authors

390 Evergreen Drive

P.O. Box 241

North Bonneville, WA 98639
No. of

$\underline{\text { Copies }}$

\section{ONSITE}

7 Paper \& CD with PDF

Pacific Northwest National Laboratory

Z Deng

K9-33

$\mathrm{T} \mathrm{Fu}$

K9-33

J Kim

K6-85

F Khan

K6-85

KD Ham

K6-85

DR Geist

K6-85

Hanford Technical Library 


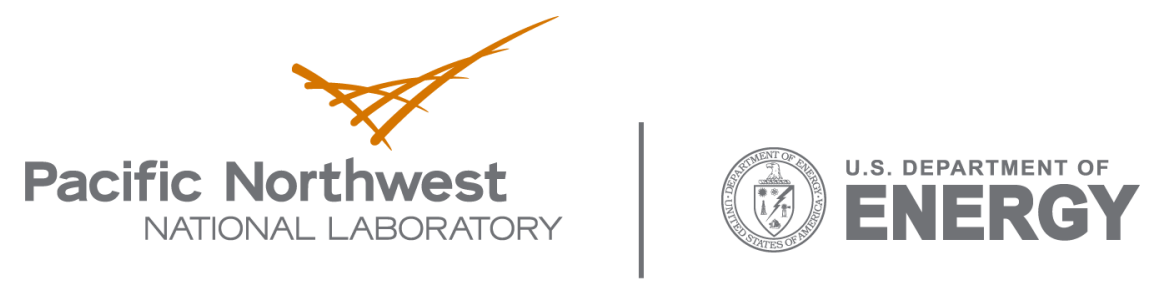

902 Battelle Boulevard

P.O. Box 999

Richland, WA 99352

1-888-375-PNNL (7665)

www.pnl.gov 